Fernando Viegas Stump

\title{
Otimização Topológica Aplicada ao Projeto de Estruturas Tradicionais e Estruturas com Gradação Funcional sujeitas a Restrição de Tensão
}

\author{
Dissertação apresentada à Escola Po- \\ litécnica da Universidade de São Paulo \\ para obtenção do Título de Mestre em \\ Engenharia Mecânica.
}


Fernando Viegas Stump

\title{
Otimização Topológica Aplicada ao Projeto de Estruturas Tradicionais e Estruturas com Gradação Funcional sujeitas a Restrição de Tensão
}

\author{
Dissertação apresentada à Escola Po- \\ litécnica da Universidade de São Paulo \\ para obtenção do Título de Mestre em \\ Engenharia Mecânica. \\ Área de concentração: \\ Engenharia de Controle e Automação \\ Mecânica \\ Orientador: \\ Prof. Dr. Emílio Carlos Nelli \\ Silva
}


Este exemplar foi revisado e alterado em relação à versão original, sob responsabilidade única do autor e com a anuência de seu orientador.

São Paulo, 9 de Junho de 2006

Assinatura do autor

Assinatura do orientador

\section{Ficha Catalográfica}

Stump, Fernando Viegas

Otimização Topológica Aplicada ao Projeto de Estruturas Tradicionais e Estruturas com Gradação Funcional sujeitas a Restrição de Tensão. /F.V Stump. São Paulo, 2006. 243 p.

Dissertação (Mestrado) - Escola Politécnica da Universidade de São Paulo. Departamento de Engenharia Mecatrônica e de Sistemas Mecânicos .

1. Otimização Topológica. 2. Restrição de Tensão Mecânica. 3. Materiais com Gradação Funcional I. Universidade de São Paulo. Escola Politécnica. Departamento de Engenharia Mecatrônica e de Sistemas Mecânicos . II. t. 
Dedico este trabalho àqueles que são exemplo e referência para a minha vida e estão sempre ao meu lado, meus pais, Patrick e Marisdalva. 


\section{Agradecimentos}

Ao Emílio C. N. Silva pela orientação a este trabalho e pela participação dedicada no meu desenvolvimento acadêmico desde o segundo ano da graduação.

Ao Glaucio H. Paulino por me conduzir e me apoiar na comunidade acadêmica, por colaborar com o meu desenvolvimento pessoal e pelas contribuições teóricas fundamentais ao desenvolvimento deste trabalho.

À EPUSP por garantir a estrutura necessária para o desenvolvimento desta pesquisa.

Ao Conselho Nacional de Desenvolvimento Científico e Tecnológico - CNPq pela bolsa de mestrado e à Coordenação de Aperfeiçoamento de Pessoal de Nível Superior - CAPES por proporcionar auxílios financeiros para divulgação desta pesquisa em congressos.

À Faculdade de Ciências da Universidade de Lisboa e à Universidade Técnica da Dinamarca pelo suporte oferecido durante os cursos de verão, que foram de grande valia para o meu amadurecimento teórico.

A Hélade por estar sempre ao meu lado nos momentos difíceis deste processo, pelo apoio na minha trajetória e nos meus projetos acadêmicos e também pelas dedicadas revisões ao texto.

A toda a minha família pelo apoio e por estarem sempre presentes; em particular à Sandra pelos conselhos acadêmicos.

Aos amigos German, Mauro, Marcelo, Luciana, Rogério, Marco, Luis, Ronny, Cícero e Wagner pelas discussões acadêmicas e pela amizade e companheirismo. 


\section{Resumo}

Este trabalho apresenta a aplicação do Método de Otimização Topológica (MOT) considerando restrição de tensão mecânica em dois problemas de Engenharia: o projeto de estruturas mecânicas sujeitas a restrição de tensão e o projeto da distribuição de material em estruturas constituídas por Materiais com Gradação Funcional (MsGF). O MOT é um método numérico capaz de fornecer de forma automática o leiaute básico de uma estrutura mecânica para que esta atenda a um dado requisito de projeto, como o limite sobre a máxima tensão mecânica no componente. Os MsGF são materiais cujas propriedades variam gradualmente com a posição. Este gradiente de propriedades é obtido através da variação contínua da microestrutura formada por dois materiais diferentes.

Neste trabalho o MOT foi implementado utilizando o modelo de material Solid Isotropic Microstructure with Penalization (SIMP) e o campo de densidades foi parametrizado utilizando a abordagem Aproximação Contínua da Distribuição de Material (ACDM). O modelo de material é utilizado em conjunto com um localizador de tensões, de modo a representar as tensões nas regiões com densidade intermediária.

O projeto de estruturas tradicionais através do MOT possui dois problemas centrais aqui tratados: o fenômeno das topologias singulares, que consiste na incapacidade do algoritmo de otimização de retirar material de certas regiões da estrutura, onde a tensão mecânica supera o limite de tensão quando os valores da densidade tendem a zero, e o problema do grande número de restrições envolvidas, pois que a tensão mecânica é uma grandeza local e deve ser restrita em todos os pontos da estrutura.

Para tratar o primeiro problema é utilizado o conceito de $\varepsilon$-relaxação. Para o segundo são utilizadas duas abordagens: uma é substituição das restrições locais por uma restrição global e a outra é a aplicação do Método do Lagrangeano Aumentado. Ambas foram implementadas e aplicadas para o projeto de estruturas planas e axissimétricas.

No projeto da distribuição de material em estruturas constituídas por MsGF é utilizado um modelo de material baseado na interpolação dos limites de HashinShtrikman. A partir deste modelo as tensões em cada fase da são obtidas a partir das matrizes localizadoras de tensão. Para tratar o fenômeno das topologias singulares é proposto um índice estimativo de falha, baseado nas tensões de von Mises em cada fase da microestrutura, que evita tal problema. O grande número de restrições é tratado através da restrição global de tensão.

Em ambos os problemas as formulações são apresentadas e sua eficiência é discutida através de exemplos numéricos. 


\section{Abstract}

This work presents the Topology Optimization Method (TOM) with stress constraint applied to two Engineering problems: the design of mechanical structures subjected to stress constraint and the design of material distribution in structures made of Functionally Graded Materials (FGMs). The TOM is a numerical method capable of synthesizing the basic layout of a mechanical structure accomplishing to a given design requirement, for example the maximum stress in the structure. The FGMs are materials with spatially varying properties, which are obtained through a continuum change of the microstructure made of two different materials.

In this work, the TOM was implemented with Solid Isotropic Microstructure with Penalization (SIMP) material model and the density field was parameterized with the Continuous Approximations of Material Distribution. To obtain the intermediate density stresses, the material model is applied together with a stress localization matrix.

The design of mechanical structures through the TOM has two major problems: the singular topology phenomenon, which is characterized by the optimization algorithm impossibility of removing material from certain regions, where the stress overpasses the limiting stress when the density goes to zero, and the large number of constraints, once the stress is a local value that must be constrained everywhere in the structure.

To deal with the first problem, it is applied the $\varepsilon$-realaxation concept, and for the second one two approaches are considered: one is to change the local stress constraint into a global stress constraint and the other is to apply the Augmented Lagrangian Method. Both approaches were implemented and applied to the design of plane and axisymmetric structures.

In the design of material distribution in structures made of FGMs a material model based on Hashin-Shtrikman bounds is applied. From this model, stresses in each phase are obtained by the stress localization matrix. To deal with the singular topology phenomenon it is proposed a modified von Mises failure criteria index that avoids such problem. A global stress constraint is applied to deal with the large number of constraints.

In both problems formulations are presented and their performance are discussed through numerical examples 


\title{
Sumário
}

\section{Lista de Figuras}

\author{
Lista de Tabelas
}

\section{Lista de Abreviaturas}

\section{Convenções e Lista de Símbolos}

1 Introdução 23

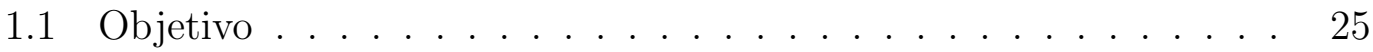

1.2 Motivação e justificativa . . . . . . . . . . . . . . . . . . 26

2 Otimização Topológica $\quad 28$

2.1 Introdução . . . . . . . . . . . . . . . . . . . . . . 28

2.2 Revisão bibliográfica do Método de Otimização Topológica . . . . 31

2.3 Formulação geral do problema de Otimização Topológica .... . 32

2.4 Modelos de material . . . . . . . . . . . . . . . . . . 36

2.4.1 Modelos baseados em microestruturas . . . . . . . . . . 37

2.4.2 Modelos artificiais . . . . . . . . . . . . . . . . . 39

2.5 Aspectos numéricos da Otimização Topológica . . . . . . . . . . . 40

2.5.1 Escala de cinza . . . . . . . . . . . . . . . 40

2.5.2 Dependência da malha . . . . . . . . . . . . . . 43

2.5.3 Instabilidade de tabuleiro . . . . . . . . . . . . . . . . 49

3 Métodos de Otimização Aplicados ao Problema de Otimização 
3.1 Método de Programação Linear Seqüencial . . . . . . . . . . . . 56

3.2 Método do Lagrangeano Aumentado . . . . . . . . . . . . . 58

4 Modelos de material $\quad 62$

4.1 Introdução . . . . . . . . . . . . . . . . . . . . . . . . 62

4.2 Conceitos básicos . . . . . . . . . . . . . . . . . . . 62

4.3 Cálculo das propriedades efetivas dos materiais . . . . . . . . . 66

4.3.1 Materiais com Gradação Funcional . . . . . . . . . . . . . 68

4.3.2 Limites das propriedades efetivas dos materiais compostos 71

4.4 Análise das tensões locais de um material composto . . . . . . . . 73

4.4.1 Exemplo do material laminado rank-2 . . . . . . . . . . 76

4.5 Critério de falha dos materiais compostos . . . . . . . . . . . 80

5 Método de Elementos Finitos utilizando Aproximação Contínua da Distribuição de Material $\quad 85$

6 Formulação do problema de Otimização Topológica considerando restrição de tensão $\quad 93$

6.1 Introdução . . . . . . . . . . . . . . . . . . . . . . 93

6.2 Revisão bibliográfica do MOT considerando restrição de tensão . 94

6.3 Fenômeno das topologias singulares . . . . . . . . . . . . . . . . . 96

6.3.1 Exemplo para o caso de treliças . . . . . . . . . . . 102

6.4 Otimização Topológica de meios contínuos com restrição de tensão 106

6.5 Formulações propostas . . . . . . . . . . . . . . . . . . . 115

6.5.1 Formulações do problema de Otimização Topológica considerando restrição de tensão . . . . . . . . . . . . . . . 115

6.5.2 Problema na forma discreta e análise de sensibilidade . . . 117

7 Otimização da distribuição de material em estruturas com gradação funcional

7.1 Introdução . . . . . . . . . . . . . . . . . . . . . . . . . . . 129 
7.2 Revisão bibliográfica sobre o projeto otimizado de estruturas com gradação funcional . . . . . . . . . . . . . . . . . . . . . 131

7.3 Modelagem numérica de estruturas constituídas por Materiais com Gradação Funcional . . . . . . . . . . . . . . . . . . . . . 135

7.4 Formulação proposta . . . . . . . . . . . . . . . . . . 140

7.4.1 Modelo de material e parametrização do campo de densidades volumétricas . . . . . . . . . . . . . . . . 140

7.4.2 Formulação do problema de otimização da distribuição de material em estruturas com gradação funcional . . . . . . . 143

7.4.3 Formulação do problema na forma discreta e análise de sensibilidade . . . . . . . . . . . . . . 151

8 Implementação numérica

9 Resultados: Otimização Topológica com restrição de tensão 168

9.1 Otimização Topológica considerando restrição global de tensão 168

9.1.1 Exemplo 1: Barra sujeita a tração axial . . . . . . . . . . . 168

9.1.2 Exemplo 2: Viga MBB . . . . . . . . . . . . . . . 182

9.1.3 Exemplo 3: Estrutura em formato de L invertido . . . . . 185

9.2 Otimização Topológica considerando restrição local de tensão . . 188

9.2.1 Exemplo 1: Barra sujeita a tração uniaxial . . . . . . . . . 189

9.2.2 Exemplo 2: Viga MBB . . . . . . . . . . . . . . . . . . 192

9.2.3 Exemplo 3: Estrutura em formato de L . . . . . . . . . . . 195

\section{Resultados: Problema de distribuição material em estruturas} com gradação funcional

10.1 Exemplo 1: Barra sujeita a tração axial . . . . . . . . . . . . . . . 199

10.2 Exemplo 2: Cilindro sujeito a pressão externa . . . . . . . . . . 208

10.3 Exemplo 3: Disco de turbina a gás . . . . . . . . . . . . . . . 214

10.4 Exemplo 4: Maximização da inércia de rotação de uma roda de inércia (Volante) . . . . . . . . . . . . . . . . . . . 221 
11 Conclusões Finais e Sugestões para desenvolvimentos futuros

11.1 Sugestões de desenvolvimentos futuros . . . . . . . . . . . 226

$\begin{array}{lr}\text { Referências } & 230\end{array}$ 


\section{Lista de Figuras}

1.1 Exemplo de convergência da solução no método de otimização topológica . . . . . . . . . . . . . . . . . . . . 24

2.1 Domínio Fixo Estendido (DFE) e notação adotada . . . . . . . 34

2.2 Representação de modelos de material baseado na microestrutura. 37

2.3 Exemplo de solução sem dependência de malha e instabilidade de tabuleiro obtida através da restrição de perímetro . . . . . . . . . 42

2.4 Representação esquemática da influência da penalização $q$ na função flexibilidade do problema de Otimização Topológica (OT) . . . 43

2.5 Exemplo do fenômeno de dependência da malha . . . . . . . . . . 44

2.6 Exemplo de não unicidade de solução. Barra sob tração uniaxial para material com coeficiente de Poisson igual a zero e extremidades (regiões hachuradas) rígidas . . . . . . . . . . . . . . 45

2.7 Exemplo de unicidade de solução obtida pela relaxação do problema 46

2.8 Representação esquemática do filtro aplicado sobe os limites móveis em um problema com variáveis de projeto nodais . . . . . . . . 49

2.9 Exemplo de solução com instabilidade de tabuleiro . . . . . . . . 49

2.10 Exemplo da aplicação de filtro como forma de solucionar o problema de instabilidade de tabuleiro e dependência de malha . . . 52

3.1 Representação da aproximação da função não-linear pela função linearizada para solução do problema linear . . . . . . . . . . . . 57

4.1 Representação de um material composto estatísticamente homogêneo e seu elemento representativo de volume ERV. . . . . . . . . . . 63

4.2 Representação esquemática da variação da microestrutura em um material gradado . . . . . . . . . . . . . . . . . 69

4.3 Representação esquemática de um ERV com um distribuição heterogênea de inclusões . . . . . . . . . . . . . . . . . . 70 
4.4 Diagrama das relações entre os campos de tensão e deformação em um material composto. . . . . . . . . . . . . . . 73

4.5 Modelo de microestrutura rank-2 f . . . . . . . . . . . . 76

4.6 Modelo de microestrutura rank-1 . . . . . . . . . . . . . . . 77

4.7 Exemplo de resistência de material segundo os modelos de Voigt e Reuss ...................... 84

5.1 Esquema de estrutura axissimétrica e respectivo sistema de coordenada e estado de tensão da estrutura . . . . . . . . . . . . . 86

5.2 Esquema de estrutura em Estado Plano de Tensão (EPT) e respectivo sistema de coordenada e estado de tensão da estrutura . 86

5.3 Sistema de coordenadas naturais, numeração dos nós e deslocamentos nodais . . . . . . . . . . . . . . . 87

5.4 Representação do elemento tradicional e do elemento com formulação Aproximação Contínua da Distribuição de Material (ACDM) 90

6.1 Representação genérica de um domínio de projeto que apresenta um ótimo singular . . . . . . . . . . . . . . . . . . . . . 98

6.2 Problema exemplo de uma treliça com três barras e duas variáveis de projeto. . . . . . . . . . . . . . . . . 103

6.3 Espaço de solução do problema de treliça que apresenta o fenômeno das topologias singulares . . . . . . . . . . . . . . . . . . 104

6.4 Espaço de solução para o problema relaxado . . . . . . . . . . . . 106

6.5 Gráfico ilustrativo da influência da do parâmetro p da norma-p . 108

6.6 Gráfico ilustrativo da influência da do parâmetro p da norma-p . 108

6.7 Alteração da tensão de limite de escoamento através da relaxação do problema . . . . . . . . . . . . . . . . . . . 113

7.1 Representação esquemática da parametrização da distribuição de densidade volumétrica proposta por Cho e Ha (2002) . . . . . . 138

7.2 Representação esquemática da interpolação das grandezas definidas nos nós do elementos e transferidas para a formulação do elemento através do pontos de Gauss. (KIM; PAULINO, 2002) . . . . . 139 
7.3 Exemplo da variação do Módulo de Young segundo o modelo de material dado pelas equações 7.2, 7.3 e 7.9. O módulo de Young foi calculado em termos do módulo de compressibilidade e cisalhamento pela relação 7.4 . . . . . . . . . . . . . . . . . . . . . . . 142

7.4 Gráficos dos elementos da matriz localizadora das tensões em termos da fração volumétrica do material mais $(+)$. . . . . . . . . 145

7.5 Gráficos dos elementos da matriz de cálculo da tensão de von Mises em termos da fração volumétrica do material mais $(+)$. . . . . 147

7.6 Gráficos representativos da tensão de escoamento segundo os modelos de Voigt Reuss e o modelo proposto neste trabalho . . . . . 149

8.1 Malha exemplo para apresentação do número de elementos nulos

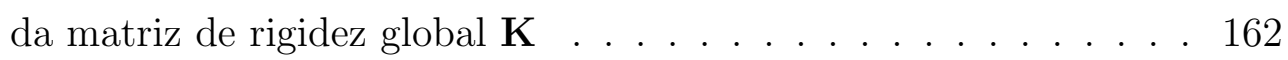

9.1 Representação da malha de elementos finitos, condições de contorno e dimensões das regiões otimizáveis e não otimizáveis (malha com 600 elementos, 656 nós, e 545 variáveis de projeto no problema de otimização.) . . . . . . . . . . . . . . . . . . . . . . 169

9.2 Soluções finais para diferentes distribuições iniciais de densidade . 170

9.3 Soluções finais para diferentes distribuições iniciais de densidade . 171

9.4 Comparação dos resultados obtidos para diferentes valores de relaxação . . . . . . . . . . . . . . . . . . . . . 172

9.5 Comparação da solução final para diferentes distribuições iniciais de densidade considerando o métodos da continuação . . . . . . . 173

9.6 Comparação do campo de tensão de von Mises nas estrutura obtidas utilizando e sem utilizar a continuação da relaxação . . . . . . 174

9.7 Curva de convergência da restrição de global de tensão para as três continuações do valor $p$ ( solução com $p=6 ; 14$, solução com $p=6 ; 14 ;, 22$ e solução com $p=6 ; 14 ; 22 ; 30$.) . . . . . . . 175

9.8 Soluções finais obtidas com a continuação de parâmetro $p$. . . . 176

9.9 Campo de tensão de von Mises nas as estruturas obtidas com a continuação de parâmetro $p \ldots \ldots$. . . . . . . . . . 177

9.10 Comparação da solução final para diferentes distribuições iniciais de densidade, considerando o métodos da continuação e filtro . . . 178 
9.11 Representação da malha refinada utilizada para o problema da barra sujeita a tração e a respectiva solução (malha com 5400 elementos, 5556 nós, e 4693 variáveis de projeto no problema de otimização) . . . . . . . . . . . . . . . . . . 179

9.12 Campo da tensão de von Mises na macro-escala, para a solução obtida com a malha refinada apresenta na Figura 9.11(b) . . . . . 180

9.13 Campos de tensão na microestrutura e da função de falha relaxada para a solução apresentada na Figura 9.11) . . . . . . . . . . . . . 181

9.14 Solução para o problema de minimização da flexibilidade com restrição de $25 \%$ de volume, utilizando continuação para a penalização $q=1,2,3$, e filtro dos limites móveis com raio igual $0,11 \ldots 181$

9.15 Viga bi-apoiada com carregamento transversal (MBB) . . . . . . . 182

9.16 Malha utilizada para a síntese da estrutura da viga MBB . . . . . 182

9.17 Solução final obtida para a viga MBB utilizando o termo de penalização das densidades intermediárias . . . . . . . . . . . . . 183

9.18 Campo da tensão de von Mises para a solução da viga MBB apresentada na Figura 9.17 . . . . . . . . . . . . . . . . . . . . 184

9.19 Solução final obtida para a viga MBB sem utilizar o termo de penalização das densidades intermediárias . . . . . . . . . . . . 184

9.20 Campo da tensão de von Mises para a solução da viga MBB sem utilizar o termo de penalização das densidades intermediárias . 184

9.21 Geometria da estrutura em formato de L para o caso axissimétrico 186

9.22 Geometria da estrutura em formato de L para o caso axissimétrico 186

9.23 Solução final obtida para a estrutura em forma de L . . . . . . . . 187

9.24 Campo da tensão de von Mises para a solução da estrutura em forma de L apresentada na Figura 9.23 . . . . . . . . . . . . . . . 187

9.25 Solução final obtida para a estrutura em forma de L, para o problema de maximização da rigidez . . . . . . . . . . . . . . . . . 188

9.26 Geometria e condições de contorno do problema da barra sob tração uniaxial . . . . . . . . . . . . . . . . . . . . . . . 189

9.27 Malha e condições de contorno utilizadas no problema da barra sujeita a tração uniaxial . . . . . . . . . . . . . . . . . . 190 
9.29 Campo da função de falha para solução do problema da barra sujeita a tração uniaxial

9.30 Curva de convergência do Método do Lagrangeano Aumentado (MLA) para o caso da viga sujeita a tração uniaxial . . . . . . . . 192

9.31 Solução obtida para a viga MBB utilizando como fator de regularização $K_{r}=0,03 \ldots \ldots \ldots$. . . . . . . . . . . 193

9.32 Campo de função de falha para estrutura obtida com fator de regularização $K_{r}=0,03 \ldots \ldots \ldots$

9.33 Solução obtida para a viga MBB utilizando como fator de regularização $K_{r}=0,003 \ldots \ldots \ldots \ldots \ldots \ldots$

9.34 Campo de função de falha para estrutura obtida com fator de regularização $K_{r}=0,003 \quad \ldots \ldots \ldots$. . . . . . . . . . 194

9.35 Solução obtida para a viga MBB utilizando como fator de regularização $K_{r}=0,001 \ldots \ldots \ldots \ldots$. . . . . . . . . . 194

9.36 Campo de função de falha para estrutura obtida com fator de regularização $K_{r}=0,001 \quad \ldots \ldots \ldots$. . . . . . . . . . 194

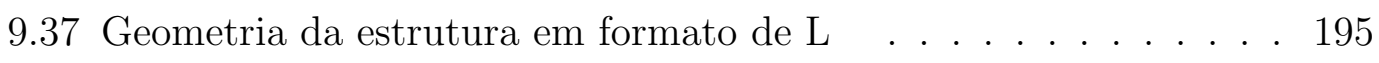

9.38 Malha de elementos finitos utilizada na solução da estrutura em formato de $\mathrm{L} \ldots \ldots \ldots \ldots \ldots$. . . . . . . . . . . . 196

9.39 Solução obtida para a estrutura em formato de L . . . . . . . . . 196

9.40 Campo de função de falha relaxada da estrutura apresentada na Figura $9.39 \ldots \ldots \ldots$. . . . . . . . . . . . . . . 197

10.1 Curva do modelo de material e dos elementos da matriz $\mathbf{B}_{v m} \quad$. . 200

10.2 Representação da malha de elementos finitos e condições de contorno (malha com 3800 elemento, 3939 nós e variáveis de projeto no problema de otimização.) ......... . 201

10.3 Soluções finais obtidas com diferentes limites móveis, considerando

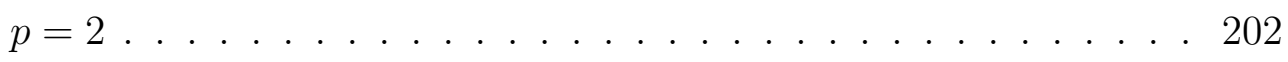

10.4 Curva de convergência do número de elementos ativos na restrição 203 
10.5 Solução obtida através da formulação $7.27,(\operatorname{sem}$ a função $\max \{\cdot, \cdot\}$ ), considerando a continuação de $p=2 ; 20 ; 50 ; 100$ e filtro com raio igual a dimensão da aresta do elemento . . . . . . . . . . . 204

10.6 Curva de convergência da restrição global de tensão do problema tratado através da formulação 7.27 , (sem a função $\max \{\cdot, \cdot\}$ ), considerando a continuação de $p=2 ; 20 ; 50 ; 100 \ldots . . . . .205$

10.7 Solução obtida através da formulação $7.28,(\operatorname{com}$ a função $\max \{\cdot, \cdot\})$, considerando a continuação de $p=2 ; 20 ; 50 ; 100$ e filtro com raio igual à dimensão da aresta do elemento . . . . . . . . . . . 205

10.8 Soluções ao final de cada passo da continuação de $p$. . . . . . . 206

10.9 Curva de convergência da restrição global de tensão do problema tratado através da formulação 7.28 , (com a função $\max \{\cdot, \cdot\})$, considerando a continuação de $p=2 ; 20 ; 50 ; 100 \ldots . . .207$

10.10Módulo de Young efetivo do Material com Gradação Funcional (MGF) para a abordagem 1 e a abordagem 2 . . . . . . . . 209

10.11Tensão de referência para MGF para a abordagem 1 e a abordagem 2210

10.12Representação esquemática do cilindro sujeito a pressão externa e respectiva seção simulada através do Método de Elementos Finitos (MEF) axissimétrico . . . . . . . . . . . . . . . . 210

10.13Representação da malha de elementos finitos, condições de contorno (malha com 2304 elementos, 2401 nós e 2401 variáveis de projeto no problema de otimização.) . . . . . . . . . . . . . . . 210

10.14Solução considerando a abordagem 1 para representação do material211

10.15Solução considerando a abordagem 1 para representação do material e filtro . . . . . . . . . . . . . . . . . . 212

10.16Solução considerando a abordagem 2 para representação do material e distribuição inicial de densidades igual a 0,25 . . . . . . . . 213

10.17Solução considerando a abordagem 2 para representação do material, filtro e distribuição inicial de densidades igual a 0,25 . . . . 214

10.18Representação esquemática da geometria e condições de contorno do disco de turbina a gás . . . . . . . . . . . . . . . . . 215 
10.19Comparação das soluções obtidas utilizando os modelos de material Hashin-Shtrikman (H-S)-linear e o H-S-transição, ambos utilizando a tensão de referência dada pelo modelo Tensão-M.A. . . . . . . . 217 10.20Índice de falha da soluções obtida utilizando o modelo de material H-S-transição associado ao modelo Tensão-M.A. com $s=1$. . . . . 218

10.21Comparação das soluções obtidas utilizando o modelo de material H-S-transição associado aos modelos Tensão-M.A. com s=3 e o modelo Tensão-M.H. . . . . . . . . . . . . . . . . . . . . . . . . 218

10.22 Comparação do quadrado das tensões de referência . . . . . . . 219

10.23Solução obtida utilizando o modelo de material H-S-transição associada ao modelo Tensão-M.H. e com filtro de raio $r=1 \mathrm{~mm}$. . . 220

10.24Geometria da roda de inércia . . . . . . . . . . . . . 221

10.25Malha de elementos finitos adotada adotada para a solução do problema da roda de inércia . . . . . . . . . . . . . . . . 222

10.26Distribuição de material obtida . . . . . . . . . . . . . . . . 222

10.27Distribuição de densidades e módulo de Young em função do raio da roda de inércia . . . . . . . . . . . . . . . . . . 223

10.28Tensão de von Mises em função do raio da roda de inércia . . . 223 


\section{Lista de Tabelas}

7.1 Resumo dos modelos de material propostos para MsGF . . . . . 151

7.2 Resumo dos modelos propostos para estimativa da tensão de referência para MsGF . . . . . . . . . . . . . . . . . . . . . . . . . 151

10.1 Propriedades mecânicas das fases constituintes do MGF adotadas para o problema da barra sob tração axial . . . . . . . . . . . . . 200

10.2 Propriedades mecânicas das fases constituintes do MGF adotada para o problema do cilindro sujeito a pressão externa . . . . . . 208

10.3 Propriedades mecânicas das fases constituintes do MGF para o problema do disco de turbina a gás . . . . . . . . . . . . . 216

10.4 Propriedades mecânicas das fases constituintes do MGF adotado para o problema da roda de inércia . . . . . . . . . . . . . 222 


\section{Lista de Abreviaturas}

OT Otimização Topológica

MOT Método de Otimização Topológica

MEMS Micro-Electro-Mechanical Systems

DFE Domínio Fixo Estendido

SIMP Solid Isotropic Microstructure with Penalization

ERV Elemento Representativo de Volume

MEF Método de Elementos Finitos

MAM Método das Assíntotas Móveis

FGM Functionally Graded Materials

MsGF Materiais com Gradação Funcional

MGF Material com Gradação Funcional

ACDM Aproximação Contínua da Distribuição de Material

CAMD Continuous Approximation of Material Distribution

MPEC Mathematical Programs with Equilibrium Constraints

PMRE Programação Matemática com Restrições de Equilíbrio

SAND Simultaneous Analysis and Design

POAS Projeto Otimizado e Análise Simultânea

H-S Hashin-Shtrikman

MLA Método do Lagrangeano Aumentado

PLS Programação Linear Seqüencial

PL Programação Linear 
MGBSE Método dos Gradientes Bi-Conjugados para Sistemas Esparsos

EPS Encapsulated PostScript

EPT Estado Plano de Tensão

CO Critério de Optimalidade

SPR Super-convergent Patch Recovery

REP Recovery by Equilibrium Patches 


\section{Convenções e Lista de Símbolos}

Os seguintes símbolos serão utilizados:

\begin{tabular}{|c|c|}
\hline símbolo & descrição \\
\hline$\Omega$ & Domínio Fixo Estendido (DFE) \\
\hline$\partial \Omega$ & Contorno do domínio $\Omega$ \\
\hline $\mathrm{x}$ & Coordenadas espaciais de um dado domínio \\
\hline $\mathbf{u}(\mathbf{x})$ & Campo de deslocamentos \\
\hline $\mathbf{f}(\mathbf{x})$ & Campo de forças externas \\
\hline $\mathbf{p}(\mathbf{x})$ & Campo de forças de campo \\
\hline $\mathrm{C}$ & Tensor constitutivo de um material homogêneo \\
\hline$\epsilon(\mathbf{x})$ & Campo de deformações \\
\hline$\chi(\mathbf{x})$ & $\begin{array}{l}\text { Função discreta representativa da distribuição de mate- } \\
\text { rial }\end{array}$ \\
\hline$\Omega_{m}$ & Domínio que possui material \\
\hline d & Vetor de deslocamentos nodais \\
\hline $\mathbf{K}$ & Matriz de rigidez global \\
\hline f & vetor de carregamento nodal \\
\hline$\chi_{c}(\mathbf{x})$ & $\begin{array}{l}\text { Função contínua representativa da distribuição de ma- } \\
\text { terial }\end{array}$ \\
\hline $\mathrm{C}^{\mathrm{H}}$ & $\begin{array}{l}\text { Tensor constitutivo efetivo de um material heterogêneo } \\
\text { ou poroso }\end{array}$ \\
\hline $\mathrm{C}_{\mathbf{0}}$ & Tensor constitutivo do material base \\
\hline$\rho$ & Densidade volumétrica ou pseudo-densidade de material \\
\hline$i, j$ & Índices utilizados nas formulas de somatória \\
\hline $\mathbf{y}$ & $\begin{array}{l}\text { Coordenadas espaciais no interior do Elemento Repre- } \\
\text { sentativo de Volume }\end{array}$ \\
\hline$\langle\boldsymbol{\sigma}\rangle$ & $\begin{array}{l}\text { Média das tensões sobre um Elemento Representativo } \\
\text { de Volume }\end{array}$ \\
\hline $\boldsymbol{\sigma}(\mathbf{y})$ & $\begin{array}{l}\text { Campo de tensão em um Elemento Representativo de } \\
\text { Volume }\end{array}$ \\
\hline
\end{tabular}




\begin{tabular}{ll}
\hline símbolo & descrição \\
\hline$\langle\boldsymbol{\epsilon}\rangle$ & Média das deformações sobre um Elemento Representa- \\
& tivo de Volume \\
$\boldsymbol{\epsilon}(\mathbf{y})$ & Campo de deformação em um Elemento Representativo \\
& de Volume \\
+ & Sobrescrito indicador da fase mais $(+)$ \\
- & Sobrescrito indicador da fase menos $(-)$ \\
$E$ & Módulo de Young \\
$\nu$ & Coeficiente de Poisson \\
$\mathbf{A}$ & Matriz localizadora de deformações \\
$\mathbf{B}$ & Matriz localizadora de tensões \\
$K$ & Módulo de compressibilidade \\
$G$ & Módulo de Cisalhamento \\
$M$ & Número de elementos da malha de elementos finitos \\
$N$ & Número de nós da malha de elementos finito \\
$\mu_{j}$ & Multiplicadores de lagrange \\
$c_{j}$ & Penalizadores das restrições no MLA \\
\hline
\end{tabular}




\section{Introdução}

Este trabalho versa sobre dois tópicos distintos, porém relacionados: o Método de Otimização Topológica (MOT) considerando restrições de tensão e a otimização de estruturas constituídas por Materiais com Gradação Funcional (MsGF)ํ․

O primeiro, isto é o MOT, consiste em uma ferramenta computacional aplicada à síntese de estruturas tradicionais. O segundo tópico, a otimização de estruturas constituídas por MsGF, consiste na aplicação dos métodos de otimização para o projeto de uma nova classe de estruturas, fabricadas com os MsGF.

O Método de Otimização Topológica (MOT) é um método computacional capaz de sintetizar estruturas mecânicas através da distribuição de material em uma região do espaço; para isto utiliza uma combinação entre métodos de otimização e o Método de Elementos Finitos (MEF). Assim, inicialmente uma região do espaço é discretizada em elementos finitos para que se possa analisar seu comportamento mecânico e, então, é distribuído material de forma racionalizada, por meio de algoritmos de otimização (BENDSøE; SIGMUND, 2003).

Um exemplo de estrutura sintetizada através do MOT é representado na figura 1.1, onde uma viga bi-apoiada com carregamento a meio vão é sintetizada e, com o intuito de reduzir o número de elementos, é considerada apenas metade da viga utilizando-se o conceito de simetria.

Uma vantagem do MOT é a sua capacidade de fornecer o leiaute ótimo de um componente mecânico para uma certa aplicação. Assim, este método pode ser aplicado durante a fase de projeto conceitual, diferentemente dos métodos tradicionais de otimização, como a otimização paramétrica ou de forma, que só podem ser aplicados após a definição do leiaute do componente. Desse modo, o MOT pode ser classificado como um processo de síntese de estruturas mecânicas.

Na literatura, o MOT tem sido aplicado a diversos problemas, como por

\footnotetext{
${ }^{1} \mathrm{Na}$ literatura este tipo de material é conhecido como Functionally Graded Materials (FGM), contudo, neste texto, será utilizada a nomenclatura em português Materiais com Gradação Funcional (MsGF). Aqui vale notar que a palavra Gradação constitui um anglicismo, porém acreditamos ser mais adequada para designar este tipo de material
} 


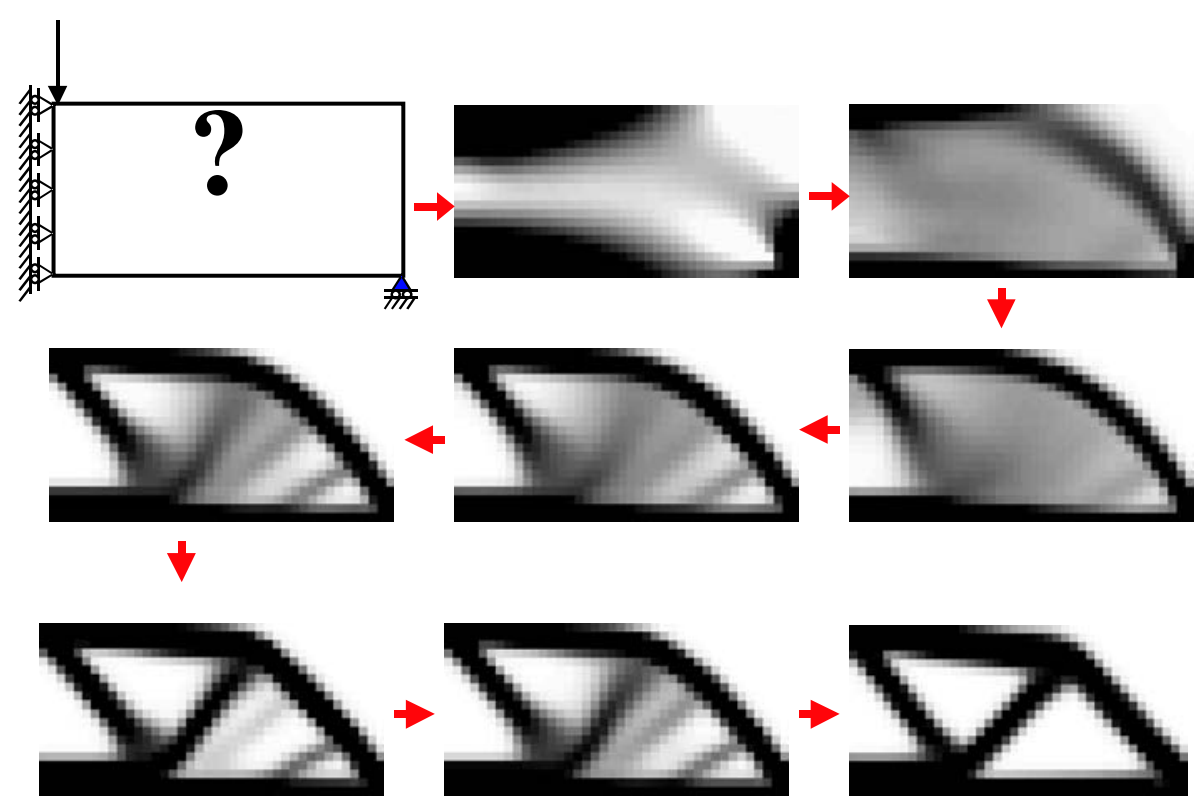

Figura 1.1: Exemplo de convergência da solução no método de otimização topológica

exemplo: o projeto de estruturas com máxima rigidez, o projeto de mecanismos flexíveis, o projeto de materiais e o projeto de estruturas para absorção de impacto, entre outros (BENDSøE; SIGMUND, 2003). Apenas recentemente o MOT foi aplicado ao projeto de estruturas tradicionais considerando restrições de tensão mecânica (DUYSINX; BENDSøE, 1998; PEREIRA; FANCELLO; BARCELLOS, 2004). Aumentando, assim, a gama de requisitos de projeto que podem ser atendidos com o auxílio do MOT.

Apesar do projeto de estruturas que atendam a critérios de falha ser um dos problemas tradicionais da Engenharia, este só foi tratado através do MOT em Duysinx e Bendsøe (1998) uma década após seu surgimento com o trabalho de Bendsøe e Kikuchi (1988). Este longo intervalo se explica devido às dificuldades inerentes ao tratamento das restrições de tensão, que serão apresentadas no capítulo 6.

Os Materiais com Gradação Funcional (MsGF) são materiais compostos, cujas propriedades variam de forma gradual ao longo do material. Esta classe de materiais apresenta algumas vantagens em relação aos materiais tradicionais. Utilizando os MsGF é possível construir componentes cuja microestrutura varie de forma gradual, de tal modo que em uma região há uma material metálico e em outra região há um material cerâmico. E, o mais importante, é que entre estas duas regiões não existe uma interface definida, ou seja, o material cerâmico é gradativamente substituído por material metálico, constituindo, assim, um material composto com a fração de cerâmica e metal variando suavemente (KIEBACK; 
NEUBRAND; RIEDEL, 2003).

Uma vantagem desse tipo de componente ou estrutura constituída por MsGF é a possibilidade de se aproveitar as propriedades dos dois materiais. Por exemplo, no caso do par metal-cerâmica pode-se projetar uma barreira térmica que possua em uma face as propriedades térmicas da cerâmica: baixa condutividade térmica e alto ponto de fusão, e na outra face as propriedades do metal: alta resistência a tração e alta resiliência. Assim, tem-se um componente que sozinho cumpre mais de uma função, a de fornecer resistência mecânica e resistência térmica (KOIZUMI, 1997).

Entretanto, o gradiente de propriedade na interface dos MsGF proporciona outras características interessantes, como: diminuição da tensão térmica residual, diminuição da propagação do escoamento plástico da fase dúctil e diminuição das tensões devido à diferença de rigidez entre as fases (EMBURY et al., 1996).

Outro ponto a ser explorado nos MsGF é a possibilidade de se projetar a distribuição de material e, conseqüentemente, a de propriedades, a fim de melhorar o desempenho da estrutura, o que, para alguns tipos de projeto, consiste na redução dos níveis de tensão mecânica na mesma.

Assim, o objetivo deste trabalho é o de estudar e implementar o Método de Otimização Topológica (MOT) considerando restrições de tensão, e aplicá-lo a duas classes de problema: o projeto de estruturas tradicionais e o projeto de estruturas constituídas por Materiais com Gradação Funcional (MsGF)

\subsection{Objetivo}

Conforme apresentado na seção anterior, o objetivo deste trabalho é estudar e implementar o Método de Otimização Topológica (MOT) considerando restrição de tensão para, então, aplicá-lo sobre dois problemas distintos: o projeto de estruturas tradicionais e o projeto de estruturas constituídas por Materiais com Gradação Funcional (MsGF).

Para a primeira classe de problemas, o projeto de estruturas tradicionais, o objetivo é implementar um software robusto capaz de sintetizar estruturas mecânicas que, através do leiaute, atendam a um dado requisito de tensão mecânica.

Na segunda classe de problemas, o projeto de estruturas constituídas por MsGF, o objetivo é implementar um software capaz de otimizar a distribuição de dois materiais em uma estrutura de modo a atender a um dado critério de 
falha. Entretanto, neste caso é considerado a possibilidade de que estes materiais se misturem no nível da microestrutura e assim constituam um MGF.

\subsection{Motivação e justificativa}

Uma motivação deste trabalho é que grande parte dos projetos de estruturas e componentes mecânicos têm como fator limitante para o seu desempenho os níveis de tensão mecânica. Esta situação ocorre no caso do projeto de discos rotativos de alta velocidade, como volantes (roda de inércia) e rotores de turbina a gás (KRESS, 2000; LIU; PARKS; CLARKSON, 2002).

A melhora no desempenho destes componentes pode ser obtida de duas formas. A primeira, e mais simples, consiste em selecionar um material mais nobre, ou seja, com resistência mecânica maior e, assim, garantir que a estrutura não falhará quando em operação.

A segunda forma de tratar este problema consiste em alterar o projeto da estrutura de modo a diminuir a tensão máxima na mesma, entretanto, a redução de tensão na estrutura é, em geral, obtida através do aumento de suas dimensões, acarretando em um aumento de peso, o que, em geral, está associado a um aumento de custo ou perda de desempenho. Assim, o objetivo é alterar o projeto da estrutura visando a diminuição da máxima tensão com a manutenção ou mesmo diminuição do peso da estrutura.

A formulação MOT apresentada neste trabalho trata o problema através desta segunda abordagem, que é mais racional e permite a redução do custo do material e o aumento de desempenho do componente.

A utilização de uma abordagem racional para o projeto de estruturas, através de métodos de otimização, é um tópico que tem atraído a comunidade científica há vários anos e a evolução dessa aplicação pode ser acompanhada através de trabalhos de revisão, desde a década de 60 até os dias atuais: Wasiutynski e Brandt (1963), Sheu e Prager (1968), Venkayya (1978), Kirsch (1989), Rozvany, Bendsøe e Kirsch (1995) e Eschenauer e Olhof (2001).

Além da importância dos métodos de otimização, demonstrada pelos trabalhos de revisão feitos ao longo de todos esses anos, a aplicação do MOT considerando restrição de tensão é um tema que tem sido classificado como fronteira do conhecimento na aplicação do MOT e merece ser tratado devido a sua grande aplicação na indústria. Esta afirmação foi feita pelo Prof. Martin P. Bendsøe no curso de verão "Homogenization and Shape Optimization", ocorrido em 2004 
em Portugal e reiterado no curso "Advanced school of Topology Optimization Theory, Methods and Applications", ocorrido em 2005 na Dinamarca.

A importância deste tema para o desenvolvimento do MOT e suas aplicações também foi exposta no Painel "Topology and Shape Design", apresentado pelo Prof. Erik Lund no " $6^{\text {th }}$ World Congress on Structural and Multidisciplinary Optimization", em 2005 no Rio de Janeiro, onde o palestrando atentou para o fato do elevado número de artigos que tratam de restrição de tensão ou deformação.

Assim, este trabalho visa a contribuir para o entendimento e desenvolvimento do tópico, em especial na comunidade científica brasileira.

Este trabalho também pretende fazer uma incursão sobre a aplicação do MOT no projeto de estruturas constituídas por MsGF. Pois, conforme dito anteriormente, a utilização dessa nova classe de materiais proporciona uma melhora de desempenho da estrutura, o que é de interesse da indústria.

É importante ressaltar também que, a possibilidade, criada pela utilização dos MsGF, de projetar a distribuição de material capaz de garantir a resistência mecânica da peça não só permite, mas também requer, a utilização de métodos de otimização, pois a definição desta distribuição não é uma tarefa trivial. Isto porque que a resistência mecânica da peça envolve o comportamento global da estrutura, devido à distribuição de rigidez, e o comportamento local, devido à intensificação da tensão causada pela microestrutura. 


\section{Otimização Topológica}

\subsection{Introdução}

O projeto de estruturas mecânicas é uma das atividades mais antigas da Engenharia. A primeira fase do projeto de estruturas consiste na definição conceitual da geometria e do material da estrutura, de modo a atender aos requisitos de projeto, porém, além de simplesmente atender aos requisitos de projeto, a Engenharia sempre esteve interessada em melhorar o desempenho das estruturas ou em reduzir o esforço (custo) necessário para atender a tais requisitos.

Com o objetivo de auxiliar o projeto e a otimização de estruturas, a OT, também denominada na literatura Otimização de Leiaute ou Otimização de Forma Generalizada, propõe um método genérico capaz de auxiliar o engenheiro na definição conceitual do leiaute ou topologia da estrutura. O leiaute ou topologia de uma estrutura é definido não somente pela sua forma, isto é, o contorno externo da estrutura, mas também por sua topologia, ou seja, furos internos e conectividade.

A grande vantagem da Otimização de Leiaute em contraste com os métodos mais tradicionais de otimização, como a Otimização de Forma ou a Otimização de Dimensão, é que estes dois últimos não são capazes de alterar o leiaute da estrutura original, ou seja, esses métodos não auxiliam o projeto conceitual da estrutura.

Considerando um Domínio Fixo Estendido (DFE), uma região do espaço onde pode existir a estrutura, um dado carregamento, uma dada fixação e uma certa quantidade de material, a Otimização de Leiaute de estruturas contínuas consiste em definir simultaneamente as formas dos contornos internos e externos da estrutura, bem como a quantidade e posições de seus buracos através da distribuição de material dentro do DFE, levando em consideração a maximização do desempenho da estrutura para um dado tipo de projeto. Para ilustrar melhor esta situação, um exemplo de formulação clássica é a obtenção do leiaute de 
uma estrutura tal que a rigidez para um dado carregamento seja máxima e a quantidade de material seja limitada a uma dada fração do DFE.

A forma de otimização do leiaute de uma estrutura pode ser dividida em duas grandes classes de abordagens (ESCHENAUER; OLHOF, 2001): a abordagem micro, ou baseada no material, e a abordagem macro, ou baseada na geometria.

A abordagem micro, a primeira a ser desenvolvida, é baseada na existência de uma microestrutura porosa que define as relações constitutivas do material em função da geometria e da densidade volumétrica de uma célula unitária representativa do material. Por sua vez, a densidade é representada por variáveis contínuas continuamente distribuídas no espaço do DFE. Nesta abordagem o DFE é discretizado por uma malha de elementos finitos que não se altera ao longo da otimização e permite calcular as respostas mecânicas (ex. campo de tensão e deformação). A otimização consiste em determinar quais pontos da estrutura devem possuir ou não material; assim sendo, a distribuição de densidades é parametrizada de modo que cada ponto do DFE possa variar entre um (1) (material sólido, em geral definido pela cor preta na apresentação dos resultados) e zero (0) (ausência de material ou presença de um material mole, em geral definido pela cor branca). Assim, durante o processo de otimização as variáveis tendem aos seus valores limites indicando regiões com presença de material (pretas) e regiões com buracos (brancas), o que define o leiaute da estrutura.

A otimização de leiaute que utiliza essa abordagem já possui uma vasta literatura introdutória encontrada em livros, como Bendsøe e Sigmund (2003) e Bendsøe e Soares (1993), com um enfoque mais voltado à aplicação, ou em Allaire (2002), no qual a formulação matemática é apresentada e discutida junto com uma implementação numérica. Um desenvolvimento teórico matemático mais aprofundado pode ser encontrado no livro de Cherkaev (2000).

Apesar da comunidade científica não aceitar completamente o uso do termo Otimização Topológica (OT) para designar a abordagem micro, neste trabalho será utilizada esta associação, de acordo com Bendsøe e Sigmund (2003) e os trabalhos de Emílio Carlos Nelli Silva (SILVA; NISHIWAKI; KIKUCHI, 2000; SILVA, 2003)

Dentre a abordagem macro, ou baseada na geometria, podem se agrupar três principais vertentes: o "bubble method"1, a otimização de leiaute, baseada no

\footnotetext{
${ }^{1} \mathrm{O}$ termo "bubble method" poderia ser traduzido para a língua portuguesa como método das bolhas porém essa nomenclatura é pouco comum de forma que se optou por manter o termo em inglês ao longo do texto.
} 
método de "level set", e os os métodos evolucionários.

O "bubble method" consiste em alterar o leiaute da estrutura através do crescimento e degeneração de furos no interior da mesma baseando-se no conceito de derivada topológica. Essa abordagem é descrita em artigos como: Eschenauer H. A. Kobelev e Schumacher (1994), Sokolowski e Zochowski (1999), Novotny et al. (2003).

O método de otimização de leiaute baseado no método de "level set" foi proposto inicialmente por Sethian e Wiegmann (1999) e vem ganhando bastante atenção na otimização estrutural. Este método é baseado na representação do leiaute da estrutura através da curva de nível zero de uma função de alta ordem. Por exemplo, no caso bi-dimensional a fronteira da estrutura é definida pelo conjunto de pontos de valor zero de uma função escalar em termos das coordenadas $x$ e $y$ do plano. Dessa forma, a fronteira da estrutura, definida pela curva de nível zero, é movimentada de modo a minimizar uma dada função objetivo. No trabalho de Sethian e Wiegmann (1999), uma forma heurística de movimentação da fronteira foi utilizada, caracterizando uma abordagem evolucionária de otimização estrutural. Posteriormente, outros autores combinaram essa abordagem com a análise de sensibilidade da função objetivo; dentre eles pode-se citar: Osher e Santosa (2001), Mei e Wang (2004), Yulin e Xiaoming (2004)

A principal vantagem do método de "level set" é a definição precisa dos contornos da estrutura. Esta vantagem é importante para tratar problemas que a carga da estrutura depende de sua geometria (por exemplo: carga devido a pressão (ALLAIRE; JOUVE; TOADER, 2004)) ou em problemas onde os fenômenos ocorrem na superfície, como por exemplo o projeto de uma aleta ou trocador de calor.

Ainda sobre o método de "level set", Burger e Osher (2005) apresentam uma revisão sobre o seu desenvolvimento, suas áreas de aplicação e desafios futuros. Para uma introdução didática ao método, ver o artigo de Liu, Korvink e Huang (2005)

Recentemente, o trabalho de Burger, Hackl e Ring (2004) aponta para uma convergência da otimização de leiaute baseada no método de "level set" com o "bubble method".

Os métodos evolucionários se baseiam no conceito de uma estrutura base,

\footnotetext{
${ }^{2}$ O termo "level set" poderia ser traduzido para a língua portuguesa como curva de nível porém essa nomenclatura é pouco comum de forma que se optou por manter o termo em inglês ao longo do texto.
} 
em geral uma malha de elementos finitos de onde serão inseridos e/ou retirados elementos. A modificação da estrutura base é feita através de critérios heurísticos. Uma descrição mais detalhada desse método pode ser encontrada nos artigos de Chu et al. (1996, 1997), Li et al. (1999), Liu, Parks e Clarkson (2000), Steven, Li e Xie (2002).

\subsection{Revisão bibliográfica do Método de Otimização Topológica}

Neste trabalho será tratada apenas a otimização de leiaute baseada na abordagem micro: Método de Otimização Topológica (MOT), ou simplesmente Otimização Topológica (OT).

O MOT foi proposto por Bendsøe e Kikuchi (1988) e se baseia fortemente; segundo o próprio autor, na contribuição de diversos pesquisadores. Neste trabalho Bendsøe apresenta uma aproximação da otimização de leiaute por um problema de distribuição de dois materiais, sendo um deles material vazio (buracos). Para isso o autor se baseia na parametrização das propriedades do material através do conceito de microestrutura.

A utilização de microestruturas no problema de projeto ótimo de estruturas já havia sido proposta nos trabalhos de Cheng e Olhoff $(1981,1982)$. Como conseqüência da utilização de microestruturas para parametrização do problema, o método de homogeneização, também desenvolvido previamente (BENSOUSSON; LIONS; PAPANICOLAOU, 1978; SANCHES-PALENCIA, 1980), passou a ser aplicado no cálculo das propriedades efetivas dos materiais obtidos. A formulação matemática para a relaxação do problema de otimização estrutural e sua relação com o método de homogeneização também já havia sido demonstrada no trabalho de Kohn e Strang (1986a, 1986b, 1986c).

A partir do trabalho de Bendsøe e Kikuchi (1988), se seguiu uma série de trabalhos dedicados a aprimorar o método e ampliar o espectro de aplicação do MOT. Um grande marco no desenvolvimento do MOT foi a utilização de modelos de material artificiais por Bendsøe (1989), Rozvany, Zhou e Birker (1992), que eliminou a necessidade de utilizar os métodos de homogeneização para a sua implementação numérica, facilitando, assim, a difusão do MOT. Dentre as publicações precursoras do método devem se citar também os trabalhos Suzuki e Kikuchi (1991) e Olhoff, Bendsøe e Rasmussen (1991) que, apesar de posteriores, auxiliaram sua consolidação; o primeiro faz uma verificação numérica de sua eficiência 
do método através de diversos exemplos, além de comparar as soluções obtidas com as soluções de Michell (MICHELL, 1904), o segundo apresenta a aplicação do MOT associada à otimização de forma e utiliza esta metodologia em alguns problemas reais, entre eles a tradicional viga MBB (Messerschmidt-Bölkow-Blohm) que passou a ser um benchmark para o MOT

Após a consolidação do MOT surgiram várias linhas de desenvolvimento e aplicação deste. Parte da comunidade científica despendeu um grande esforço para a compreensão e o tratamento de alguns problemas inerentes à sua formulação, enquanto outra parte se dedicou à aplicação do novo método em diferentes problemas da Engenharia.

Dentre as contribuições para o desenvolvimento do método, os principais tópicos desenvolvidos foram: o controle da instabilidade de tabuleiro, o tratamento da dependência da malha e o controle das escalas de cinza. Estes três tópicos estão intrinsecamente relacionados, pois os métodos que tratam cada um deles, em geral, influenciam os demais. As principais contribuições nesta área foram dadas por: Jog e Haber (1996), Haber, Jog e Bendsøe (1996), Sigmund (1997), Sigmund e Petersson (1998), Petersson e Sigmund (1998), Cardoso e Fonseca (1999), Zhou, Shyy e Thomas (2001), Stolpe e Svanberg (2001a), Bourdin (2001), Poulsen (2002), Rahmatalla e Swan (2003), Poulsen (2003), Zhang e Duysinx (2003), Rahmatalla e Swan (2004), Matsui e Terada (2004). Uma revisão bibliográfica destes será feita adiante, na seção 2.5 .

Além dos métodos para o tratamento desses problemas numéricos, desenvolveuse também uma série de algoritmos de otimização aplicados ao MOT e, neste sentido, as principais contribuições foram dadas por: Zhang et al. (1996), Beckers e Fleury (1997), Bulman, Sienz e Hinton (2001), Bruyneel, Duysinx e Fleury (2002), Svanberg (2002), Kim, Kim e Kim (2004), Bruyneel e Duysinx (2005).

\subsection{Formulação geral do problema de Otimização Topológica}

A formulação matemática do Método de Otimização Topológica será apresentada para o problema clássico de maximização da rigidez com restrição de volume. Apesar deste não ser o problema tratado neste trabalho, esta apresentação auxiliará a definição das bases teóricas do método e, posteriormente, será apresentada a formulação do problema especifico considerando restrição de tensão mecânica.

O problema de maximização da rigidez de uma estrutura linear elástica sob 
a ação de um único caso de carga é equivalente ao problema de minimização da flexibilidade, definida como o trabalho realizado pelas forças externas. Por sua vez, minimizar a flexibilidade equivale a minimizar a energia de deformação elástica total .

Isso pode ser observado analisando a equação 2.1 do trabalho das cargas aplicadas:

$$
W(\mathbf{u}(\mathbf{x}))=\int_{\Omega} \mathbf{f}(\mathbf{x})^{T} \mathbf{u}(\mathbf{x}) d \Omega+\int_{\partial \Omega} \mathbf{p}(\mathbf{x})^{T} \mathbf{u}(\mathbf{x}) d \partial \Omega
$$

onde $\mathbf{x}$ representa as coordenadas espaciais de cada ponto da estrutura, $\mathbf{u}(\mathbf{x})$ representa o campo de deslocamentos nas condições de equilíbrio, $\mathbf{f}(\mathbf{x})$ as forças de campo aplicadas na estrutura e $\mathbf{p}(\mathbf{x})$ as forças aplicadas na superfície da estrutura.

Sendo assim, o problema de maximização da rigidez com restrição de volume, define a minimização da energia de deformação elástica total tal que as condições de equilíbrio dada, pelo princípio do trabalho dos deslocamentos virtuais, sejam atendidas e que a função discreta $\chi(\mathbf{x})$ defina uma estrutura de volume menor ou igual a um volume de referência. O problema escrito dessa forma é caracterizado por possuir como variável uma função de parâmetros discretos continuamente distribuídos no espaço, e pode ser escrito conforme o problema 2.2.

$$
\begin{aligned}
& \underset{\chi(\mathbf{x})}{\operatorname{minimizar}} \int_{\Omega} \mathbf{f}(\mathbf{x})^{T} \mathbf{u}(\mathbf{x}) d \Omega+\int_{\partial \Omega} \mathbf{p}(\mathbf{x})^{T} \mathbf{u}(\mathbf{x}) d \partial \Omega \\
& \text { tal que } \\
& \quad \int_{\Omega} \tilde{\boldsymbol{\epsilon}}(\mathbf{x})^{T} \mathbf{C}(\mathbf{x}) \boldsymbol{\epsilon}(\mathbf{x}) d \Omega-\int_{\Omega} \mathbf{f}(\mathbf{x})^{T} \tilde{\mathbf{u}}(\mathbf{x}) d \Omega-\int_{\partial \Omega} \mathbf{p}(\mathbf{x})^{T} \tilde{\mathbf{u}}(\mathbf{x}) d \partial \Omega=0 \\
& \quad \int_{\Omega} \chi(\mathbf{x}) d \Omega \leq \Omega_{r e f}
\end{aligned}
$$

Onde a função discreta $\chi(\mathbf{x})$ é a variável de projeto que define que pontos do DFE possuem material:

$$
\chi(\mathbf{x})= \begin{cases}1 & \text { se } \mathbf{x} \in \Omega_{m} \\ 0 & \text { se } \mathbf{x} \in \Omega \backslash \Omega_{m}\end{cases}
$$

Assim, o tensor constitutivo do material ao longo do domínio $\Omega$ é dado por 2.4:

$$
\mathbf{C}=\chi(\mathbf{x}) \mathbf{C}_{0}
$$

Ainda no problema $2.2, \tilde{\boldsymbol{\epsilon}}(\mathbf{x})$ representa o campo de deformação virtual, obtido a partir do campo de deslocamentos virtuais $\tilde{\mathbf{u}}(\mathbf{x})$,

A notação utilizada neste problema está representada na figura 2.1, onde: 
$\Omega$ representa o Domínio Fixo Estendido (DFE)

$\partial \Omega$ representa o contorno do DFE

$\partial \Omega_{N}$ representa o contorno do DFE sujeito às condições de contorno de Neumann: pressão aplicada conhecida

$\partial \Omega_{D}$ representa o contorno do DFE sujeito às condições de contorno de Dirichlet: deslocamento conhecido

$\Omega_{M}$ representa região do DFE que apresenta material

$\partial \Omega_{M}$ representa o contorno de $\Omega_{M}$

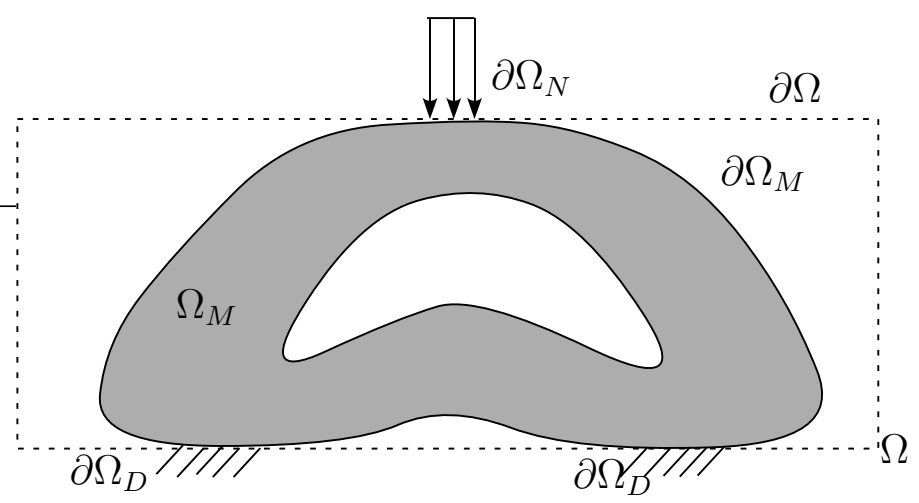

Figura 2.1: Domínio Fixo Estendido (DFE) e notação adotada

Para se calcular numericamente a função objetivo $W[\mathbf{u}(\mathbf{x})]$, é necessário obter o campo de deslocamento da estrutura. Uma forma tradicional de resolver este problema é aplicando o MEF. Este será aqui descrito de forma sucinta, apenas para permitir a apresentação da formulação do MOT. A descrição da formulação do MEF, utilizada neste trabalho, será feita no capítulo 5. Partindo da equação da energia potencial total 2.5:

$$
\Pi=U-W=\frac{1}{2} \int_{\Omega} \boldsymbol{\epsilon}(\mathbf{x})^{T} \mathbf{C}(\mathbf{x}) \boldsymbol{\epsilon}(\mathbf{x}) d \Omega-\int_{\Omega} \mathbf{f}(\mathbf{x})^{T} \mathbf{u}(\mathbf{x}) d \Omega-\int_{\partial \Omega} \mathbf{p}(\mathbf{x})^{T} \mathbf{u}(\mathbf{x}) d \partial \Omega
$$

e então, aplicando o procedimento típico de discretização da estrutura em $M$ elementos finitos e interpolado o campo de deslocamento através de variáveis nodais, obtemos a equação 2.5 na sua forma matricial 2.6 :

$$
\Pi=U-W=\frac{\mathbf{d}^{T} \mathbf{K} \mathbf{d}}{2}-\mathbf{f}^{T} \mathbf{d}
$$

onde $\mathbf{d}, \mathbf{K}$ e $\mathbf{f}$ são: o vetor de deslocamento, a matriz de rigidez e o vetor de carga, respectivamente. Seguindo o procedimento do MEF, a condição de equilíbrio é 
obtida pelo princípio da mínima energia potencial total, que requer a condição de estacionalidade de $\Pi$ em relação a $\mathbf{d}$ :

$$
\frac{\partial \Pi}{\partial \mathbf{d}}=0
$$

o que leva ao conhecido sistema linear

$$
\mathbf{K d}=\mathbf{f}
$$

que permite obter os deslocamentos da estrutura para um dado carregamento. Assim, pode-se definir a formulação do problema em função de parâmetros discretos discretamente distribuídos no espaço:

$$
\underset{\chi \in B}{\operatorname{minimizar}} W(\mathbf{d})
$$

$$
\mathrm{Kd}=\mathbf{f}
$$

onde $B$

$$
B=\left\{\begin{array}{l|l}
\chi & \chi \\
\Omega & \\
\Omega & =V_{\text {ref }}
\end{array}\right\}
$$

Analisando as formulações apresentadas, observa-se que este é um problema de otimização de parâmetros discretos, comumente chamado de problema (0-1). É sabido que, de um modo geral, este problema não tem solução (ALLAIRE, 2002; SIGMUND; PETERSSON, 1998), pois eventualmente podem-se gerar seqüências de funções $\chi(x)$ que fornecem sempre um valor menor de função objetivo. Apesar de aparentemente estranho, isto pode ser compreendido se considerarmos que, em alguns problemas, a inclusão de furos em certas partes do DFE melhora a função objetivo, o que pode implicar que a solução ótima só é atingida no limite, quando as dimensões dos furos tendem a zero.

Matematicamente, isso significa que o espaço de soluções admissível, definido pela função $\chi(\mathbf{x})$ e atendendo à restrição de volume dada por 2.10, é não compacto. Assim, para que o problema 2.2 apresente solução é necessário alterar o espaço de solução, de modo que este se torne compacto e contenha a solução ótima $\chi^{*}(\mathbf{x})$. Isso pode ser feito através da adoção de restrições extras ao problema, como limitar o perímetro da função $\chi(\mathbf{x})$, abordagem que foi utilizada na implementação numérica proposta por Haber, Jog e Bendsøe (1996). Outra forma de tornar o espaço de solução compacto é através da relaxação matemática do problema; a idéia de relaxação consiste em aumentar o espaço de soluções admissível de forma a garantir a existência de solução. Neste caso o aumento do 
espaço de solução é feito pela modificação da função $\chi(\mathbf{x})$ que passa a possuir valores contínuos entre 0 e 1 .

No caso do problema estrutural, a forma de relaxar o problema foi proposta em Kohn e Strang (1986a, 1986b, 1986c), nos quais os autores fazem a conexão entre três campos do saber que, em geral, eram tratados de forma separada: projeto ótimo de estruturas, relaxação e homogeneização. Os autores propuseram que a relaxação do problema de projeto ótimo, apresentado em 2.2, fosse feita através da consideração de materiais compostos, obtidos pela "furação" de um meio homogêneo. Propuseram também que os valores das propriedades efetivas do material composto fossem obtidos de forma exata pelo método de homogeneização. Por sua vez, o método da homogeneização é utilizado no cálculo das propriedades efetivas. Desse modo, nasce o conceito de modelo de material utilizado no Método de Otimização Topológica.

\subsection{Modelos de material}

Nesta seção serão apresentados os principais modelos de material aplicados na relaxação do problema de otimização.

Conforme a formulação apresentada na seção 2.3, a função de valores discretos $\chi$ deve ser substituída por uma função contínua $\chi_{c}$ que parametrize o tensor constitutivo do material para as densidades volumétricas $\rho$, variando de 0 (vazio) a 1 (sólido), passando pelas densidades intermediárias, que por sua vez, representam materiais porosos. Dessa forma, o espaço das soluções admissível é aumentado, relaxando o problema. As principais classes de modelo de material são:

- modelos de material baseados na existência de uma microestrutura, que é representada por uma célula unitária com geometria parametrizável. Estes modelos de material podem ser subdivididos em dois grupos, o daqueles que possuem uma microestrutura ótima e os que possuem microestruturas sub-ótimas, no sentido matemático de relaxação do problema de otimização de mínima flexibilidade.

As propriedades efetivas dos materiais compostos são, em geral, calculadas utilizando o método de homogeneização, o que levou a literatura a nomear essa classe de modelo de material de "Método da Homogeneização". Porém, existem outros métodos para o cálculo das propriedades efetivas de materiais compostos (ESCHENAUER; OLHOF, 2001). 
- modelos de material artificial. Estes modelos não são baseados na existência de uma microestrutura, apenas fornecem uma função contínua que parametriza a rigidez do material para densidade $\rho$, variando entre 0 e 1 . Uma das formulações mais conhecidas na literatura para esta classe de modelo é o SIMP.

\subsubsection{Modelos baseados em microestruturas}

Os modelos de material baseados em uma microestrutura consistem na definição de uma função $\chi_{c}(\mathbf{x})$, a partir da escolha de uma microestrutura composta por células unitárias de dimensões infinitesimais que se repete indefinidamente ao longo da estrutura. Este material é então interpretado como um material composto, uma vez que sua célula unitária é composta por dois materiais. A figura 2.2 representa esta situação.

Exemplo de microestrutura perfurada

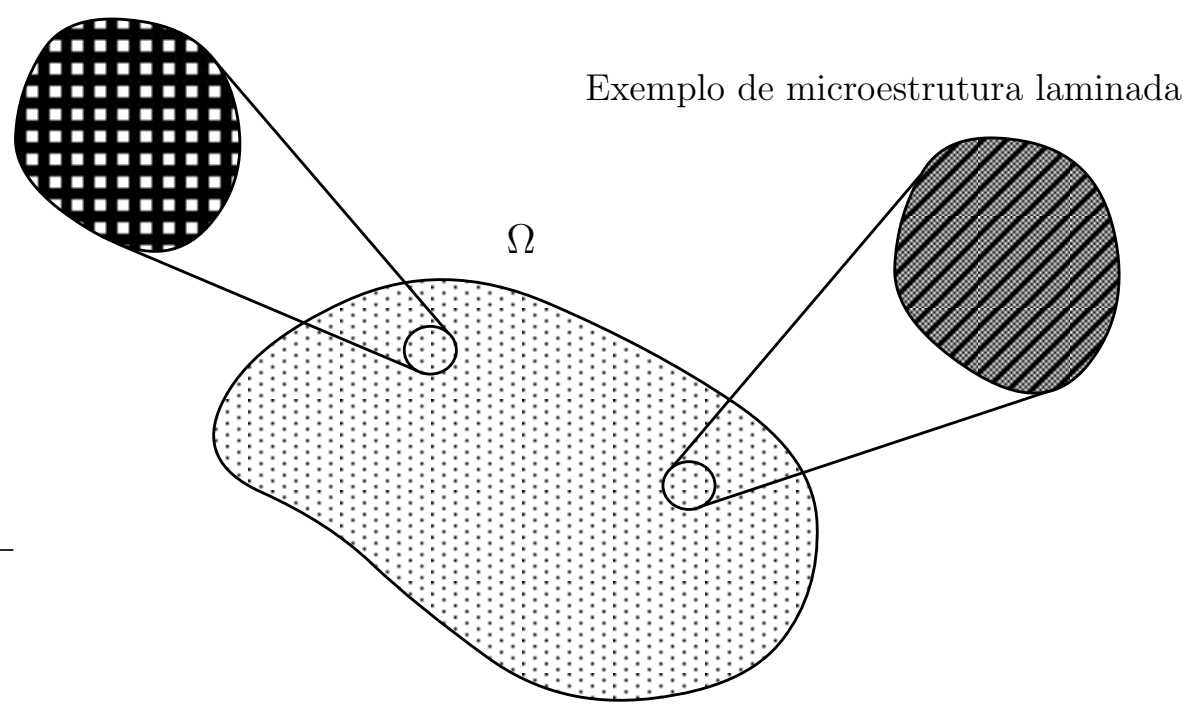

Figura 2.2: Representação de modelos de material baseado na microestrutura.

A partir da definição da célula unitária e de sua parametrização, como por exemplo a direção e as dimensões da laminação ou as dimensões e a rotação de um furo retangular dentro de uma célula unitária, é possível, através do método da homogeneização, obter as propriedades mecânicas efetivas do material, também chamadas de propriedades homogeneizadas.

O método de homogeneização foi desenvolvido inicialmente como um forma de solução de equações diferenciais parciais cujos parâmetros variam rapidamente no espaço. Dentro da Engenharia, este método tem sido aplicado para a obtenção das propriedades efetivas de materiais compostos (SANCHEZ-PALENCIA; ZAOUI, 
1985). Uma maior descrição desse método pode ser encontrada, em ordem de profundidade, nos livros: Bendsøe e Sigmund (2003), Allaire (2002) e Cherkaev (2000).

Nota-se que a parametrização da geometria leva à definição uma densidade volumétrica de material $(\rho)$ que, em geral, é utilizada para representar graficamente a solução do MOT, definindo assim a idéia de regiões brancas $\left(\rho=\rho_{\min } \geq 0\right)$, pretas $(\rho=1)$ e cinzas $\left(\rho_{\min }<\rho<1\right)$.

Um ponto importante quanto aos modelos de material baseados na microestrutura diz respeito à capacidade da microestrutura em relaxar o problema discreto de parâmetros continuamente distribuídos (2.2), assim, as microestruturas podem ser divididas em microestruturas ótimas, aquelas que garantem uma relaxação total do problema, e microestruturas sub-ótimas, que garantem apenas uma relaxação parcial. Este conceito pode ser estendido a qualquer formulação de OT (ALlAIRE; AUBRY, 1999). Para o problema tradicional de minimização da flexibilidade está provada a existência de solução, ou seja, a relaxação total do problema, através da utilização de microestruturas laminadas do tipo rank-1, rank-2, rank-n ${ }^{3}$ (ALLAIRE; AUBRY, 1999; ALLAIRE; KOHN, 1993).

As microestruturas laminadas do tipo rank-n, são microestruturas que possuem $n$ camadas de laminação e cada camada é por sua vez constituída por uma sub camada que também é laminada. Essa estrutura se repete por $n$ vezes. Por exemplo, uma estrutura rank-2 possui uma primeira camada de laminação constituída por dois materiais, sendo que um dos materiais também é um material laminado, porém em um escala de grandeza menor. Um explicação mais detalhada desse tipo de estrutura é feita adiante na subseção 4.4.1, onde é apresentada o cálculo das propriedades efetivas de um material rank-2.

Para outras formulações e funções objetivo não está claro na literatura, em termos matemáticos, a necessidade e/ou possíveis formas de relaxação do problema.

Para o problema de minimização da flexibilidade com restrição de tensão, recentemente, foi apresentada por Lipton (2004) uma prova matemática da necessidade da relaxação e um espaço de soluções fechado que garante existência de solução. Apesar deste trabalho lançar luz sobre a solução dos problemas de otimização, ele se restringe a apresentar as provas matemáticas para a relaxação do problema e sua implementação numérica não é apresentada.

\footnotetext{
${ }^{3} \mathrm{O}$ termo rank-n poderia ser traduzido para a língua portuguesa como microestrutura laminada de posto- $n$, porém essa nomenclatura é pouco comum, de forma que se optou por manter o termo em inglês ao longo do texto.
} 
Em termos práticos, a escolha da micro estrutura irá influenciar a solução do problema, mais especificamente em relação à presença de cinza (BENDSØE; SIGMUND, 1999).

\subsubsection{Modelos artificiais}

Os modelos de material artificiais se baseiam na idéia de que a microestrutura é desconhecida porém seu tensor constitutivo não é. Esta forma de parametrização do material foi proposta inicialmente por Bendsøe (1989) e, posteriormente, estudada por Rozvany, Zhou e Birker (1992), e consiste em parametrizar o tensor constitutivo por uma função contínua, aqui denominada $f_{\text {SIMP }}(\rho)$. Assim, temos $\chi_{c}$ dada por:

$$
\chi_{c}(\mathbf{x})=f_{S I M P}(\rho(\mathbf{x}))
$$

Logo, tal qual a equação 2.4, o tensor constitutivo ao longo da estrutura é dado por 2.12 e localmente por 2.13:

$$
\begin{gathered}
\mathbf{C}^{\mathbf{H}}=\chi_{c}(\mathbf{x}) \mathbf{C}_{0} \\
\mathbf{C}^{\mathbf{H}}=f_{S I M P}(\rho) \mathbf{C}_{0}
\end{gathered}
$$

onde $\mathbf{C}_{0}$ é o tensor constitutivo do material original a ser distribuído e $\mathbf{C}^{\mathbf{H}}$ é o tensor efetivo, que será utilizado no cálculo da resposta mecânica da estrutura. A função $f_{S I M P}(\rho)$, a princípio, é qualquer função que tenha imagem entre $0 \mathrm{e}$ 1, porém na literatura se consagrou a utilização de uma função exponencial em relação à $\rho$ :

$$
f_{\text {SIMP }}(\rho)=\rho^{q}
$$

Assim, é inserido na formulação o parâmetro $q$, que deve ser definido empiricamente, porém sua influência no resultado final é clara: para $q>1$ as densidades intermediárias são penalizadas, gerando resultados sem a presença de cinzas ou com pouca presença de cinzas. 


\subsection{Aspectos numéricos da Otimização Topológica}

A utilização dos modelos de materiais baseados em microestruturas por Bendsøe e Kikuchi (1988) ou a utilização de modelos artificiais por Bendsøe (1989) e Rozvany, Zhou e Birker (1992) permitiu a obtenção de soluções numéricas para o problema 2.2 de variáveis discretas e parâmetros distribuídos. Utilizando o conceito de modelo de material, o problema 2.4 é então escrito conforme apresentado em 2.15, utilizando variáveis contínuas discretamente distribuídas no espaço:

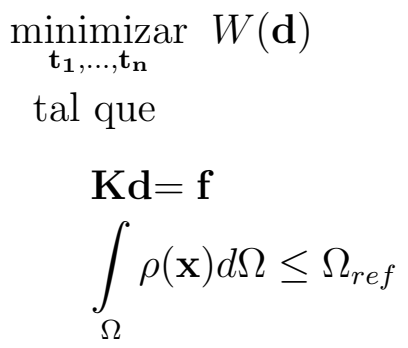

onde $\mathbf{t}_{1}, \ldots, \mathbf{t}_{\mathbf{n}}$ representam, de maneira genérica, os parâmetros do modelo de material adotado e $\rho$ a fração volumétrica de material em cada ponto do DFE. Por exemplo, no caso do material SIMP, teríamos apenas um vetor $\mathbf{t}_{\mathbf{1}}=\boldsymbol{\rho}$ representando as densidades volumétricas dos elementos. No caso de um modelo de material de material laminado rank-2, $\mathbf{t}_{\mathbf{1}}$ representaria a fração entre os materiais na primeira camada de laminação, $\mathbf{t}_{2}$ o ângulo da primeira camada em relação aos eixos coordenados, e assim por diante. Conseqüentemente, a densidade volumétrica seria escrita como $\rho(\mathbf{x})=f\left(\mathbf{t}_{\mathbf{1}}, \ldots, \mathbf{t}_{\mathbf{n}}\right)$.

Do ponto de vista matemático, o problema inicialmente proposto na sua forma 2.2 (função de parâmetros discretos continuamente distribuídos) é resolvido utilizando uma microestrutura ótima, garantindo assim a obtenção da solução ótima relaxada. Contudo, do ponto de vista da Engenharia, a solução ótima do problema relaxado não é útil para grande parte das aplicações, pois esta, como era de se esperar, costuma apresentar uma grande quantidade de regiões cinzas. Devido a este fato, desenvolveram-se algumas ferramentas ou alterações na formulação, de modo a se obter estruturas úteis do ponto de vista de Engenharia, ainda que estas sejam sub-ótimas do ponto de vista matemático.

\subsubsection{Escala de cinza}

Nos problemas tradicionais onde se está interessado em obter uma distribuição discreta de material, a relaxação total do problema através da utilização das 
microestruturas ótimas não é interessante, devido à presença de escala de cinza no resultado final.

Uma forma alternativa à relaxação para se obter um problema bem-posto e sem a presença de escala de cinza, é através da solução do problema na sua forma discreta, associado à restrição do espaço de solução.

O conceito de restrição de perímetro da estrutura ótima como forma de restrição do espaço, a fim de que este se torne compacto, o que torna o problema bem-posto, foi proposta inicialmente por Ambrosio e Buttazzo (1993).

Nessa linha Haber, Jog e Bendsøe (1996) propuseram uma implementação numérica da restrição sobre o perímetro da região sólida ( $\partial \Omega_{M}$, figura 2.1$)$, assim, as soluções ótimas, que são representadas pela oscilação entre pontos com material e pontos sem material, são retiradas do espaço de solução, uma vez que estas, no limite para o tamanho característico das oscilações tendendo a zero, têm o perímetro tendendo a infinito.

Diferentemente da relaxação, ao se discretizar a formulação de OT, com restrição de perímetro, se obtém um problema de otimização inteira. Contudo, em Haber, Jog e Bendsøe (1996) o problema discreto foi aproximado por um problema com variáveis contínuas a fim de se utilizar os métodos tradicionais de programação matemática. Neste caso, as densidades intermediárias foram fortemente penalizadas para se retornar ao problema discreto e obter uma solução $0-1$.

Os resultados numéricos apresentados demonstram que a formulação é capaz de retirar as regiões cinzas da solução devido à penalização e manter o problema bem-posto.

Em uma abordagem mais fiel à restrição do espaço de solução, Beckers (1997) apresenta uma formulação similar de restrição de perímetro, muito embora trata o problema na sua forma discreta, através de um método eficiente de programação matemática inteira, aplicada no espaço dual do problema. Graças à eficiência desse método de otimização, Beckers é capaz de tratar problemas de larga-escala com malhas de até 60 mil elementos.

O tratamento da escala de cinza, através da solução do problema, na sua forma discreta ou na forma contínua com penalização, associada à restrição de perímetro, mostrou-se eficiente, como se observa nos trabalhos acima citados. Entretanto, poucos trabalhos seguiram essa abordagem, principalmente devido à dificuldade do algoritmo de otimização em tratar tal restrição (tanto na forma 
discreta como contínua), além da existência de soluções alternativas para o caso do problema na forma contínua com penalização. Uma implementação mais eficiente, ainda que mais complexa, da restrição de perímetro é apresentada em Zhang e Duysinx (2003). Um exemplo de estrutura obtida com restrição de perímetro é apresentada na Figura 2.3.

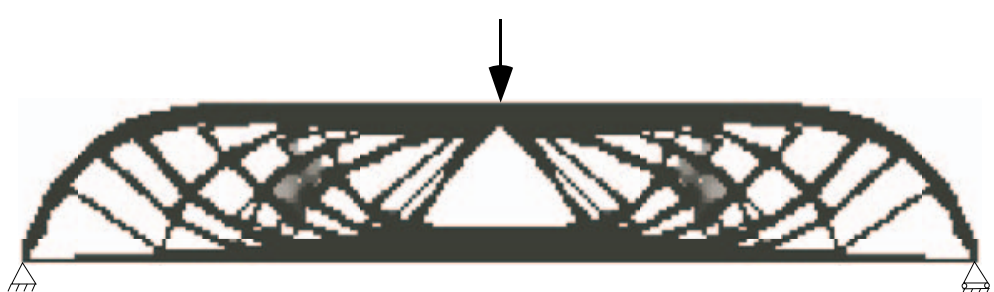

Figura 2.3: Exemplo de solução sem dependência de malha e instabilidade de tabuleiro obtida através da restrição de perímetro

A forma de se obter soluções 0-1, utilizando a relaxação do problema feita através do modelo de material, é inserindo ao problema formas de penalização das densidades intermediárias. Esta é uma das maneiras mais simples e eficientes de minimizar o surgimentos de escala de cinza. Grande parte dos artigos, que tratam da aplicação do MOT utilizam esta abordagem.

O modelo de material SIMP foi proposto considerando na sua formulação um fator de penalização ( $q$ na equação 2.14) que evita o surgimento de cinzas através da diminuição da rigidez para as densidades volumétricas intermediárias. Outras formas de penalização podem ser utilizadas, como a adição de termos na função objetivo que quando extremados tendem a diminuir a presença das regiões cinzas. Implementações numéricas dessa abordagem podem ser encontradas em Allaire et al. (1997) e Pereira, Fancello e Barcellos (2004).

Em geral, os métodos de penalização das densidades intermediárias devem vir acompanhados da utilização de métodos de continuação, pois, geralmente, estes métodos tendem a aumentar o grau da função objetivo, de modo que esta passa a ter um maior número de mínimos locais.

No caso da penalização das densidades intermediárias através do parâmetro $q$ do método SIMP, é feita a continuação do valor de $q$ ao longo do processo iterativo. Existem diversas formas de se fazer a continuação. Em geral, se inicia com o parâmetro $q=1$ e, após o método convergir para uma solução, o valor de $q$ é aumentado em uma unidade, para então convergir a uma segunda solução. Este procedimento é repetido até que $q$ atinja o seu valor limite. Na literatura este valor é, em geral, $q=3$ ou $q=4$ (BENDSøE; SIGMUND, 2003).

Este procedimento de continuação é necessário para que a solução MOT não 
convirja para um mínimo local, pois para valores de $q=3$ ou $q=4$, a função objetivo, em geral, será mal comportada e apresentará múltiplos mínimos locais. Dessa forma, inicia-se com um valor baixo $(q=1)$ a fim de que o método convirja para um ponto próximo ao ponto ótimo global do espaço de solução, depois o valor de $q$ é aumentado, para que tenda a gerar uma solução discreta (0-1).

Uma representação esquemática dessa situação é exposta na Figura 2.4, onde se verifica que a função $f(\rho)$ é convexa, enquanto a função $f\left(\rho^{3}\right)$ é mal comportada. Assim, iniciando $\operatorname{com} q=1$ é possível que o método de otimização convirja

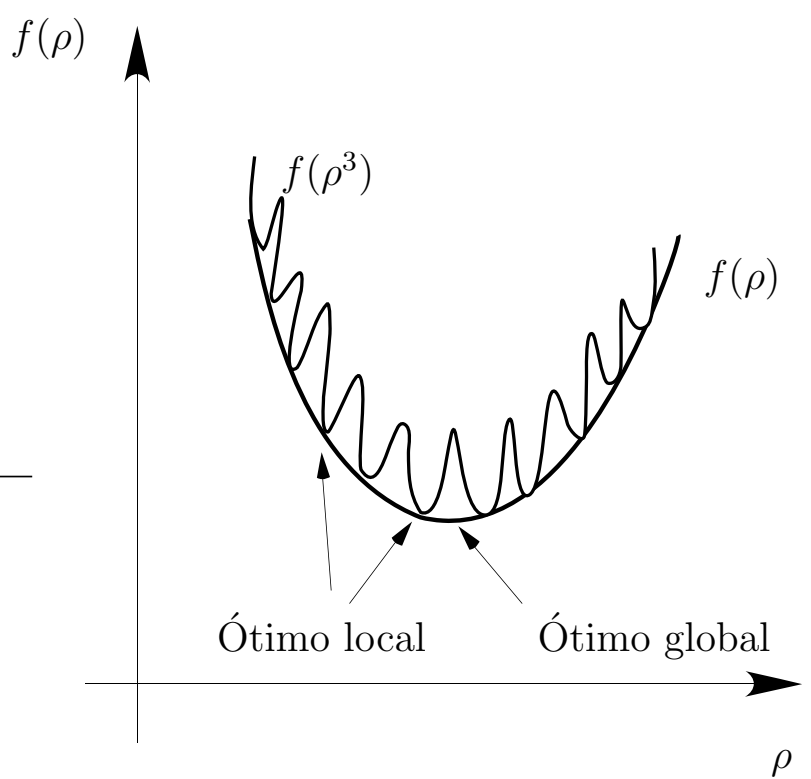

Figura 2.4: Representação esquemática da influência da penalização $q$ na função flexibilidade do problema de OT

para o ótimo global, e posteriormente, com o aumento de $q$, a solução convirja para um ótimo local próximo do ótimo global do problema.

Apesar deste procedimento apresentar bons resultados na maioria dos casos, este método é heurístico e não é possível provar a convergência deste ou mesmo que a solução final não apresentará escala de cinza (STOLPE; SVANBERG, 2001b).

Além da necessidade de se obter estruturas úteis, a solução numérica do problema 2.15 também apresenta o problema de dependência da malha e o problema de instabilidade de tabuleiro. A seguir serão descritas as causas e métodos para tratar ambos os problemas.

\subsubsection{Dependência da malha}

O problema de dependência da malha é caracterizado pelo fato de que um mesmo problema de Otimização Topológica, um mesmo domínio fixo estendido e as mes- 
mas condições de contorno, apresenta diferentes soluções conforme a discretização da malha de elementos finitos. Seria esperado que a discretização da malha apenas melhorasse a definição dos contornos da estrutura, porém observa-se que, com o aumento da discretização, a topologia da estrutura ótima tende a se alterar, aumentando o número de membros da estrutura, conforme se observa na Figura 2.5 .

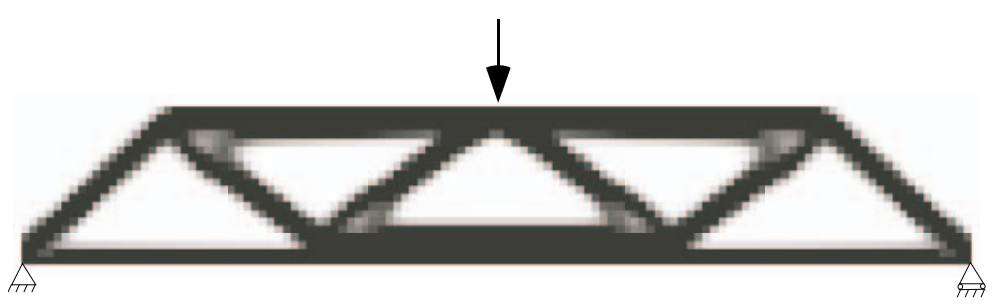

Malha de 120 x 20 elementos

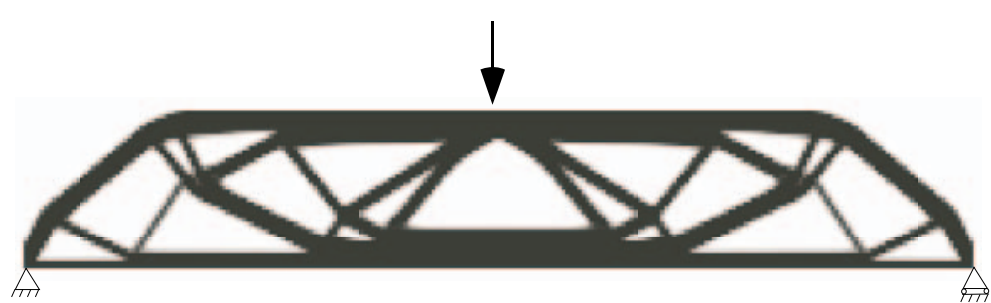

Malha de 240 x 40 elementos

Figura 2.5: Exemplo do fenômeno de dependência da malha

O problema de dependência da malha pode ser dividido em duas categorias, conforme sua origem. Para os casos onde sempre se obtêm topologias diferentes, a medida que se aumenta a discretização da malha, o problema de dependência da malha é a manifestação numérica da não existência de solução do problema 2.2. Existe também a possibilidade do problema não apresentar unicidade de solução; essa situação pode ocorrer conforme as condições de contorno aplicadas ao problema. Por exemplo, no caso de uma barra sob tração uniaxial (Figura 2.6), as soluções de uma única barra de maior diâmetro ou de diversas barras de diâmetro menor, porém com a mesma área da barra única, apresentam a mesma rigidez (SIGMUND; PETERSSON, 1998).

Uma vez que a dependência da malha é uma manifestação numérica do fato do problema 2.2 discreto de parâmetros distribuídos não possuir solução, ser malposto, uma forma de se evitar a dependência de malha é através da relaxação desse problema, tornando-o bem-posto. Contudo, esta abordagem não é interessante para a maioria das aplicações de Engenharia, conforme dito anteriormente, pois apresenta escala de cinza, o que impede a identificação de uma geometria. Um exemplo da unicidade de solução obtida através da relaxação do problema é 
apresentado na Figura 2.7.

Assim, o problema de dependência da malha está relacionado com o problema de escala de cinza, pois ao se resolver o problema na sua forma discreta ou na forma contínua com penalização, evita-se o problema de escala de cinza mas surge o problema de dependência da malha. Este, por sua vez, poderá ser resolvido com o método de restrição de perímetro, já descrito na seção anterior 2.5.1,uma vez que este é uma forma de regularização do problema através da restrição do espaço de solução.

A princípio, este método é a única regularização aplicável ao problema discreto, logo, é um método necessário para se utilizar otimização inteira no problema de Otimização Topológica. Conseqüentemente o problema de escala de cinza é automaticamente contornado.

Apesar deste fato, a restrição de perímetro tem sido utilizada nas implementações associadas a relaxação do problema, isto é, formulações com variáveis contínuas, como nos trabalhos de Haber, Jog e Bendsøe (1996), Duysinx (1996), Beckers (1997), pois esta restrição também permite controlar, de certa forma, a quantidade e tamanho dos furos através do valor máximo do perímetro. Do ponto de vista da aplicação em Engenharia, isto é interessante pois permite controlar o número de barras na estrutura otimizada, o que, em alguns casos, pode contribuir para reduzir o custo de fabricação (ZHOU; SHYY; THOMAS, 2001).

Um ponto negativo da restrição de perímetro é que a unicidade de solução não é garantida, pois o problema passa a possuir múltiplos mínimos locais.

Seguindo a abordagem de restrição do espaço de solução, Petersson e Sigmund (1998) propõe uma restrição sob o gradiente espacial da densidade volumétrica. Utilizando o modelo de material SIMP, é possível, para o caso bi-dimensional,
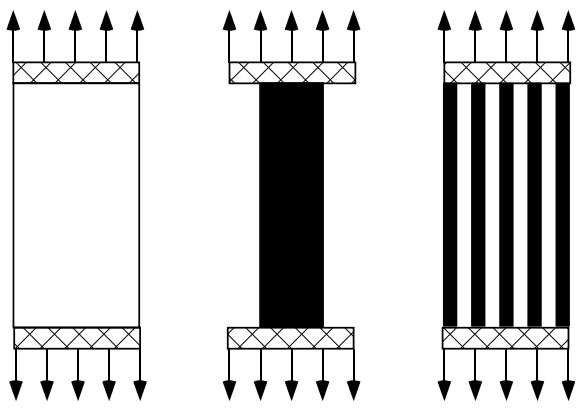

Figura 2.6: Exemplo de não unicidade de solução. Barra sob tração uniaxial para material com coeficiente de Poisson igual a zero e extremidades (regiões hachuradas) rígidas 


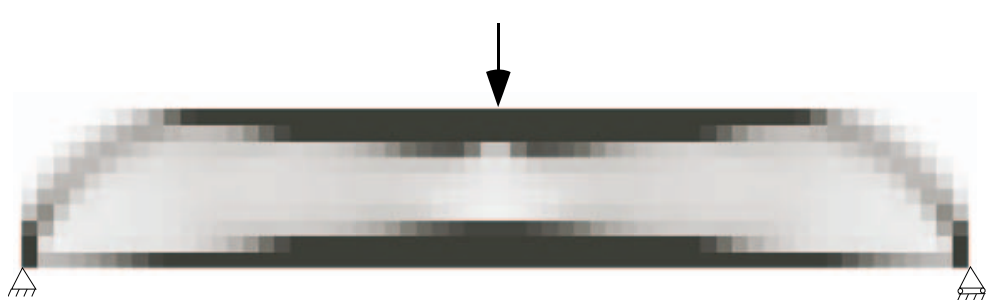

Malha de 60 x 10 elementos

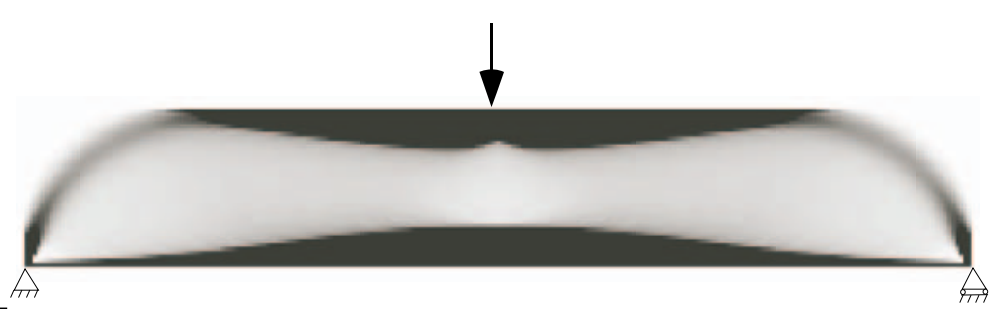

Malha de 240 x 40 elementos

Figura 2.7: Exemplo de unicidade de solução obtida pela relaxação do problema

inserir uma restrição local na forma:

$$
\left|\frac{\partial \rho}{\partial x_{i}}\right| \leq G \quad(i=1,2)
$$

o que impede o surgimento de oscilações bruscas no campo de densidades, característica das funções $\chi(\mathbf{x})$ minimizantes do problema original (mal-posto). O inconveniente, nesta abordagem, é o grande número de restrições locais inseridas ao problema de otimização, o que em geral é difícil de ser tratado. Uma segunda abordagem é considerar uma restrição global do gradiente, que pode ser escrita na forma:

$$
\int_{\Omega}(\nabla \rho)^{T}(\nabla \rho) d \Omega \leq C
$$

Esta abordagem é discutida em Bendsøe e Sigmund (2003). A restrição de gradiente na sua forma global se relaciona com a restrição de perímetro, pois a equação 2.17 pode ser interpretada como um índice representativo do perímetro.

Pereira (2001) utiliza o índice global do gradiente, representado no lado esquerdo da equação 2.17, como forma de regularização do problema. Neste caso o autor adiciona esta à função objetivo

No caso da utilização de restrições, como a de perímetro ou do gradiente do material, é necessário, em geral, fazer uma continuação no valor da restrição, utilizando um valor alto nas primeiras iterações e ir diminuindo no decorrer do processo iterativo. Ou seja, iniciar com uma restrição branda e ir tornando-a mais severa ao longo da otimização, de modo a conduzir a solução a um ponto 
do espaço de solução no qual o valor desejado da restrição seja atendido.

Outra forma de se fazer uma continuação das restrições é através da utilização das chamadas "variáveis artificiais", que são previstas dentro do Método das Assíntotas Móveis (MAM) (SVANBERG, 1987). Estas variáveis aumentam o espaço de solução, permitindo que a restrição de perímetro seja violada no início do processo iterativo e ao final a restrição se torne satisfeita. Essa abordagem de utilização de variáveis artificiais também é conhecida como relaxação das restrições ou formulação restrita (bounded formulation) (TAYLOR; BENDSØE, 1984).

O problema de dependência da malha também pode ser resolvido através da utilização de filtros espaciais. A idéia básica do funcionamento dos filtros é de substituir a possível função não regular por uma função regularizada, que é obtida através da convolução desta com uma função suave (BOURDIN, 2001). Tal qual os métodos de relaxação ou restrição do espaço de soluções, o processo de filtragem também é uma forma de transformar o problema originalmente mal-posto em um problema bem-posto.

No entanto, diferentemente dos outros métodos, os métodos de filtragens foram propostos inicialmente como uma heurística e, posteriormente, Bourdin (2001) demonstrou a existência de solução para o problema utilizando o modelo de material SIMP, associado a um determinado tipo de filtro, aplicado sobre o campo de densidades.

Bourdin (2001) demonstra, em seu trabalho, que a aplicação do filtro, de uma maneira formal, sob o campo de densidades, implica na alteração dos gradientes de modo similar ao método de filtragem dos gradientes, proposto inicialmente por Sigmund (1997). Considerando a densidade constante sob cada elemento da malha de elementos finitos, Sigmund (1997) propôs que o gradiente da função objetivo fosse alterado antes de ser inserido no algoritmo de otimização.

Swan e Kosaka (1997a) propuseram uma forma de filtro baseada na alteração direta do campo de densidades. Nesta abordagem, a densidade volumétrica de cada elemento da malha é substituída por uma forma de média ponderada entre a densidade do elemento e seus vizinhos. Assim, esse procedimento caracteriza um filtro de vizinhança fixa.

Vale notar que o filtro proposto por Swan e Kosaka (1997a) também altera o gradiente da função objetivo, pois passa a acoplar a densidade de um elemento com seus vizinhos, fazendo com que a rigidez de cada elemento também seja escrita em função dos elementos vizinhos. 
Baseado no filtro proposto por Swan e Kosaka (1997a), Cardoso e Fonseca (1999) propuseram um filtro espacial no qual a densidade volumétrica de cada elemento passa a depender, não apenas dos elementos vizinhos, mas de todos os elementos que se encontram dentro de um raio previamente estipulado. Neste filtro, a vinculação entre as densidades é feita através dos limites superiores e inferiores das densidades volumétricas a cada passo do método de otimização, assim, ambos limites são dados pela equação 2.18:

$$
l_{i}=\frac{l_{i} V_{i}+\bar{w} \sum_{j=1}^{n v} l_{j} V_{j}}{V_{i}+\bar{w} \sum_{j=1}^{n v} V_{j}}
$$

onde

$$
\bar{w}=\frac{\alpha \sum_{j=1}^{n v} w_{i}}{n v}
$$

$\mathrm{e}$

$$
w_{i}=\frac{R_{\max }-R_{i j}}{R_{\max }}
$$

onde $l_{i}$ é o limite móvel superior ou inferior da variável de projeto $i, V_{i}$ é o volume do elemento $i, n v$ é o número de elementos com centro dentro de um círculo de raio $R_{\max }$ e $R_{i j}$ é a distância entre o centro do elemento $i$ e o centro do elemento $j$.

No caso de se utilizar as densidades volumétricas definidas sobre os nós da malha de elementos finitos, ao invés dos próprios elementos, como é o caso da formulação ACDM, que será apresentada na seção 2.5.3, este filtro pode ser generalizado, fazendo que $V_{i}$ represente o volume associado densidade $i, n v$ represente o número de nós com centro dentro de um círculo de raio $R_{\max }$ e $R_{i j}$ represente a distância entre o nó $i$ e o nó $j$. Um representação esquemática dessa situação é feita na Figura 2.8.

A diferença entre os filtros de vizinhança fixa e os filtros espaciais é que, no primeiro, o raio de influência do filtro é dependente apenas dos elementos conectados ao elemento, e no segundo, o raio de influência é definido independentemente da conectividade da malha. Em termos práticos, os filtros de vizinhança fixa não são capazes de evitar o problema de dependência de malha como os filtros espaciais, como se verifica na Figura 2.10. Entretanto, ambos os filtros são capazes de minimizar o problema de instabilidade de tabuleiro como será apresentado na subseção 2.5.3. 


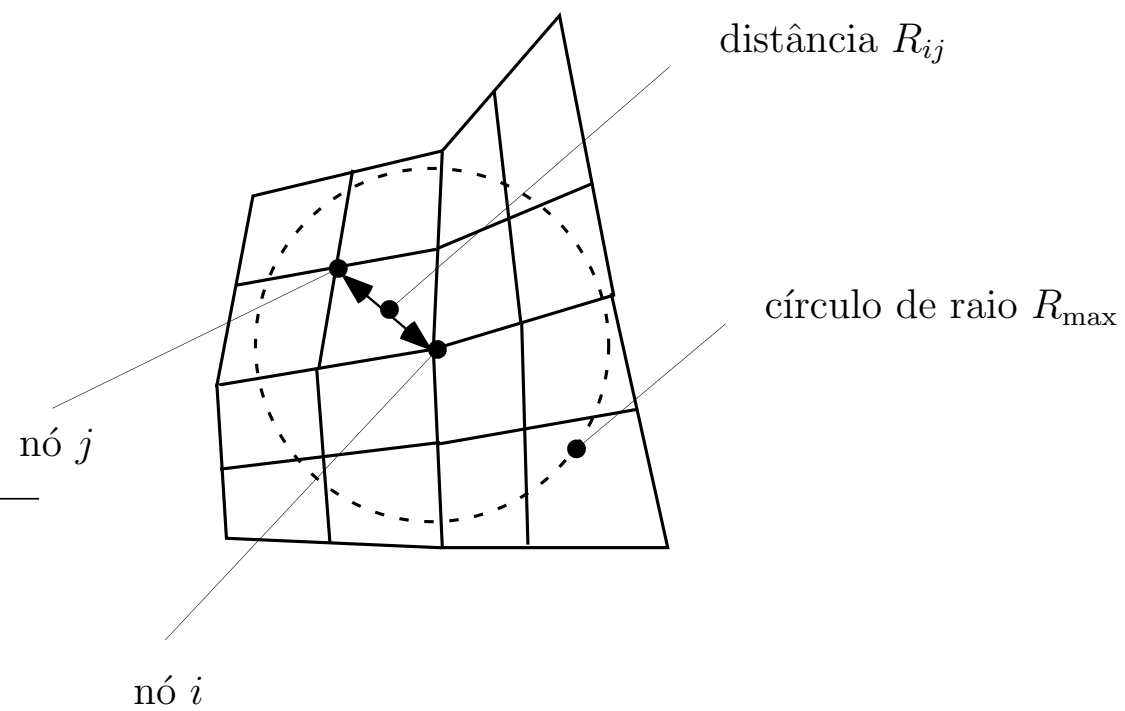

Figura 2.8: Representação esquemática do filtro aplicado sobe os limites móveis em um problema com variáveis de projeto nodais

Outro ponto importante do filtro proposto por Cardoso e Fonseca (1999) é que este é aplicado sobre os limites móveis das densidades volumétricas a cada passo do processo iterativo de otimização. Esta abordagem somente é possível de ser aplicada quando se utiliza um algoritmo de otimização em que os limites móveis são explicitamente definidos, como é caso da programação linear. Por exemplo, esse tipo de filtro não pode ser aplicado em conjunto com o MAM.

A vantagem desta abordagem é a sua capacidade de controlar a dependência da malha sem grandes alterações na formulação do problema. Porém tem como desvantagem que influencia a convergência do método de otimização, um vez que atua sobre os limites móveis.

\subsubsection{Instabilidade de tabuleiro}

O problema de instabilidade de tabuleiro, conhecido na literatura como checkerboard, é caracterizado pelo surgimento de regiões, na solução final, onde elementos com e sem material (pretos e brancos) se alternam entre elementos vizinhos de modo a se criar um padrão similar à um tabuleiro de damas, como se observa na Figura 2.9.

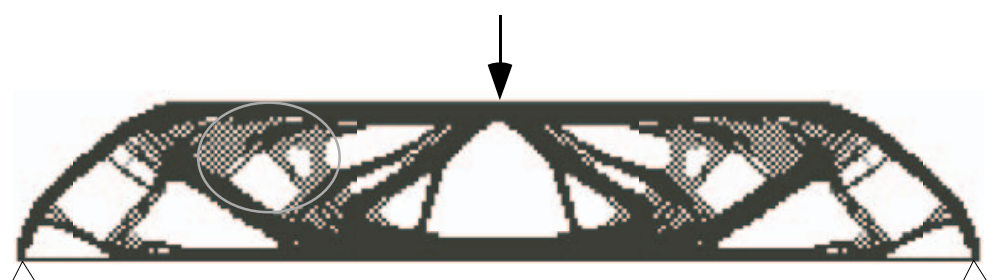

Figura 2.9: Exemplo de solução com instabilidade de tabuleiro 
Esse é um dos primeiros problemas com que o desenvolvimento do MOT se deparou, e diferentemente da não-unicidade de solução, é um problema que não foi previsto nos trabalhos precursores que desenvolveram a base matemática para o trabalho de Bendsøe e Kikuchi (1988). Isto porque o problema de instabilidade de tabuleiro é inerente a implementação numérica e não à formulação do MOT.

A causa do problema de instabilidade de tabuleiro pode ser apresentada de duas formas. A explicação mais simples e direta é de que quando o campo de densidades apresenta o padrão geométrico de um tabuleiro de damas, a rigidez dessa região é artificialmente mais elevada que a rigidez de uma região homogênea, com mesmo volume de material. Essa situação se acentua nos casos de carga que provocam cisalhamento (BENDSØE; SIGMUND, 2003).

Assim, no problema de máxima rigidez com restrição de volume, o padrão de tabuleiro maximiza a função objetivo a um mesmo custo (volume); logo este padrão tem preferência na solução otimizada.

A rigidez artificial do padrão de tabuleiro ocorre quando se utiliza o MEF baseado nos deslocamentos associados à elementos com funções de interpolação bi-lineares, por exemplo, elementos quadriláteros de quatro nós, ou triangulares de três nós.

A segunda forma de se explicar esse problema se baseia no fato de que se está resolvendo um problema variacional misto, com o objetivo de determinar dois campos físicos, o campo de deslocamentos e o campo de densidades.

Jog e Haber (1996) apresentam uma explicação para o fenômeno de instabilidade de tabuleiro a luz da teoria dos Método dos Elementos Finitos Mixtos, os autores propõem que a formulação do MOT leva a um problema similar às formulações de MEF para o escoamento de Stoke, onde se tem o campo de pressão e velocidade a serem definidos.

Em seu trabalho, Jog e Haber (1996) escrevem o problema de OT para o caso bi-dimensional utilizando o modelo de material SIMP $\operatorname{com} q=1$, na forma de um sistema não-linear dado por:

$$
\left[\begin{array}{cc}
\mathbf{K}(\boldsymbol{\rho}) & \mathbf{B}^{T} \\
\mathbf{B} & \mathbf{0}
\end{array}\right]\left\{\begin{array}{l}
\mathbf{u} \\
\boldsymbol{\rho}
\end{array}\right\}=\left\{\begin{array}{l}
\mathbf{f} \\
\mathrm{g}
\end{array}\right\}
$$

onde $\mathbf{K}$ representa a matriz de rigidez do MEF e esta é dependente do campo de densidades, $\mathbf{B}$ está relacionado à derivada do campo de tensões com o campo de deslocamentos, $\mathbf{u}$ e $\boldsymbol{\rho}$ parametrizam os campos de deslocamentos e densidades 
respectivamente, $\mathbf{f}$ está relacionado com as cargas externas aplicadas e ao campo de tensão e $\mathbf{g}$ está relacionado com campo de densidades e a derivada da energia de deformação em relação ao campo de densidades.

Então, através de simulações numéricas, os autores demonstram que, no caso dos elementos de baixa ordem, o sistema não-linear se torna mal condicionado para alguns campos de deslocamentos, o que propicia o aparecimento das instabilidades de tabuleiro.

Apesar da complexidade do problema de instabilidade de tabuleiro, a sua solução é simples. A primeira abordagem é atacar a raiz do problema e utilizar elementos de alta ordem para representar o campo de deslocamentos. Jog e Haber (1996) propõem que a combinação entre a interpolação do campo de deslocamento do campo de densidades, para os elementos quadrados, que apresentam estabilidade são Q8/UD, Q9/UD, Q8/Q4 e Q9/Q4. A nomenclatura adotada para representar estas combinações é: QX representa um elemento quadrado "Q" com "X" nós, e UD um elemento quadrado com campo constante, a sigla antes da barra indica o campo de deslocamento e a sigla depois da barra indica o campo de densidades.

Entretanto, a abordagem na qual se utilizam elementos de alta ordem apresenta o inconveniente de aumentar o custo computacional. Então, de um modo geral, formas mais econômicas são preferidas.

Um ponto importante para compreender a utilização de outras formas para tratar o problema de instabilidade de tabuleiro é que os métodos utilizados para a solução da dependência de malha também resolvem este problema. Isso se deve ao fato de que o padrão geométrico do tabuleiro de damas possui a mesma característica de oscilação brusca do campo de densidades que a solução ótima do problema discreto pode apresentar.

Assim sendo, um dos métodos bastante difundidos para o tratamento do problema de instabilidade de tabuleiro são os filtros, pois estes, em geral, são de fácil aplicação e reduzido custo computacional. A Figura 2.10 mostra como a utilização do filtro aplicado sobre o gradiente, utilizando uma vizinhança fixa ou espacial é capaz de evitar o surgimento da instabilidade de tabuleiro (BOURDIN, 2001).

Na mesma linha de aplicação dos métodos de regularização do problema discreto, a utilização da restrição de perímetro também é capaz de evitar o surgimento de instabilidade de tabuleiro, como se verifica na Figura 2.3, que apresenta 


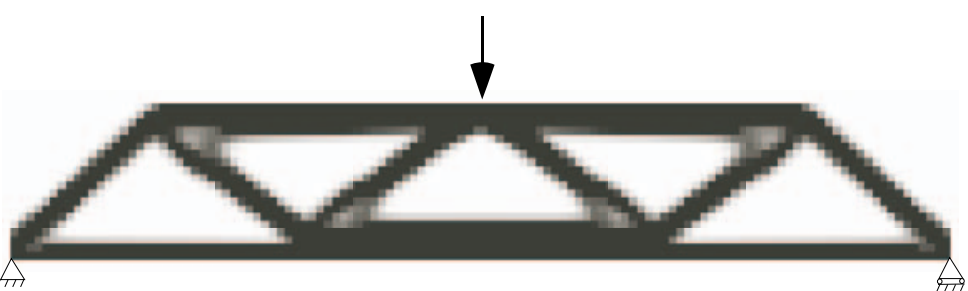

Malha de 60 x 10 elementos, solução obtida com filtro espacial

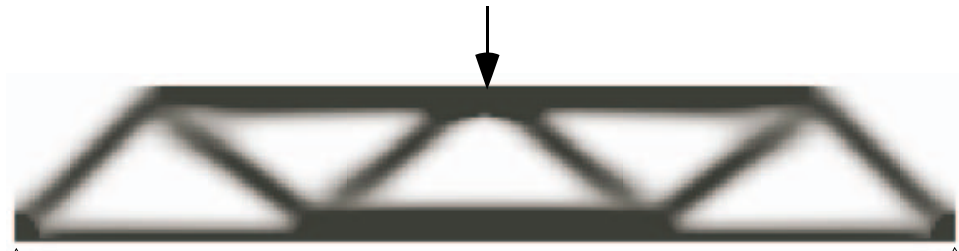

Malha de 240 x 40 elementos, solução obtida com filtro espacial (Solução independente da malha)

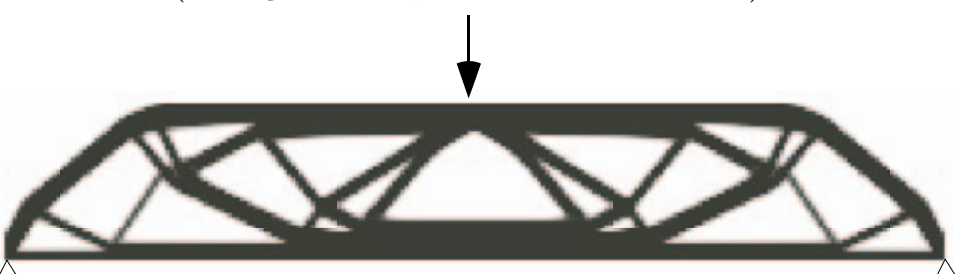

Malha de 240 x 40 elementos, solução obtida com filtro de vizinhança fixa (Solução sem instabilidade de tabuleiro)

Figura 2.10: Exemplo da aplicação de filtro como forma de solucionar o problema de instabilidade de tabuleiro e dependência de malha

uma estrutura sem presença desse fenômeno.

Observando as geometrias obtidas com um filtro de vizinhança fixa e a restrição de perímetro, observa-se que, apesar de ambos garantirem a independência da malha, as soluções são qualitativamente diferentes. De um modo geral, pode-se dizer que, com a aplicação de filtros, os membros pequenos da estrutura tendem a desaparecer, enquanto a restrição de perímetro permite o surgimento destes pequenos membros, conforme o valor dado à restrição. Assim, cada um destes métodos pode ser apropriado a uma necessidade do projeto.

Contudo, conforme dito anteriormente, o tratamento numérico da restrição de perímetro de uma forma eficiente é complexo. Assim, mais recentemente, uma outra abordagem que tenta evitar as dificuldades das restrições de perímetro, e seja capaz de obter membros pequenos a um custo computacional baixo, foi proposta por Rahmatalla e Swan (2003). Basicamente, Rahmatalla e Swan (2003) demonstraram numericamente que a utilização da formulação Q4/Q4 é capaz de minimizar o efeito de instabilidade de tabuleiro. Porém, em um artigo posterior (RAHMATALLA; SWAN, 2004), os mesmos autores mostram que esta imple- 
mentação apresenta um fenômeno similar à instabilidade de tabuleiro o qual foi denominado de "layering" e "island" e que poderiam ser traduzidos como "padrão de camadas"e "ilhas", respectivamente. Paralelamente Matsui e Terada (2004) propuseram a mesma formulação e a denominaram de Aproximação Contínua da Distribuição de Material (ACDM); na literatura: Continuous Approximation of Material Distribution (CAMD). Neste trabalho os autores defendem, a partir de experimentos numéricos, que tal formulação é livre do problema de instabilidade de tabuleiro.

Além desses métodos apresentados, existem métodos específicos para o tratamento da instabilidade de tabuleiro como o proposto por Poulsen (2002). 


\section{Métodos de Otimização Aplicados ao Problema de Otimização Topológica}

Este capítulo visa fazer uma breve panorama dos métodos de otimização aplicados ao MOT bem como apresentar os métodos de otimização utilizados nesse trabalho.

Conforme apresentado na seção 2.2, o MOT foi proposto inicialmente por Bendsøe e Kikuchi (1988) e neste trabalho os autores utilizaram como otimizador um método baseado no Critério de Optimalidade $(\mathrm{CO})$.

Os métodos baseados no CO, são algoritmos empíricos de atualização das variáveis de projeto que se apóiam na condição de estacionalidade da função Lagrangeana do problema (BENDSØE; SIGMUND, 2003). Uma descrição desse método pode ser encontrada em Hassani e Hinton (1998).

Esses métodos, conhecidos também simplesmente por CO, se tornaram bastante populares nas aplicações de OT.

O CO tem como principal vantagem a sua eficiência, porém é um método muito específico uma vez que a regra de atualização das variáveis deve ser deduzida para cada tipo de problema. Esta situação dificulta a aplicação do CO em problemas genéricos, em especial aqueles com várias restrições.

Uma alternativa a especificidade dos métodos baseados no CO é a aplicação de métodos de programação matemática. Estes métodos, são bastante gerais e podem ser utilizados independente da formulação adotada, ou seja não precisam ser alterados conforme a aplicação. Essa abordagem tem sido aplicada com sucesso na literatura (BENDSøE; SIGMUND, 2003).

Dentro os métodos de programação matemática aplicados ao MOT, destacamse o Método das Assíntotas Móveis (MAM) e o método de Programação Linear Seqüencial (PLS).

O método de PLS consiste na solução de uma seqüencia de aproximações 
lineares do problema original. Estes sub-problemas lineares, por sua vez são resolvidos através de um algoritmo de programação linear, como por exemplo o SIMPLEX (PRESS et al., 1999). Um apresentação mais detalhada da PLS será feita adiante na seção 3.1 .

O MAM foi proposto por Svanberg (1987), opera de forma similar ao método de PLS uma vez que este resolve uma seqüencia de aproximações mais simples do problema original. No caso do MAM os problemas aproximados são nãolineares e convexos e construídos a partir da sensibilidade do problema original e do histórico das iterações. Baseado no algoritmo básico proposto por Svanberg alguns aprimoramentos deste método foram desenvolvidos, destacando se os trabalhos de Zhang et al. (1996) e Bruyneel, Duysinx e Fleury (2002). Um estudo da eficiência numérica deste método pode ser encontrada em Bruyneel e Duysinx (2005).

Apesar da eficiência e generalidade dos métodos de programação matemática, estes não são capazes de tratar de forma eficiente um grande número de restrições lineares, a menos das restrições de caixa. Isto não é um problema para a maioria das aplicações do MOT, pois em geral as suas formulações possuem um número de restrições da ordem de, no máximo, algumas dezenas.

Porém, isto não verdade para o problema de OT com restrição local de tensão, que possui uma ordem de milhares de restrições. Com vista nesta dificuldade Pereira, Fancello e Barcellos (2004) propuseram a utilização do MLA para tratar este problema.

A principal idéia do MLA é de transformar um problema de otimização com restrição em um problema sem restrições. Esse método será apresentado mais detalhadamente na seção 3.2

Neste trabalho, foram utilizados dois métodos de otimização, a Programação Linear Seqüencial (PLS) e o Método do Lagrangeano Aumentado (MLA). Inicialmente faremos a descrição do PLS. 


\subsection{Método de Programação Linear Seqüencial}

Considere um problema genérico, não linear, na forma 3.1:

$$
\begin{aligned}
& \underset{\boldsymbol{\rho}}{\operatorname{minimizar}} f(\boldsymbol{\rho}) \\
& \text { tal que } \\
& \qquad g_{j}(\boldsymbol{\rho}) \leq 0 \\
& \quad \rho_{\min } \leq \rho_{i} \leq \rho_{\max }
\end{aligned}
$$

onde vetor de variáveis de projeto $\boldsymbol{\rho} \in \mathbb{R}^{n}, f(\boldsymbol{\rho})$ é a função objetivo a ser minimizada, atendendo às restrições de desigualdade $g_{j}(\boldsymbol{\rho})$ para $j=1 \ldots m$ e às restrições de caixa $\rho_{\min } \leq \rho_{i} \leq \rho_{\max }$ para $i=1 \ldots n$.

Para resolver o problema 3.1 através da PLS é necessário transformá-lo em um problema linear. Para isso é utilizada uma expansão em séries de Taylor das funções $f(\boldsymbol{\rho})$ e $g_{j}(\boldsymbol{\rho})$, ao redor de um dado ponto $\left(\boldsymbol{\rho}^{0}\right)$ do espaço de solução.

Considerando então a função $f(\boldsymbol{\rho})$ temos

$$
f(\boldsymbol{\rho})=f\left(\boldsymbol{\rho}^{0}\right)+\frac{\partial f\left(\boldsymbol{\rho}^{0}\right)}{\partial \boldsymbol{\rho}}\left(\boldsymbol{\rho}-\boldsymbol{\rho}^{0}\right)+\frac{\partial^{2} f\left(\boldsymbol{\rho}^{0}\right)}{\partial \boldsymbol{\rho}^{2}} \frac{\left(\boldsymbol{\rho}-\boldsymbol{\rho}^{0}\right)^{2}}{2 !}+\ldots+\frac{\partial^{N} f\left(\boldsymbol{\rho}^{0}\right)}{\partial \boldsymbol{\rho}^{N}} \frac{\left(\boldsymbol{\rho}-\boldsymbol{\rho}^{0}\right)^{N}}{N !}+e(\boldsymbol{\rho})
$$

onde $e(\boldsymbol{\rho})$ representa um erro associado ao truncamento desta série que a princípio possui infinitos termos. Assim, considerando apenas os termos de primeira ordem temos:

$$
f(\boldsymbol{\rho}) \approx f\left(\boldsymbol{\rho}^{0}\right)+\left(\frac{\partial f\left(\boldsymbol{\rho}^{0}\right)}{\partial \boldsymbol{\rho}}\right)^{T} \boldsymbol{\rho}-\left(\frac{\partial f\left(\boldsymbol{\rho}^{0}\right)}{\partial \boldsymbol{\rho}}\right)^{T} \boldsymbol{\rho}^{0}
$$

e fazendo o mesmo para as restrições $g_{j}(\boldsymbol{\rho})$ é possivel representar o problema 3.1 por uma sub-problema linear dado por:

$$
\begin{aligned}
& \underset{\boldsymbol{\rho}}{\operatorname{minimizar}} \tilde{f}(\boldsymbol{\rho})=\frac{\partial f\left(\boldsymbol{\rho}^{0}\right)}{\partial \boldsymbol{\rho}} \boldsymbol{\rho} \\
& \text { tal que } \\
& \left.\qquad \frac{\partial g_{j}\left(\boldsymbol{\rho}^{0}\right)}{\partial \boldsymbol{\rho}}\right)^{T} \boldsymbol{\rho} \leq\left(\frac{\partial g_{j}\left(\boldsymbol{\rho}^{0}\right)}{\partial \boldsymbol{\rho}}\right)^{T} \boldsymbol{\rho}^{0}-g_{j}\left(\boldsymbol{\rho}^{0}\right) \\
& \text { limov }_{\text {inferior }} \leq \rho_{i} \leq \text { limov }_{\text {superior }}
\end{aligned}
$$

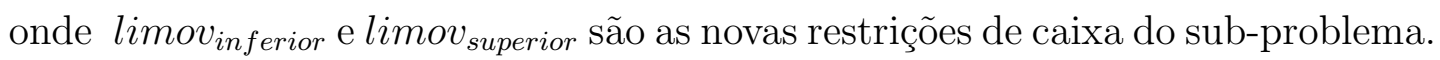
A definição dessa nova restrição de caixa é necessária uma vez que o sub-problema é válido apenas na vizinhança do ponto $\boldsymbol{\rho}^{0}$. Observe que nesse sub-problema linear, a função objetivo é formada apenas pelos termos não constantes da aproximação 3.3, e nas restrições os termos constantes ficam a direita da desigualdade. Assim, a função objetivo e as restrições são representadas apenas por funções li- 
neares em função de $\boldsymbol{\rho}$

O gráfico da Figura 3.1 apresenta esquematicamente a aproximação da função não-linear $f\left(\rho_{i}\right)$ pela função linear $\tilde{f}\left(\rho_{i}\right)$ ao redor de um ponto $\rho_{i}^{0}$, para um problema de uma variável. Nessa figura, é possível verificar a necessidade da correta definição dos dos limites móveis superior e inferior para que o problema linear se aproxime de forma satisfatória do problema não-linear.

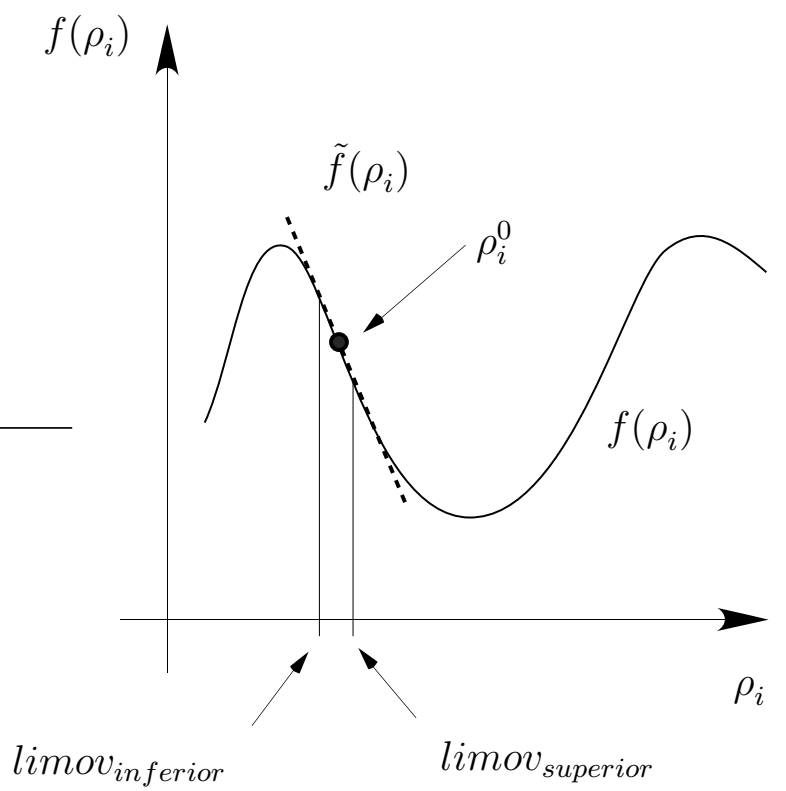

Figura 3.1: Representação genérica da aproximação da função não linear $f\left(\rho_{i}\right)$ pela função linear $\tilde{f}\left(\rho_{i}\right)$ utilizada pelo algoritmo de $\mathrm{PL}$

Seguindo a idéia da PLS , é necessário então resolver o sub-problema linearizado (3.4), para isso deve ser utilizado um método de Programação Linear (PL), como por exemplo o método SIMPLEX (DANTZIG, 1963). A solução desse subproblema passa a ser o novo ponto $\boldsymbol{\rho}^{0}$ do espaço de solução no qual será feita a nova aproximação linear.

Assim o procedimento do método de PLS é definido no Algoritmo 1.

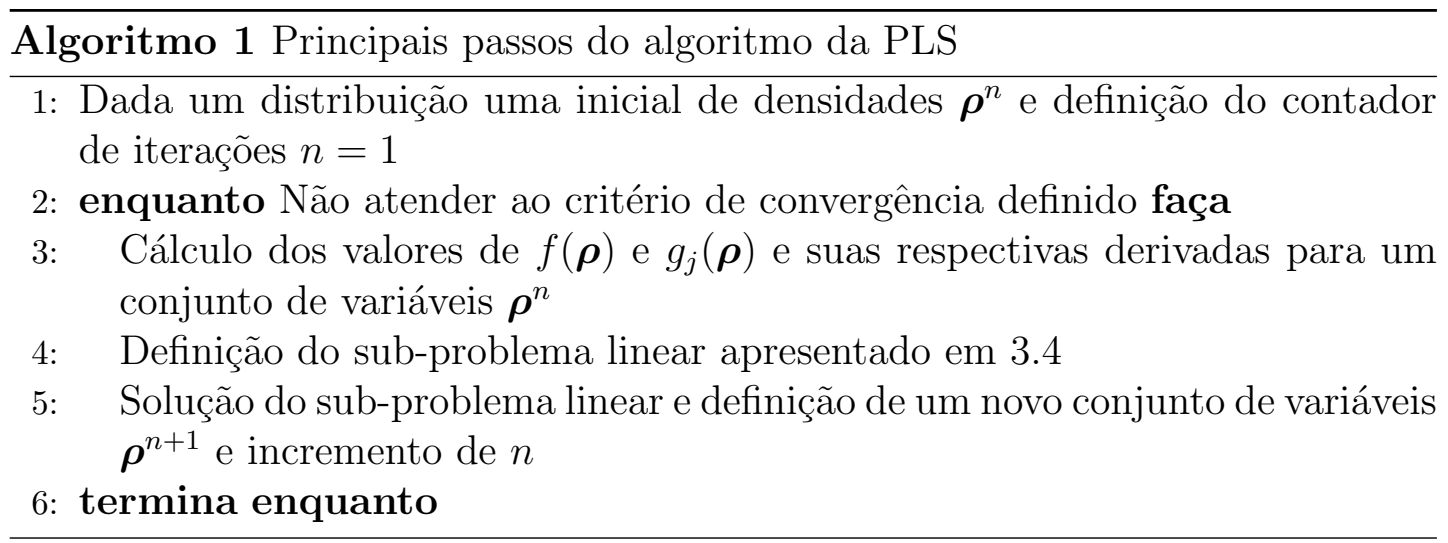




\subsection{Método do Lagrangeano Aumentado}

O Método do Lagrangeano Aumentado (MLA) é um algoritmo do tipo primadual, em que as variáveis desses dois espaço são atualizadas em etapas distintas.

Este algoritmo inicia-se pela definição de um conjunto de multiplicadores de Lagrange (variáveis duais). Definida as variáveis duais, é necessário aplicar um método de otimização para a solução das variáveis primais, que neste caso consistem nas densidades volumétricas. A partir do novo campo de densidades é necessário fazer a atualização do conjunto de multiplicadores de Lagrange. Esse processo é repetido até atingir a convergência do campo de densidades.

Aqui será apresentada de forma sucinta a formulação do MLA, segundo proposto em Bertsekas (1982). Assim como foi feito para o problema o método de PLS, considere o mesmo problema de otimização não-linear com restrições de desigualdade e restrições de caixa dado representado 3.1 e aqui reproduzido:

$$
\begin{aligned}
& \underset{\boldsymbol{\rho}}{\operatorname{minimizar}} f(\boldsymbol{\rho}) \\
& \text { tal que } \\
& \qquad g_{j}(\boldsymbol{\rho}) \leq 0 \\
& \rho_{\min } \leq \rho_{i} \leq \rho_{\max }
\end{aligned}
$$

Para aplicar o MLA, inicialmente, é necessário transformar as restrições de desigualdade desse problema em restrições igualdade. Para isto basta acrescentar um vetor da variáveis de folga $\left(\mathbf{z}=\left(z_{1}, \ldots, z_{r}\right)\right)$, assim temos:

$$
\begin{aligned}
& \underset{\boldsymbol{\rho}}{\operatorname{minimizar}} f(\boldsymbol{\rho}) \\
& \text { tal que } \\
& \quad g_{1}(\boldsymbol{\rho})+z_{1}^{2}=\ldots=g_{j}(\boldsymbol{\rho})+z_{r}^{2}=0 \\
& \quad \rho_{\min } \leq \rho_{i} \leq \rho_{\max }
\end{aligned}
$$

Agora escrevendo o Lagrangiano Aumentado desse novo problema temos:

$$
L(\boldsymbol{\rho}, \mathbf{z}, \boldsymbol{\mu}, \mathbf{c})=f(\boldsymbol{\rho})+\sum_{j=1}^{r}\left\{\mu_{j}\left[g_{j}(\boldsymbol{\rho})+z_{j}^{2}\right]+\frac{c_{j}}{2}\left|g_{j}(\boldsymbol{\rho})+z_{j}^{2}\right|^{2}\right\}
$$

onde $\mu_{j}$ é o multiplicador de lagrange e $c_{j}$ o parâmetro de penalização, ambos associados à restrição $g_{j}$. Assim é possível obter o ponto ótimo do problema original, fazendo a minimização da função Lagrangiano Aumentado, em função de $(\boldsymbol{\rho}, \mathbf{z})$ utilizando os valores ótimos de $(\boldsymbol{\mu}, \mathbf{c})$. 
Porém a minimização de $L(\rho, z, \mu, c)$ em função da variável $\mathbf{z}$ pode ser feita de forma explicita. Para isso basta notar que:

$$
\min _{z} L(\boldsymbol{\rho}, \mathbf{z}, \boldsymbol{\mu}, \mathbf{c})=f(\boldsymbol{\rho})+\sum_{j=1}^{r} \min _{z}\left\{\mu_{j}\left[g_{j}(\boldsymbol{\rho})+z_{j}^{2}\right]+\frac{c_{j}}{2}\left[g_{j}(\boldsymbol{\rho})+z_{j}^{2}\right]^{2}\right\}
$$

e para cada $z_{j}$, a equação 3.11 é equivalente a 3.12 :

$$
\min _{u_{j} \geq 0}\left\{\mu_{j}\left[g_{j}(\boldsymbol{\rho})+u_{j}\right]+\frac{c_{j}}{2}\left[g_{j}(\boldsymbol{\rho})+u_{j}\right]^{2}\right\}
$$

E por sua vez a função 3.12 é quadrática em relação a $u_{j}$. Logo o mínimo global dessa função é dado por $\hat{u}_{j}$ tal que a primeira derivada da função em relação $u_{j}$ a seja igual a zero. Assim têm se:

$$
\mu_{j}+c_{j}\left[g_{j}(\boldsymbol{\rho})+\hat{u}_{j}\right]=0
$$

e $\log 0$

$$
\hat{u}_{j}=-\left[\frac{\mu_{j}}{c_{j}}+g_{j}(\boldsymbol{\rho})\right]
$$

Analisando o problema 3.12, verifica-se que existem duas possibilidades para a solução de $\hat{u}_{j}$. Ou $\hat{u}_{j}>0$ e assim esta é dada pela equação 3.14 , ou a solução do problema 3.12 é exatamente $u_{j}^{*}=0$. Assim a solução de $\hat{u}_{j}$ pode ser escrita como:

$$
u_{j}^{*}=\max \left\{0,-\left[\frac{\mu_{j}}{c_{j}}+g_{j}(\boldsymbol{\rho})\right]\right\}
$$

e logo pode se escrever:

$$
g_{j}(\boldsymbol{\rho})+u_{j}=g_{j}(\boldsymbol{\rho})+\max \left\{0,-\left[\frac{\mu_{j}}{c_{j}}+g_{j}(\boldsymbol{\rho})\right]\right\}
$$

Assim, substituindo 3.16 em 3.10 temos:

$$
\begin{aligned}
L(\boldsymbol{\rho}, \boldsymbol{\mu}, \mathbf{c})= & f(\boldsymbol{\rho}) \\
& +\sum_{j=1}^{r}\left\{\mu_{j}\left[g_{j}+\max \left\{0,-\left[\frac{\mu_{j}}{c_{j}}+g_{j}(\boldsymbol{\rho})\right]\right\}\right]\right\} \\
& +\sum_{j=1}^{r}\left\{\frac{c_{j}}{2}\left[g_{j}(\boldsymbol{\rho})+\max \left\{0,-\left[\frac{\mu_{j}}{c_{j}}+g_{j}(\boldsymbol{\rho})\right]\right\}\right]^{2}\right\}
\end{aligned}
$$

e com alguma algebra é possível chegar em

$$
L(\boldsymbol{\rho}, \boldsymbol{\mu}, \mathbf{c})=f(\boldsymbol{\rho})+\sum_{j=1}^{r} \frac{1}{2 c_{j}}\left\{\left[\max \left\{0, \mu_{j}+c_{j} g_{j}(\boldsymbol{\rho})\right\}\right]^{2}-\mu_{j}^{2}\right\}
$$


E assim, no problema de otimização sem restrições dado por:

$$
\min _{\boldsymbol{\rho}, \boldsymbol{\mu}} L(\boldsymbol{\rho}, \boldsymbol{\mu}, \mathbf{c})=f(\boldsymbol{\rho})+\sum_{j=1}^{r} \frac{1}{2 c_{j}}\left\{\left[\max \left\{0, \mu_{j}+c_{j} g_{j}(\boldsymbol{\rho})\right\}\right]^{2}-\mu_{j}^{2}\right\}
$$

onde o parâmetro de penalização $c_{j}$ é constante e previamente definido.

Agora então, é possível escrever o problema de otimização original $3.6 \mathrm{com}$ restrições de desigualdade em um problema de otimização apenas com restrições de caixa:

$$
\begin{aligned}
& \underset{\boldsymbol{\rho}}{\operatorname{minimizar}} f(\boldsymbol{\rho})+\sum_{j=1}^{r} \frac{1}{2 c_{j}}\left\{\left[\max \left\{0, \mu_{j}+c_{j} g_{j}(\boldsymbol{\rho})\right\}\right]^{2}-\mu_{j}^{2}\right\} \\
& \text { tal que } \\
& \qquad \rho_{\min } \leq \rho_{i} \leq \rho_{\max }
\end{aligned}
$$

Porém, a solução ótima desse problema será idêntica ao problema original 3.6) apenas se os multiplicadores de Lagrange $\boldsymbol{\mu}$ possuir valores ótimos.

Para resolver este problema o MLA prevê que o problema 3.19 seja resolvido em duas etapas, que devem ser repetidas iterativamente. Inicialmente se resolve o problema primal dado por 3.20, considerando multiplicadores de Lagrange $\boldsymbol{\mu}$ fixos. Obtida a solução do problema primal o problema dual é resolvido, fornecendo novos valores de $\boldsymbol{\mu}$ para então se obter um nova solução do problema primal.

Assim, seguindo a formulação clássica do MLA, apresentada em Bertsekas (1982), os multiplicadores de Lagrange são atualizados entre a solução de cada sub-problema prinal, segundo a regra dada por:

$$
\mu_{j}^{k+1}=\max \left\{0, \mu_{j}^{k}+c_{j}^{k} g_{j}(\boldsymbol{\rho})\right\}
$$

Quanto ao parâmetro de penalização $c_{j}$, foi utilizada a regra de atualização proposta por Andreani et al. (2005). Assim, o procedimento adotado neste trabalho é descrito no Algoritmo 2.

Nesta implementação do MLA, é necessário definir os valores de $v$ e $\gamma$, que irão comandar a atualização do parâmetro de penalização $c_{j}$. Na prática estes valores são definidos para cada problema e são obtidos através de tentativa e erro. 


\section{Algoritmo 2 Principais passos do algoritmo do MLA}

1: Definição de uma distribuição uma inicial de densidades $\boldsymbol{\rho}^{0}$, um conjunto de multiplicadores de lagrange $\mu_{j}^{0}$, um conjunto de parâmetros de penalização $c_{j}^{0}$ e definição do contador de iterações $k=1$

2: Definição dos parâmetros $v \in[0,1[$ e $\gamma>1$

3: enquanto Não atender ao critério de convergência definido faça

4: Cálculo de:

$$
\vartheta_{j}^{0}=\max \left\{g_{j}\left(\boldsymbol{\rho}^{0}\right), \frac{\mu_{j}^{0}}{c_{j}^{0}}\right\}
$$

5: $\quad$ Definição do problema na sua forma primal dada por 3.20

6: Cálculo de $\frac{\partial L(\boldsymbol{\rho}, \boldsymbol{\mu}, \mathbf{c})}{\partial \boldsymbol{\rho}}$

7: Solução do problema de otimização 3.20 através do algoritmo de PLS apresentado em no Algoritmo 1

8: Atualização do multiplicadores de Lagrange segundo a regra:

$$
\mu_{j}^{k+1}=\max \left\{0, \mu_{j}^{k}+c_{j}^{k} g_{j}(\boldsymbol{\rho})\right\}
$$

e cálculo do parâmetro

$$
\vartheta_{j}^{k}=\max \left\{g_{j}\left(\boldsymbol{\rho}^{k}\right), \frac{\mu_{j}^{k}}{c_{j}^{k}}\right\}
$$

9: $\quad$ Atualização do parâmetros de penalização segundo a regra:

10: $\mathbf{s e}$

$$
\left|\vartheta_{j}^{k}\right| \leq v\left|\vartheta_{j}^{k-1}\right|
$$

então

11:

$$
c_{j}^{k+1}=c_{j}^{k}
$$

12: $\quad$ se não

13:

$$
c_{j}^{k+1}=\gamma c_{j}^{k}
$$

14: termina se

15: Incrementa o valor de $k$

16: termina enquanto 


\section{Modelos de material}

\subsection{Introdução}

Os modelos de material podem ser vistos por uma ótica diferente da apresentada na seção 2.4. Parte-se do princípio de que os modelos de material artificiais ou baseados em microestruturas sub-ótimas não são capazes de garantir a relaxação total do problema 2.2, porém, do ponto de vista da Engenharia, essas microestruturas são capazes de fornecer soluções úteis (BENDSøE; SIGMUND, 1999). Assim sendo, pode-se investigar a utilização de outros modelos de materiais, como aqueles que historicamente vem sendo desenvolvidos na área de Engenharia dos Materiais, chamados de modelos micromecânicos ou modelos constitutivos de materiais compostos. Estes modelos têm como objetivo determinar as propriedades efetivas ou médias de materiais compostos a partir das propriedades de cada um de seus componentes.

Entende-se por materiais compostos aqueles que possuem dois ou mais diferentes materiais dispostos em uma região do espaço, de tal forma que o material resultante possa ser interpretado como um meio contínuo (HASHIN, 1983). Vários materiais podem ser interpretados como materiais compostos; pode-se citar, por exemplo: concreto, meios porosos ou com a presença de trincas, materiais laminados e mesmo os agregados policristalinos, como os metais.

\subsection{Conceitos básicos}

A idéia básica dos modelos micromecânicos está em se definir, a partir de informações sobre a microestrutura, as relações constitutivas do material em sua meso ou macro-escala. Para o caso de elasticidade linear, estas relações são representadas pela lei de Hooke generalizada; assim, é possível, ao se realizar a análise de uma dada estrutura constituída por um material complexo e não homogêneo, substituir esse material por um material homogêneo equivalente tal que este apresente em uma macro escala, o mesmo comportamento do material não 
homogêneo.

Os modelos micromecânicos clássicos utilizados para estimar/calcular as propriedades efetivas do material homogêneo equivalente se baseiam em dois conceitos principais: a existência de um Elemento Representativo de Volume (ERV) e a condição de que este elemento esteja sujeito a condições de contorno homogêneas. Para que uma região ou volume de um dado material composto seja qualificado como ERV dois critérios devem ser atendidos: primeiro, este volume deve ser suficientemente pequeno em relação às dimensões do corpo, por exemplo, na figura 4.1 deve-se ter $(l \ll L)$; em segundo lugar, a inclusão ou heterogeneidade deve ser muito menor que o tamanho característico do ERV, no caso $(d \ll l$ ) (ABOUDI; PINDERA; ARNOLD, 1999).

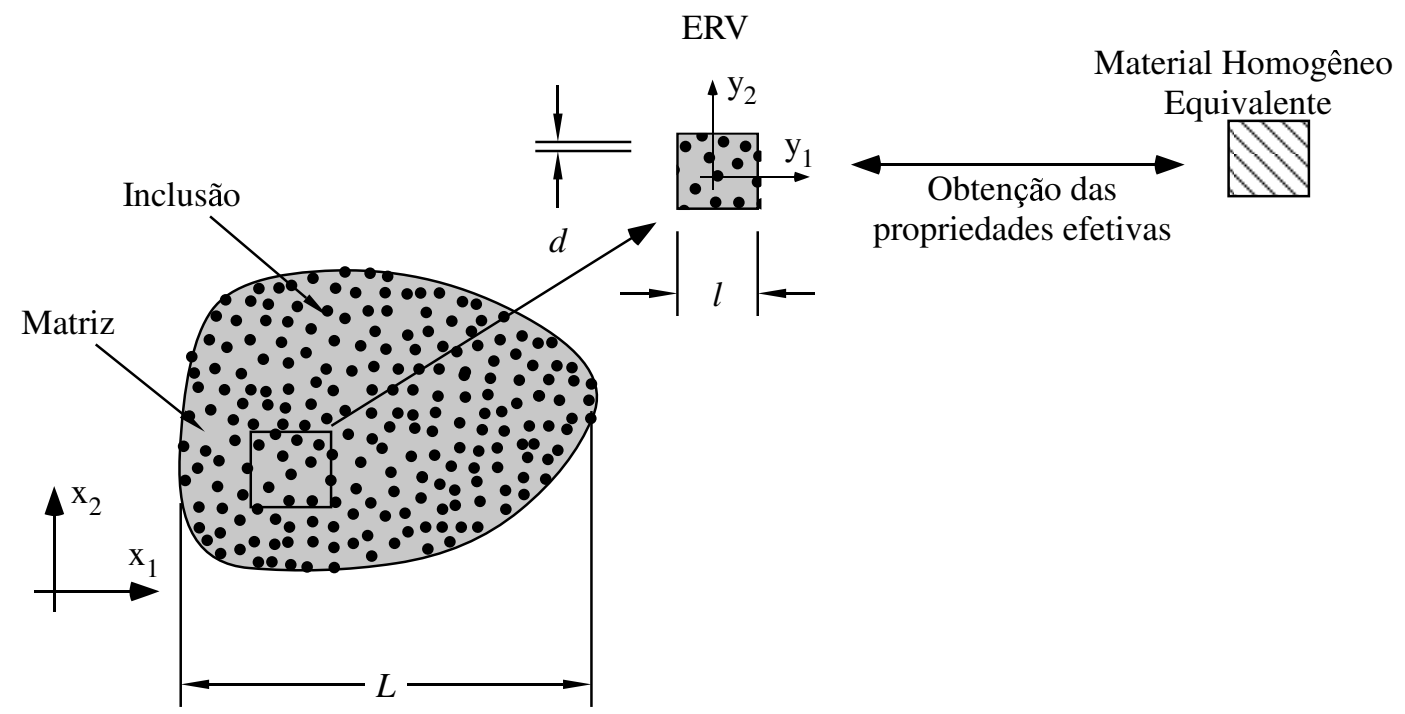

Figura 4.1: Representação de um material composto estatísticamente homogêneo e seu elemento representativo de volume ERV.

A partir dessas hipóteses tem-se que os campos de tensão e deformação $\boldsymbol{\sigma}^{\mathbf{0}}(\mathbf{x})$ e $\boldsymbol{\epsilon}^{\mathbf{0}}(\mathbf{x})$, obtidos pela análise de um problema de condições de contorno de um corpo constituído pelo material equivalente homogêneo, são iguais à média dos campos locais de tensão e deformação $\boldsymbol{\sigma}(\mathbf{y})$ e $\boldsymbol{\epsilon}(\mathbf{y})$, dentro de um ERV com centro em $\mathbf{x}$ e coordenadas locais definidas por $\mathbf{y}$, que são calculados levando em consideração a não homogeneidade (ZAOUI, 2002; HASHIN, 1983). Assim, é possível definir dois campos de tensão, o campo de macro-tensão, que é função apenas do sistema de coordenadas globais $\left(x_{1}, x_{2}\right)$, e o campo de micro-tensões, que é função das coordenadas locais $\left(y_{1}, y_{2}\right)$.

Ou seja, considerando a hipótese de que o ERV está sujeito a condições de contorno homogêneas quanto à tensão ou à deformação, o teorema das tensões médias e o teorema de deformações médias permite concluir que a macro-tensão é igual à média das tensões locais sob o volume $V$ do ERV (HASHIN, 1983; ABOUDI, 
1991):

$$
\begin{gathered}
\langle\boldsymbol{\sigma}\rangle=\frac{1}{V} \int_{V} \boldsymbol{\sigma}(\mathbf{y}) d V=\boldsymbol{\sigma}^{0} \\
\langle\boldsymbol{\epsilon}\rangle=\frac{1}{V} \int_{V} \boldsymbol{\epsilon}(\mathbf{y}) d V=\boldsymbol{\epsilon}^{0}
\end{gathered}
$$

Dessa forma, é possível definir o tensor constitutivo $\mathbf{C}^{H}$ de propriedades efetivas, tal que:

$$
\langle\boldsymbol{\sigma}\rangle=\mathbf{C}^{H}\langle\boldsymbol{\epsilon}\rangle
$$

Neste texto a notação $\langle\cdot\rangle$ representa a média de uma dada grandeza dentro do ERV, dada pela equação 4.4 .

$$
\langle\cdot\rangle=\frac{1}{V} \int_{V}(\cdot) d V
$$

Particularizando a análise para o caso de um material composto por duas fases isotrópicas, podemos escrever as equações 4.1 e 4.2 como:

$$
\begin{gathered}
\langle\boldsymbol{\sigma}\rangle=\rho\left\langle\boldsymbol{\sigma}^{+}\right\rangle+(1-\rho)\left\langle\boldsymbol{\sigma}^{-}\right\rangle \\
\langle\boldsymbol{\epsilon}\rangle=\rho\left\langle\boldsymbol{\epsilon}^{+}\right\rangle+(1-\rho)\left\langle\boldsymbol{\epsilon}^{-}\right\rangle
\end{gathered}
$$

onde os sobrescritos $(+)$ e $(-)$ definem a fase na qual a grandeza é calculada. As fase $(+)$ e $(-)$ são constituídas por materiais isotrópicos com módulo de Young $E^{+}$e $E^{-}$, tal que $E^{+}>E^{-}$e coeficiente de Poisson $\nu^{+}$e $\nu^{-}$, respectivamente, definindo assim os tensores constitutivos $\mathbf{C}^{+}$e $\mathbf{C}^{-}$.

Para facilitar a compreensão da notação aqui adotada, $\boldsymbol{\sigma}$ representa o campo de tensão na peça levando em consideração a microestrutura, assim $\boldsymbol{\sigma}^{+}$representa a tensão sobre a fase mais $(+)$, ou seja $\boldsymbol{\sigma}^{+}$é igual a zero na fase menos $(-)$e o inverso se aplica para $\boldsymbol{\sigma}^{-}$. Dessa forma $\left\langle\boldsymbol{\sigma}^{+}\right\rangle$representa a média das tensões sobre a fase mais $(+)$ na microestrutura e $\left\langle\boldsymbol{\sigma}^{-}\right\rangle$representa a média sobre a fase menos (-), também na microestrutura.

Considerando as relações constitutivas locais

$$
\left\langle\boldsymbol{\sigma}^{+}\right\rangle=\mathbf{C}^{+}\left\langle\boldsymbol{\epsilon}^{+}\right\rangle \quad, \quad\left\langle\boldsymbol{\sigma}^{-}\right\rangle=\mathbf{C}^{-}\left\langle\boldsymbol{\epsilon}^{-}\right\rangle
$$

e sua inversa

$$
\left\langle\boldsymbol{\epsilon}^{+}\right\rangle=\mathbf{S}^{+}\left\langle\boldsymbol{\sigma}^{+}\right\rangle \quad, \quad\left\langle\boldsymbol{\epsilon}^{-}\right\rangle=\mathbf{S}^{-}\left\langle\boldsymbol{\sigma}^{-}\right\rangle
$$


é possível re-escrever 4.1 e 4.2 como:

$$
\begin{array}{r}
\langle\boldsymbol{\sigma}\rangle=\rho \mathbf{C}^{+}\left\langle\boldsymbol{\epsilon}^{+}\right\rangle+(1-\rho) \mathbf{C}^{-}\left\langle\boldsymbol{\epsilon}^{-}\right\rangle \\
\langle\boldsymbol{\epsilon}\rangle=\rho \mathbf{S}^{+}\left\langle\boldsymbol{\sigma}^{+}\right\rangle+(1-\rho) \mathbf{S}^{-}\left\langle\boldsymbol{\sigma}^{-}\right\rangle
\end{array}
$$

A relação entre a macro-tensão $\langle\boldsymbol{\sigma}\rangle$ e a macro-deformação $\langle\boldsymbol{\epsilon}\rangle$ com as médias das micro-tensões $\left(\left\langle\boldsymbol{\sigma}^{+}\right\rangle,\left\langle\boldsymbol{\sigma}^{-}\right\rangle\right)$e as médias das micro-deformações $\left(\left\langle\boldsymbol{\epsilon}^{+}\right\rangle,\left\langle\boldsymbol{\epsilon}^{-}\right\rangle\right)$ é única e dada pelas equações 4.11 e 4.12 (ABOUDI, 1991; REITER; DVORAK; TVERGAARD, 1997):

$$
\begin{gathered}
\left\langle\boldsymbol{\epsilon}^{+}\right\rangle=\mathbf{A}^{+}\langle\boldsymbol{\epsilon}\rangle \quad, \quad\left\langle\boldsymbol{\epsilon}^{-}\right\rangle=\mathbf{A}^{-}\langle\boldsymbol{\epsilon}\rangle \\
\left\langle\boldsymbol{\sigma}^{+}\right\rangle=\mathbf{B}^{+}\langle\boldsymbol{\sigma}\rangle \quad, \quad\left\langle\boldsymbol{\sigma}^{-}\right\rangle=\mathbf{B}^{-}\langle\boldsymbol{\sigma}\rangle
\end{gathered}
$$

onde os tensores $\mathbf{B}^{+}, \mathbf{B}^{-}, \mathbf{A}^{+}$e $\mathbf{A}^{-}$são chamados de fator matricial ou tensorial de concentração mecânica (REITER; DVORAK; TVERGAARD, 1997). Na literatura os tensores $\mathbf{B}^{+}, \mathbf{B}^{-}, \mathbf{A}^{+}$e $\mathbf{A}^{-}$também são chamados de "localizadores de tensão ou deformação" ou "tensores de influência" (SUQUET, 1985). Neste trabalho esses tensores serão denominados de "localizadores de tensão ou deformação".

Substituindo 4.11 em 4.9 obtém-se:

$$
\begin{aligned}
\langle\boldsymbol{\sigma}\rangle & =\underbrace{\left[\rho \mathbf{C}^{+} \mathbf{A}^{+}+(1-\rho) \mathbf{C}^{-} \mathbf{A}^{-}\right]}_{\mathbf{C}^{H}}\langle\boldsymbol{\epsilon}\rangle \\
\mathbf{C}^{H} & =\rho \mathbf{C}^{+} \mathbf{A}^{+}+(1-\rho) \mathbf{C}^{-} \mathbf{A}^{-}
\end{aligned}
$$

E substituindo 4.11 em 4.6 obtém-se:

$$
\mathbf{I}=\rho \mathbf{A}^{+}+(1-\rho) \mathbf{A}^{-}
$$

Resolvendo o sistema de equações dado por 4.14 e 4.15 onde I é a representação matricial de um tensor identidade de $4^{a}$. ordem obtém-se:

$$
\mathbf{A}^{+}=\frac{\left(\mathbf{C}^{+}-\mathbf{C}^{-}\right)^{-1}\left(\mathbf{C}^{H}-\mathbf{C}^{-}\right)}{\rho} \quad, \quad \mathbf{A}^{-}=\frac{-\left(\mathbf{C}^{+}-\mathbf{C}^{-}\right)^{-1}\left(\mathbf{C}^{H}-\mathbf{C}^{+}\right)}{1-\rho}
$$

De maneira análoga, é possível obter os valores de $\mathbf{B}^{+}$e $\mathbf{B}^{-}$utilizando as relações $4.5,4.10$ e 4.12 .

$$
\mathbf{B}^{+}=\frac{\left(\mathbf{S}^{+}-\mathbf{S}^{-}\right)^{-1}\left(\mathbf{S}^{H}-\mathbf{S}^{-}\right)}{\rho} \quad, \quad \mathbf{B}^{-}=\frac{-\left(\mathbf{S}^{+}-\mathbf{S}^{-}\right)^{-1}\left(\mathbf{S}^{H}-\mathbf{S}^{+}\right)}{1-\rho}
$$


Dessa forma, é possível obter as matrizes localizadoras de tensão capazes de fornecer a média de tensões em cada fase do material composto. É importante notar que as equações 4.16 e 4.17 são válidas independentemente do modelo micromecânico utilizado para determinação de $\mathbf{C}^{H}$ (REITER; DVORAK; TVERGAARD, 1997), pois a única hipótese utilizada é de que existe um ERV que está sujeito a um campo homogêneo de tensão e deformação.

\subsection{Cálculo das propriedades efetivas dos mate- riais}

O cálculo das propriedades efetivas de um material composto pode ser feito através do Método da Homogeneização. Porém, como visto na seção 2.4.1, para se aplicar o Método da Homogeneização é necessário que se tenha conhecimento preciso da geometria da microestrutura do material composto. Normalmente, quando se lida com materiais compostos reais, como agregados policristalinos, materiais fibrosos ou com inclusões dispersas, a geometria da microestrutura é, em geral, desconhecida, ou apenas conhecida estatisticamente e qualitativamente. Dessa forma, desenvolveram-se alguns modelos genéricos que visam a definir as propriedades efetivas do material, tendo como hipótese apenas alguns parâmetros quantitativos e qualitativos da microestrutura.

Os modelos mais elementares para a estimativa das propriedades efetivas dos materiais são os modelos de Voigt (VOIGT apud 1889 Aboudi (1991)) e o modelo de Reuss. (REUSS 1929 apud Aboudi (1991)). O modelo de Voigt parte do princípio de que ambas as fases do material composto estão sujeitas às mesmas deformações, assim $\mathbf{A}^{+}=\mathbf{A}^{-}=\mathbf{I}$, o que leva à equação 4.18:

$$
\mathbf{C}^{H}=\rho \mathbf{C}^{+}+(1-\rho) \mathbf{C}^{-}
$$

O modelo de Reuss adota a hipótese de que ambas as fases do material composto estão sujeitas à mesma tensão, assim temos que $\mathbf{B}^{+}=\mathbf{B}^{-}=\mathbf{I}$ e, conseqüentemente:

$$
\mathbf{C}^{H}=\left[\rho\left(\mathbf{C}^{+}\right)^{-1}+(1-\rho)\left(\mathbf{C}^{-}\right)^{-1}\right]^{-1}
$$

Os modelos de Voigt e Reuss são insatisfatórios do ponto de vista mecânico, uma vez que violam as condições de equilíbrio das tensões (Voigt) e a compatibilidade das deformações (Reuss). Na literatura de Otimização Topológica, os modelos de Voigt e Reuss, bem como um modelo híbrido proveniente de uma combinação de ambos, foram utilizados nos trabalhos de Swan e Kosaka 
(1997a, 1997b).

Uma classe mais elaborada de modelos de material é aquela na qual os modelos micromecânicos se baseiam na solução de Eshelby para o problema de uma inclusão elíptica em um meio homogêneo.

O modelo de inclusão de Eshelby considera uma inclusão elíptica $(i)$ de tensor constitutivo $\mathbf{c}^{i}$ dentro de uma matriz elástica homogênea de dimensões infinitas e tensor constitutivo $\mathbf{C}^{m}$, sujeita a um campo de tensão e deformação homogêneo $\boldsymbol{\sigma}^{m}$ e $\boldsymbol{\epsilon}^{m}$, respectivamente. Dessa forma os campos de tensão e deformação dentro da inclusão $\left(\boldsymbol{\sigma}^{i}\right.$ e $\left.\boldsymbol{\epsilon}^{i}\right)$ são dados por (ZAOUI, 2002):

$$
\boldsymbol{\epsilon}^{i}=\left[\mathbf{I}+\mathbf{P}_{i}^{m}\left(\mathbf{c}^{i}-\mathbf{C}^{m}\right)\right]^{-1} \boldsymbol{\epsilon}^{m} \quad, \quad \boldsymbol{\sigma}^{i}=\mathbf{c}^{i} \boldsymbol{\epsilon}^{i}
$$

onde

$$
P_{i_{t j k l}}^{m}=-\left(\int_{i} G_{t k}^{m}\left(\mathbf{x}-\mathbf{x}^{\prime}\right) d V\right)_{l j(t j)(k l)}
$$

onde $(t j)(k l)$ indica que o tensor é simétrico em relação a $(t j)$ e $(k l)$ e $\mathbf{G}^{0}\left(x-x^{\prime}\right)$ é o tensor de Green para um meio infinito de módulo $\mathbf{C}^{m}$. Este tensor relaciona o deslocamento do ponto $\mathbf{x}$ devido a uma carga unitária aplicada em $\mathbf{x}^{\prime}$.

A partir do campo de tensão dentro de um ERV sujeito a uma deformação macroscópica uniforme $\epsilon^{0}$, é possível definir uma estimativa do tensor constitutivo do material composto, e esta é dada pela equação 4.22:

$$
\mathbf{C}^{H}=\left\langle\mathbf{c}\left[\mathbf{I}+\mathbf{P}_{i}^{m}\left(\mathbf{c}-\mathbf{C}^{m}\right)\right]^{-1}\right\rangle\left\langle\left[\mathbf{I}+\mathbf{P}_{i}^{m}\left(\mathbf{c}-\mathbf{C}^{m}\right)\right]^{-1}\right\rangle^{-1}
$$

onde $\mathbf{c}$ representa o tensor constitutivo do material em cada ponto dentro do ERV e $\mathbf{C}^{m}$ o tensor constitutivo da matriz.

Baseados na equação 4.22, vários modelos de material foram desenvolvidos, dentre os quais o modelo de Mori-Tanaka e o modelo Auto-consistente são os que mais se destacam. Observa-se na equação 4.22 que o valor de $\mathbf{C}^{m}$ é arbitrário e que $\mathbf{P}_{i}^{m}$ é dependente do formato da inclusão.

Assim, o modelo de Mori-Tanaka considera o valor de $\mathbf{C}^{m}$ igual ao valor real da matriz do material composto $\mathbf{C}^{\text {matriz }}$ e a geometria da inclusão deve ser escolhida conforme o material específico. Essa hipótese é razoável quando se trata de materiais compostos com uma pequena fração volumétrica referente às inclusões, de tal modo que a matriz do material composto seja facilmente definida. Uma discussão mais aprofundada sobre este modelo pode ser encontrada em Weng (1990). 
Outro modelo baseado na equação 4.22 é o modelo Auto-consistente, que considera a inclusão $i$ inserida em uma matriz com tensor constitutivo $\mathbf{C}^{m} \mathrm{com}$ valores iguais ao que se procura, no caso $\mathbf{C}^{H}$. Observa-se então que a equação 4.22 passa a ser resolvida de forma iterativa, uma vez que não se tem os valores de $\mathbf{P}_{i}^{m}$ e $\mathbf{C}^{m}$ definidos a priori.

Esse segundo modelo de material é mais adequado para os materiais compostos nos quais a densidade volumétrica é próxima a $50 \%$ e não é possível se definir com clareza qual das duas fases cumprem o papel de matriz do composto (ABOUDI, 1991).

Outros modelos micromecânicos, como o modelo de Esferas, o modelo Autoconsistente generalizado, o modelo Diferencial ou o Método das Células podem ser encontrados em Aboudi (1991). Vale a pena notar que o modelo Método das Células foi aplicado no Método de Otimização Topológica (MOT) em Fuchs, Paley e Miroshny (1999).

\subsubsection{Materiais com Gradação Funcional}

Os Materiais com Gradação Funcional (MsGF) são aqueles cujas propriedades variam continuamente ao longo do espaço. Esta variação de propriedades é, em geral, obtida através da mudança contínua da microestrutura do material, de tal modo que a fase que configura a matriz do material composto em um dado ponto passa a ser a inclusão em uma outra região (ABOUDI; PINDERA; ARNOLD, 1999). Assim, uma característica importante do material com gradiente é que a fração volumétrica das fases varia entre $0 \%$ e $100 \%$ entre dois pontos da estrutura.

Na literatura este tipo de material é conhecido como Functionally Graded Materials (FGM), contudo, neste texto, será utilizada a nomenclatura em português: Materiais com Gradação Funcional (MsGF). Este tipo de material tem atraído a atenção de engenheiros e pesquisadores devido a seu bom desempenho quando submetido a cargas térmicas e mecânicas (YIN; SUN; PAULINO, 2004).

Do ponto de vista da microestrutura o material com gradação possui três regiões distintas. Na Figura 4.2 está representada esquematicamente a microestrutura dos Materiais com Gradação Funcional (MsGF), na qual se pode observar que existem duas regiões onde é possível definir claramente uma fase atuando como matriz e outra como inclusão de um material composto (regiões A e C da Figura 4.2) e uma região de transição onde não é possível definir qual dos materiais atua como matriz ou inclusão do material composto. Em geral a região de 

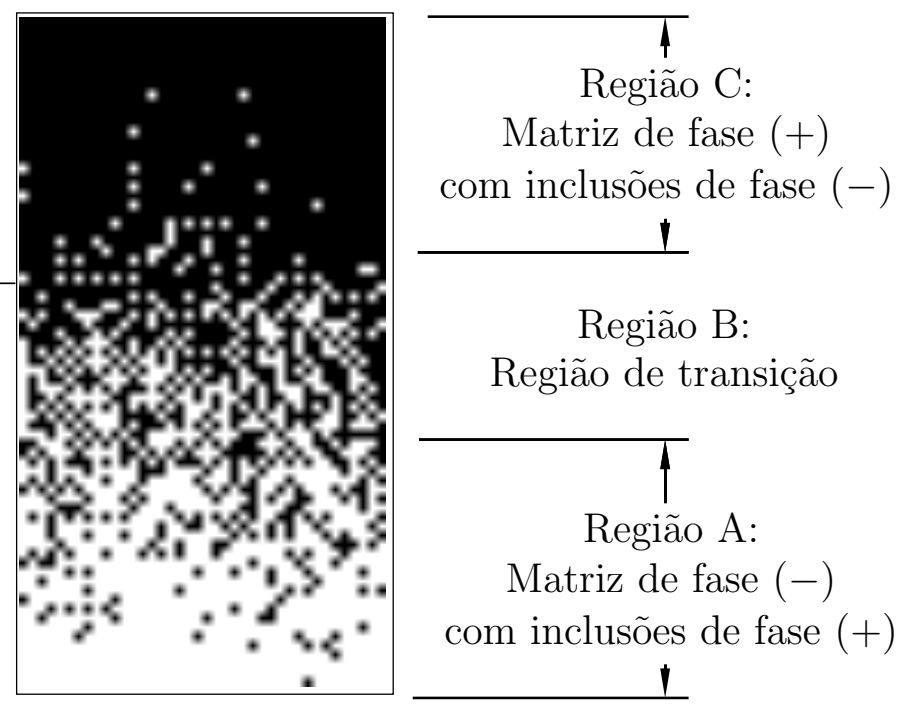

Figura 4.2: Representação esquemática da variação da microestrutura em um material gradado

transição possui uma morfologia denominada esquelética, ou na forma de esqueleto (REITER; DVORAK; TVERGAARD, 1997).

Devido ao fato dos MsGF possuirem uma transição contínua da microestrutura que proporciona uma distribuição macroscópica não uniforme das propriedades mecânicas, a abordagem clássica de se estimar as propriedades efetivas do material composto, que considera apenas as características locais de um Elemento Representativo de Volume (ERV), é questionável (PINDERA; ABOUDI; ARNOLD, 1995). Isto porque a hipótese de que as dimensões do ERV são pequenas o suficiente em relação à variação do campo de tensão pode não ser verificada ,pois o campo de tensão macroscópica $\boldsymbol{\sigma}^{0}$ pode deixar de ser constante dentro do ERV, justamente devido ao fato de que a gradação de propriedades tende a gerar uma variação no campo de tensões.

Devido a essa característica, Pindera, Aboudi e Arnold (1995) propõem um modelo de material de alta ordem, não local, baseado no Método das Células (ABOUDI; PINDERA; ARNOLD, 1994; ABOUDI, 1991), no qual as propriedades de um ponto são dependentes não apenas da microestrutura no ponto, mas também da variação desta ao longo do material. Dessa forma, o conceito do ERV é revisto, e neste modelo passa a representar não apenas um ponto da estrutura, mas toda uma região que apresenta gradação. Assim, a análise das macro-tensões é feita de maneira acoplada com a análise das micro-tensões. Em um artigo posterior Aboudi, Pindera e Arnold (1999) fazem uma discussão sobre a validade da aplicação do conceito do ERV para os MsGF e apresentam uma generalização deste modelo de material de alta ordem unidimensional para o caso tridimensional, onde se apresentam três direções de gradiente das propriedades. 
Uma outra abordagem para se estimar as propriedades efetivas dos MsGF foi proposta por Yin, Sun e Paulino (2004), Yin et al. (2005) e se baseia na extensão do modelo de Mori-Tanaka, de modo a considerar a interação entre as partículas (inclusões na matriz elástica). Neste modelo, o ERV possui uma distribuição heterogênea de material, de modo que se possa constatar um gradiente da distribuição de inclusões. Essa situação está representada esquematicamente na figura 4.3 .

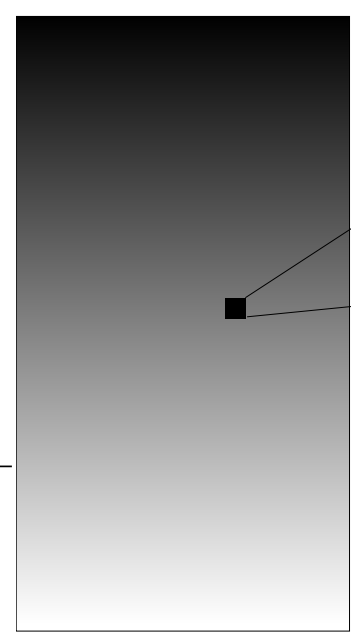

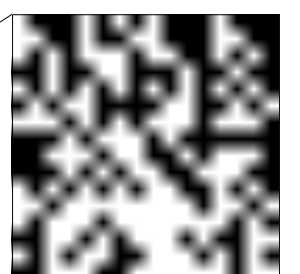

ERV de um material com gradação de propriedades segundo a abordagem de Yin, Sun e Paulino (2004)

Figura 4.3: Representação esquemática de um ERV com um distribuição heterogênea de inclusões

Os métodos para a estimativa das propriedades efetivas dos MsGF e materiais heterogêneos em geral, através de modelos não locais ou de alta ordem, ainda é um tópico em aberto na literatura e outros autores têm-se dedicado ao tema como Luciano e Willis (2004), Buryachenko e Pagano (2003), Luciano e Willis (2000), Gasik (1998), Torquato (1998).

Quanto à aplicação dos modelos micromecânicos tradicionais para a estimativa das propriedades efetivas dos MsGF, os trabalhos de Reiter e Dvorak (1998) e Reiter, Dvorak e Tvergaard (1997) apresentam um estudo da capacidade do modelo de Mori-Tanaka e do modelo Auto-consistente em estimar as propriedades efetivas do material com gradiente. Este estudo é feito a partir da comparação dos campos de tensão e deformação obtidos através da simulação numérica de dois tipos de corpo de prova, um no qual a gradação é representada por camadas homogêneas e outro no qual a microestrutura é representada de uma forma explícita.

Nesses trabalhos os autores têm como principal conclusão que a utilização do modelo de Mori-Tanaka nas regiões onde é possível definir que fase desempenha o papel de matriz e que fase desempenha o papel de inclusão (regiões A e C na 
figura 4.2) e a utilização do modelo Auto-consistente para a região de transição é uma consideração válida para um material com gradiente em que a razão entre os módulos de elasticidade das fases é em torno de 10 ou menor.

\subsubsection{Limites das propriedades efetivas dos materiais com- postos}

Um ponto importante no estudo dos materiais compostos é a determinação dos limites superiores e inferiores que as propriedades efetivas podem possuir, para uma dada razão volumétrica entre as fases que constituem tal material.

Uma das principais contribuições nessa área foi apresentada no trabalho de Hashin e Shtrikman (1963), o qual demonstrou que os limites superiores e inferiores dos módulos de compressibilidade e de cisalhamento efetivos de um material composto, que seja quase-isotrópico e quase-homogêneo, podem ser definidos sem que sejam feitas hipóteses sobre a configuração geométrica da microestrutura. Aqui o conceito de quase-homogêneo indica que o material é estatisticamente homogêneo, ou seja, todos os ERV do material são estatisticamente equivalentes.

Posteriormente Walpole (1966b, 1966a) generalizou o conceito para materiais multi-fase com fases anisotrópicas. Uma descrição mais detalhada dessa teoria pode ser encontrada em Walpole (1981), Zaoui (2002), Hashin (1983).

Para o caso dos materiais isotrópicos, os limites superiores e inferiores de H-S são dados em função dos módulos de compressibilidade $(K)$ e cisalhamento $(G)$. Neste caso estamos considerando duas fases isotrópicas, indicadas pelos sobrescritos $(+)$ e $(-)$, com propriedades ordenas tal que $K^{+}>K^{-}$e $G^{+}>G^{-}$. Dessa forma, no caso bidimensional, os limites superior $K_{\max }$ e inferior $K_{\min }$ de Hashin-Shtrikman para o módulo de compressibilidade são dados por:

$$
\begin{gathered}
K_{\text {max }}=(1-\rho) K^{-}+\rho K^{+}-\frac{(1-\rho) \rho\left(K^{+}-K^{-}\right)^{2}}{(1-\rho) K^{+}+\rho K^{-}+G^{+}} \\
K_{\min }=(1-\rho) K^{-}+\rho K^{+}-\frac{(1-\rho) \rho\left(K^{+}-K^{-}\right)^{2}}{(1-\rho) K^{+}+\rho K^{-}+G^{-}}
\end{gathered}
$$

e os limites superior $G_{\max }$ e inferior $G_{\min }$ do módulo de cisalhamento são dados por:

$$
G_{\max }=(1-\rho) G^{-}+\rho G^{+}-\frac{(1-\rho) \rho\left(G^{+}-G^{-}\right)^{2}}{(1-\rho) G^{+}+\rho G^{-}+\frac{K^{+} G^{+}}{K^{+}+2 G^{+}}}
$$




$$
G_{\min }=(1-\rho) G^{-}+\rho G^{-}-\frac{(1-\rho) \rho\left(G^{+}-G^{-}\right)^{2}}{(1-\rho) G^{+}+\rho G^{-}+\frac{K^{-} G^{-}}{K^{-}+2 G^{-}}}
$$

Uma fórmula genérica para o caso bi ou tri-dimensional pode ser encontrada em Allaire (2002, p. 144). Para se obter os limites de H-S para o módulo de elasticidade $E$, que é mais comumente utilizado na Engenharia, utilizam-se as relações:

$$
\begin{gathered}
E_{\max }=\frac{9 K_{\max }}{1+3 \frac{K_{\max }}{G_{\min }}} \\
E_{\min }=\frac{9 K_{\min }}{1+3 \frac{K_{\min }}{G_{\min }}}
\end{gathered}
$$

conseqüentemente, os coeficientes de Poisson relativos aos limites superior e inferior do módulo de elasticidade são dados por:

$$
\begin{gathered}
\nu_{\max }=\frac{1-2 / 3 \frac{G_{\max }}{K_{\max }}}{2+2 / 3 \frac{G_{\max }}{K_{\max }}} \\
\nu_{\min }=\frac{1-2 / 3 \frac{G_{\min }}{K_{\min }}}{2+2 / 3 \frac{G_{\min }}{K_{\min }}}
\end{gathered}
$$

É importante notar que os limites de H-S têm como hipótese que o material é estatisticamente homogêneo e que as dimensões da inclusão do material composto tendem a zero, o que valida a hipótese de se definir um ERV do material. Entretanto, Torquato (1998) atenta para o fato de que, no caso dos materiais compostos estatisticamente heterogêneos, como é o caso dos MsGF, os limites de H-S, rigorosamente falando, não são mais válidos. Uma revisão dos estudos sobre os limites das propriedades efetivas de materiais compostos estatisticamente heterogêneos pode ser encontrada em Torquato (2000, 1991). Nessa abordagem, os limites das propriedades efetivas passam a depender não apenas da densidade volumétrica, mas também de funções que representam a distribuição estatística das inclusões do material composto. 


\subsection{Análise das tensões locais de um material composto}

A análise das tensões locais de um material composto consiste em calcular as médias das micro-tensões em de cada fase constituinte do material composto em um dado ponto da estrutura.

Para melhor compreender as relações em um material composto, a Figura 4.4 apresenta como os campos de tensão e deformação na micro e na macro escala se relacionam. Observando essa figura se pode melhor compreender a ordem lógica em que os modelos micromecânicos são desenvolvidos.

Propriedades Efetivas

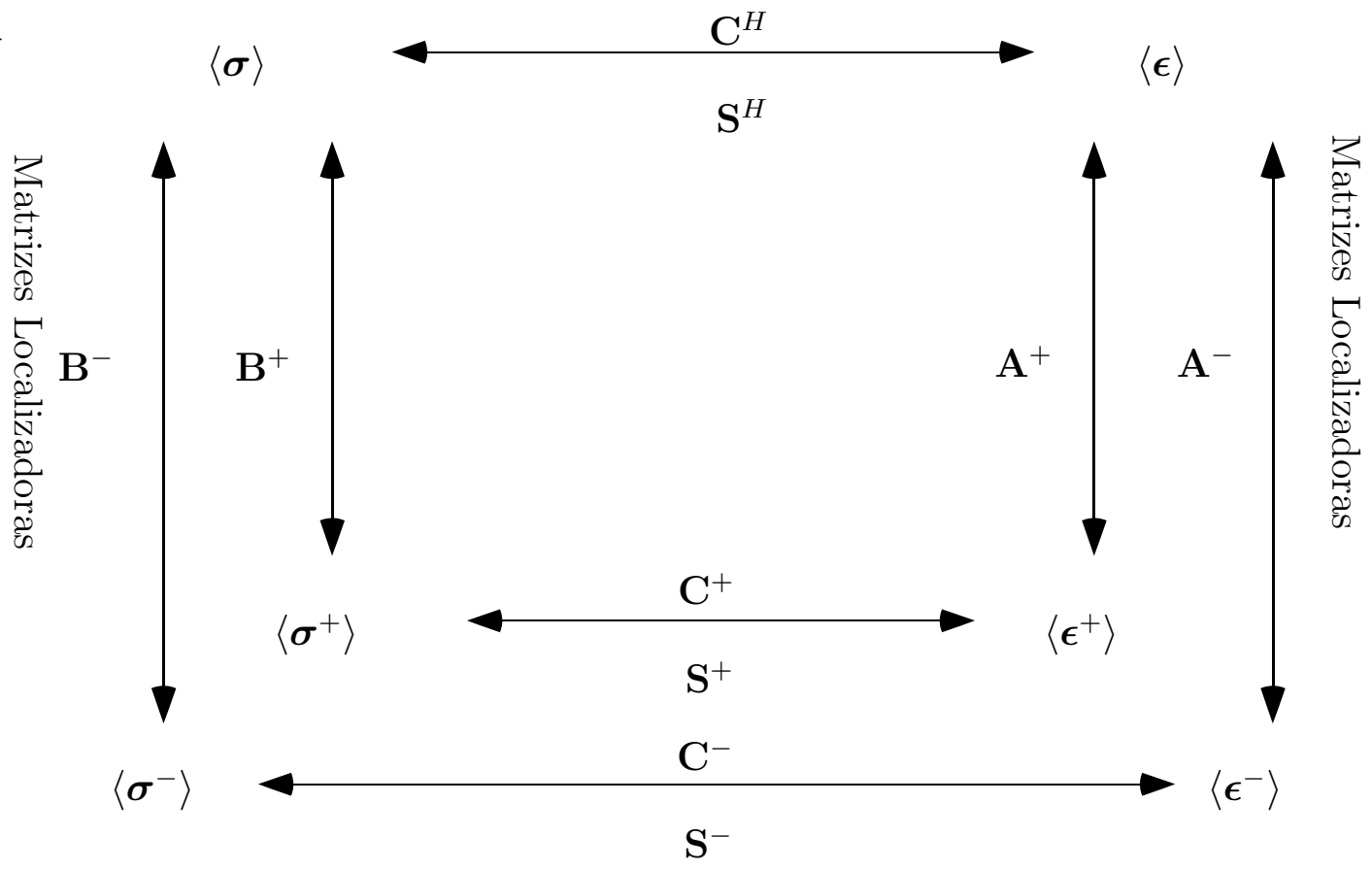

Propriedades locais

Figura 4.4: Diagrama das relações entre os campos de tensão e deformação em um material composto.

Os modelos micromecânicos baseados nos modelos de inclusão de Eshelby, bem como os modelos de Voigt e Reuss, iniciam-se obtendo as relações entre o campo de tensão ou deformação na microestrutura (micro-tensão) com a macrotensão e macro-deformação (tensores $\mathbf{B}^{+}, \mathbf{A}^{+} \mathbf{B}^{-}$e $\mathbf{A}^{-}$) e, a partir destes, se obtêm as propriedades efetivas que relacionam os campos de tensão e deformações na macro-escala. Dessa forma, as matrizes localizadoras são as primeiras grandezas a serem obtidas, e sua definição é clara. Por exemplo, o modelo de Voigt tem como hipótese que o campo de macro-deformação é igual ao campo de micro- 
deformação em ambas as fases $\left(\mathbf{A}^{+}=\mathbf{A}^{-}=\mathbf{I}\right)$. O modelo de Reuss faz a mesma hipótese, porém para o campo de tensão.

Já os modelos de material baseados no Método da Homogeneização calculam diretamente as propriedades efetivas do material composto, sem que as matrizes localizadoras sejam explicitamente definidas.

Na literatura, devido a fatores históricos, a aplicação do MOT considerando a restrição de tensão baseou-se nos conceitos do Método da Homogeneização para fazer o cálculo das micro-tensões. Os trabalhos de Allaire, Jouve e Maillot (2004), Lipton (2002) utilizam diretamente o Método da Homogeneização e Duysinx e Sigmund (1998), a partir do Método da Homogenização, desenvolvem um localizador de tensão para o modelo de material SIMP. Para contextualizar estes trabalhos, aqui será feita uma breve descrição do Método de Homogeneização.

Partindo da hipótese de que o campo de deslocamentos do material composto pode ser descrito por uma expansão assintótica na forma:

$$
\mathbf{u}(\mathbf{x}, \mathbf{y})=\mathbf{u}_{0}(\mathbf{x})+\delta \mathbf{u}_{1}(\mathbf{x}, \mathbf{y})+\ldots
$$

onde $\mathbf{u}(\mathbf{x}, \mathbf{y})$ é o campo de deslocamento, $\delta$ é uma dimensão característica da célula unitária, x e y são as coordenadas globais e locais, respectivamente (Figura 4.1), o Método da Homogeneização fornece o tensor constitutivo de um material composto através da equação:

$$
C_{i j k l}^{H}(\mathbf{x})=\frac{1}{|\mathbf{Y}|} \int_{\mathbf{Y}}\left[C_{i j k l}(\mathbf{x}, \mathbf{y})-C_{i j p q}(\mathbf{x}, \mathbf{y}) \frac{\partial \psi_{p}^{k l}}{\partial y_{q}}\right] d \mathbf{y}
$$

onde $\psi^{k l}$ representa o campo de deslocamentos na microestrutura obtido pela solução do problema da célula unitária. Este é dado na forma integral por:

$$
\int_{\mathbf{Y}}\left[C_{i j p q}(\mathbf{x}, \mathbf{y}) \frac{\partial \psi_{p}^{k l}}{\partial y_{q}}\right] \frac{\partial \varphi_{i}}{\partial y_{j}} d \mathbf{y}=\int_{\mathbf{Y}} C_{i j p q}(\mathbf{x}, \mathbf{y}) \frac{\partial \varphi_{i}}{\partial y_{j}} d \mathbf{y} \quad \text { para todos } \varphi \in U_{Y}
$$

onde $U_{Y}$ representa todo o conjunto de deslocamentos periódicos dentro da célula unitária (para maiores referencias sobre este método ver Bendsøe e Sigmund (2003), Allaire (2002)).

No contexto do Método de Homogeneização, os localizadores de deformação são dados em função do campo de deslocamento $\psi$ dentro da célula unitária. Para uma descrição formal da obtenção desses localizadores ver a seção 1.36 de Allaire (2002), onde estes são denominados de corretores.

Do ponto de vista físico, o Método de Homogeneização fornece as proprieda- 
des efetivas do material, tal que o campo de deslocamentos efetivo convirja para o campo de deslocamentos real a medida que o tamanho característico da célula unitária tende a zero. Porém, o campo de deformação, gradiente do campo de deslocamentos, não converge localmente, assim, é necessário utilizar os corretores a fim de que se tenha a convergência do campo de deformação e, conseqüentemente, do campo de tensão. Dessa forma, fica claro que tais corretores são definidos a partir do campo de deslocamentos dentro da célula unitária.

Os localizadores se justificam devido à existência do segundo termo da expansão assintótica do campo de deslocamento $\left(\delta \mathbf{u}_{1}(\mathbf{x}, \mathbf{y})\right)$, ou seja, as propriedades efetivas fornecem o deslocamento médio que não é dependente do campo de deslocamento local $\left(\mathbf{u}_{1}(\mathbf{x}, \mathbf{y})\right)$, no caso de materiais periódicos, pois a média deste é nula, e os corretores recuperam a influência deste segundo termo na derivada dos deslocamentos.

Fazendo um paralelo entre os modelos micromecânicos tradicionalmente utilizados nas ciências dos materiais, como o de Mori-Tanaka e o Auto-consistente, e os modelos micromecânicos obtidos pelo Método de Homogeneização, os localizadores são obtidos nos primeiros a partir de campos de deformações dentro do ERV e nos segundos a partir do campo de deslocamento dentro da célula unitária.

Devido ao fato desses modelos fazerem hipóteses similares, apesar de não haver uma prova formal, observa-se que, em alguns casos, se obtêm exatamente os mesmos localizadores de tensão. Por exemplo, para o caso do material laminado rank-2.

O trabalho de maior impacto na aplicação do MOT considerando restrição de tensões, de Duysinx e Sigmund (1998), utilizou um localizador de tensões baseado no modelo de material laminado rank-2, no qual é possível se obter o campo de deslocamento $\psi$ (no problema 4.33) de forma analítica e, conseqüentemente, uma representação analítica das propriedades efetivas e dos localizadores. O trabalho de Allaire, Jouve e Maillot (2004) utiliza o modelo de material rank-n e, conseqüentemente, seu localizador expresso na sua forma analítica. O trabalho de Lipton (2002) utiliza uma microestrutura constituída de uma célula unitária quadrada com inclusões circulares e, em seu trabalho, o localizador é escrito de uma forma diferente e é denominado de tensor de covariância.

De maneira correlata, os trabalhos de Otimização Topológica (OT) envolvendo plasticidade do material necessitam do cálculo das micro-tensões, assim os trabalhos de Swan e Kosaka (1997b, 1997a) utilizam uma média ponderada das tensões no modelo de Voigt e Reuss, da mesma forma que são calculadas as 
propriedades efetivas.

A seguir será apresentado um exemplo do cálculo das propriedades efetivas de um material laminado rank-2 atrávés do Método da Homogeneização, assim será possível demonstrar a relação deste com as equações gerais apresentadas na seção 4.2 .

\subsubsection{Exemplo do material laminado rank-2}

O tensor constitutivo das propriedades efetivas de um material laminado pode ser determinado analiticamente através do Método da Homogeneização. Para se obter uma gama maior de tensores constitutivos efetivos, é possível, do ponto de vista teórico, fazer sub-laminações da estrutura laminada, ou seja, cada fase do material laminado é por sua vez um material laminado. A figura 4.5 apresenta um caso particular de microestrutura laminada com duas escalas de laminação, rank-2. Uma primeira escala, aqui denominada de escala $\mu$, possui duas camadas de material, a camada $L_{\mu}$ de espessura $\mu$, que possui um material isotrópico cujas propriedades são $E^{+}$e $\nu^{+}$, e um camada complementar $L_{1-\mu}$, de espessura $1-\mu$ que, por sua vez, é constituída por um material laminado, também com duas camadas $L_{\gamma}$ e $L_{1-\gamma}$, de espessuras $\gamma$ e $1-\gamma$, respectivamente. Porém, a laminação na escala $\gamma$ é ortogonal à laminação na escala $\mu$. A camada $L_{\gamma}$ é constituída de material $E^{+}$e $\nu^{+}$e a camada $L_{1-\gamma}$ de material $E^{-}$e $\nu^{-}$.

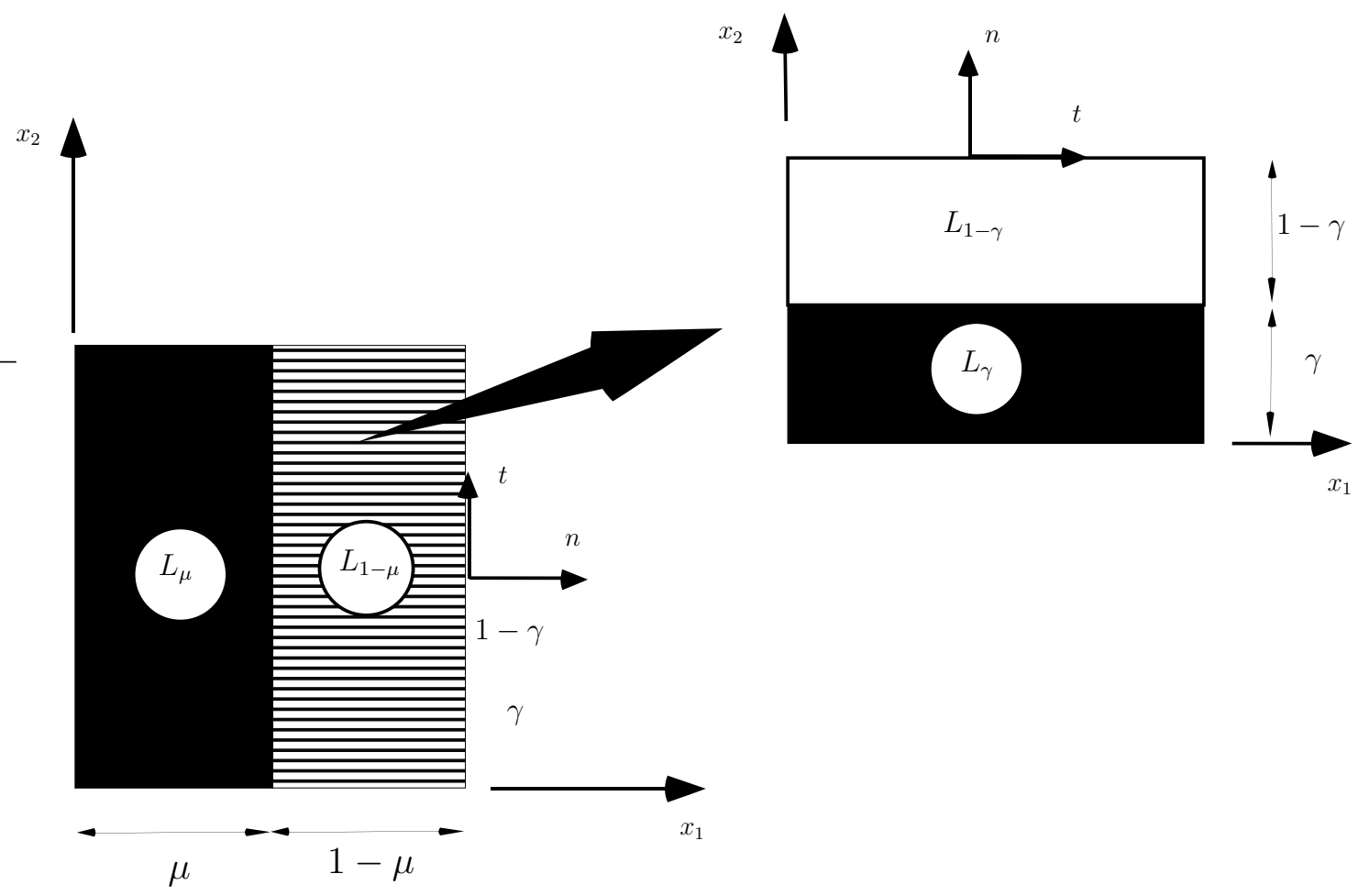

Figura 4.5: Modelo de microestrutura rank-2 
Assim, é possível calcular as propriedades efetivas deste material de forma analítica, cuja célula unitária é dada pela figura 4.5. Inicialmente deve-se calcular as propriedades efetivas do material rank-1. Considerando uma célula unitária alinhada com um sistema de coordenadas locais, conforme apresentado na figura 4.6, onde $M^{+}$e $M^{-}$representam materiais isotrópicos de propriedades $E^{+}, \nu^{+} \mathrm{e}$ $E^{-}, \nu^{-}$, respectivamente.

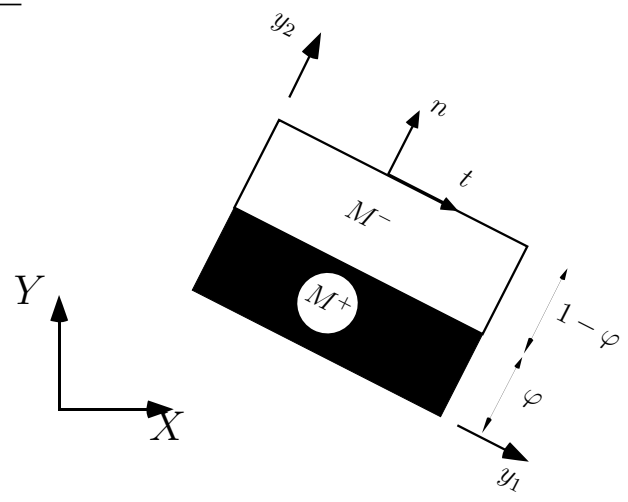

Figura 4.6: Modelo de microestrutura rank-1

Assim o tensor constitutivo efetivo ou homogeneizado é dado pelas equações (BENDSøE; SIGMUND, 2003):

$$
\begin{gathered}
C_{1111}^{H}=\frac{C_{1111}^{+} C_{1111}^{-}}{\varphi C_{1111}^{-}+(1-\varphi) C_{1111}^{+}} \\
C_{2222}^{H}=\varphi C_{2222}^{+}+(1-\varphi) C_{2222}^{-}-\left[\frac{\varphi\left(C_{1122}^{+}\right)^{2}}{C_{1111}^{+}}+\frac{(1-\varphi)\left(C_{1122}^{-}\right)^{2}}{C_{1111}^{-}}\right]+ \\
{\left[\frac{\varphi C_{1122}^{+}}{C_{1111}^{+}}+\frac{(1-\varphi) C_{1122}^{-}}{C_{1111}^{-}}\right]^{2}+\frac{C_{1111}^{+} C_{1111}^{-}}{\varphi C_{1111}^{-}+(1-\varphi) C_{1111}^{+}}} \\
C_{1122}^{H}=\left[\frac{\varphi C_{1122}^{+}}{C_{1111}^{+}}+\frac{(1-\varphi) C_{1122}^{-}}{C_{1111}^{-}}\right] \frac{C_{1111}^{+} C_{1111}^{-}}{\varphi C_{1111}^{-}+(1-\varphi) C_{1111}^{+}} \\
C_{1212}^{H}=\frac{C_{1212}^{+} C_{1212}^{-}}{\varphi C_{1212}^{-}+(1-\varphi) C_{1212}^{+}}
\end{gathered}
$$

Para se obter as propriedades efetivas do material rank-2 basta utilizar tais equações novamente, de tal forma que a fase (-) seja substituída pelas propriedades efetivas dadas pelas equações acima.

Considerando que a aplicação das equações 4.34, 4.35, 4.36 e 4.37 na escala de laminação $\gamma$, seguido de uma rotação de $90^{\circ}$, permite obter os tensores cons- 
titutivos homogeneizados:

$$
\mathbf{S}^{\gamma}=\left(\mathbf{C}^{\gamma}\right)^{-1}
$$

Fazendo esse procedimento recursivo, para se obter as propriedades efetivas do material laminado rank-2, apresentado na Figura 4.5, obtêm-se o tensor de propriedades efetivas dadas do material laminado na escala $\mu$ :

$$
\begin{gathered}
C_{1111}^{\mu}=\frac{C_{1111}^{+} C_{1111}^{\gamma}}{\mu C_{1111}^{\gamma}+(1-\mu) C_{1111}^{+}} \\
C_{2222}^{\mu}=\mu C_{2222}^{+}+(1-\mu) C_{2222}^{\gamma}-\left[\frac{\mu\left(C_{1122}^{+}\right)^{2}}{C_{1111}^{+}}+\frac{(1-\mu)\left(C_{1122}^{\gamma}\right)^{2}}{C_{1111}^{\gamma}}\right]+ \\
{\left[\frac{\mu C_{1122}^{+}}{C_{1111}^{+}}+\frac{(1-\mu) C_{1122}^{\gamma}}{C_{1111}^{\gamma}}\right]^{2}+\frac{C_{1111}^{+} C_{1111}^{\gamma}}{\mu C_{1111}^{\gamma}+(1-\mu) C_{1111}^{+}}} \\
C_{1122}^{\mu}=\left[\frac{\mu C_{1122}^{+}}{C_{1111}^{+}}+\frac{(1-\mu) C_{1122}^{\gamma}}{C_{1111}^{\gamma}}\right] \frac{C_{1111}^{+} C_{1111}^{\gamma}}{\mu C_{1111}^{\gamma}+(1-\mu) C_{1111}^{+}} \\
C_{1212}^{\mu}=\frac{C_{1212}^{+} C_{1212}^{\gamma}}{\mu C_{1212}^{\gamma}+(1-\mu) C_{1212}^{+}}
\end{gathered}
$$

Logo pode se escrever o tensor constitutivo efetivo do material laminado rank2 na forma:

$$
\mathbf{S}^{\mu}=\left(\mathbf{C}^{\mu}\right)^{-1}
$$

A partir dos tensores efetivos de flexibilidade dados por $\mathbf{S}^{\mu}$ e $\mathbf{S}^{\gamma}$, seguindo o procedimento exposto em Bendsøe e Sigmund (2003), é possível calcular os tensores localizadores de tensão, para cada camada do material laminado. $\left(L_{\mu}\right.$, $L_{1-\mu}, L_{\gamma}$ e $\left.L_{1-\gamma}\right)$ e estes são dados por:

$$
\begin{gathered}
\mathbf{B}_{\text {rank1 }}^{L_{\gamma}}=\left[\begin{array}{ccc}
1+\frac{(1-\gamma)\left(S_{1,1}^{+}-S_{1,1}^{-}\right)}{\gamma S_{1,1}^{+}+(1-\gamma) S_{1,1}^{-}} & \frac{(1-\gamma)\left(S_{1,2}^{+}-S_{1,2}^{-}\right)}{\gamma S_{1,1}^{+}+(1-\gamma) S_{1,1}^{-}} & 0 \\
0 & 1 & 0 \\
0 & 0 & 1
\end{array}\right] \\
\mathbf{B}_{\text {rank } 1}^{L_{1-\gamma}}=\left[\begin{array}{ccc}
1-\frac{(1-\gamma)\left(S_{1,1}^{+}-S_{1,1}^{-}\right)}{\gamma S_{1,1}^{+}+(1-\gamma) S_{1,1}^{-}} & -\frac{(1-\gamma)\left(S_{1,2}^{+}-S_{1,2}^{-}\right)}{\gamma S_{1,1}^{+}+(1-\gamma) S_{1,1}^{-}} & 0 \\
0 & 1 & 0 \\
0 & 0 & 1
\end{array}\right]
\end{gathered}
$$




$$
\begin{gathered}
\mathbf{B}_{\text {rank } 2}^{L_{\mu}}=\left[\begin{array}{ccc}
1 & 0 & 0 \\
\frac{(1-\mu)\left(S_{2,1}^{\gamma}-S_{2,1}^{+}\right)}{(1-\mu) S_{2,2}^{+}+\mu S_{2,2}^{\gamma}} & 1+\frac{(1-\mu)\left(S_{2,2}^{\gamma}-S_{2,2}^{+}\right)}{(1-\mu) S_{2,2}^{+}+\mu S_{2,2}^{\gamma}} & 0 \\
0 & 0 & 1
\end{array}\right] \\
\mathbf{B}_{\text {rank2 }}^{L_{1-\mu}}=\left[\begin{array}{ccc}
1 & 0 & 0 \\
-\frac{\mu\left(S_{2,1}^{\gamma}-S_{2,1}^{+}\right)}{(1-\mu) S_{2,2}^{+}+\mu S_{2,2}^{\gamma}} & 1-\frac{\mu\left(S_{2,2}^{\gamma}-S_{2,2}^{+}\right)}{(1-\mu) S_{2,2}^{+}+\mu S_{2,2}^{\gamma}} & 0 \\
0 & 0 & 1
\end{array}\right]
\end{gathered}
$$

Assim, é possível se determinar os localizadores de tensão em cada fase do material que é dado por:

- localizador para a camada $L_{\mu}: \mathbf{B}_{\text {rank2 }}^{L_{\mu}}$

- localizador para a camada $L_{\gamma}: \mathbf{B}_{\text {rank2 }}^{L_{\gamma}}=\mathbf{B}_{\text {rank } 1}^{L_{\gamma}} \mathbf{B}_{\text {rank2 }}^{1-\mu}$

- localizador para a camada $L_{1-\gamma}: \mathbf{B}_{\text {rank } 2}^{L_{1-\gamma}}=\mathbf{B}_{\text {rank } 1}^{L_{1-\gamma}} \mathbf{B}_{\text {rank2 } 2}^{1-\mu}$

Estas matrizes, $\mathbf{B}_{\text {rank2 }}^{L_{\mu}}, \mathbf{B}_{\text {rank2 } 2}^{L_{1-\mu}}, \mathbf{B}_{r a n k 1}^{L_{\gamma}}$ e $\mathbf{B}_{\text {rank1 }}^{L_{1-\gamma}}$ também são obtidas de forma idêntica através das equações 4.17 e 4.16 apresentadas na seção 4.2 .

Assim, os trabalhos que se utilizam, do Método da Homogeneização e os trabalhos que se baseiam em outros modelos micromecânicos são perfeitamente comparáveis, pois os campos de micro-tensão, apesar de calculados por teorias diferentes, apresentam o mesmo resultado.

No caso da utilização do material SIMP, Duysinx e Bendsøe (1998) propõem utilizar como localizador de tensão do material, o localizador da camada $L_{\gamma}$, pois, nesse trabalho, o autor está interessado em obter um problema 0-1, no qual um dos materiais representa um buraco, no caso o material (-).

Para obter o localizador de tensão, neste caso em que um dos materiais não possui rigidez, ou seja, representa um buraco, basta fazer o limite para $E^{-}$tende a zero. Assim se obtêm as matrizes:

$$
\begin{aligned}
\lim _{E^{-} \rightarrow 0} \mathbf{B}_{\text {rank } 1}^{L_{\gamma}} & =\left[\begin{array}{ccc}
\frac{1}{\gamma} & 0 & 0 \\
0 & 1 & 0 \\
0 & 0 & 1
\end{array}\right] \\
\lim _{E^{-} \rightarrow 0} \mathbf{B}_{\text {rank } 1}^{L_{1-\gamma}} & =\left[\begin{array}{lll}
0 & 0 & 0 \\
0 & 1 & 0 \\
0 & 0 & 1
\end{array}\right]
\end{aligned}
$$




$$
\begin{aligned}
\lim _{E^{-} \rightarrow 0} \mathbf{B}_{\text {rank2 }}^{L_{\mu}} & =\left[\begin{array}{ccc}
1 & 0 & 0 \\
0 & \frac{1}{\mu} & 0 \\
0 & 0 & 1
\end{array}\right] \\
\lim _{E^{-} \rightarrow 0} \mathbf{B}_{\text {rank2 }}^{L_{1-\mu}} & =\left[\begin{array}{ccc}
1 & 0 & 0 \\
0 & 0 & 0 \\
0 & 0 & 1
\end{array}\right]
\end{aligned}
$$

E, conseqüentemente, as matrizes de localização das tensões nas fases de interesse para o material poroso fica igual a:

$$
\mathbf{B}_{\text {rank2 }}^{L_{\mu}}=\left[\begin{array}{ccc}
1 & 0 & 0 \\
0 & \frac{1}{\mu} & 0 \\
0 & 0 & 1
\end{array}\right] \quad, \quad \mathbf{B}_{\text {rank2 }}^{L_{\gamma}}=\left[\begin{array}{ccc}
\frac{1}{\gamma} & 0 & 0 \\
0 & 0 & 0 \\
0 & 0 & 1
\end{array}\right]
$$

No artigo Duysinx e Sigmund (1998) este mesmo resultado é apresentado e, com base nestas equações, os autores propõem a utilização do localizador de tensão para o modelo de material SIMP dado por :

$$
\mathbf{B}_{\text {simp }}=\left[\begin{array}{ccc}
\frac{1}{\rho^{q}} & 0 & 0 \\
0 & \frac{1}{\rho^{q}} & 0 \\
0 & 0 & \frac{1}{\rho^{q}}
\end{array}\right]
$$

\subsection{Critério de falha dos materiais compostos}

A definição de um critério de falha de um material composto é um problema significativamente mais complexo que o cálculo analítico de suas propriedades efetivas, além de que fazer uma definição analítica da falha do material composto ainda é impraticável (HASHIN, 1983) pois:

- o conhecimento de um critério de micro falha ainda é incompleto;

- as tensões e deformações que irão causar a micro falha não podem ser determinadas analiticamente, uma vez que dependem de detalhes geométricos da microestrutura do material que, em geral, é desconhecida

- mesmo se um modelo de microestrutura for adotado, a análise da interação entre as micro falhas das diferentes fases apresenta uma dificuldade que torna seu cálculo proibitivo. 
Dada esta complexidade que envolve o tema e a extensa literatura na área, nesse trabalho, será feito apenas um breve panorama do tópico, aprofundando nas abordagens utilizadas no campo da OT.

Em Hashin (1983), o autor afirma que a definição analítica do critério de falha de um material composto é impraticável. Mesmo passadas duas décadas, Dvorak (2000), em seu trabalho de revisão, não apresenta grandes diferenças na forma com que este problema é tratado, de modo que ainda hoje a afirmação de Hashin (1983) continua sendo válida.

Grande parte destes trabalhos se dedicam à definição de modos de falha em materiais laminados ou fibrosos; por exemplo, em Hashin (1983) são descritos os modos de falha para um material composto em classes tais como: modo de tensão na fibra, modo de compressão da fibra, modo de tração da matriz, modo de compressão da matriz. Outros modelos mais elaborados de falha em materiais compostos são: a micro-flambagem de compostos fibrosos, que é apresentada em Budiansky e Fleck (1993) e a micro-flambagem de compostos laminados, apresentada em Fleck, Sivashanker e Sutcliffe (1997). Uma descrição sistemática dos critérios de falha é apresentada em Hashin (1983), Aboudi (1991), Torquato (2000), Dvorak (2000).

Apesar desse vasto campo de pesquisa relativo aos critérios de falha de materiais compostos, pouca é a influência destes trabalhos na aplicação MOT considerando restrição de tensão. Isto ocorre principalmente devido à complexidade dos critérios de falha, o que inviabiliza a aplicação destes no MOT que, para o caso de restrições de tensão, já possui dificuldades implícitas. Neste caso, a dificuldade não está apenas na implementação numérica, mas também na provável alteração do espaço de solução do problema de otimização devido as não linearidades ou descontinuidades de tais critérios.

Por exemplo, se adotado o critério de falha para materiais fibrosos unidirecionais, seguindo o modelo apresentado em Hashin (1983), seriam necessárias 4 restrições para cada ponto da estrutura, o que provavelmente aumentaria o problema do fenômeno das singularidades das tensões, que será apresentado na seção 6.3 .

Outro ponto importante é que as aplicações do MOT considerando restrição de tensão têm sido estudadas e desenvolvidas na síntese de estruturas e não no projeto de estruturas formadas por materiais compostos, como também é feito neste trabalho. Dessa forma, o critério de falha é aplicado apenas sob uma das fases do material composto intermediário, aquele que existe na forma de 
escala de cinza ao longo da otimização. Assim, é razoável aplicar um critério de falha tradicional, como o de von Mises, na fase sólida, por exemplo, uma das camadas do material laminado, e comparar este com a tensão de escoamento de tal material.

Por exemplo, no caso de uma estrutura tri-dimensional genérica, a tensão de von Mises calculada na macro-escala é dada pela equação 4.54:

$$
f_{v m}(\langle\boldsymbol{\sigma}\rangle)=\sqrt{\langle\boldsymbol{\sigma}\rangle^{T} \mathbf{V}\langle\boldsymbol{\sigma}\rangle}
$$

onde:

$$
\mathbf{V}=\left[\begin{array}{llllll}
1 & -1 / 2 & -1 / 2 & 0 & 0 & 0 \\
-1 / 2 & 1 & -1 / 2 & 0 & 0 & 0 \\
-1 / 2 & -1 / 2 & 1 & 0 & 0 & 0 \\
0 & 0 & 0 & 3 & 0 & 0 \\
0 & 0 & 0 & 0 & 3 & 0 \\
0 & 0 & 0 & 0 & 0 & 3
\end{array}\right]
$$

e

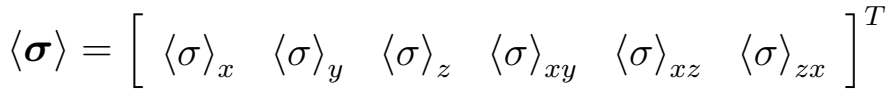

O tensor de tensões $\langle\boldsymbol{\sigma}\rangle$, escrito em forma de vetor na equação 4.56, representa as componentes de tensão na macro escala.

Para o caso de estruturas em estado plano de tensão e estruturas a axissimétricas,que são as esttruturas tratadas neste trabalho o tensor das tensões é dado por 4.58 e 4.57 , respectivamente.

$$
\begin{array}{r}
\langle\boldsymbol{\sigma}\rangle=\left\{\begin{array}{c}
\langle\sigma\rangle_{r} \\
\langle\sigma\rangle_{\theta} \\
\langle\sigma\rangle_{z} \\
\langle\sigma\rangle_{r z}
\end{array}\right\} \\
\langle\boldsymbol{\sigma}\rangle=\left\{\begin{array}{c}
\langle\sigma\rangle_{x} \\
\langle\sigma\rangle_{y} \\
\langle\sigma\rangle_{x y}
\end{array}\right\}
\end{array}
$$

A matrix $\mathbf{V}$ também deve ser modificada em cada um dos casos de estado de tensão. Para isto, basta retirar a linha e a coluna referente a componente de tensão inexistente no modelo.

Assim, neste texto, será utilizada a notação $f_{v m}(\langle\boldsymbol{\sigma}\rangle)$ para representar a tensão de Von Mises. 
Park (1995), sob a justificativa de um primeira abordagem na área, propõe:

$$
\frac{f_{v m}(\langle\boldsymbol{\sigma}\rangle)}{\rho}
$$

dessa forma a tensão de Von Mises sob o campo das macro-tensões é comparada com a tensão de escoamento do material.

Já Duysinx e Sigmund (1998) fazem uma justificativa baseada no materiais laminados rank-2 para propor um localizador de tensão, conforme apresentado na seção 4.4.1 e, assim, comparam a micro-tensão com a tensão de escoamento do material. É interessante notar que o localizador de tensão proposto por Duysinx e Sigmund (1998) leva a uma equação similar à proposta por Park (1995), e é dada por:

$$
\frac{f_{v m}(\langle\boldsymbol{\sigma}\rangle)}{\rho^{q}}
$$

onde $q$ representa o parâmetro penalizador do modelo de material SIMP. O trabalho de Pereira, Fancello e Barcellos (2004) utiliza a mesma abordagem.

Aqui vale notar que o trabalho de Park (1995) utiliza o modelo de material baseado no método da homogeneização com uma célula unitária quadrada com um furo retangular que pode ser rotacionado, de modo que não há um parâmetro de penalização $q$ em sua formulação.

No caso da aplicação do MOT em materiais compostos, mais especificamente os MsGF o trabalho de Lipton (2002) utiliza como restrição uma integral da micro-tensão sobre as duas fases e a compara com um valor único.

Outros trabalhos também tratam sobre critério de escoamento em materiais compostos aplicados ao MOT, dentre estes se destacam Swan e Kosaka (1997a) e Schwarz, Maute e Ramm (2001).

Swan e Kosaka (1997a) fazem uma estimativa da tensão de escoamento de um material composto, baseando-se no modelos de Voigt e Reuss. Segundo Swan e Kosaka (1997a) a resistência, ou tensão de escoamento, no modelo de Reuss é controlada pelo material mais fraco, assim, a curva de resistência em função da fração volumétrica é descontínua, pois, no caso do material mais rígido (material + ) ser o material mais fraco, a resistência do composto será controlada pelo material mais fraco para $0 \leq \rho<1$ e pelo material mais resistente para $\rho$ igual a 1 . Enquanto a resistência para o modelo de Voigt é simplesmente a média ponderada pela fração volumétrica das resistências de cada material. Para auxiliar a compreensão, essa situação é apresentada na Figura 4.7, onde $\sigma_{y}^{+}$e $\sigma_{y}^{-}$representam a tensão de escoamento do material mais $(+)$ e do material menos $(-)$, respecti- 
vamente. Assim, Swan e Kosaka (1997a) propõem uma função que fornece uma

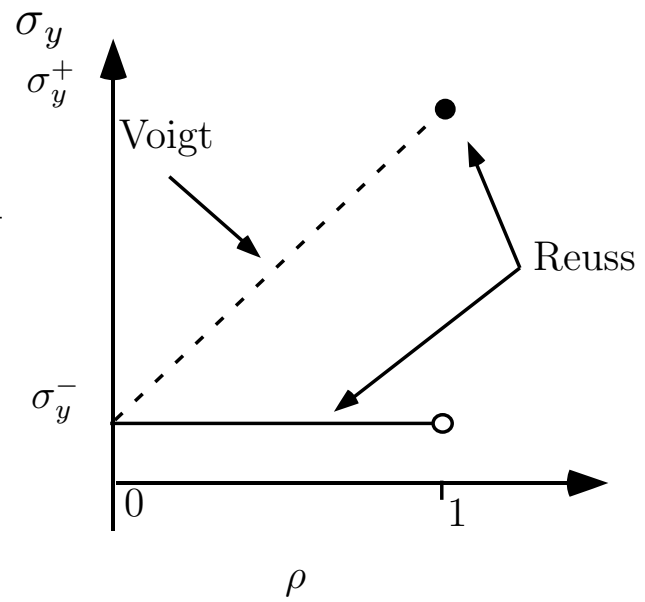

Figura 4.7: Exemplo de resistência de material segundo os modelos de Voigt e Reuss

valor intermediário de resitência, isto é, entre os valores de resistência de Voigt e Reuss apresentados no gráfico da Figura 4.7.

Já o trabalho de Schwarz, Maute e Ramm (2001), estima a tensão de escoamento de um material poroso, através do modelo de material SIMP, assim o escoamento é dado da mesma forma que o módulo de Young efetivo. 


\section{$5 \quad$ Método de Elementos Finitos utilizando Aproximação Contínua da Distribuição de Material}

Aqui serão apresentadas as formulações do Método de Elementos Finitos (MEF) utilizadas neste trabalho. A apresentação será feita de forma sucinta, apenas para situar o leitor quanto à notação e formulação utilizadas. Uma explanação mais aprofundada do método pode ser encontrada em Bathe (1996).

Neste trabalho foram utilizadas duas formulações de elementos. A formulação axissimétrica e a formulação de elemento em Estado Plano de Tensão (EPT)

A formulação axissimétrica consiste em uma aproximação bi-dimensional para a simulação estruturas com geometria axissimétrica sujeitas a carregamentos axissimétricos. Esta formulação foi implementada com o objetivo de se trabalhar com a otimização de estruturas rotativas, levando em consideração as forças de campo.

A formulação de elementos em EPT também consiste em uma aproximação bidimensional para estruturas planas finas e que possuem carregamento apenas no plano. Ou seja, estruturas como placas e vigas podem ser consideradas como estruturas em EPT desde que sua dimensão característica no plano em que estão aplicados o carregamentos seja significativamente maior de que a espessura perpendicular a este plano.

Para melhor ilustrar a formulação axissimétrica, um esquema desse tipo de estrutura é apresentado na figura 5.1.

No caso de uma estrutura em EPT, um esquema desse tipo de estrutura e seu o campo de tensão estão representados na figura 5.2, onde $P$ representa um força e $M$ um momento, ambos aplicados no plano da estruturas.

Assim, considerando o campo de tensão, para o caso axissimétrico, represen- 

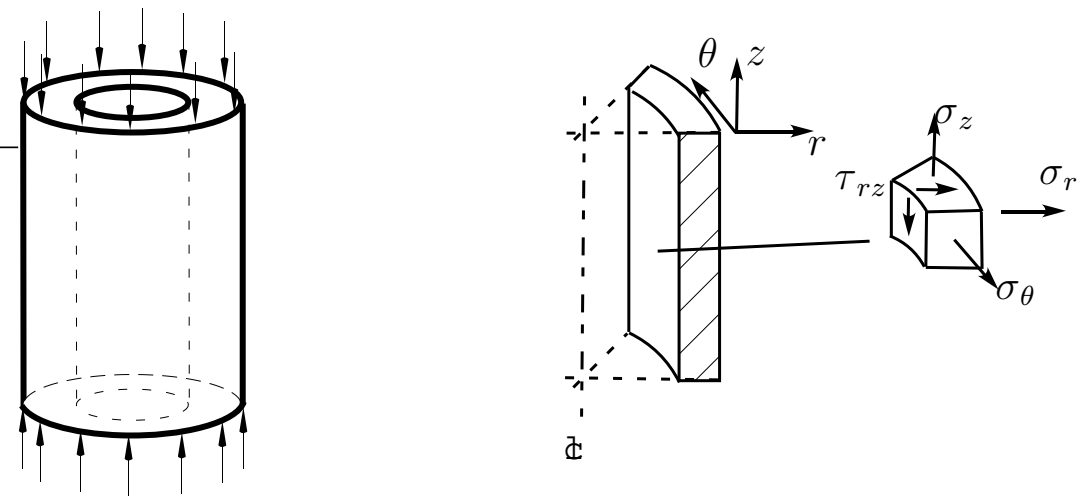

Figura 5.1: Esquema de estrutura axissimétrica e respectivo sistema de coordenada e estado de tensão da estrutura

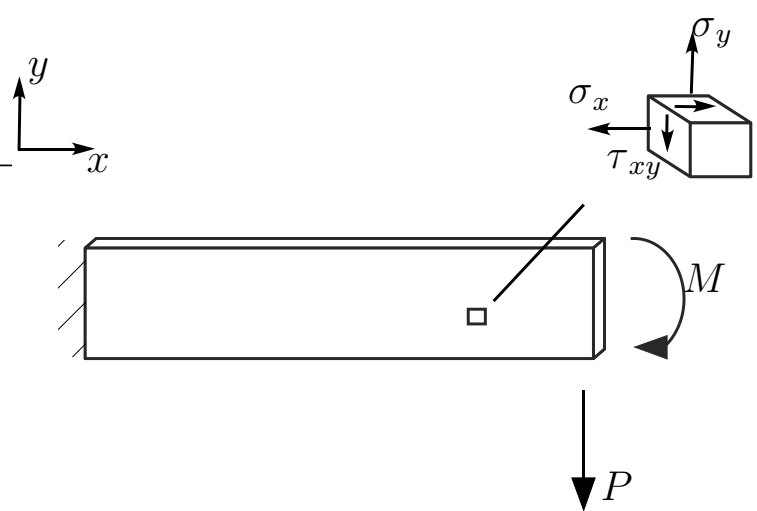

Figura 5.2: Esquema de estrutura em EPT e respectivo sistema de coordenada e estado de tensão da estrutura

tado na Figura 5.1 e dado por 5.1:

$$
\boldsymbol{\sigma}=\left\{\begin{array}{c}
\sigma_{r} \\
\sigma_{\theta} \\
\sigma_{z} \\
\sigma_{r z}
\end{array}\right\}
$$

tem-se o tensor constitutivo que relaciona os campos de tensão e deformação para um material homogêneo isotrópico dado por 5.2 (BATHE, 1996).

$$
\mathbf{C}^{\mathbf{H}}=\frac{1}{(1+\nu)(1-2 \nu)}\left[\begin{array}{cccc}
1-\nu & \nu & \nu & 0 \\
\nu & 1-\nu & \nu & 0 \\
\nu & \nu & 1-\nu & 0 \\
0 & 0 & 0 & \frac{1-2 \nu}{2}
\end{array}\right]
$$

logo o campo de deformação, para esta abordagem axissimétricas, é dado por 
(5.3):

$$
\boldsymbol{\epsilon}=\left\{\begin{array}{c}
\epsilon_{r} \\
\epsilon_{\theta} \\
\epsilon_{z} \\
\epsilon_{r z}
\end{array}\right\}=\left\{\begin{array}{c}
\frac{\partial u}{\partial r} \\
\frac{u}{r} \\
\frac{\partial v}{\partial z} \\
\frac{\partial u}{\partial z}+\frac{\partial v}{\partial r}
\end{array}\right\}
$$

Para o caso da formulação em EPT o campo de tensão representado na figura 5.2 é dado por 5.4:

$$
\boldsymbol{\sigma}=\left\{\begin{array}{c}
\sigma_{x} \\
\sigma_{y} \\
\sigma_{x y}
\end{array}\right\}
$$

assim, de forma análoga ao problema axissimétrico o tensor constitutivo que relaciona o campo de tensão e deformação para um material homogêneo isotrópico é dado por 5.5:

$$
\mathbf{C}^{\mathbf{H}}=\frac{E}{1-\nu^{2}}\left[\begin{array}{ccc}
1 & \nu & 0 \\
\nu & 1 & 0 \\
0 & 0 & \frac{1-\nu}{2}
\end{array}\right]
$$

logo o campo de deformação, para esta formulação é dado por (5.6):

$$
\boldsymbol{\epsilon}=\left\{\begin{array}{c}
\epsilon_{x} \\
\epsilon_{y} \\
\epsilon_{x y}
\end{array}\right\}=\left\{\begin{array}{c}
\frac{\partial u}{\partial x} \\
\frac{\partial u}{\partial y} \\
\frac{\partial u}{\partial x y}
\end{array}\right\}
$$

Em ambas as formulações, axissimétrica e EPT optou-se por utilizar os elementos isoparamétricos bi-lineares quadriláteros de 4 nós e adotou-se a numeração dos nós, bem como o sistema de coordenadas naturais e os deslocamentos nodais apresentados na figura (5.3), apenas para manter a clareza da notação das duas formulação, a figura (5.3) apresenta dois sistemas de coordenadsas globais, uma para elementos axissimétricos e outra para elemento em EPT.

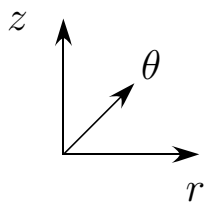

Sistema de coordenadas para o elemento axissimétrico
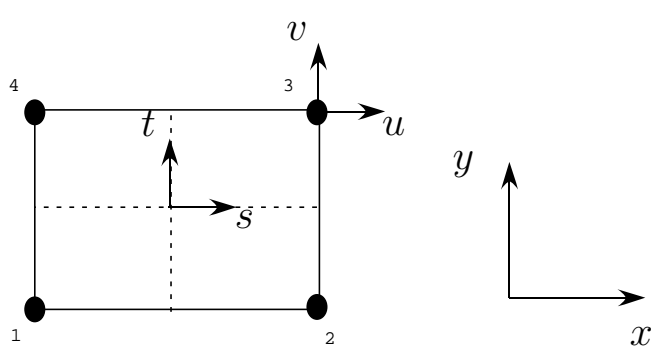

Sistema de coordenadas para

o elemento em EPT

Figura 5.3: Sistema de coordenadas naturais, numeração dos nós e deslocamentos nodais 
Assim, seguindo a formulação tradicional do MEF, as funções de forma para a interpolação dos deslocamentos e coordenadas globais deste elemento são dadas pelas equações (5.7):

$$
\begin{aligned}
& N_{1}=\frac{1}{4}(1-s)(1-t) \\
& N_{2}=\frac{1}{4}(1+s)(1-t) \\
& N_{3}=\frac{1}{4}(1+s)(1+t) \\
& N_{4}=\frac{1}{4}(1-s)(1+t)
\end{aligned}
$$

Para se obter a matriz de rigidez do elemento, é necessário escrever a matriz $\mathbf{B}$ que relaciona os deslocamentos nodais com o campo de deformação no interior do elemento. Aqui há novamente uma diferenciação entre o elemento axissimétrico e o elemento em EPT. Para a formulação axissimétrica a matriz $\mathbf{B}$ é dada por 5.8 e para a formulação em EPT, esta matriz é dada por 5.9:

$$
\begin{gathered}
\mathbf{B}=\left[\begin{array}{cccccccc}
\frac{\partial N_{1}}{\partial r} & 0 & \frac{\partial N_{2}}{\partial r} & 0 & \frac{\partial N_{3}}{\partial r} & 0 & \frac{\partial N_{4}}{\partial r} & 0 \\
\frac{N_{1}}{r} & 0 & \frac{N_{2}}{r} & 0 & \frac{N_{3}}{r} & 0 & \frac{N_{4}}{r} & 0 \\
0 & \frac{\partial N_{1}}{\partial z} & 0 & \frac{\partial N_{2}}{\partial z} & 0 & \frac{\partial N_{3}}{\partial z} & 0 & \frac{\partial N_{4}}{\partial z} \\
\frac{\partial N_{1}}{\partial z} & \frac{\partial N_{1}}{\partial r} & \frac{\partial N_{2}}{\partial z} & \frac{\partial N_{2}}{\partial r} & \frac{\partial N_{3}}{\partial z} & \frac{\partial N_{3}}{\partial r} & \frac{\partial N_{4}}{\partial z} & \frac{\partial N_{4}}{\partial r}
\end{array}\right] \\
\mathbf{B}=\left[\begin{array}{cccccccc}
\frac{\partial N_{1}}{\partial x} & 0 & \frac{\partial N_{2}}{\partial x} & 0 & \frac{\partial N_{3}}{\partial x} & 0 & \frac{\partial N_{4}}{\partial x} & 0 \\
0 & \frac{\partial N_{1}}{\partial y} & 0 & \frac{\partial N_{2}}{\partial y} & 0 & \frac{\partial N_{3}}{\partial y} & 0 & \frac{\partial N_{4}}{\partial y} \\
\frac{\partial N_{1}}{\partial y} & \frac{\partial N_{1}}{\partial x} & \frac{\partial N_{2}}{\partial y} & \frac{\partial N_{2}}{\partial x} & \frac{\partial N_{3}}{\partial y} & \frac{\partial N_{3}}{\partial x} & \frac{\partial N_{4}}{\partial y} & \frac{\partial N_{4}}{\partial x}
\end{array}\right]
\end{gathered}
$$

e para ambos os casos, considerando que o vetor de deslocamento é dado por

$$
\mathbf{d}=\left[\begin{array}{l}
u_{1} \\
v_{1} \\
u_{2} \\
v_{2} \\
u_{3} \\
v_{3} \\
u_{4} \\
v_{4}
\end{array}\right]
$$

Observa-se que a matriz $\mathbf{B}$ é escrita em termos das derivadas das funções de forma, dada por 5.7, em relação às coordenadas globais do sistema: $r$ e $z$ para o caso axissimétrico e $x$ e $y$ para o caso EPT, porém essas funções de forma são escritas em termos das coordenadas locais: $s$ e $t$. Logo, para se relacionar as 
derivadas em ambos os sistemas de coordenadas é necessário, utilizar a matriz Jacobiana, dada para o caso axissimétrico por 5.11:

$$
\mathbf{J}=\left[\begin{array}{ll}
\frac{\partial r}{\partial s} & \frac{\partial z}{\partial s} \\
\frac{\partial r}{\partial t} & \frac{\partial z}{\partial t}
\end{array}\right]
$$

Dessa forma, é possível obter as derivadas $\frac{\partial N_{i}}{\partial r} \mathrm{e} \frac{\partial N_{i}}{\partial z}$, para $i=1,2,3,4$, através de:

$$
\left[\begin{array}{c}
\frac{\partial N_{i}}{\partial r} \\
\frac{\partial N_{i}}{\partial z}
\end{array}\right]=\mathbf{J}^{-1}\left[\begin{array}{c}
\frac{\partial N_{i}}{\partial s} \\
\frac{\partial N_{i}}{\partial t}
\end{array}\right]
$$

Para o caso EPT a matriz Jacobiana é dada por 5.13:

$$
\mathbf{J}=\left[\begin{array}{ll}
\frac{\partial x}{\partial s} & \frac{\partial y}{\partial s} \\
\frac{\partial x}{\partial t} & \frac{\partial y}{\partial t}
\end{array}\right]
$$

e de forma análoga ao caso axissimétrico se obtém as derivadas $\frac{\partial N_{i}}{\partial x}$ e $\frac{\partial N_{i}}{\partial y}$, para $i=1,2,3,4$.

A partir desses resultados é possível escrever a matriz $\mathbf{B}$ e, conseqüentemente, calcular a matriz de rigidez de um elemento $e$ (5.14):

$$
\mathbf{k}_{e}=\iint_{z} \int_{r} r \mathbf{B}_{\theta}^{T} \mathbf{C}_{e}^{\mathbf{H}} \mathbf{B}_{e} d \theta d r d z=2 \pi \int_{z} \int_{r} r \mathbf{B}_{e}^{T} \mathbf{C}_{e}^{\mathbf{H}} \mathbf{B}_{e} d r d z
$$

onde $\mathbf{B}_{e}$ representa a matriz $\mathbf{B}$ dada por 5.8 calculada para o elemento $e$ e $\mathbf{C}_{e}^{\mathbf{H}}$ representa o tensor constitutivo homogêneo dentro do mesmo elemento (5.2).

Para o caso de elemento em EPT a única diferença esta no domínio de integração que é feito apenas em $x$ e $y$. Assim a matriz de rigidez do elemento em EPT é dada por 5.15:

$$
\mathbf{k}_{e}=\int_{x} \int_{y} \mathbf{B}_{e}^{T} \mathbf{C}_{e}^{\mathbf{H}} \mathbf{B}_{e} d x d y
$$

Neste trabalho é utilizada a formulação ACDM (Aproximação Contínua da Distribuição de Material) proposta por Matsui e Terada (2004), assim o campo de densidades é interpolado dentro dos elementos e as variáveis de projeto são definidas sobre os nós do elemento. Esta abordagem, também foi utilizada no problema de distribuição de material em estruturas constituídas por MsGF, porém neste caso a justificativa para está opção se baseia no trabalho de Kim e Paulino (2002), comforme será apresentado na seção 7.3.

A Figura 5.4 apresenta as duas formas de parametrização do campo de densidades: a forma tradicional, na qual se define uma densidade volumétrica para 
cada elemento finito, criando assim um campo descontínuo, representado por patamares constantes; e a formulação ACDM, que cria um campo de densidades contínuo.

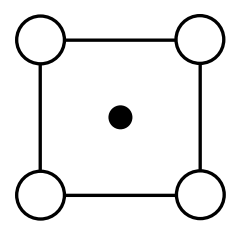

Parametrização tradicional do campo de densidades no

MOT

$\bigcirc$ Deslocamentos

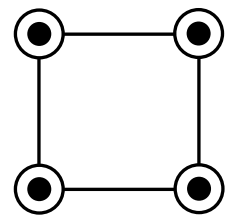

Parametrização ACDM do campo de densidades no

MOT

- Variáveis de projeto $\rho_{i}$

Figura 5.4: Representação do elemento tradicional e do elemento com formulação Aproximação Contínua da Distribuição de Material (ACDM)

Na abordagem ACDM, a densidade volumétrica deixa de ser constante dentro do elemento e esta passa a ser dada por:

$$
\rho(s, t)=\sum_{i=1}^{4} \rho_{i} N_{i}
$$

onde $N_{i}$ é tal que o campo de densidades $\rho$ seja sempre não negativo no interior do elemento. Conseqüentemente, o tensor constitutivo do elemento $\left(\mathbf{C}_{e}^{\mathbf{H}}\right)$ também deixa de ser constante, assim utilizando como modelo de material a formulação SIMP, apresentada na seção 2.4.2, este tensor é dado por:

$$
\mathbf{C}_{e}^{\mathbf{H}}=\rho(s, t)^{q} \mathbf{C}_{0}
$$

Assim, é possível substituir a equação 5.17 na definição da matriz de rigidez do elemento, dada por 5.14, e então aplicar a quadratura de Gauss para a avaliação numérica da integral. Dessa forma, a matriz de rigidez do elemento, para o caso axissimétrico, passa a ser escrita como:

$$
\mathbf{k}_{e}=2 \pi \sum_{k=1}^{2} \sum_{l=1}^{2} w_{k} w_{l} r \mathbf{B}_{e l}^{T}\left[\left(\sum_{i=1}^{4} \rho_{i} N_{i}\left(s_{k}, t_{l}\right)\right)^{q} \mathbf{C}_{0}\right] \mathbf{B}_{e} \operatorname{det}(\mathbf{J}) d s d t
$$

onde $w_{k}$ e $w_{l}$ são os pesos utilizados na integração numérica por quadratura de Gauss e $w_{1}=w_{2}=1$, e $s_{k} t_{l}$ são os pontos de Gauss utilizados na integração e $s_{1}=t_{1}=-1 / \sqrt{3}$ e $s_{2}=t_{2}=1 / \sqrt{3}$, ambos para o caso de integração com 4 pontos de Gauss. O mesmo procedimento é aplicado para o caso do elemento em EPT.

Feito o cálculo da matriz de rigidez local, esta é inserida na matriz de rigidez 
global $\mathbf{K}$, através da conectividade de cada elemento, que associa a cada elemento os graus de liberdade globais. Assim, é possível escrever o sistema linear 5.19:

$$
\mathbf{K d}=\mathbf{f}
$$

Para considerar forças de campo, é necessário determinar o termo à direita da equação 5.19, que representa as cargas aplicadas ao modelo. Dessa forma, o vetor de força é a somatória dos esforços nodais, ou seja, as cargas externas aplicadas diretamente sobre o nó e as forças de campo dadas por 5.20:

$$
\mathbf{f}_{e}=\iint_{z} \int_{\theta} r \mathbf{N}^{T} \mathbf{f}_{c} d \theta d r d z=2 \pi \iint_{z} r \mathbf{N}^{T} \mathbf{f}_{c} d r d z
$$

onde $\mathbf{N}$ é a matriz de interpolação dos deslocamentos dada por (5.21)

$$
\mathbf{N}=\left[\begin{array}{cccccccc}
N_{1} & 0 & N_{2} & 0 & N_{3} & 0 & N_{4} & 0 \\
0 & N_{1} & 0 & N_{2} & 0 & N_{3} & 0 & N_{4}
\end{array}\right]
$$

Para o problema em questão, as forças de campo $\mathbf{f}_{c}$ são dadas por:

$$
\mathbf{f}_{c}=\varrho\left[\begin{array}{c}
\omega r_{p} \\
a_{z}
\end{array}\right]
$$

onde $\varrho$ é a densidade do material, $\omega$ a velocidade angular da estrutura, $r_{p}$ a distância do ponto $p$ ao centro de rotação, e $a_{z}$ a aceleração na direção $z$.

Observe que utilizando a parametrização ACDM da distribuição de densidade volumétrica, a densidade real do material também passa a variar no interior do elemento, e é dada por:

$$
\varrho=\rho(s, t)^{q} \varrho_{0}
$$

onde $\varrho_{0}$ representa a densidade real do material que está sendo utilizado.

Assim como na matriz de rigidez, é necessário utilizar a integração numérica por quadratura de Gauss para avaliar a integral dada por 5.20, que passa a ser dada, seguindo a mesma notação de 5.18, por 5.24:

$$
\mathbf{f}_{e}=2 \pi \sum_{k=1}^{2} \sum_{l=1}^{2} w_{k} w_{l} r \mathbf{N}^{T}\left(s_{k}, t_{l}\right)\left[\left(\sum_{i=1}^{4} \rho_{i} N_{i}\left(s_{k}, t_{l}\right)\right)^{q} \varrho_{0}\right]\left[\begin{array}{c}
\omega r_{p} \\
a_{z}
\end{array}\right] \operatorname{det}(\mathbf{J}) d s d t
$$

Está provado que o valor da integral obtida pelo método de quadratura de Gauss representa a integral exata para um polinômio de grau igual a, no máximo, três (BATHE, 1996), atendendo assim às necessidades deste trabalho. 
Para o caso de elemento em EPT não foram consideradas forças de campo, dessa forma o vetor de $\mathbf{f}_{e}$ é dado apenas pelas forças externas aplicadas no elemento $e$. 


\section{Formulação do problema de Otimização Topológica considerando restrição de tensão}

\subsection{Introdução}

O problema de otimização topológica considerando restrição de tensão apresenta algumas dificuldades que precisam ser contornadas.

A primeira grande dificuldade está no problema conhecido como fenômeno das topologias singulares, ou simplesmente singularidade das tensões, que consiste na degeneração do espaço de solução. Este problema implica na incapacidade dos métodos tradicionais de otimização, baseados nos gradientes, de atingir o ponto ótimo, quando este é singular. Este é um tópico central para a solução do problema de Otimização Topológica (OT) considerando restrição de tensão e, atualmente, não há uma solução definitiva para tal problema. Uma explanação e uma revisão bibliográfica sobre o assunto será feita na seção 6.3.

A outra dificuldade decorre do fato de que a tensão mecânica é uma grandeza local, logo, para garantir que a máxima tensão mecânica da estrutura seja limitada, é necessário restringir todos os pontos da estrutura. No caso da análise da estrutura ser feita pelo Método de Elementos Finitos (MEF), é suficiente restringir a tensão mecânica apenas no centro de cada elemento da estrutura, conseqüentemente, o número de restrições em um problema simples pode ser relativamente grande, o que implica em tempos computacionais elevados tanto para o cálculo da sensibilidade das tensões como para a solução do problema de otimização através de métodos de programação linear.

Apesar dessas complicações não estarem completamente resolvidas, na literatura existem algumas proposições para sua solução. 


\subsection{Revisão bibliográfica do MOT considerando restrição de tensão}

Devido às dificuldades inerentes às formulações de OT considerando restrições de tensão em meios contínuos, algumas abordagens foram desenvolvidas a fim de evitar tais problemas. Entre estas abordagens destacam-se a aplicação de métodos heurísticos, métodos probabilísticos e, principalmente, a alteração da formulação do problema a fim de utilizar métodos tradicionais de programação matemática.

Aqui será tratada apenas a aplicação do Método de Otimização Topológica (MOT) aplicado a meios contínuos, ou seja, o MOT aplicado a treliças considerando restrição de tensão não está presente nesta revisão bibliográfica. Apenas os trabalhos aplicados à treliças que versam sobre o fenômeno das topologias singulares serão considerados.

Dentre os métodos heurísticos, existe o método evolucionário de otimização estrutural, que foi proposto como uma alternativa simplificada em relação aos métodos tradicionais baseados em programação matemática (STEVEN; LI; XIE, 2002). O método evolucionário se baseia na remoção de material das regiões subutilizadas e na adição de material nas regiões super-utilizadas, do ponto de vista da função objetivo, ou seja o quanto cada região do domínio contribui para o desempenho. Esta abordagem permite a utilização de variáveis discretas, o que no caso do problema de otimização topológica pode significar a retirada ou adição de elementos da malha de elementos finitos.

Alguns trabalhos utilizam-se dos métodos evolucionários a fim de tratar o problema de otimização considerando a máxima tensão mecânica. Li et al. (1999) propuseram um procedimento evolucionário para a minimização da tensão mecânica, posteriormente Li et al. (2001) e Steven, Li e Xie (2002) expandiram o conceito, propondo um procedimento para, simultaneamente, maximizar a rigidez e minimizar a máxima tensão mecânica da estrutura.

De forma similar ao método evolucionário, o método de desenvolvimento metamórfico proposto por Liu, Parks e Clarkson (2000) consiste em adicionar ou remover elementos ao redor de um estrutura simulando assim o crescimento ou degeneração da mesma. Os trabalhos de Liu, Parks e Clarkson (2002) e Liu, Parks e Clarkson (2005) apresentam a utilização desse método em problemas axissimétrico levando em consideração a restrição de tensão.

A principal vantagem dos métodos heurísticos é a possibilidade de resolverem 
o problema na sua forma discreta (0-1), através da retirada ou acréscimo de elementos na estrutura, evitando assim o fenômeno da singularidades das tensões. Porém, devido ao fato desses métodos basearem-se em regras empíricas para a atualização das variáveis, eles não garantem a obtenção de uma solução ótima.

Dentre os métodos probabilísticos, o método de simulated annealing (recozimento simulado) foi utilizado por Shim e Manoochehri (1997) para a solução do problema de minimização do volume com restrição local de tensão mecânica. Neste trabalho, alguns exemplos numéricos foram apresentados demonstrando a capacidade do método de sintetizar estruturas que atendem às restrições de tensão. Entretanto, não é feito um estudo sobre o fato da solução ótima obtida ser singular ou não.

Neste trabalho o problema será tratado através dos métodos tradicionais de otimização baseados em gradientes e, para isso, a formulação do problema será alterada de modo a melhorar a eficiência e capacidade do método de encontrar uma solução ótima singular.

Esta abordagem foi preferida em relação à utilização de métodos heurísticos, evolucionários ou probabilísticos pois:

- Os gradientes da função objetivo e das restrições possuem uma informação valiosa sobre o problema e podem ser facilmente calculados a um custo computacional menor ou equivalente a uma avaliação da função objetivo. Desse modo, a não utilização dessa informação, como no caso dos métodos probabilísticos, é contraproducente.

- Em geral, os métodos probabilísticos necessitam de um maior número de iterações, em relação aos métodos tradicionais de otimização, para obter a solução ou família de soluções ótimas. Por exemplo, as estruturas obtidas por simulated annealing (SHIM; MANOOCHEHRI, 1997) necessitam de um número de iterações (avaliação da função objetivo) da ordem de 400, enquanto as estruturas obtidas através dos métodos clássicos (PEREIRA, 2001) necessitam de apenas uma ordem de 100 iterações. Assim, dado que neste caso a avaliação da função objetivo representa um alto custo computacional, a aplicação de métodos heurísticos torna-se pouco interessante.

- A utilização dos métodos tradicionais de otimização aplicados ao MOT está consolidada na literatura, uma vez que a maior parte da literatura utiliza esta abordagem, como pode ser constatado nos livros de Bendsøe e Sigmund (2003), Allaire (2002) e na revisão de Eschenauer e Olhof (2001). 
Desse modo, a eficiência desta abordagem tem sido constantemente testada pela comunidade científica.

- A literatura referente ao tratamento do fenômeno das topologias singulares é, em sua maioria, baseada nos métodos tradicionais de otimização, pois estes fornecem uma base teórica sólida para o estudo de tal fenômeno. Desse modo, a utilização de métodos tradicionais permite basear este trabalho nessa literatura, que será apresentada a seguir.

Neste contexto, dentre as aplicações do MOT para problemas contínuos que utilizam métodos de otimização baseados no gradiente destacam-se: Park (1995), Yang e Chen (1996), Duysinx e Bendsøe (1998), Duysinx e Sigmund (1998), Pereira (2001), Pereira, Fancello e Barcellos (2004) e Allaire, Jouve e Maillot (2004). Uma revisão contextualizada destes trabalhos será feita adiante na seção 6.4 .

\subsection{Fenômeno das topologias singulares}

O problema de topologias singulares foi identificado inicialmente por Sved e Ginos (1968). Em seu trabalho é apresentado um problema de otimização de uma estrutura com três barras e três casos de carga, cujo objetivo é minimizar o volume da estrutura com restrição de tensão mecânica, assim, é demonstrado que a solução ótima global não pertence a um domínio contínuo das variáveis de projeto que satisfazem às condições de equilíbrio e compatibilidade de deslocamentos do problema mecânico. Sved nomeou este ponto ótimo desse problema como sendo um mínimo global singular.

A existência desses pontos implica que os métodos clássicos de otimização, para variáveis contínuas, baseados nos gradientes, não são capazes de atingir o mínimo global singular. Do ponto de vista mecânico, o ponto ótimo singular só pode ser atingido se uma das barras for retirada da estrutura. Neste sentido, Sved e Ginos (1968) propõem que seja feita a procura do ótimo global através da omissão de cada uma das barras que podem ter a seção transversal igual a zero.

O problema das singularidades das tensões somente voltou a ser estudado na década de 90, com os trabalhos de Kirsch (1990), Cheng e Jiang (1992) e Rozvany e Birker (1994).

Kirsch (1990) apresentou um estudo sobre o problema, denominado por ele como "fenômeno das topologias ótimas singulares". Em seu trabalho, o autor 
demonstrou que o problema decorre da tentativa da solução de um problema de topologia através da aproximação deste por um problema de dimensionamento, no qual se permite que as dimensões (ex. áreas) atinjam o valor zero. Posteriormente, este fenômeno ficou conhecido na literatura simplesmente como singularidade das tensões.

Através de um exemplo com duas variáveis de projeto, foi demonstrado que o domínio viável, para o caso de minimização de volume com restrição de tensão, pode possuir o ponto ótimo global conectado, apenas por uma linha, um espaço uni-dimensional, ao domínio viável, isto é, um espaço bi-dimensional,

A Figura 6.1 apresenta esquematicamente um espaço de soluções no qual o domínio viável possui uma região "sólida" e, conectado a esta, uma "extensão" em cuja extremidade se encontra o ponto ótimo singular $\left(O p t_{\text {singular }}\right)$. Observe que neste ponto o valor de $\rho_{1}$ deve ser idêntico a zero. Aqui se observa como o tratamento do problema de otimização de topologia, quando aproximado por um problema de dimensionamento pode gerar algumas dificuldades não previstas. No caso de se considerar a aproximação $\rho_{1} \geq \rho_{\min }>0$, onde $\rho_{\min }$ é um valor próximo de zero, o ponto ótimo do problema se torna o ponto indicado por $O p t_{\text {local }}$ que, em geral, é chamado de ótimo local.

Aqui vale a pena notar que a solução ótima singular pode ser ou não a solução ótima global do problema. No caso do exemplo adotado por Kirsch (1990) ambos os pontos coincidem, o que justifica o fato de que a outra solução ótima seja em geral chamada de ótimo local. Em um problema com $n$, variáveis não é possível se saber quantos ótimos singulares existem no espaço de solução e se algum destes corresponde ao ótimo global.

Cheng e Jiang (1992) continuaram o estudo iniciado por Kirsch (1990) explicando o fenômeno das topologias singulares sob dois pontos de vistas. Uma das explicações se baseia no fato de que o problema apresenta um ponto ótimo que está conectado ao domínio viável apenas por um espaço unidimensional, conforme apresentado esquematicamente na Figura 6.1.

Outra abordagem utilizada por Cheng e Jiang (1992) para explicar o fenômeno das topologias singulares se baseia no conceito de tensão limitante. Neste trabalho os autores demonstraram que a restrição de tensão apresenta uma descontinuidade quando a seção transversal é idêntica a zero. Por exemplo, em um problema com $n$ barras onde $A_{n}$ representa a seção transversal da barra $n$, a tensão em uma barra $i$, quando esta tende a zero, pode não ser igual a zero. Matematicamente 


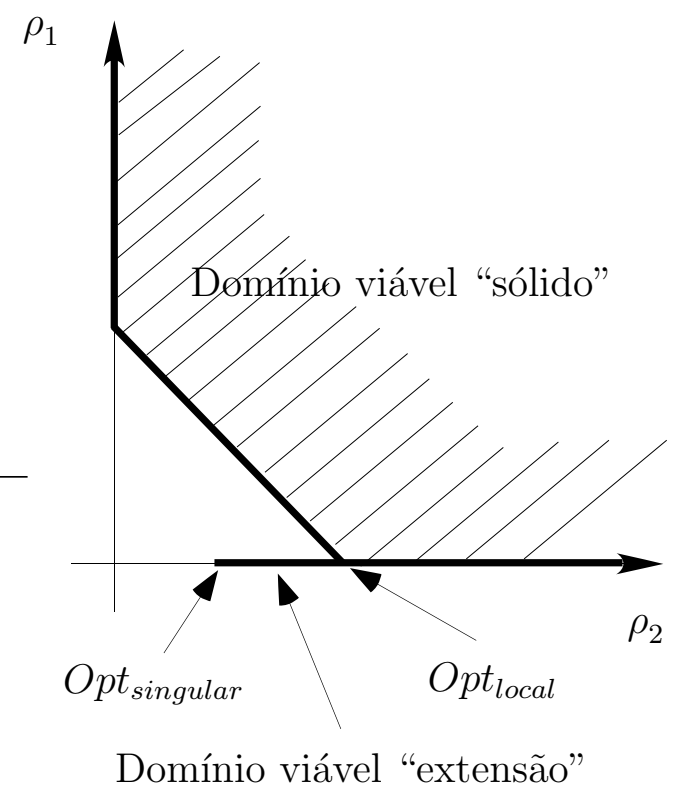

Figura 6.1: Representação genérica de um domínio de projeto que apresenta um ótimo singular

esta situação é expressa pela equação 6.1:

$$
\sigma_{i}^{*}\left(A_{1} \ldots A_{i} \ldots A_{n}\right)=\lim _{A_{i} \rightarrow 0} \sigma_{i}\left(\left(A_{1} \ldots A_{i} \ldots A_{n}\right)\right) \neq\left.\sigma_{i}\left(\left(A_{1} \ldots A_{i} \ldots A_{n}\right)\right)\right|_{A_{i}=0}
$$

Esta descontinuidade decorre do fato de que não existe sentido físico em se calcular a tensão em uma barra que foi retirada da estrutura, ou seja, a tensão em uma barra de seção transversal nula é por princípio nula, porém para o modelo matemático seu valor é finito. Cheng e Jiang (1992) definiram esse valor $\left(\sigma_{i}^{*}\right)$ como sendo uma tensão limitante. Logo, o problema das topologias singulares ocorre quando a tensão limitante $\sigma_{i}^{*}$ em um elemento é maior que a tensão de referência do material. Assim, os métodos de otimização baseado em programação matemática não são capazes de retirar esse elemento da estrutura.

Rozvany e Birker (1994) estudaram o mesmo problema porém sobre o óptica da teoria de leiaute exato ótimo (exact layout optimization), o que é uma generalização da teoria de Michell (MICHELL, 1904). Assim, em seu trabalho Rozvany e Birker (1994) concluíram, entre outros pontos, que: a topologia ótima, o ponto ótimo do espaço de solução, será singular apenas se existir alguma restrição local de tensão e se a tensão em um elemento que esteja desaparecendo seja maior que a tensão de referência. Rozvany e Birker (1994) definiram também que o ponto ótimo singular é caracterizado por se conectar ao espaço de solução de dimensão $n$ apenas por um hiperplano de dimensão $k$, tal que $k<n$, onde $n$ é o número de variáveis de projeto do problema de otimização.

A partir desses trabalhos o fenômeno das topologias singulares pôde ser me- 
lhor compreendido e, conseqüentemente, foram propostas algumas alternativas para que a solução ótima singular fosse determinada através de métodos de otimização clássicos.

O conceito de $\varepsilon$-relaxação proposto por Cheng e Guo (1997) foi a abordagem de maior aceitação na literatura. Cheng e Guo (1997) propõem tal método a partir de um problema de minimização de volume com restrição local de tensão para uma estrutura treliçada.

Considerando inicialmente a formulação tradicional dada por 6.2:

$$
\begin{aligned}
& \underset{\mathbf{A}, \mathbf{d}}{\operatorname{minimizar}} P(\mathbf{A})=\sum_{j=1}^{M} A_{j} L_{j} \\
& \text { tal que } \\
& \quad \mathbf{K}(\mathbf{A}) \mathbf{d}=\mathbf{f} \\
& \quad \sigma_{j}^{\min } \leq \sigma_{j} \leq \sigma_{j}^{\max } \text { se } A_{j}>0 \\
& \sigma_{j}=E_{j} \mathbf{B}_{j} \mathbf{d} \\
& A_{j} \geq 0
\end{aligned}
$$

onde $A_{j}$ e $L_{j}$ representam a área e o comprimento de elemento da estrutura, o índice $j$ representa um dos $M$ elementos da estrutura, A é o vetor de áreas da estrutura, $\mathbf{K}(\mathbf{A})$ é matriz de rigidez global do sistema, $\mathbf{f}$ é o vetor de forças aplicadas à estrutura, $\mathbf{d}$ é o vetor de deslocamentos nodais da estrutura, $E_{j}$ é o módulo de Young do elemento $j, B_{j}$ é a matriz que relaciona o deslocamento com a deformação do elemento $j, \sigma_{j}$ é a tensão no elemento $j$ e $\sigma_{j}^{\min }$ e $\sigma_{j}^{\max }$ são as tensões admissíveis mínima e máxima, respectivamente.

Analisando a formulação 6.2 observa-se que existe uma descontinuidade das restrições referentes às tensões, dada pela condição:

$$
\text { se } A_{j}>0
$$

Assim, para retirar essa descontinuidade, em seu trabalho anterior Cheng e Jiang (1992), já haviam proposto que a restrição de tensão do problema 6.2 fosse substituída pela restrição;

$$
A_{j} \sigma_{j}^{\min } \leq A_{j} \sigma_{j} \leq A_{j} \sigma_{j}^{\max }
$$

o que no caso das treliças representa a força interna de cada barra. Entretanto esta substituição não altera o fenômeno de singularidade das tensões.

Com base no fato de que esta formulação continua apresentando um ponto 
ótimo singular, Cheng e Guo (1997) propuseram uma formulação em que tal fenômeno não ocorre. Seguindo a mesma notação, esta formulação é dada por:

$$
\begin{aligned}
& \underset{\mathbf{A}, \mathbf{d}}{\operatorname{minimizar}} P(\mathbf{A})=\sum_{j=1}^{M} A_{j} L_{j} \\
& \text { tal que } \\
& \mathbf{K}(\mathbf{A}) \mathbf{d}=\mathbf{f} \\
& A_{j}\left(\sigma_{j}^{\min }-\sigma_{j}\right) \leq \varepsilon \\
& A_{j}\left(\sigma_{j}-\sigma_{j}^{\max }\right) \leq \varepsilon \\
& \sigma_{j}=E_{j} \mathbf{B}_{j} \mathbf{d} \\
& A_{j} \geq \varepsilon^{2}
\end{aligned}
$$

onde $\varepsilon$ é um valor positivo próximo de zero. O valor de $\varepsilon$ irá definir o nível de relaxação do problema. O problema escrito nesta forma não apresenta o fenômeno das singularidades. Uma forma simples de justificar este fato é que as restrições:

$$
\begin{aligned}
& A_{j}\left(\sigma_{j}^{\min }-\sigma_{j}\right) \leq \varepsilon \\
& A_{j}\left(\sigma_{j}-\sigma_{j}^{\max }\right) \leq \varepsilon
\end{aligned}
$$

sempre podem ser atendidas para um valor de $A_{j}$ suficientemente pequeno uma vez que $\varepsilon$ é maior que zero.

Em seu artigo Cheng e Guo (1997) provam que para $\varepsilon$ tendendo a zero, o mínimo global do problema 6.5 tende ao mínimo global do problema original 6.2.

Posteriormente, Rozvany (2001) em seu trabalho de revisão demonstrou que o método da $\varepsilon$-relaxação é um caso particular de substituição das restrições por funções de contorno suaves (smooth envelope functions). Neste trabalho o autor sugere um outra função, que transforma as restrições do problem original 6.2 na forma:

$$
\begin{gathered}
\sigma_{j}^{\min }\left(e^{\frac{A_{0}}{A_{j}}}\right)-\sigma_{j} \leq 0 \\
\sigma_{j}-\sigma_{j}^{\max }\left(e^{\frac{A_{0}}{A_{j}}}\right) \leq 0
\end{gathered}
$$

onde $A_{0}$ é um valor fixo que determina o nível de relaxação da restrição, de forma similar ao valor $\varepsilon$ no método da $\varepsilon$-relaxação.

Um trabalho importante para o estudo do método da $\varepsilon$-relaxação, quanto a capacidade deste em permitir que os métodos tradicionais de otimização atinjam o mínimo global, foi apresentado por Stolpe e Svanberg (2001a). Neste trabalho os autores demonstraram, através de exemplos numéricos, que o ótimo global de 
um problema pode ser alterado ao longo da continuação do parâmetro $\varepsilon$. Assim, em termos práticos, não se pode garantir que com a continuação de $\varepsilon$ a solução caminhará para o ótimo global, independentemente de quão suave é feita esta continuação de $\varepsilon$.

Aqui vale a pena notar, conforme frisado por Guo, Cheng e Yamazaki (2004), que o método da $\varepsilon$-relaxação não é capaz de alterar a não-convexidade do problema original, ou seja, a aplicação deste método não garante que o mínimo global será obtido. Este método apenas evita o fenômeno das topologias singulares. A obtenção do ótimo global ainda é um tema desafiador na área de otimização; alguns trabalhos recentes como Stolpe (2003) e Stolpe (2004) estudam este tópico.

A formulação da $\varepsilon$-relaxação foi estendida para outros problemas que também apresentam o fenômeno das topologias singulares, como é o caso da restrição local de flambagem (GUO; CHENG; YAMAZAKI, 2001), a restrição global de flambagem (EVGRAFOV, 2005), e a restrição de tensão com carregamentos estocásticos (EVGRAFOV; PATRIKSSON, 2003).

Visando diminuir o número de passos do método da continuação para o valor de $\varepsilon$, Guo e Cheng (2000) propuseram uma forma de se obter uma aproximação do ponto ótimo singular a partir de uma extrapolação da solução ótima em termos de $\varepsilon$. Esta extrapolação é calculada a partir da sensibilidade dos multiplicadores de Lagrange, associados às restrições ativas, em função do parâmetro de relaxação $\varepsilon$. Neste trabalho os autores demonstraram, através de exemplos numéricos, que uma aproximação do ponto ótimo, com erro de $0,2 \%$, pode ser obtida mesmo para valores altos do parâmetro de relaxação, como $\varepsilon=1,0$.

Uma outra abordagem que recentemente tem sido apresentada para a solução do fenômeno das singularidades é o estudo do problema à luz da teoria de Programação Matemática com Restrições de Equilíbrio (PMRE), conhecido na literatura como Mathematical Programs with Equilibrium Constraints (MPEC) (EVGRAFOV, 2004).

Tradicionalmente o problema de otimização apresentado na sua forma relaxada, dada por 6.5, é resolvido considerando como variáveis de projeto apenas as seções transversais $A_{j}$, uma vez que para $A_{j}>0$ os deslocamentos são dados de forma única por $\mathbf{K}(\mathbf{A}) \mathbf{d}=\mathbf{f}$. Essa forma de tratar o problema de otimização é conhecida como programação implícita (EVGRAFOV; PATRIKSSON, 2005). Em contrapartida, no caso de se utilizar os métodos PMRE tanto as seções transversais (A) como os deslocamentos (d) passam a fazer parte das variáveis de projeto para o algoritmo de otimização. Na Engenharia essa abordagem é conhecida 
na literatura como Simultaneous Analysis and Design (SAND), que poderia ser traduzido como Projeto Otimizado e Análise Simultânea (POAS).

Assim, as variáveis do algoritmo de otimização se dividem em dois grupos: o das variáveis de estado, que representam o estado do sistema físico (ex. forças internas e deslocamentos) e o das variáveis de projeto (ex. seções transversais). Sob essa nova forma de tratar o problema, Petersson (2001) apresenta um estudo sobre a continuidade entre as variáveis de projeto e as variáveis de estado para o caso onde a topologia é alterada, ou seja, $A_{j}=0$ no caso do problema 6.2. Patriksson e Petersson (2002) apresentam um estudo similar, mas considerando também restrições laterais (contato) e carregamentos estocásticos.

Seguindo essa linha Evgrafov (2005), baseado na literatura específica de PMRE (SCHOLTES, 2001; FACCHINEI; PANG, 2003), propõem um nova forma de tratamento da singularidade das tensões, porém, aplicando uma forma de relaxação sobre a condição de equilíbrio, no caso de um problema de minimização de volume com restrições laterais (contato) e de tensão.

Essa abordagem de tratamento da singularidade das tensões, através dos métodos de Programação Matemática com Restrições de Equilíbrio (PMRE) e sua teoria, apesar de incipiente quanto a sua aplicação no MOT, aparentemente tem a capacidade de proporcionar novas possibilidades para o tratamento do fenômeno das topologias singulares.

\subsubsection{Exemplo para o caso de treliças}

Para facilitar a compreensão do fenômeno das topologias singulares e como este é tratado através do método da $\varepsilon$-relaxação, apresentaremos o exemplo proposto por Kirsch (1990).

Considerando um problema com três barras dispostas conforme apresentado na Figura 6.3, com comprimentos iguais $\left(L_{1}=L_{2}=L_{3}=1\right)$, módulo de Young unitário $(E=1)$ e sujeita a uma força $P=10$, é possível escrever o problema de otimização na forma 6.2. Fazendo uma pequena alteração na função objetivo, de modo que o ponto ótimo global seja o ponto ótimo singular, o problema fica escrito na forma 6.8 .

Observe que na formulação 6.8 o valor de $A_{2}$, apesar de definido como $A_{2} \geq 0$, caso este atinja o valor zero, a matriz de rigidez do MEF se tornaria singular e conseqüentemente os deslocamentos se tornam indefinidos. 


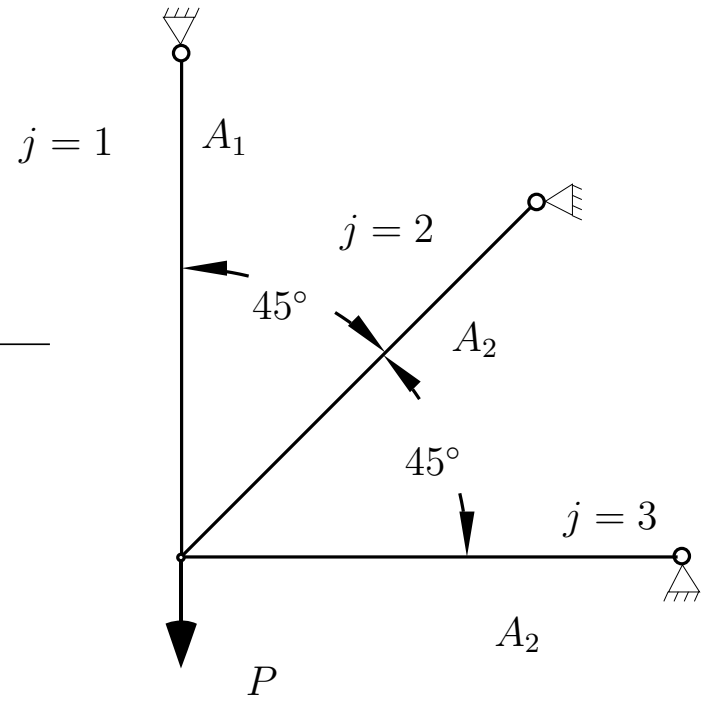

Figura 6.2: Problema exemplo de uma treliça com três barras e duas variáveis de projeto.

$$
\begin{aligned}
& \underset{A_{1}, A_{2}, d_{1}, d_{2}}{\operatorname{minimizar}} P=2 A_{1}+A_{2} \\
& \text { tal que } \\
& {\left[\begin{array}{ll}
3 / 2 A_{2} & 1 / 2 A_{2} \\
1 / 2 A_{2} & A_{1}+1 / 2 A_{2}
\end{array}\right]\left[\begin{array}{l}
d_{1} \\
d_{2}
\end{array}\right]=\left[\begin{array}{l}
0 \\
-10
\end{array}\right]} \\
& -20 \leq \sigma_{1} \leq 20 \quad \text { se } A_{1}>0 \\
& -20 \leq \sigma_{2} \leq 20 \quad \text { se } \quad A_{2}>0 \\
& -20 \leq \sigma_{3} \leq 20 \text { se } A_{2}>0 \\
& \sigma_{1}=\left[\begin{array}{ll}
0 & 1
\end{array}\right]\left[\begin{array}{l}
d_{1} \\
d_{2}
\end{array}\right] \\
& \sigma_{2}=\left[\begin{array}{ll}
\frac{\sqrt{2}}{2} & \frac{\sqrt{2}}{2}
\end{array}\right]\left[\begin{array}{l}
d_{1} \\
d_{2}
\end{array}\right] \\
& \sigma_{3}=\left[\begin{array}{ll}
1 & 0
\end{array}\right]\left[\begin{array}{l}
d_{1} \\
d_{2}
\end{array}\right] \\
& A_{1} \geq 0 \quad ; \quad A_{2} \geq 0
\end{aligned}
$$

O problema de otimização nesta forma pode ser resolvido através do método de Programação Matemática com Restrições de Equilíbrio (PMRE), como o utilizado por Evgrafov (2004) associado a alguma forma de tratamento da singularidade ocasionada por $A_{2}=0$.

Entretanto, a forma mais tradicional de se resolver este problema é utilizar uma formulação implícita e considerar que $A_{1}>0$ e $A_{2}>0$, assim pode-se escrever o problema como 6.9: 


$$
\begin{aligned}
\underset{A_{1}, A_{2}}{\operatorname{minimizar}} & P=2 A_{1}+A_{2} \\
\text { tal que } & \\
g_{1}: & \frac{3}{2\left(3 A_{1}+A_{2}\right)}-1 \leq 0 \\
g_{2}: & \frac{\sqrt{2}}{2\left(3 A_{1}+A_{2}\right)}-1 \leq 0 \\
g_{3}: \quad & \frac{1}{2\left(3 A_{1}+A_{2}\right)}-1 \leq 0 \\
& A_{1} \geq A_{\min }>0 \quad A_{2} \geq A_{\min }>0
\end{aligned}
$$

Com a formulação do problema escrita nesta forma, é possível representar de forma gráfica o espaço de solução desse problema em termos das variáveis $A_{1}$ e $A_{2}$.

A Figura 6.3 apresenta este espaço de solução, onde as linha cheias identificadas como $g_{1}$ e $g_{2}$ representam as restrições $g_{1}$ e $g_{2}$ do problema, as linhas traço e ponto representam as curvas de nível da função objetivo, e a seta perpendicular a curva de nível superior direita indica a direção na qual a função objetivo diminui. A restrição $g_{3}$ não está representada pois esta não influencia o problema.

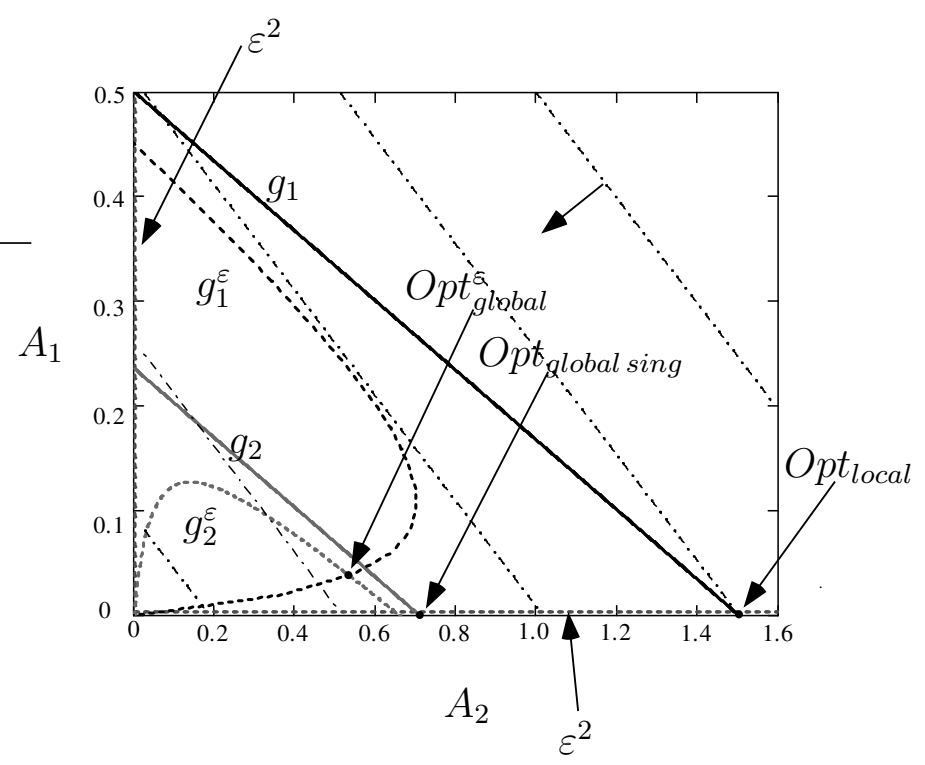

Figura 6.3: Espaço de solução para o problema original (restrições em linhas cheias) e espaço de solução para o problema $\varepsilon$-relaxado (restrições em linhas tracejadas) para $\varepsilon=0,05$.

Analisando o domínio viável nesse espaço de solução, observa-se que considerando $A_{1} \geq A_{\min }>0$ e $A_{2} \geq A_{\min }>0$, a solução ótima do problema na forma 6.9 é o ponto indicado por $O p t_{\text {local }}$. Porém, esta não é a solução ótima global do problema original 6.8, que se quer resolver. 
Neste exemplo é possível verificar as características da solução ótima singular representada pelo ponto $O p t_{\text {global sing. }}$. Observa-se que a vizinhança deste ponto tem dimensão 1 ( $k=1$, pois apenas $A_{2}$ faz parte desse espaço de solução) que é menor que a dimensão do espaço de solução original, igual a $2(n=2)$. Assim se verifica a característica do ótimo singular segundo Rozvany e Birker (1994).

Aplicando o método de $\varepsilon$-relaxação proposto por Cheng e Guo (1997), as restrições do problema 6.8 são modificadas de modo que este passa a ser dado na forma 6.10:

$$
\begin{aligned}
\underset{A_{1}, A_{2}}{\operatorname{minimizar}} P=2 A_{1}+A_{2} \\
\text { tal que } \\
g_{1}^{\varepsilon}: \quad A_{1}\left[\frac{3}{2\left(3 A_{1}+A_{2}\right)}-1\right] \leq \varepsilon \\
g_{2}^{\varepsilon}: \quad A_{2}\left[\frac{\sqrt{2}}{2\left(3 A_{1}+A_{2}\right)}-1\right] \leq \varepsilon \\
g_{3}^{\varepsilon}: \quad A_{2}\left[\frac{1}{2\left(3 A_{1}+A_{2}\right)}-1\right] \leq \varepsilon \\
A_{1} \geq \varepsilon^{2} ; \quad A_{2}>\varepsilon^{2}
\end{aligned}
$$

Representando de forma gráfica o espaço de solução para a formulação relaxada do problema (6.10), no mesmo gráfico apresentado na Figura 6.3, observa-se que o ponto ótimo global do problema, indicado por $O p t_{\text {global }}^{\varepsilon}$, não é um ponto singular.

Assim, a vizinhança do ponto ótimo passa a ter dimensão 2 e este ponto pode ser alcançado utilizando os métodos tradicionais de otimização. Outra questão que se verifica facilmente é que a restrição na sua forma $\varepsilon$-relaxada não é convexa e sua consideração pode gerar o surgimento de ótimos locais.

Fazendo a continuação do valor de $\varepsilon$, conforme proposto por Cheng e Guo (1997), pode se observar na Figura 6.4 como o problema relaxado se aproxima do problema original a medida que $\varepsilon$ se aproxima de zero. É interessante notar que à medida que o problema $\varepsilon$-relaxado se aproxima do problema original, a geometria do espaço de solução viável, na região do ponto ótimo, se torna mais "estreita". Esta situação justifica iniciar o problema com valores altos de $\varepsilon$, de modo que o método de otimização convirja para um ponto como aquele representado por $O p t_{\text {global }}^{\varepsilon=0.1}$ na Figura 6.4 e então fazer com que o método de otimização acompanhe este ponto junto com a diminuição de $\varepsilon$.

Quanto ao método da continuação, aqui vale notar que a continuação do valor 


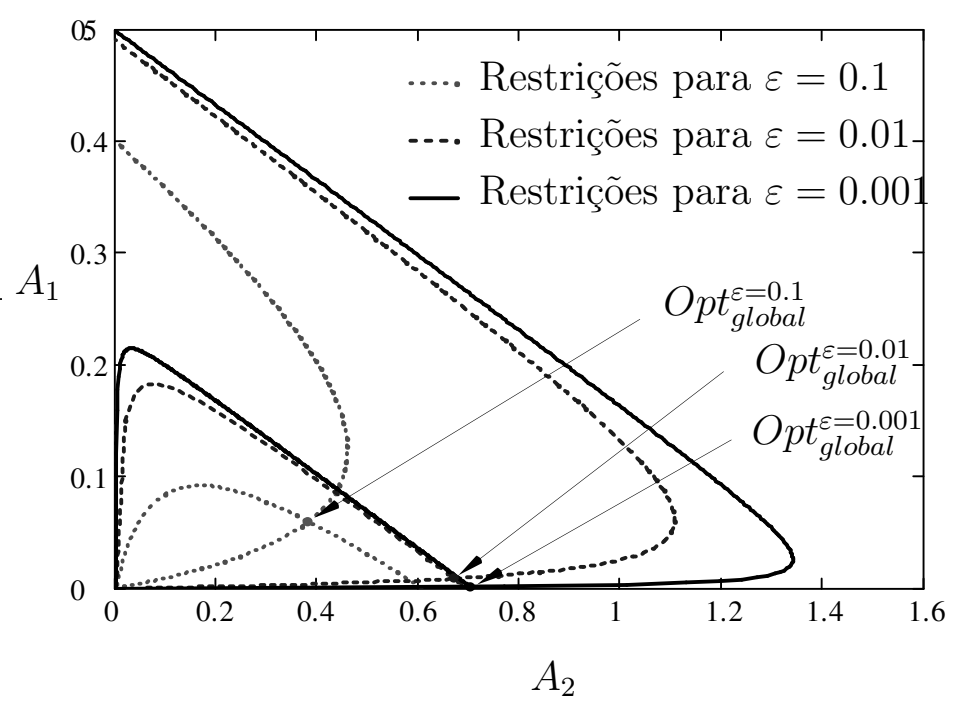

Figura 6.4: Espaço de solução para o problema relaxado, alteração da solução ótima conforme a continuação do valor de $\varepsilon$

de $\varepsilon$ não garante que o ótimo global do problema relaxado se aproxime de forma contínua ao ótimo global do problema original, ou seja, durante a continuação do valor de $\varepsilon$ outros ótimos globais podem surgir (STOLPE; SVANBERG, 2001b), porém, isto pouco afeta os métodos de otimização baseados nos gradiente, pois a partir do momento em que a solução converge para um dos pontos ótimos do problema relaxado, a solução caminhará junto a este ponto a medida que se faça a continuação do valor de $\varepsilon$.

\subsection{Otimização Topológica de meios contínuos com restrição de tensão}

Neste trabalho optou-se por utilizar a abordagem de adequação da formulação do problema de OT considerando restrição de tensão, para que seja possível utilizar os métodos tradicionais de otimização baseados no gradiente.

Aqui será apresentada uma visão histórica da aplicação do Método de Otimização Topológica considerando restrições de tensão.

O primeiro trabalho a tratar do problema de Otimização Topológica com restrição de tensão foi a tese de doutoramento de Park (1995). Neste trabalho o autor sugeriu duas formulações e realizou alguns testes com essas formulações. Apesar de não ter sido publicado em periódicos científicos, este trabalho foi um forte inspirador do trabalho de Yang e Chen (1996). 
A primeira abordagem proposta por Park (1995) parte da seguinte formulação:

$$
\underset{\text { variáveis de projeto }}{\operatorname{minimizar}} \text { flexibilidade }
$$

tal que

equações de equilibrio

restrição de volume

restrição de tensão local

Nesta formulação a restrição de tensão é feita localmente na forma:

$$
\max \left\{f_{\text {falha }}(\langle\boldsymbol{\sigma}\rangle)\right\} \leq f_{\text {falha }}\left(\boldsymbol{\sigma}_{\text {ref }}\right) \quad \text { em } \Omega
$$

onde $f_{\text {falha }}(\langle\boldsymbol{\sigma}\rangle)$ representa uma medida tensão mecânica pontual, (ex. von Mises ou Tresca) e $f_{\text {falha }}\left(\boldsymbol{\sigma}_{r e f}\right)$ a mesma medida de tensão mecânica em função de um estado de tensão $\boldsymbol{\sigma}_{r e f}$ de referência. No caso de um material dúctil como o metal, em geral é utilizada a tensão de escoamento, que neste texto será representada por $\langle\sigma\rangle_{y}$.

Para manter a coerência com a nomenclatura apresentada no capítulo 4, o símbolo $\langle\boldsymbol{\sigma}\rangle$ representa a tensão na macro-escala, que por sua vez consiste na média das tensões na micro-escala representadas simplesmente por $\boldsymbol{\sigma}, f_{v m}(\langle\boldsymbol{\sigma}\rangle)$, ou simplesmente $\langle\sigma\rangle_{v m}$ representa a tensão de von Mises, calculada a partir do tensor de tensões na macro-escala e dada pela equação 4.54 .

Com base na formulação 6.11, Park (1995) propõe a aproximação da restrição local por uma restrição global, a norma-p das tensões, onde um valor $p$ pondera a influência dos valores máximos de tensão no restrição global. Dessa forma, o problema de restrição do máximo valor de tensão é substituído por uma restrição global dada por 6.13 :

$$
\left\{\int_{\Omega}\left[f_{v m}(\langle\boldsymbol{\sigma}\rangle)\right]^{p} d \Omega\right\}^{\frac{1}{p}} \leq\langle\sigma\rangle_{y}
$$

de modo que quando $p$ tende a infinito o lado esquerdo desta equação (6.13) tende a ser igual ao valor máximo da tensão, lado esquerdo da equação 6.12.

Para exemplificar melhor o comportamento numérico da função norma-p (6.13) e assim justificar sua escolha como forma de representação da máxima tensão local através de uma função global, tomemos como exemplo a função $\operatorname{sen}(x)$ para $x \in[0, \pi]$. É sabido que o máximo valor dessa função neste intervalo 
é igual a 1, como pode se observar na Figura 6.5:

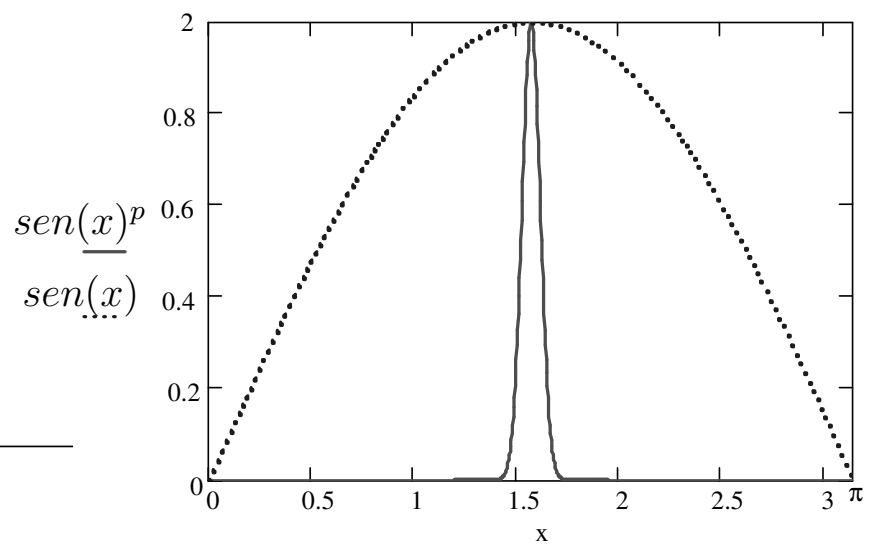

Figura 6.5: Gráfico ilustrativo da influência do parâmetro p da norma-p, através das funções $\operatorname{sen}(x)$ e $\operatorname{sen}(x)^{p}$ para $p=512$

Observando também a função $\operatorname{sen}(x)^{p}$ no gráfico da Figura 6.5 verifica-se que para valores altos de $p$ o ponto máximo da função original $(x=1)$ se torna mais pronunciado em relação ao resto da função. Ou seja elevar a função a um valor $p>1$ é uma forma de ponderar a integral, ou somatório, desta função pelo próprio valor da função no ponto.

Aplicando agora a norma-p sobre a função sen $(x)$ temos:

$$
N P=\left\{\int_{0}^{\pi} \operatorname{sen}(x)^{p} d x\right\}^{\frac{1}{p}}
$$

e avaliando esta integral para diversos valores de $p$ é possível verificar que o seu valor converge assintoticamente para o máximo valor da função original. Esta situação pode ser verificada na Figura 6.6 onde se observa que para $p>100$ o valor da norma-p se distância em apenas $1 \%$ do valor máximo

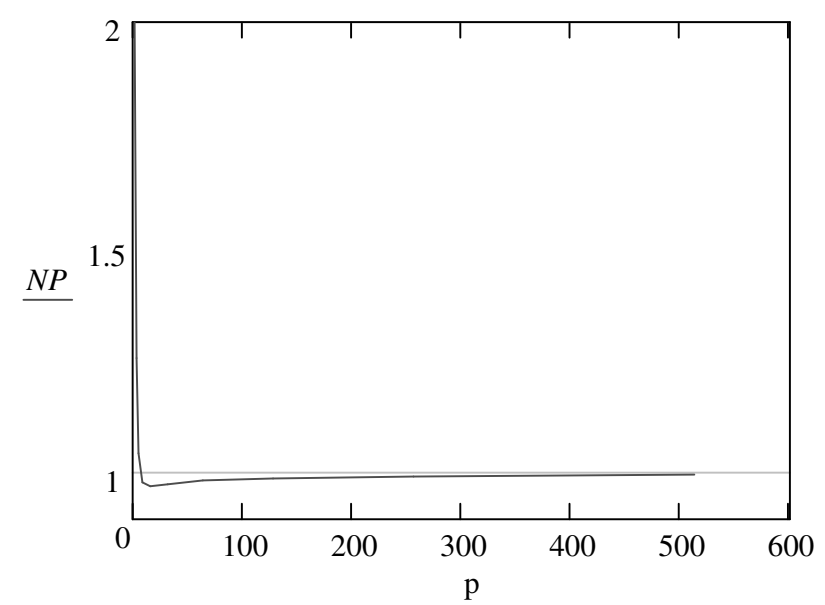

Figura 6.6: Gráfico do valor da norma-p em função do valor de $p$ 
Com base na idéias de aproximação da tensão local por um função global, a formulação proposta por Park (1995) é escrita como:

$$
\begin{aligned}
& \underset{\rho}{\operatorname{minimizar}} \int_{\Omega} \mathbf{f}(\mathbf{x})^{T} \mathbf{u}(\mathbf{x}) d \Omega+\int_{\partial \Omega} \mathbf{p}(\mathbf{x})^{T} \mathbf{u}(\mathbf{x}) d \partial \Omega \\
& \text { tal que } \\
& \quad \int_{\Omega} \tilde{\boldsymbol{\epsilon}}(\mathbf{x})^{T} \mathbf{E}(\mathbf{x}) \boldsymbol{\epsilon}(\mathbf{x}) d \Omega-\int_{\Omega} \mathbf{f}(\mathbf{x})^{T} \tilde{\mathbf{u}}(\mathbf{x}) d \Omega-\int_{\partial \Omega} \mathbf{p}(\mathbf{x})^{T} \tilde{\mathbf{u}}(\mathbf{x}) d \partial \Omega=0 \\
& \quad \int_{\Omega} \rho(x) d \Omega \leq \Omega_{r e f} \\
& \\
& \left\{\int_{\Omega}\left[f_{v m}(\langle\boldsymbol{\sigma}\rangle)\right]^{p} d \Omega\right\}^{\frac{1}{p}} \leq\langle\sigma\rangle_{y}
\end{aligned}
$$

Apesar de Park (1995) propor esta formulação, a implementação numérica realizada em seu trabalho é diferente. A restrição local é tratada como um termo adicionado à função objetivo, criando assim uma otimização multi-objetivo. Neste caso a função acrescentada é dada por:

$$
\frac{w}{2} \max \left\{\left(\int_{\Omega}\left[f_{v m}(\langle\boldsymbol{\sigma}\rangle)\right]^{p} d \Omega\right)^{\frac{1}{p}}-\langle\sigma\rangle_{y}, 0\right\}^{2}
$$

onde $w$ é um valor fixo que pondera a influência das tensões em relação ao problema tradicional de mínima flexibilidade. Dessa forma, o problema implementado fica definido como:

$$
\begin{aligned}
\underset{\rho}{\operatorname{minimizar}} & \int_{\Omega} \mathbf{f}(\mathbf{x})^{T} \mathbf{u}(\mathbf{x}) d \Omega+\int_{\partial \Omega} \mathbf{p}(\mathbf{x})^{T} \mathbf{u}(\mathbf{x}) d \partial \Omega \\
+\frac{w}{2} \max & \left\{\left(\left(\int_{\Omega}\left[f_{v m}(\langle\boldsymbol{\sigma}\rangle)\right]^{p} d \Omega\right)^{\frac{1}{p}}-\langle\sigma\rangle_{y}\right), 0\right\}^{2}
\end{aligned}
$$

tal que

$$
\begin{aligned}
& \int_{\Omega} \tilde{\boldsymbol{\epsilon}}(\mathbf{x})^{T} \mathbf{E}(\mathbf{x}) \boldsymbol{\epsilon}(\mathbf{x}) d \Omega-\int_{\Omega} \mathbf{f}(\mathbf{x})^{T} \tilde{\mathbf{u}}(\mathbf{x}) d \Omega-\int_{\partial \Omega} \mathbf{p}(\mathbf{x})^{T} \tilde{\mathbf{u}}(\mathbf{x}) d \partial \Omega=0 \\
& \int_{\Omega} \rho(x) d \Omega \leq \Omega_{r e f}
\end{aligned}
$$

Utilizando essa abordagem, Park (1995) obtém estruturas para $w=0, w=$ $0.01, w=0.1, w=1, w=10.0$ e $w=100$. Observando os resultado obtidos para um viga engastada, verifica-se que o aumento do valor de $w$ propicia o surgimento 
de elementos cinzas na estrutura.

A segunda formulação proposta por Park (1995), aparentemente, visa diminuir o fenômeno de surgimento de escala de cinza devido à minimização da tensão mecânica.

Assim, o autor propõem minimizar a máxima tensão mecânica expressa de uma forma global através da norma-p, considerando as equações de equilíbrio e restrição de volume. Para penalizar os elementos com densidade intermediária, Park (1995) sugere que a função de falha, no caso von Mises, seja dividida pela densidade do elemento. Dessa forma, a formulação é dada por 6.18:

$$
\begin{aligned}
& \underset{\rho}{\operatorname{minimizar}}\left\{\int_{\Omega}\left[\frac{f_{v m}(\langle\boldsymbol{\sigma}\rangle)}{\rho}\right]^{p} d \Omega\right\}^{\frac{1}{p}} \\
& \text { tal que } \\
& \quad \int_{\Omega} \tilde{\boldsymbol{\epsilon}}(\mathbf{x})^{T} \mathbf{E}(\mathbf{x}) \boldsymbol{\epsilon}(\mathbf{x}) d \Omega-\int_{\Omega} \mathbf{f}(\mathbf{x})^{T} \tilde{\mathbf{u}}(\mathbf{x}) d \Omega-\int_{\partial \Omega} \mathbf{p}(\mathbf{x})^{T} \tilde{\mathbf{u}}(\mathbf{x}) d \partial \Omega=0 \\
& \quad \int_{\Omega} \rho(x) d \Omega \leq \Omega_{r e f}
\end{aligned}
$$

O localizador de tensão proposto pelo autor é baseado na idéia de que a tensão mecânica é intensificada devido à porosidade do material. Um estudo desses localizadores de tensão é feito na seção 4.4 e sua relação com o critério de falha do material na seção 4.5.

Com esta formulação, Park (1995) obtém estruturas para os valores de $p=5$, $p=10$ e $p=20$, porém os resultados não são satisfatórios pois não apresentam uma geometria bem definida, devido à presença de escala de cinza, justamente o oposto do previsto ao se propor a divisão da função de falha pela densidade do elemento.

A partir desse trabalho pode se perceber que uma abordagem simples do problema de OT com restrição de tensão não é capaz de gerar resultados satisfatórios.

Seguindo a mesma linha de tratar restrição de tensão mecânica através de um índice global, Yang e Chen (1996) fazem um estudo de duas funções globais para a tensão. O autor utiliza a função proposta por Park (1995) apresentada 
em 6.19 e a função de Kreisselmeier-Steinhauser (KS), dada em 6.20.

$$
\begin{gathered}
G_{N P}=\left\{\int_{\Omega}\left[\frac{f_{v m}(\langle\boldsymbol{\sigma}\rangle)}{\langle\sigma\rangle_{y}}\right]^{p} d \Omega\right\}^{\frac{1}{p}} \\
G_{K S}=\frac{1}{p} \ln \sum_{i=1}^{M} e^{p \frac{f_{v m}\left(\langle\boldsymbol{\sigma}\rangle_{i}\right)}{\langle\sigma\rangle}}
\end{gathered}
$$

De forma similar a Park (1995), em seu trabalho, Yang e Chen (1996) consideraram tais funções como função objetivo ou associando esta à flexibilidade criando, assim, uma função multi-objetivo.

Observe que neste caso Yang e Chen (1996) desconsideram o localizador de tensões devido ao fato das regiões cinzas representarem, de certa forma, materiais porosos, conforme proposto por Park (1995). Porém, isto aparentemente melhorou os resultados numéricos.

As principais conclusões do trabalho de Yang e Chen (1996) são que: as estruturas otimizadas quanto à tensão ou à flexibilidade são distintas, as soluções obtidas com as funções KS ou norma-p são similares e a importância de se estabelecer os limites móveis suficientemente pequenos para a obtenção da solução.

Posteriormente, Duysinx e Bendsøe (1998) apresentaram um trabalho que marcou a aplicação do MOT considerando restrições de tensão. Os autores trataram este problema e apresentaram uma base teórica para a aplicação dos localizadores de tensão ao MOT e para o surgimento do fenômeno das topologias singulares no caso de estruturas contínuas.

Segundo Duysinx e Bendsøe (1998), o fenômeno das topologias singulares ocorre também para o caso de Otimização Topológica de estruturas contínuas devido ao fato de que a tensão na microestrutura, por exemplo a micro-tensão em um material poroso $\left(\boldsymbol{\sigma}^{+}\right)$, tende a valores finitos quando a densidade volumétrica referente a esta fase tende a 0 . Sendo assim, caso o valor da tensão seja maior que a tensão de referência, a mesma situação de tensão limitante apresentada por Cheng e Jiang (1992), irá ocorrer, caracterizando o fenômeno das topologias singulares.

Dessa forma, baseado nos trabalhos referentes ao fenômeno das topologias singulares, apresentados na seção 6.3, Duysinx e Bendsøe (1998) propuseram e implementaram uma formulação dada por: 6.21, de minimização do volume com 
restrição local de tensão considerando a $\varepsilon$-relaxação do problema.

$$
\begin{aligned}
& \underset{\rho}{\operatorname{minimizar}} \int_{\Omega} \rho d \Omega \\
& \text { tal que } \\
& \qquad\left(\frac{f_{v m}(\langle\boldsymbol{\sigma}\rangle)}{\rho^{q}} \frac{1}{\langle\boldsymbol{\sigma}\rangle_{y}}-1\right) \leq \varepsilon \\
& \quad 0<\varepsilon^{2} \leq \rho \leq 1
\end{aligned}
$$

Nesta formulação é considerada uma restrição local de tensão na micro-escala dada pelo termo:

$$
\frac{f_{v m}(\langle\boldsymbol{\sigma}\rangle)}{\rho^{q}}
$$

conforme apresentado na seção 4.5; mais especificamente na equação 4.60. Junto a esta é aplicado o conceito de $\varepsilon$-relaxação, conforme apresentado pela equação 6.7 .

No mesmo ano, DUYSINX; SIGMUND (1998 apud Sant'Anna, Guilherme e Fonseca (2003)) propuseram uma formulação alternativa baseada na idéia de uma restrição global de tensão, diminuindo assim os problemas relativos ao alto custo computacional das restrições locais. Dessa forma, foi proposta uma restrição sobre a norma-p (6.23) das tensões e sobre a média-p (6.24) da tensões de von Mises:

$$
\begin{aligned}
& \text { norma }-\mathrm{p} \\
& \qquad\left[\sum_{e=1}^{M} \max \left\{\left(\frac{f_{v m}(\langle\boldsymbol{\sigma}\rangle)}{\rho^{q}} \frac{1}{\langle\boldsymbol{\sigma}\rangle_{y}}+\varepsilon-\frac{\varepsilon}{\rho_{e}}\right)^{p}, 0\right\}\right]^{\frac{1}{p}} \leq 1 \\
& \text { média }-\mathrm{p} \\
& {\left[\frac{1}{M} \sum_{e=1}^{M} \max \left\{\left(\frac{f_{v m}(\langle\boldsymbol{\sigma}\rangle)}{\rho^{q}} \frac{1}{\langle\boldsymbol{\sigma}\rangle_{y}}+\varepsilon-\frac{\varepsilon}{\rho_{e}}\right)^{p}, 0\right\}\right]^{\frac{1}{p}} \leq 1}
\end{aligned}
$$

Nesse trabalho Duysinx e Sigmund (1998) também identificaram que a $\varepsilon$ relaxação na forma proposta por Cheng e Guo (1997) e utilizada em Duysinx e Bendsøe (1998) não é adequada no caso de OT para estruturas contínuas (DUYSINX, 2005), pois no caso de se ter material sólido $(\rho=1)$, é de se esperar que não exista a influência do valor de $\varepsilon$. Assim, os autores propuseram uma nova forma de relaxação dada por:

$$
\rho\left(\frac{f_{v m}(\langle\boldsymbol{\sigma}\rangle)}{\rho^{q}} \frac{1}{\langle\boldsymbol{\sigma}\rangle_{y}}-1\right) \leq \varepsilon(1-\rho)
$$


onde se percebe claramente que para $\rho=1$ não há o efeito de relaxação sobre as restrições.

As fórmulas de $\varepsilon$-relaxação do problema podem ser interpretadas como uma alteração do limite de escoamento do material, assim teríamos a restrição da formulação 6.21 dada por 6.26 e a restrição 6.25 dada por 6.27 :

$$
\begin{gathered}
\frac{f_{v m}(\langle\boldsymbol{\sigma}\rangle)}{\rho^{q}} \leq\langle\boldsymbol{\sigma}\rangle_{y}\left(\frac{\varepsilon}{\rho}+1\right) \\
\frac{f_{v m}(\langle\boldsymbol{\sigma}\rangle)}{\rho^{q}} \leq\langle\boldsymbol{\sigma}\rangle_{y}\left(\frac{\varepsilon}{\rho}-\varepsilon+1\right)
\end{gathered}
$$

Representando graficamente o lado direito de ambas equações (6.26 e 6.27), observa-se na Figura 6.7 como cada função se comporta em relação a $\rho$.

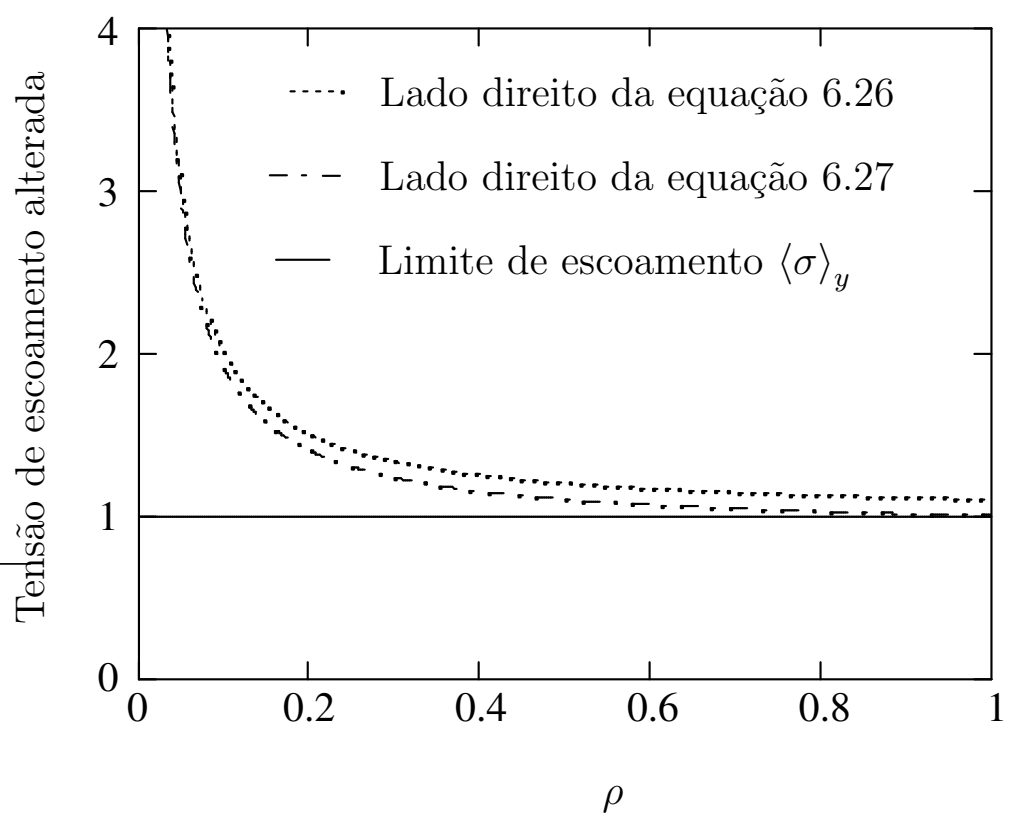

Figura 6.7: Alteração da tensão de limite de escoamento segundo as abordagens de Duysinx e Bendsøe (1998) e Duysinx e Sigmund (1998) para $\varepsilon$ igual a 0.1

Outro trabalho importante no desenvolvimento da aplicação do MOT considerando restrições de tensão foi realizado por Pereira (2001) e Pereira, Fancello e Barcellos (2004). Nestes trabalhos os autores utilizam a mesma formulação proposta por Duysinx e Bendsøe (1998) junto com a $\varepsilon$-relaxação na forma apre- 
sentada em 6.25. Assim, a formulação é dada por 6.28 :

$$
\begin{aligned}
& \underset{\rho}{\operatorname{minimizar}} \int_{\Omega} \rho d \Omega \\
& \text { tal que } \\
& \quad \rho\left(\frac{f_{v m}(\langle\boldsymbol{\sigma}\rangle)}{\rho^{q}} \frac{1}{\langle\boldsymbol{\sigma}\rangle_{y}}-1\right) \leq \varepsilon(1-\rho) \\
& \quad 0<\varepsilon^{2} \leq \rho \leq 1
\end{aligned}
$$

A importância dos trabalhos de Pereira (2001) e Pereira, Fancello e Barcellos (2004) se deve ao tratamento numérico que os autores propuseram. A principal diferença na implementação numérica é a utilização do MLA para considerar as restrições de tensão. Assim, cada restrição local da tensão é incluída na função objetivo ponderada por um multiplicador de lagrange mais um termo de penalização.

A grande vantagem dessa abordagem é a redução do custo computacional necessário para o cálculo da sensibilidade do problema. Por exemplo, quando aplicado o método adjunto é necessário resolver apenas um sistema linear a cada iteração, caso contrário seria necessário resolver $N$ sistemas lineares, onde $N$ indica o número de restrições.

Em Pereira, Fancello e Barcellos (2004), os autores justificam o uso do MLA devido à natureza local das restrições de tensão, que é comparável à restrição de contato unilateral, na qual o Método do Lagrangeano Aumentado têm-se mostrado um abordagem eficiente (BATHE, 1996).

Observando os resultados obtidos nos artigos Duysinx e Bendsøe (1998) e Pereira, Fancello e Barcellos (2004) conclui-se que o MLA permitiu a utilização de malhas mais refinadas aumentando assim a precisão da análise do campo de tensões. Dessa forma Pereira, Fancello e Barcellos (2004) obtiveram melhores resultados no que diz respeito à capacidade do método de retirar os pontos de concentração de tensão da estrutura.

Outros trabalhos como Allaire, Jouve e Maillot (2004) e Navarrina et al. (2005) tratam da aplicação do MOT considerando tensão mecânica, porém, estes pouco acrescentam quanto às formas de tratar o fenômeno das topologias singulares ou o grande número de restrições.

Allaire, Jouve e Maillot (2004) apresentam um problema de minimização da integral da tensão mecânica sobre a estrutura com restrição de volume. Neste artigo os autores utilizam como modelo de material uma microestrutura composta 
por uma célula unitária rank-n e apresentam a formulação dos localizadores de tensão para este caso, conforme discutido na seção 4.4 .

Já Navarrina et al. (2005) apresentam o problema de minimização de volume com restrição local de tensão, porém sem se utilizar ou mesmo discutir o conceito de $\varepsilon$-relaxação.

\subsection{Formulações propostas}

Com base na revisão bibliográfica anteriormente exposta, aqui serão apresentadas as formulações utilizadas neste trabalho. Na subseção 6.5.1, serão apresentadas as formulações em si, e na subseção 6.5.2 serão apresentadas as discretizações destas formulações e o cálculo de sensibilidade. O desenvolvimento da formulação na sua forma discretizada se baseia no MEF apresentado no capítulo 5

\subsubsection{Formulações do problema de Otimização Topológica considerando restrição de tensão}

Neste trabalho foram estudadas e implementadas duas formulações para o problema de OT com restrição de tensão.

Numa primeira abordagem foi implementada a formulação integral da restrição, conforme proposta por Duysinx e Sigmund (1998), que aqui será denominada OT com restrição global de tensão. Numa segunda abordagem, foi implementada a formulação com restrição local, associada ao MLA, conforme proposto por Pereira, Fancello e Barcellos (2004), e será denominada OT com restrição local de tensão.

A abordagem considerando a restrição global de tensão tem como principal vantagem a redução do grande número de restrições do problema inicial em apenas uma restrição. Isto torna possível a utilização de um método tradicional de PL, para solucionar o problema. A principal desvantagem deste método é que o controle da local da máxima tensão fica prejudicado. 
Dessa forma se propõem a formulação dada por 6.29:

$$
\begin{aligned}
& \underset{\rho}{\operatorname{minimizar}} \int_{\Omega} \rho d \Omega \\
& \text { tal que } \\
& \quad\left[\frac{1}{\Omega} \int_{\Omega}\left(\max \left\{\frac{f_{v m}(\langle\boldsymbol{\sigma}\rangle)}{\rho^{q}} \frac{1}{\langle\boldsymbol{\sigma}\rangle_{y}}-\varepsilon(1-\rho), 0\right\}\right)^{p}\right]^{\frac{1}{p}} \leq 1 \\
& \quad 0<\rho_{\min } \leq \rho \leq 1
\end{aligned}
$$

Aqui vale lembrar que associada à esta formulação está sendo utilizado o modelo de material SIMP descrito anteriormente no capítulo 5.

Em alguns exemplos onde o surgimento de escala de cinza se mostrou mais pronunciado, foi necessário utilizar um função penalizadora das densidades intermediarias dada por: 6.30:

$$
F_{q}(\rho)=K_{q} \int_{\Omega} \rho(1-\rho) d \Omega
$$

onde $K_{q}$ representa um fator fixo de controle da penalização.

Assim, a formulação proposta fica dada por 6.31:

$$
\begin{aligned}
& \underset{\rho}{\operatorname{minimizar}} \int_{\Omega} \rho d \Omega+K_{q} \int_{\Omega} \rho(1-\rho) d \Omega \\
& \text { tal que } \\
& \quad\left[\frac{1}{\Omega} \int_{\Omega}\left(\max \left\{\frac{f_{v m}(\langle\boldsymbol{\sigma}\rangle)}{\rho^{q}} \frac{1}{\langle\boldsymbol{\sigma}\rangle_{y}}-\varepsilon(1-\rho), 0\right\}\right)^{p}\right]^{\frac{1}{p}} \leq 1 \\
& \quad 0<\rho_{\min } \leq \rho \leq 1
\end{aligned}
$$

A segunda abordagem, que considera uma restrição local de tensão, tem como principal vantagem um controle mais preciso da restrição local. Porém, a sua implementação numérica só é viável se associada ao Método do Lagrangeano Aumentado para fazer o tratamento do grande número de restrições locais.

Com base na revisão bibliográfica, pode-se concluir que o trabalho de Pereira, Fancello e Barcellos (2004), que utilizou esta abordagem, obteve os melhores resultados numéricos quanto a capacidade de reduzir a tensão máxima da estrutura.

Dessa forma foi implementada a formulação proposta por Pereira, Fancello e 
Barcellos (2004) e dada por 6.32

$$
\begin{aligned}
& \underset{\rho}{\operatorname{minimizar}} \int_{\Omega} \rho d \Omega \\
& \text { tal que } \\
& \quad \rho\left(\frac{f_{v m}(\langle\boldsymbol{\sigma}\rangle)}{\rho^{q}} \frac{1}{\langle\boldsymbol{\sigma}\rangle_{y}}-1\right) \leq \varepsilon(1-\rho) \\
& \quad 0<\rho_{\text {min }} \leq \rho \leq 1
\end{aligned}
$$

e associada a esta formulação é utilizado o MLA.

Seguindo o trabalho de Pereira, Fancello e Barcellos (2004) a regularização do problema de OT e o controle das densidades intermediárias, foi feito de forma diferente daquele do problema com restrição global de tensão.

Neste caso, o filtro aplicado ao limites móveis, conforme apresentado na seção 2.5 foi substituído pela inserção da função de regularização 6.33 na função objetivo.

$$
F_{r}(\rho)=K_{r} \int_{\Omega}(\nabla \rho)^{T}(\nabla \rho) d \Omega
$$

O controle das densidades intermediárias foi feito pelo fator de penalização $q$ do modelo SIMP em conjunto com uma função penalizadora dada em 6.30. Assim o problema implementado é dado por 6.34

$$
\begin{aligned}
& \underset{\rho}{\operatorname{minimizar}} \int_{\Omega} \rho d \Omega+K_{q} \int_{\Omega} \rho(1-\rho) d \Omega+K_{r} \int_{\Omega}(\nabla \rho)^{T}(\nabla \rho) d \Omega \\
& \text { tal que } \\
& \quad \rho\left(\frac{f_{v m}(\langle\boldsymbol{\sigma}\rangle)}{\rho^{q}} \frac{1}{\langle\boldsymbol{\sigma}\rangle_{y}}-1\right) \leq \varepsilon(1-\rho) \\
& \quad 0<\rho_{\min } \leq \rho \leq 1
\end{aligned}
$$

\subsubsection{Problema na forma discreta e análise de sensibili- dade}

Para se fazer a implementação numérica da formulação proposta, é necessário discretizar o problema de modo, que as funções envolvidas possam ser calculadas utilizando o campo de tensão proveniente do MEF.

Inicialmente, trataremos o problema de OT com restrição global de tensão 
(6.29). Este problema, na sua forma discreta, é dado por 6.35:

$\underset{\rho}{\operatorname{minimizar}} \sum_{e=1}^{M} \int_{\Omega_{e}} \rho d \Omega_{e}+K_{q} \sum_{e=1}^{M} \int_{\Omega_{e}} \rho(1-\rho) \rho d \Omega_{e}$

tal que

$$
\begin{aligned}
& {\left[\frac{1}{\Omega} \sum_{e=1}^{M} \Omega_{e}\left(\max \left\{\frac{f_{v m}\left(\langle\boldsymbol{\sigma}\rangle_{e}\right)}{\rho^{q}} \frac{1}{\langle\boldsymbol{\sigma}\rangle_{y}}-\varepsilon(1-\rho), 0\right\}\right)^{p}\right]^{\frac{1}{p}} \leq 1} \\
& 0<\rho_{\text {min }} \leq \rho_{i} \leq 1
\end{aligned}
$$

onde $M$ representa o número de elementos da malha, $\Omega_{e}$ representa o volume do elemento $e,\langle\boldsymbol{\sigma}\rangle_{e}$ representa a tensão de von Mises no centro do elemento, $K_{q}$ representa um fator controle da penalização das densidades intermediárias, e $\langle\boldsymbol{\sigma}\rangle_{y}$ representa a tensão de escoamento do material,.

Para utilizar métodos de otimização baseados nos gradientes, é necessário fazer o cálculo da sensibilidade das funções envolvidas no problema, ou seja a derivada da função objetivo e das restrições em relação às variáveis de projeto. No caso específico de se utilizar PLS, é necessário aproximar o problema não linear 6.35 por um problema linear. Para isto é utilizada a expansão em série de Taylor e utilizados apenas os termos de primeira ordem.

Fazendo a expansão em série de Taylor do primeiro termo da função objetivo do problema 6.35 e considerando apenas os termos de primeira ordem, tem-se:

$$
V=V\left(\boldsymbol{\rho}^{0}\right)+\sum_{i=1}^{N} \frac{d V\left(\boldsymbol{\rho}^{0}\right)}{d \rho_{i}}\left[\rho_{i}-\rho_{i}^{0}\right]
$$

Para avaliar esta função utilizando a parametrização das densidades proposta no capítulo 5 é necessário escrever a função objetivo em termos das densidades nodais. Assim, para o caso de elementos axissimétricos, tem-se:

$$
V(\boldsymbol{\rho})=\left.\sum_{e=1}^{M}\left(2 \pi \int_{z} \int_{r} r\left(\sum_{i=1}^{4} \rho_{i} N_{i}(s, t)\right)^{q} d r d z\right)\right|_{e}
$$

onde a integral é feita sobre cada elemento da malha de elementos finitos. Assim a derivada de $V$ em relação a $\rho_{i}$ é dada por:

$$
\frac{d V\left(\boldsymbol{\rho}^{0}\right)}{d \rho_{i}}=\left.\sum_{e=1}^{M}\left(2 \pi \int_{z} \int_{r} r q\left(\sum_{j=1}^{4} \rho_{j} N_{j}(s, t)\right)^{q-1} N_{i}(s, t) d r d z\right)\right|_{e}
$$

De maneira análoga, para o caso de elementos em EPT a derivada de $V$ em 
relação a $\rho_{i}$ é dada por:

$$
\frac{d V\left(\boldsymbol{\rho}^{0}\right)}{d \rho_{i}}=\left.\sum_{e=1}^{M}\left(\int_{x} \int_{y} q\left(\sum_{j=1}^{4} \rho_{j} N_{j}(s, t)\right)^{q-1} N_{i}(s, t) d x d y\right)\right|_{e}
$$

Agora o segundo termo da função objetivo é $F_{q}(\boldsymbol{\rho})$, ou seja o termo de penalização das densidades intermediárias é dado por:

$$
\begin{aligned}
F_{q}(\boldsymbol{\rho}) & =K_{q} \sum_{e=1}^{M} \int_{\Omega_{e}} \rho(1-\rho) d \Omega_{e} \\
& =\left.K_{q} \sum_{e=1}^{M}\left(2 \pi \int_{z} \int_{r} r\left(\sum_{i=1}^{4} \rho_{i} N_{i}(s, t)\right)\left(1-\left(\sum_{i=1}^{4} \rho_{i} N_{i}(s, t)\right)\right) d r d z\right)\right|_{e}
\end{aligned}
$$

Fazendo a expansão em série de Taylor de maneira análoga ao do volume, é necessário calcular a derivada de $F_{q}(\boldsymbol{\rho})$ em relação a $\rho_{i}$. Sendo dada por:

$$
\frac{d F_{q}(\boldsymbol{\rho})}{d \rho_{i}}=\left.K_{q} \sum_{e=1}^{M}\left(2 \pi \int_{z} \int_{r}\left[N_{i}(s, t)-2\left(\sum_{j=1}^{4} \rho_{j} N_{j}(s, t)\right) N_{i}(s, t)\right] d r d z\right)\right|_{e}
$$

Novamente de maneira análoga, para o caso de elemento em EPT a derivada $F_{q}(\boldsymbol{\rho})$ em relação a $\rho_{i}$ é dada por:

$$
\frac{d F_{q}(\boldsymbol{\rho})}{d \rho_{i}}=\left.K_{q} \sum_{e=1}^{M}\left(\int_{x} \int_{y}\left[N_{i}(s, t)-2\left(\sum_{j=1}^{4} \rho_{j} N_{j}(s, t)\right) N_{i}(s, t)\right] d x d y\right)\right|_{e}
$$

Observe que para avaliar numericamente as equações $6.38,6.39$ e 6.42 é necessário aplicar a quadratura de Gauss.

A mesma expansão em série de Taylor e cálculo das derivadas deve ser feito para as restrições. Considerando a restrição dada por $G_{1}$ temos:

$$
G_{1} \equiv\left[\frac{1}{\Omega} \sum_{e \in A t v}\left(\frac{f_{v m}\left(\langle\boldsymbol{\sigma}\rangle_{e}\right)}{\rho^{q}} \frac{1}{\langle\boldsymbol{\sigma}\rangle_{y}}-\varepsilon(1-\rho)\right)^{p}\right]^{\frac{1}{p}} \leq 1
$$

Observa-se na equação 6.43 que a somatória considera apenas os elementos pertencentes ao conjunto Atv que é definido por 6.44:

$$
A t v=\left\{e=1, \ldots, M \mid \frac{f_{v m}\left(\langle\boldsymbol{\sigma}\rangle_{e}\right)}{\rho^{q}} \frac{1}{\langle\boldsymbol{\sigma}\rangle_{y}}-\varepsilon(1-\rho)>0\right\}
$$

Assim, a expansão em série de Taylor, com apenas os elementos de primeira 
ordem, fica:

$$
G_{1}=G_{1}\left(\boldsymbol{\rho}^{0}\right)+\sum_{i=1}^{N} \frac{d G_{1}\left(\boldsymbol{\rho}^{0}\right)}{d \rho_{i}}\left[\rho_{i}-\rho_{i}^{0}\right]
$$

logo, é necessário calcular o valor do termo $\frac{\partial G_{1}\left(\boldsymbol{\rho}^{0}\right)}{\partial \rho_{i}}$. Entretanto, diferentemente do volume, para se fazer o cálculo da sensibilidade da restrição, é necessário considerar que $G_{1}$ é uma função implícita de $\rho_{i}$ uma vez que temos o sistema linear

$$
\mathbf{K}(\boldsymbol{\rho}) \mathbf{d}=\mathbf{f}(\boldsymbol{\rho})
$$

e a tensão $\langle\boldsymbol{\sigma}\rangle_{e}$ é função do deslocamentos $\mathbf{d}$.

Dessa forma, neste trabalho, será utilizado o método adjunto, logo, temos a sensibilidade da restrição em função da variável $\rho_{i}$ dada por:

$$
\frac{d G_{1}\left(\boldsymbol{\rho}^{0}\right)}{d \rho_{i}}=\underbrace{\frac{\partial G_{1}\left(\boldsymbol{\rho}^{0}\right)}{\partial \rho_{i}}}_{\text {Parte explícita }}+\underbrace{\boldsymbol{\lambda}^{T}\left(\frac{d \mathbf{f}}{d \rho_{i}}-\frac{d \mathbf{K}}{d \rho_{i}} \mathbf{d}\right)}_{\text {Parte implícita }}
$$

onde

$$
\mathbf{K} \boldsymbol{\lambda}^{T}=\frac{d G_{1}\left(\boldsymbol{\rho}^{0}\right)}{d \mathbf{d}}
$$

que é chamado de problema adjunto. A derivada $\frac{d G_{1}\left(\boldsymbol{\rho}^{0}\right)}{d \mathbf{d}}$ representa um vetor de derivadas da função $G_{1}$ em função dos deslocamentos $d_{i}$, assim este tem dimensão igual ao número total de graus de liberdade $n g$ do problema e é representado por:

$$
\frac{d G_{1}\left(\boldsymbol{\rho}^{0}\right)}{d \mathbf{d}}=\left[\begin{array}{c}
\frac{d G_{1}\left(\boldsymbol{\rho}^{0}\right)}{d d_{1}} \\
\vdots \\
\frac{d G_{1}\left(\boldsymbol{\rho}^{0}\right)}{d d_{i}} \\
\vdots \\
\frac{d G_{1}\left(\boldsymbol{\rho}^{0}\right)}{d d_{n g}}
\end{array}\right]
$$

Inicialmente, será apresentada a sensibilidade do termo explícito da equação 6.47. Para facilitar o cálculo das derivadas que seguem, será considerado que:

$$
\begin{aligned}
\frac{f_{v m}\left(\langle\boldsymbol{\sigma}\rangle_{e}\right)}{\rho^{q}} & =\frac{\sqrt{\left(\mathbf{C}_{e}\langle\epsilon\rangle_{e}\right)^{T} \mathbf{V C}_{e}\langle\epsilon\rangle_{e}}}{\rho^{q}} \\
& =\frac{\sqrt{\left(\rho^{q} \mathbf{C}_{0}\langle\epsilon\rangle_{e}\right)^{T} \mathbf{V} \rho^{q} \mathbf{C}_{0}\langle\epsilon\rangle_{e}}}{\rho^{q}} \\
& =\frac{\rho^{q} \sqrt{\left(\mathbf{C}_{0}\langle\epsilon\rangle_{e}\right)^{T} \mathbf{V C}_{0}\langle\epsilon\rangle_{e}}}{\rho^{q}} \\
& =\sqrt{\mathbf{C}_{0}\langle\epsilon\rangle_{e}^{T} \mathbf{V C}_{0}\langle\epsilon\rangle_{e}}
\end{aligned}
$$


Assim, a derivada da parte explícita é dada por:

$$
\begin{aligned}
\frac{\partial G_{1}\left(\boldsymbol{\rho}^{0}\right)}{\partial \rho_{i}} & =\frac{1}{p}\left[\frac{1}{\Omega} \sum_{e \in A t v} \Omega_{e}\left(\sqrt{\mathbf{C}_{0}\langle\epsilon\rangle_{e}^{T} \mathbf{V C}_{0}\langle\epsilon\rangle_{e}} \frac{1}{\langle\boldsymbol{\sigma}\rangle_{y}^{e}}-\varepsilon(1-\rho)\right)^{p}\right]^{\frac{1-p}{p}} \\
& \cdot \frac{1}{\Omega} \sum_{e \in A t v}\left[\Omega_{e} p\left(\sqrt{\mathbf{C}_{0}\langle\epsilon\rangle_{e}^{T} \mathbf{V C}_{0}\langle\epsilon\rangle_{e}} \frac{1}{\langle\boldsymbol{\sigma}\rangle_{y}^{e}}-\varepsilon(1-\rho)\right)^{p-1} \frac{\partial \rho}{\partial \rho_{i}} \varepsilon\right]
\end{aligned}
$$

Aqui, vale lembrar que o campo de densidade volumétrica está sendo parametrizado com a formulação ACDM, conforme apresentado no capítulo 5, dessa forma a derivada campo de densidade em função da densidade nodal é dada por:

$$
\frac{\partial \rho^{q}}{\partial \rho_{i}}=q\left(\sum_{j=1}^{4} \rho_{j} N_{j}\right)^{q-1} N_{i}
$$

Agora será apresentado o cálculo das derivadas que envolvem a parte implícita da equação 6.47. Inicialmente será apresentada as derivada em função de $\rho_{i}\left(\frac{d \mathbf{f}}{d \rho_{i}}\right.$ e $\left.\frac{d \mathbf{K}}{d \rho_{i}}\right)$

Considerando o vetor de forças $\mathbf{f}$, calculado a partir do vetor de forças $\mathbf{f}_{e}$ de cada elemento da malha de elementos finitos, conforme apresentado no capítulo 5 e na subseção 7.4.1, $\mathbf{f}_{e}$, para o caso axissimétrico, é dado por:

$$
\mathbf{f}_{e}=\iint_{z} \int_{r} r \mathbf{N}^{T} \mathbf{f}_{c} d \theta d r d z=2 \pi \int_{z} \int_{r} r \mathbf{N}^{T} \mathbf{f}_{c} d r d z
$$

onde

$$
\mathbf{f}_{c}=\rho^{q} \varrho_{0}\left[\begin{array}{c}
\omega r_{p} \\
a_{z}
\end{array}\right]
$$

Para obter a derivada de $\mathbf{f}$ em relação a $\rho_{i}$ basta fazer:

$$
\frac{d \mathbf{f}_{c}}{d \rho_{i}}=\frac{\partial \rho^{q}}{\partial \rho_{j}} \varrho_{0}\left[\begin{array}{c}
\omega r_{p} \\
a_{z}
\end{array}\right]
$$

e, conseqüentemente:

$$
\frac{d \mathbf{f}_{e}}{d \rho_{i}}=2 \pi \int_{z} \int_{r} r \mathbf{N}^{T} \frac{d \mathbf{f}_{c}}{d \rho_{i}} d r d z
$$

Para finalizar, basta montar o vetor de derivada da forças $\mathbf{f}$ em relação a $\rho_{i}\left(\frac{d \mathbf{f}}{d \rho_{i}}\right)$ utilizando a conectividade dos elementos.

Para o caso de elemento em EPT a derivada de $\mathbf{f}$ em relação a $\rho_{i}$ é nula, uma vez que não estão sendo consideradas as forças de campo.

A derivada da matriz de rigidez em termos de $\rho_{i}$, para o caso de elemento em 
axissimétrico, é obtida de forma simples.

Partindo da matriz de rigidez $\mathbf{k}_{e}$ de $u$ m elemento, conforme apresentado no capítulo 5, dada por:

$$
\mathbf{k}_{e}=\iint_{z} \int_{r} r \mathbf{B}_{e}^{T} \mathbf{C}_{e}^{\mathbf{H}} \mathbf{B}_{e} d \theta d r d z=2 \pi \int_{z} \int_{r} r \mathbf{B}_{e}^{T} \mathbf{C}_{e}^{\mathbf{H}} \mathbf{B}_{e} d r d z
$$

Para se obter a derivada da matriz de rigidez do elemento, basta calcular a derivada de $\mathbf{C}_{e}^{\mathbf{H}}$ em relação a $\rho_{i}$, que é dada por 7.64 :

$$
\frac{d \mathbf{C}_{e}^{\mathbf{H}}}{d \rho_{i}}=\frac{\partial \rho^{q}}{\partial \rho_{i}} \mathbf{C}_{0}
$$

e então calcular:

$$
\frac{d \mathbf{k}_{e}}{d \rho_{i}}=2 \pi \int_{z} \int_{r} r \mathbf{B}_{e}^{T} \frac{d \mathbf{C}_{e}^{\mathbf{H}}}{d \rho_{i}} \mathbf{B}_{e} d r d z
$$

E para finalizar, deve-se montar a matriz de derivada da rigidez global.

No caso de elemento em EPT, basta fazer o mesmo procedimento, porém integrando apenas em função de $x$ e $y$.

Seguindo o cálculo das derivadas que envolvem a parte implícita da equação 6.47, será apresentada a seguir as derivadas envolvidas no problema adjunto 6.48, que estão em função dos deslocamentos d. Assim, os termos do vetor representado em 6.49 é dado por:

$$
\begin{aligned}
\frac{\partial G_{1}\left(\boldsymbol{\rho}^{0}\right)}{d d_{i}} & =\frac{1}{p}\left[\frac{1}{\Omega} \sum_{e \in A t v} \Omega_{e}\left(\sqrt{\mathbf{C}_{0}\langle\epsilon\rangle_{e}^{T} \mathbf{V C}_{0}\langle\epsilon\rangle_{e}} \frac{1}{\langle\boldsymbol{\sigma}\rangle_{y}^{e}}-\varepsilon(1-\rho)\right)^{p}\right]^{\frac{1-p}{p}} \\
& \cdot \frac{1}{\Omega} \sum_{e \in A t v}\left[\Omega_{e} p\left(\sqrt{\mathbf{C}_{0}\langle\epsilon\rangle_{e}^{T} \mathbf{V C}_{0}\langle\epsilon\rangle_{e}} \frac{1}{\langle\boldsymbol{\sigma}\rangle_{y}^{e}}-\varepsilon(1-\rho)\right)^{p-1}\right. \\
& \left.\cdot \frac{1}{\langle\boldsymbol{\sigma}\rangle_{y}^{e}} \frac{d \sqrt{\mathbf{C}_{0}\langle\epsilon\rangle_{e}^{T} \mathbf{V C}_{0}\langle\epsilon\rangle_{e}}}{d d_{i}}\right]
\end{aligned}
$$

onde:

$$
\frac{d \sqrt{\mathbf{C}_{0}\langle\epsilon\rangle_{e}^{T} \mathbf{V C}_{0}\langle\epsilon\rangle_{e}}}{d d_{i}}=\left[\frac{d \sqrt{\mathbf{C}_{0}\langle\epsilon\rangle_{e}^{T} \mathbf{V C}_{0}\langle\epsilon\rangle_{e}}}{d\langle\epsilon\rangle_{e}}\right]^{T}\left[\frac{d\langle\epsilon\rangle_{e}}{d d_{i}}\right]
$$

Observa-se que os termos à direita da equação 6.60 são vetores, sendo que o primeiro que representa derivada da tensão de von Mises em função da deformação 
é dado por:

$$
\frac{d \sqrt{\mathbf{C}_{0}\langle\epsilon\rangle_{e}^{T} \mathbf{V C}_{0}\langle\epsilon\rangle_{e}}}{d\langle\epsilon\rangle_{e}}=\left[\begin{array}{c}
\frac{d \sqrt{\mathbf{C}_{0}\langle\epsilon\rangle_{e}^{T} \mathbf{V} \mathbf{C}_{0}\langle\epsilon\rangle_{e}}}{d \epsilon_{r}} \\
\frac{d \sqrt{\mathbf{C}_{0}\langle\epsilon\rangle_{e}^{T} \mathbf{V} \mathbf{C}_{0}\langle\epsilon\rangle_{e}}}{d \epsilon_{\theta}} \\
\frac{d \sqrt{\mathbf{C}_{0}\langle\epsilon\rangle_{e}^{T} \mathbf{V C}_{0}\langle\epsilon\rangle_{e}}}{d \epsilon_{z}} \\
\frac{d \sqrt{\mathbf{C}_{0}\langle\epsilon\rangle_{e}^{T} \mathbf{V C}_{0}\langle\epsilon\rangle_{e}}}{d \epsilon_{r z}}
\end{array}\right]
$$

e considerando a aproximação para estruturas axissimétricas, onde o tensor constitutivo $\mathbf{C}_{0}$ é dado por 5.2 em função das propriedades $E_{0}$ e $\nu_{0}$, as componentes do vetor 6.61 são dadas por:

$$
\begin{gathered}
\frac{d \sqrt{\mathbf{C}_{0}\langle\epsilon\rangle_{e}^{T} \mathbf{V C}_{0}\langle\epsilon\rangle_{e}}}{d \epsilon_{r}}=\frac{1}{2} \frac{1}{\sqrt{\mathbf{C}_{0}\langle\epsilon\rangle_{e}^{T} \mathbf{V C}_{0}\langle\epsilon\rangle_{e}}}\left(-\epsilon_{\theta}+2 \epsilon_{r}-\epsilon_{z}\right) \frac{E_{0}^{2}}{\left(1-\nu_{0}^{2}\right)} \\
\frac{d \sqrt{\mathbf{C}_{0}\langle\epsilon\rangle_{e}^{T} \mathbf{V C}_{0}\langle\epsilon\rangle_{e}}}{d \epsilon_{\theta}}=\frac{1}{2} \frac{1}{\sqrt{\mathbf{C}_{0}\langle\epsilon\rangle_{e}^{T} \mathbf{V C}_{0}\langle\epsilon\rangle_{e}}}\left(-\epsilon_{z}-\epsilon_{r}+2 \epsilon_{\theta}\right) \frac{E_{0}^{2}}{\left(1-\nu_{0}^{2}\right)} \\
\frac{d \sqrt{\mathbf{C}_{0}\langle\epsilon\rangle_{e}^{T} \mathbf{V C}_{0}\langle\epsilon\rangle_{e}}}{d \epsilon_{z}}=\frac{1}{2} \frac{1}{\sqrt{\mathbf{C}_{0}\langle\epsilon\rangle_{e}^{T} \mathbf{V C}_{0}\langle\epsilon\rangle_{e}}}\left(-\epsilon_{\theta}-\epsilon_{r}+2 \epsilon_{z}\right) \frac{E_{0}^{2}}{\left(1-\nu_{0}^{2}\right)} \\
\frac{d \sqrt{\mathbf{C}_{0}\langle\epsilon\rangle_{e}^{T} \mathbf{V C}_{0}\langle\epsilon\rangle_{e}}}{d \epsilon_{r z}}=\frac{1}{2} \frac{1}{\sqrt{\mathbf{C}_{0}\langle\epsilon\rangle_{e}^{T} \mathbf{V} \mathbf{C}_{0}\langle\epsilon\rangle_{e}}}\left(\frac{3}{2} \epsilon_{r z}\right) \frac{E_{0}^{2}}{\left(1-\nu_{0}^{2}\right)}
\end{gathered}
$$

O segundo termo a direita da equação 6.60 representa a derivado do tensor de tensões em função do deslocamento, e este é representado por:

$$
\frac{d\langle\epsilon\rangle_{e}}{d d_{i}}=\mathbf{B}\left[\begin{array}{c}
\frac{d d}{d d_{1}}=0 \\
\vdots \\
\frac{d d}{d d_{i}}=1 \\
\vdots \\
\frac{d d}{d d_{8}}=0
\end{array}\right]
$$

sendo que $\mathbf{B}$ representa a matrix que relaciona os deslocamentos nodais com o campo de deformação no interior do elemento, e no caso da formulação do elemento finito utilizado neste trabalho esta é dada por 5.8.

As derivadas representadas na equação 6.60 aqui apresentadas, para o caso de elemento axissimétrico, através das equações 6.61, 6.62 , 6.63, 6.64, 6.65 e 
6.66 também foram implementadas para o caso dos elementos em EPT. Para manter o texto concisão esta derivadas são apresentadas adiante, na formulação com restrição local, através da equações $6.85,6.86,6.87,6.88$ e 6.89 .

Assim tem-se todos os termos necessários para o cálculo de sensibilidade do problema proposto na sua forma discreta dada por 6.35 .

De maneira similar ao problema "OT com restrição global de tensão", é necessário fazer a discretização do problema "OT com restrição local de tensão" 6.34, que na forma discretizada passa a ser dado por 6.67:

$$
\begin{aligned}
\underset{\rho}{\operatorname{minimizar}} \Gamma(\boldsymbol{\rho})= & \sum_{e=1}^{M} \int_{\Omega_{e}} \rho d \Omega_{e} \\
& +K_{q} \sum_{e=1}^{M} \int_{\Omega_{e}} \rho(1-\rho) \rho d \Omega_{e} \\
& +K_{r} \sum_{e=1}^{M} \int_{\Omega_{e}}\left(\frac{\partial \rho}{\partial x}\right)^{2}+\left(\frac{\partial \rho}{\partial y}\right)^{2} d \Omega_{e}
\end{aligned}
$$

tal que

$$
\begin{array}{ll}
g_{e}(\boldsymbol{\rho})=\rho\left(\frac{f_{v m}\left(\langle\boldsymbol{\sigma}\rangle_{e}\right)}{\rho^{q}} \frac{1}{\langle\boldsymbol{\sigma}\rangle_{y}}-1\right)-\varepsilon(1-\rho) \leq 0 & \text { para } e=1 \ldots M \\
0<\rho_{\min } \leq \rho_{i} \leq 1 & \text { para } i=1 \ldots N
\end{array}
$$

onde, assim como no problema 6.35, $M$ representa o número de elementos da malha, $\boldsymbol{\rho}$ representa o vetor de densidade nodais com $N$ componentes, $\rho$ representa o campo de contínuo densidades no interior do elemento, $\langle\boldsymbol{\sigma}\rangle_{e}$ representa a tensão de von Mises no centro do elemento $e$, e $\langle\boldsymbol{\sigma}\rangle_{y}$ representa a tensão de escoamento do material.

Seguindo a formulação do MLA apresentada ne seção 6.5.1 é possível escrever o problema 6.67 na forma:

$$
\begin{aligned}
\underset{\rho}{\operatorname{minimizar}} L(\boldsymbol{\rho}, \boldsymbol{\mu}, \mathbf{c})= & \Gamma(\boldsymbol{\rho}) \\
& +\sum_{e=1}^{M} \frac{1}{2 c_{e}}\left\{\left[\max \left\{0, \mu_{e}+c_{e} g_{e}(\rho)\right\}\right]^{2}-\mu_{e}^{2}\right\}
\end{aligned}
$$

tal que

$$
0<\rho_{\min } \leq \rho_{i} \leq 1
$$$$
\text { para } i=1 \ldots N
$$

onde $\boldsymbol{\mu}$ representa o vetor de multiplicadores de Lagrange e c representa o vetor de e penalização, ambos com $M$ componentes, cada uma associada as $M$ restrições. 
Para resolver o problema 6.68, através do MLA é necessário fazer a análise de sensibilidade da função objetivo que no caso é o prório Langrangeano aumentado.

Inicialmente apresentaremos o termos que compõem $\Gamma(\boldsymbol{\rho})$. Assim, para o caso de elementos em EPT tem se o volume dado por:

$$
V(\boldsymbol{\rho})=\sum_{e=1}^{M} \int_{\Omega_{e}} \rho d \Omega_{e}=\left.\sum_{e=1}^{M}\left(\int_{x} \int_{y}\left(\sum_{i=1}^{4} \rho_{i} N_{i}(s, t)\right)^{q} d x d y\right)\right|_{e}
$$

onde a integral é feita sobre cada elemento da malha de elementos finitos. Assim a derivada de $V$ em relação a $\rho_{i}$ é dada por:

$$
\frac{d V(\boldsymbol{\rho})}{d \rho_{i}}=\left.\sum_{e=1}^{M}\left(\int_{x} \int_{y}\left(\sum_{j=1}^{4} \rho_{j} N_{j}(s, t)\right)^{q-1} N_{i}(s, t) d x d y\right)\right|_{e}
$$

A derivada do termo de penalização das densidades intermediárias é $F_{q}(\boldsymbol{\rho})$ para o caso do elemento em EPT está apresentado na equação 6.42

Finalmente o termo de regularização é dado por:

$$
F_{r}(\boldsymbol{\rho})=K_{q} \sum_{e=1}^{M} \int_{\Omega_{e}}\left(\frac{\partial \rho}{\partial x}\right)^{2}+\left(\frac{\partial \rho}{\partial y}\right)^{2} d \Omega_{e}
$$

Escrevendo os gradientes do campo de densidades em relação as densidades nodais $\rho_{j}$. Tem-se:

$$
\begin{aligned}
& \frac{\partial \rho}{\partial x}=\sum_{j=1}^{4} \rho_{j} \frac{\partial N_{j}(s, t)}{\partial x} \\
& \frac{\partial \rho}{\partial y}=\sum_{j=1}^{4} \rho_{j} \frac{\partial N_{j}(s, t)}{\partial y}
\end{aligned}
$$

sendo que $\frac{\partial N_{j}(s, t)}{\partial x}$ e $\frac{\partial N_{j}(s, t)}{\partial y}$ são dados pela relação:

$$
\left[\begin{array}{c}
\frac{\partial N_{j}}{\partial x} \\
\frac{\partial N_{j}}{\partial y}
\end{array}\right]=\mathbf{J}^{-1}\left[\begin{array}{c}
\frac{\partial N_{j}}{\partial s} \\
\frac{\partial N_{j}}{\partial t}
\end{array}\right]
$$

onde $\mathbf{J}$ representa a matriz jacobiana dada por 5.13

Assim, a derivada da função 6.71 em função das densidades nodais é dada por:

$$
\frac{d F_{r}(\boldsymbol{\rho})}{d \rho_{i}}=K_{r} \sum_{e=1}^{M} \int_{x} \int_{y}\left[2\left(\frac{\partial \rho_{e}}{\partial x}\right) \frac{\partial N_{i}}{\partial x}+2\left(\frac{\partial \rho_{e}}{\partial y}\right) \frac{\partial N_{i}}{\partial y}\right] d x d y
$$


E logo tem-se a derivada de todos os termos de $\Gamma(\boldsymbol{\rho})$ em função da densidade nodal $\rho_{i}$.

Assim, pode-se partir para a derivada do segundo termo do Lagrangeano aumentado dado por:

$$
\Lambda(\boldsymbol{\rho})=\sum_{e=1}^{M} \frac{1}{2 c_{e}}\left\{\left[\max \left\{0, \mu_{e}+c_{e} g_{e}(\boldsymbol{\rho})\right\}\right]^{2}-\mu_{e}^{2}\right\}
$$

Escrevendo apenas os termo de $\Lambda(\boldsymbol{\rho})$ diferente de zero têm-se:

$$
\Lambda(\boldsymbol{\rho})=\sum_{e \in A t v} \frac{1}{2 c_{e}}\left\{\left[\mu_{e}+c_{e} g_{e}(\boldsymbol{\rho})\right]^{2}-\mu_{e}^{2}\right\}
$$

onde

$$
A t v=\left\{e=1, \ldots, M \mid \mu_{e}+c_{e} g_{e}(\boldsymbol{\rho})>0\right\}
$$

De forma similar a derivada da restrição em função da densidade $\left(\frac{\partial G_{1}\left(\boldsymbol{\rho}^{0}\right)}{\partial \rho_{i}}\right)$, para o caso da "OT com restrição global de tensão", o cálculo de da derivada de $\Lambda(\boldsymbol{\rho})$ em função da densidade $\left(\frac{\partial \Lambda(\boldsymbol{\rho})}{\partial \rho_{i}}\right)$ é feito através do método adjunto. Dessa forma, se tem:

$$
\frac{d \Lambda(\boldsymbol{\rho})}{d \rho_{i}}=\underbrace{\frac{\partial \Lambda(\boldsymbol{\rho})}{\partial \rho_{i}}}_{\text {Parte explícita }}+\underbrace{\boldsymbol{\lambda}^{T}\left(\frac{d \mathbf{f}}{d \rho_{i}}-\frac{d \mathbf{K}}{d \rho_{i}} \mathbf{d}\right)}_{\text {Parte implícita }}
$$

onde

$$
\mathbf{K} \boldsymbol{\lambda}^{T}=\frac{d \Lambda(\boldsymbol{\rho})}{d \mathbf{d}}
$$

e $\frac{d \Lambda(\boldsymbol{\rho})}{d \mathbf{d}}$ é dado de forma análoga a 6.49 .

Inicialmente, será apresento a sensibilidade da parte explícita da equação 6.78. Novamente, por motivo de simplicidade, o indíce de falha do material escrito será escrito como 6.50 e dado por:

$$
\frac{f_{v m}\left(\langle\boldsymbol{\sigma}\rangle_{e}\right)}{\rho^{q}}=\sqrt{\mathbf{C}_{0}\langle\epsilon\rangle_{e}^{T} \mathbf{V C}_{0}\langle\epsilon\rangle_{e}}
$$

Assim, a derivada da parte explícita da equação 6.78 é dada por:

$$
\frac{\partial \Lambda(\boldsymbol{\rho})}{\partial \rho_{i}}=\sum_{e \in A t v}\left\{\left[\mu_{e}+c_{e} g_{e}(\boldsymbol{\rho})\right] \frac{\partial g_{e}(\boldsymbol{\rho})}{\partial \rho_{i}}\right\}
$$

onde

$$
\frac{\partial g_{e}(\boldsymbol{\rho})}{\partial \rho_{i}}=\frac{\partial \rho^{q}}{\partial \rho_{i}}\left(\sqrt{\mathbf{C}_{0}\langle\epsilon\rangle_{e}^{T} \mathbf{V C}_{0}\langle\epsilon\rangle_{e}} \frac{1}{\langle\boldsymbol{\sigma}\rangle_{y}}-1\right)+\frac{\partial \rho^{q}}{\partial \rho_{i}} \varepsilon
$$

Novamente, vale lembrar que o campo de densidades volumétricas está sendo parametrizado com a formulação ACDM, conforme apresentado no capítulo 5, 
dessa forma a derivada campo de densidade em função da densidade nodal é dada por:

$$
\frac{\partial \rho^{q}}{\partial \rho_{i}}=q\left(\sum_{j=1}^{4} \rho_{j} N_{j}\right)^{q-1} N_{i}
$$

As derivadas que envolvem a parte implícita da equação 6.78 podem ser divididas em dois grupos, o grupo das derivadas em função da densidade nodal $\rho_{i}$ $\left(\frac{d \mathbf{f}}{d \rho_{i}}\right.$ e $\left.\frac{d \mathbf{K}}{d \rho_{i}}\right)$ e o grupo das derivadas em função dos deslocamentos $\mathbf{d}\left(\frac{d \Lambda(\boldsymbol{\rho})}{d \mathbf{d}}\right)$.

As derivadas do primeiro grupo são calculadas de maneira análoga ao problema com restrição global de tensão, porém levando em consideração que se trata de um elemento em EPT e que por não haver forças de campo, tem se $\frac{d \mathbf{f}}{d \rho_{i}}=\mathbf{0}$.

A derivada do segundo grupo $\frac{\partial \Lambda(\boldsymbol{\rho})}{d d_{i}}$ que representa um termo genérico do vetor $\frac{d \Lambda(\boldsymbol{\rho})}{d \mathbf{d}}$, (análogo ao vetor $\frac{\partial G_{1}(\boldsymbol{\rho})}{d d_{i}}$ apresentado em 6.49) é dada por:

$$
\frac{\partial \Lambda(\boldsymbol{\rho})}{d d_{i}}=\sum_{e \in A t v}\left\{\left[\mu_{e}+c_{e} g_{e}(\boldsymbol{\rho})\right] \rho \frac{d \sqrt{\mathbf{C}_{0}\langle\epsilon\rangle_{e}^{T} \mathbf{V C}_{0}\langle\epsilon\rangle_{e}}}{d d_{i}} \frac{1}{\langle\boldsymbol{\sigma}\rangle_{y}}\right\}
$$

onde:

$$
\frac{d \sqrt{\mathbf{C}_{0}\langle\epsilon\rangle_{e}^{T} \mathbf{V C}_{0}\langle\epsilon\rangle_{e}}}{d d_{i}}=\left[\frac{d \sqrt{\mathbf{C}_{0}\langle\epsilon\rangle_{e}^{T} \mathbf{V} \mathbf{C}_{0}\langle\epsilon\rangle_{e}}}{d\langle\epsilon\rangle_{e}}\right]^{T}\left[\frac{d\langle\epsilon\rangle_{e}}{d d_{i}}\right]
$$

Assim como no caso da restrição global de tensão, observa-ser que os termos à direita da equação 6.84 são vetores, sendo que o primeiro que representa derivada da tensão de von Mises em função da deformação é dado por:

$$
\frac{d \sqrt{\mathbf{C}_{0}\langle\epsilon\rangle_{e}^{T} \mathbf{V} \mathbf{C}_{0}\langle\epsilon\rangle_{e}}}{d\langle\epsilon\rangle_{e}}=\left[\begin{array}{c}
\frac{d \sqrt{\mathbf{C}_{0}\langle\epsilon\rangle_{e}^{T} \mathbf{V C}_{0}\langle\epsilon\rangle_{e}}}{d \epsilon_{x}} \\
\frac{d \sqrt{\mathbf{C}_{0}\langle\epsilon\rangle_{e}^{T} \mathbf{V} \mathbf{C}_{0}\langle\epsilon\rangle_{e}}}{d \epsilon_{y}} \\
\frac{d \sqrt{\mathbf{C}_{0}\langle\epsilon\rangle_{e}^{T} \mathbf{V} \mathbf{C}_{0}\langle\epsilon\rangle_{e}}}{d \epsilon_{x y}}
\end{array}\right]
$$

e considerando a formulação elementos em EPT, onde o tensor constitutivo $\mathbf{C}_{0}$ é dado por 5.5 em função das propriedades $E_{0}$ e $\nu_{0}$, as componentes do vetor 6.85 são dadas por:

$$
\begin{aligned}
\frac{d \sqrt{\mathbf{C}_{0}\langle\epsilon\rangle_{e}^{T} \mathbf{V C}_{0}\langle\epsilon\rangle_{e}}}{d \epsilon_{x}}= & \frac{1}{2} \frac{1}{\sqrt{\mathbf{C}_{0}\langle\epsilon\rangle_{e}^{T} \mathbf{V C}_{0}\langle\epsilon\rangle_{e}}} \\
& \cdot\left[\left(-4+16 \nu-4 \nu^{2}\right) \epsilon_{y}+\left(8-8 \nu+8 \nu^{2}\right) \epsilon_{x}\right]\left(\frac{E_{0}}{\left(1-\nu_{0}^{2}\right)}\right)^{2}
\end{aligned}
$$




$$
\begin{gathered}
\frac{d \sqrt{\mathbf{C}_{0}\langle\epsilon\rangle_{e}^{T} \mathbf{V C}_{0}\langle\epsilon\rangle_{e}}}{d \epsilon_{y}}=\frac{1}{2} \frac{1}{\sqrt{\mathbf{C}_{0}\langle\epsilon\rangle_{e}^{T} \mathbf{V C}_{0}\langle\epsilon\rangle_{e}}} \\
\cdot\left(-4+16 \nu-4 \nu^{2}\right) \epsilon_{x}+\left(8-8 \nu+8 \nu^{2}\right) \epsilon_{y}\left(\frac{E_{0}}{\left(1-\nu_{0}^{2}\right)}\right)^{2} \\
\frac{d \sqrt{\mathbf{C}_{0}\langle\epsilon\rangle_{e}^{T} \mathbf{V C}_{0}\langle\epsilon\rangle_{e}}}{d \epsilon_{x y}}=\frac{1}{2} \frac{1}{\sqrt{\mathbf{C}_{0}\langle\epsilon\rangle_{e}^{T} \mathbf{V C}_{0}\langle\epsilon\rangle_{e}}} \\
\cdot\left(6-12 \nu+6 \nu^{2}\right) \epsilon_{x y}\left(\frac{E_{0}}{\left(1-\nu_{0}^{2}\right)}\right)^{2}
\end{gathered}
$$

O segundo termo a direita da equação 6.84 representa a derivado do tensor de tensões em função do deslocamento, e este é representado por:

$$
\frac{d\langle\epsilon\rangle_{e}}{d d_{i}}=\mathbf{B}\left[\begin{array}{c}
\frac{d d}{d d_{1}}=0 \\
\vdots \\
\frac{d d}{d d_{i}}=1 \\
\vdots \\
\frac{d d}{d d_{8}}=0
\end{array}\right]
$$

sendo que $\mathbf{B}$ representa a matrix que relaciona os deslocamentos nodais com o campo de deformação no interior do elemento, e no caso da formulação do elemento finito em EPT, esta é dada por 5.9.

Assim, tem-se todos os termos necessários para o cálculo de sensibilidade do problema "OT com restrição local de tensão" proposto na sua forma discreta dada por 6.68 


\section{Otimização da distribuição de material em estruturas com gradação funcional}

\subsection{Introdução}

Os Materiais com Gradação Funcional (MsGF), são materiais cujas propriedades variam gradualmente com a posição. Conforme apresentado na subseção 4.3.1, estes materiais possuem um gradiente de propriedades devido à variação contínua da microestrutura, da composição química, ou da organização atômica do material (KIEBACK; NEUBRAND; RIEDEL, 2003).

Segundo Koizumi (1997) o conceito de MsGF foi proposto em 1984 por pesquisadores japoneses com o intuito de fabricar materiais para barreiras térmicas. Desde então, o desenvolvimento dos métodos de fabricação e aplicação dos MsGF tem sido foco de diversos grupos de pesquisa ao redor do mundo.

Pode-se observar a importância dada ao desenvolvimento dessa classe de materiais pelas edições especiais da revista Composites Part B: Engineering editada por Pindera et al. (1997) e da revista Journal of the Mechanics and Physics of Solids editada por Suresh e Needleman (1996), que visam mostrar um panorama do desenvolvimento dos Materiais com Gradação Funcional.

Os processos de fabricação dos MsGF têm em geral duas etapas: uma primeira etapa, de construção do gradiente espacial e a segunda, de consolidação dessa estrutura com gradiente (KIEBACK; NEUBRAND; RIEDEL, 2003).

Os processos de construção do gradiente podem ser classificados em: constitutivos, por homogeneização e por segregação. Os processos constitutivos constroem a estrutura com gradiente de maneira descontínua, passo-a-passo, criando camadas com propriedades diferentes a partir de materiais base ou materiais granulados. Os processos de fabricação por homogeneização ${ }^{1}$ criam o gradiente

\footnotetext{
${ }^{1}$ Homogeneização, aqui faz referência a um processo de fabricação, à diferença do seu signi-
} 
a partir do transporte de material entre duas regiões que, inicialmente, possuem uma interface bem definida. Já os processos por segregação produzem o gradiente a partir de um material composto homogêneo que é submetido a campos externos, como por exemplo, o campo elétrico ou gravitacional (KIEBACK; NEUBRAND; RIEDEL, 2003).

Os processo de consolidação do material que seguem o processo de construção do gradiente são, em geral: a secagem, a sinterização ou a solidificação. Estes devem ser adaptados para a fabricação dos MsGF, de modo a não destruir o gradiente previamente construído. Os principais processos de fabricação dos MsGF se baseiam na metalurgia do pó e na fundição controlada (KIEBACK; NEUBRAND; RIEDEL, 2003).

Diversos pesquisadores trabalham sobre o desenvolvimento de métodos de fabricação para Materiais com Gradação Funcional e uma revisão destes processo pode ser encontrada em Kieback, Neubrand e Riedel (2003) e Mortensen e Suresh (1995).

Quanto à aplicação dos MsGF, se destacam alguns campos. Inicialmente deve-se citar a utilização destes materiais como barreiras térmicas, como na sua proposta inicial. Uma apresentação desta classe de aplicação pode ser encontrada em Lee et al. (1996).

Outro campo de aplicação dos MsGF é a bio-engenharia, como o desenvolvimento de próteses odontológicas (HEDIA, 2005). Uma apresentação das vantagens e aplicações dos Materiais com Gradação Funcional em bioengenharia pode ser encontrada em Pompe et al. (2003).

A grande vantagem dos MsGF é a possibilidade de projetar e fabricar o gradiente de propriedades de forma a melhor atender as necessidades de projeto. Assim, desenvolveram-se estudos sobre como o gradiente do material influencia o desempenho do sistema. Ravichandran (1995) faz um estudo da tensão térmica residual em função do gradiente de propriedade, tensão esta que ocorre devido à diferença dos coeficientes de expansão térmica dos materiais. Cho e Oden (2000) apresentam um estudo paramétrico do perfil de propriedades em uma placa sujeita a um carregamento térmico.

O passo seguinte no projeto de revestimentos ou estruturas fabricadas com MsGF é a aplicação de métodos de otimização. A seguir será apresentada uma revisão bibliográfica deste tópico.

ficado no capítulo 4, em que dá nome a um método matemático 


\subsection{Revisão bibliográfica sobre o projeto otimi- zado de estruturas com gradação funcional}

Com a possibilidade de se projetar e fabricar estruturas utilizando os Materiais com Gradação Funcional, o passo seguinte à análise, no que diz respeito ao desenvolvimento dessas estruturas, é a aplicação de métodos de otimização.

Um dos primeiros trabalhos a aplicar métodos de otimização no projeto de estruturas com gradação de funcional é o de Markworth e Saunders (1995). Os autores fazem a otimização de um gradiente unidimensional de propriedades com o objetivo de maximizar ou minimizar o fluxo de calor na estrutura. Neste trabalho, por se tratar de um problema uni-dimensional, a fração volumétrica das fases do material é parametrizada por uma função quadrática e, neste caso, os coeficientes da função passam a ser as variáveis de projeto.

Nesta mesma linha, Tanaka et al. (1996) apresentam a otimização do perfil de propriedades da parede de um cilindro sujeito a uma diferença de temperatura entre as faces externa e interna. O objetivo deste trabalho é obter um dado perfil de tensões previamente definido. De maneira similar ao trabalho de Markworth e Saunders (1995), aqui os autores também utilizam uma função que parametriza a fração volumétrica dos materiais que compõem o MGF.

Tratando também de problemas unidimensionais, Tanigawa e Matsumoto (1997) apresentam a otimização de uma placa com gradiente de propriedades na espessura, cujo objetivo é minimizar a máxima tensão mecânica durante a fase transiente de um carregamento térmico.

Continuando a tratar problemas unidimensionais, Aboudi, Pindera e Arnold (1997) fazem a minimização de uma função integral da tensão mecânica. Para parametrizar o problema os autores utilizam um modelo de material de altaordem (ABOUDI; PINDERA; ARNOLD, 1999), apresentado brevemente na subseção 4.3.1, e adotam como variável de projeto a distância entre as inclusões de material heterogêneo na matriz.

Ootao et al. (1999) propõem o uso de redes neurais para a modelagem do campo de temperatura e tensão de uma esfera oca sujeita a carregamentos térmicos. Para tratar o problema de otimização, os autores utilizam as redes neurais para definir, na parede da esfera, a distribuição de propriedades que minimiza a máxima tensão mecânica para um dado carregamento térmico transiente. Devido à simetria radial do problema, este também se reduz a um problema uni-dimensional, e a distribuição de densidade volumétrica passa a ser parametrizada por uma 
função com apenas um parâmetro, que é tratado como variável de projeto

Um tratamento mais genérico para o problema de controle de tensão em Materiais com Gradação Funcional sujeito a carregamentos térmicos foi apresentado por Cho e Ha (2002) e também por Turteltaub (2001, 2002), de modo independente. Estes trabalhos têm como principal característica não fazer nenhuma definição a priori sobre a distribuição espacial das propriedades, diferentemente dos demais anteriormente citados que utilizam funções pré-definidas para representar a distribuição de propriedades.

Cho e Ha (2002) apresentam a otimização da distribuição de propriedades para a minimização da máxima tensão mecânica devido a carregamentos térmicos estáticos. Para isto os autores utilizam conceitos similares aos do Método de Otimização Topológica. A distribuição de material é então parametrizada pela fração volumétrica definida sobre cada nó de uma malha composta de superelementos, e, associada a esta malha, existe uma malha de elementos finitos mais discretizada, com a qual se calcula os campos de tensão e temperatura do problema. Mais adiante, na seção 7.3, inclui-se a Figura 7.1 que representa esta situação, juntamente com uma discussão sobre as formas de parametrização da distribuição de material .

Desse modo, o campo de densidades volumétricas é interpolado por funções bilineares e as propriedades do material, decorrentes da densidade volumétricas são transferidas para a malha de elementos finitos utilizada para análise, nos pontos de Gauss da integração numérica. A otimização é feita através de métodos de penalização interior e o cálculo de sensibilidade das funções envolvidas é feito através do Método das Diferenças Finitas.

Um ponto importante de comparação do trabalho de Cho e Ha (2002), em relação à implementação desenvolvida nesta dissertação é que os autores consideram apenas a tensão na macro-escala $\langle\boldsymbol{\sigma}\rangle$ seguindo a notação do capítulo 2 , enquanto neste trabalho são consideradas as tensões na microestrutura.

A partir de Cho e Ha (2002), o primeiro autor desenvolve uma linha de trabalhos, nos quais aprimoramentos e alterações sobre a implementação básica são realizadas.

Em um trabalho seguinte, Cho e Park (2003) utilizam uma função multiobjetivo composta por uma combinação linear da máxima tensão mecânica e da energia de deformação da estrutura, que corresponde a duas vezes a flexibilidade definida no problema de Otimização Topológica (OT) do capítulo 2. Cho e Park 
(2003) utilizam também um esquema de refino h-adaptativo na malha que representa o campo de fração volumétrica. Os autores justificam a aplicação deste refinamento da malha como uma forma de se obter maior flexibilidade do campo de propriedades, sem que se aumente demasiadamente o número de variáveis. Esta solução é necessária, apenas quando se utiliza a o Método das Diferenças Finitas para calcular a sensibilidade do problema, como é o caso de Cho e Park (2003), pois neste caso o número de variáveis de projeto é crítico quanto ao tempo computacional.

Com o intuito de melhorar a eficiência deste método em relação ao tempo computacional, Cho e Shin (2004) utilizam redes neurais para realizar a simulação do problema de forma mais rápida e, assim, permitir o uso de um maior número de variáveis de projeto.

Cho e Choi (2004) apresentam sobre a mesma estrutura de Cho e Ha (2002) uma nova função objetivo, dada pela razão da máxima tensão mecânica da estrutura e a tensão de escoamento do material no ponto onde esta tensão ocorre. Assim, a tensão é calculada sobre a macro-escala $(\langle\boldsymbol{\sigma}\rangle)$ e a tensão de escoamento $\left(\langle\boldsymbol{\sigma}\rangle_{y}\right)$ é dada pela média das tensões de escoamento de cada material ponderada pela densidade volumétrica de cada material.

Dessa forma, a tensão na microestrutura está sendo indiretamente tratada, pois a tensão de escoamento, analisada em função da tensão na macro-escala, dependerá dos materiais e da geometria da microestrutura. Apesar de que neste trabalho Cho e Choi (2004) utilizam uma interpolação linear que tem apenas como justificativa física que a tensão de escoamento de um material composto deve estar entre a tensão de escoamento dos dois materiais que o constituem, porém, é sabido que a tensão de escoamento, ou qualquer outro critério de falha, é influenciado por características geométricas da microestrutura (TORQUATO, 2000).

Em contrapartida aos trabalhos de Cho, anteriormente citados, Turteltaub (2001, 2002) trata o problema de distribuição ótima de Material com Gradação Funcional em problemas termo-elásticos baseando-se na teoria do Método de Otimização Topológica.

Em Turteltaub (2001) é apresentado um método, baseado na teoria de OT, capaz de definir o campo de propriedades necessário para se obter uma dada distribuição de temperatura, ao final de um intervalo de tempo, para uma placa sujeita a carregamentos térmicos. Neste trabalho é simulado apenas o campo térmico e não o campo termo-elástico acoplado, como a maiorias dos trabalhos 
(MARKWORTH; SAUNDERS, 1995; TANAKA et al., 1996; TANIGAWA; MATSUMOTO, 1997; OOTAO et al., 1999; CHO; HA, 2002).

Turteltaub (2002) faz um expansão e generalização de seu trabalho anterior considerando um problema termo-elástico transiente. É utilizada uma função multi-objetivo do erro quadrático dos campos de tensão e temperatura em relação a campos pré-definidos das mesmas grandezas. Então se utilizam coeficientes para ponderar o controle do campo de tensões e do campo de temperaturas.

Ainda tratando de problemas termo-elásticos, outros autores contribuíram para o desenvolvimento do tema, como Nadeau e Ferrari (1999), que apresentam a otimização de uma barreira de resistência térmica, onde as variáveis de projeto são os parâmetros da microestrutura composta de inclusões esféricas em uma matriz elástica. Boussaa (2000) apresenta a otimização de um tubo metálico com revestimento cerâmico e uma camada intermediária com gradiente de microestrutura que varia entre metal e cerâmica. Neste trabalho o autor determina o perfil de propriedades da camada intermediária de modo a minimizar a tensão mecânica nesta camada. Parashkevova, Ivanova e Bontcheva (2004) apresentam a minimização da tensão mecânica em uma placa com gradiente de propriedades, sujeita a carregamentos térmicos, considerando efeitos termo-elásticos e plásticos. Chen e Tong (2005) apresentam uma fundamentação teórica para a análise de sensibilidade de problemas termo-elásticos considerando o acoplamento entre os campos. Os autores apresentam também um problema de otimização considerando como variáveis de projeto os valores nodais das propriedades dos elementos isoparamétricos com gradiente proposto por Kim e Paulino (2002). Uma descrição destas formulação de elemento será feita adiante na seção 7.3.

Uma outra linha de projeto e otimização de estruturas compostas por MsGF trata de problemas apenas mecânicos, sem considerar os problemas da termo elasticidade. Assim, como o trabalho desenvolvido nesta dissertação que trata dos problemas envolvendo apenas campos mecânicos decorrentes da aplicação de forças externas e de campo.

Dentre esses, destacam-se Turteltaub e Washabaugh (1999), que apresentam a formulação clássica do MOT de minimização da flexibilidade para a distribuição de dois materiais em uma estrutura sujeita a forças de campo dependentes da densidade. Huang et al. (2002) apresentam a otimização de um volante (roda de inércia) considerando duas funções objetivo: minimizar a tensão máxima e maximizar a energia cinética armazenada no volante. Para tratar esta otimização multi-objetivo, os autores utilizam o Método de Tchebycheff de Ponderação para 
encontrar o conjunto ótimo de Pareto. Huang et al. (2003) apresentam a otimização da variação do módulo de Young ao redor de um furo em uma placa a fim de minimizar a máxima tensão mecânica. Já Turteltaub (2005) apresenta a otimização da distribuição de material em uma estrutura sujeita a carregamentos mecânicos dinâmicos, a fim de minimizar a energia de deformação da estrutura, integrada no tempo. Silva e Paulino (2005) apresentam a aplicação da base teórica do Método de Otimização Topológica para realizar distribuição de propriedades de uma estrutura com gradação de funcional, a fim de minimizar a sua flexibilidade.

No trabalho de Lipton (2002), a base teórica do Método de Otimização Topológica foi aplicada em particular ao projeto otimizado de estruturas constituídas por Materiais com Gradação Funcional, considerando restrição de tensão. Neste trabalho, o autor propõe a maximização da rigidez torsional, considerando como restrição um índice global da tensão mecânica na seção transversal de uma barra. Um ponto importante neste trabalho é que o autor considera a tensão na microestrutura através dos corretores de tensão apresentados na seção 4.4, que, em seu trabalho, são chamados de tensores de covariância. Apesar de se basear no MOT, o autor não considera o fenômeno das topologias singulares apresentado na seção 6.3, explicitando este fato no texto. Entretanto, este fenômeno não deve ocorrer pois a fração de volume das inclusões pode variar apenas entre 0 e 0,5. Assim, quando a densidade tende a 0 , o tensor de covariância também tende a zero de modo que a tensão passa a ser igual à tensão na matriz homogênea, e, conseqüentemente, não ocorre o fenômeno da tensão limitante descrito em Cheng e Jiang (1992), Duysinx e Bendsøe (1998) que causa o fenômeno das topologias singulares.

\subsection{Modelagem numérica de estruturas constituídas por Materiais com Gradação Funcional}

Antes de se aplicar os métodos de otimização para o projeto de estruturas constituídas por Materiais com Gradação Funcional (MsGF), é necessário fazer algumas escolhas quanto à modelagem numérica destas estruturas.

Neste caso, dois pontos importantes devem ser definidos: a escolha do modelo de material e a forma de representação do campo de densidades volumétricas.

Quanto ao modelo de material, existem diversas opções para a modelagem de materiais compostos e algumas opções para a modelagem de MsGF. Na literatura 
de otimização apresentada na seção anterior (7.2), os trabalhos descritos utilizam várias abordagens para relacionar o campo de densidades volumétricas com as propriedades efetivas. A seguir são apresentados os modelos de material utilizados em cada trabalho.

Markworth e Saunders (1995) utilizam o modelo de Voigt. Tanigawa e Matsumoto (1997) e Ootao et al. (1999) utilizam o modelo de material proposto por Kerner (1956). Nadeau e Ferrari (1999) utilizam o modelo de Mori-Tanaka para o cálculo das propriedades elásticas efetivas, o modelo de Hatta-Taya (HATTA; TAYA, 1985) para a condutividade térmica efetiva e o modelo de Rosen-Hashin (ROSEN; HASHIN, 1970) para o coeficiente efetivo de expansão térmica. Boussaa (2000) utiliza o modelo Auto-Consistente e Huang et al. (2003) utilizam um modelo de material similar ao SIMP.

Os trabalhos de Lipton (2002) e Huang et al. (2002) utilizam uma microestrutura pré-definida seguida da utilização do método de homogeneização ou métodos similares. Os trabalhos de Turteltaub $(2002,2005)$ utilizam uma interpolação dos limites superiores e inferiores de Hashin-Shtrikman.

Os trabalho de Cho e seu co-autores (CHO; HA, 2002; CHO; PARK, 2003; CHO; CHOI, 2004; CHO; SHIN, 2004) utilizam a lei de mistura modificada, apresentada em Suresh e Mortensen (1997), para a estimativa do módulo de Young e o modelo de Schapery (SCHAPERY, 1968) para a estimativa do coeficiente efetivo de expansão térmica.

Já Chen e Tong (2005) utilizam o modelo de Voigt e o modelo de WakashimaTsukamoto (WAKASHIMA; TSUKAMOTO, 1991) apresentado também em Cho e Oden (2000). Neste trabalho Chen e Tong (2005) atentam para o fato de que os diferentes modelos de material alteram a sensibilidade do problema e conseqüentemente, podem alterar a solução obtida pelo método de otimização. Fazendo um paralelo com o MOT, no que diz respeito à solução, a escolha do modelo de material é similar à escolha da penalização $q$ no modelo SIMP, que também pode alterar a solução obtida.

Dentre os artigos acima citados, observa-se que todos utilizam modelos de material tradicionais desenvolvidos inicialmente para materiais compostos. $\mathrm{O}$ trabalho de Aboudi, Pindera e Arnold (1997) é o único que apresenta a associação de métodos de otimização ao uso de um modelo de material de alta-ordem desenvolvido especificamente para um MGF. O trabalho de Tanaka et al. (1996), apesar de utilizar o modelo tradicional de Mori-Tanaka, restringe o mesmo apenas para densidades volumétricas $\rho$ nos intervalos $0 \leq \rho \leq 0,3$ e $0,7 \leq \rho \leq 1$, sendo 
que no primeiro intervalo o material mais rígido é considerado como inclusão e no segundo intervalo este material passa a ser matriz. Entre estes dois intervalos, $(0,3<\rho<0,7)$ é utilizada a interpolação, através de inferência Fuzzy, entre as curvas válidas nos intervalos superiores e inferiores. A curva obtida através desta interpolação é qualitativamente similar a curva do modelo proposto por Reiter e Dvorak (1998), que consideram o modelo de Mori-Tanaka nas regiões onde é possível definir claramente a inclusão e a matriz, e o modelo Auto-consistente na região de transição.

Diferentemente das abordagens acima descritas, em alguns casos pode-se trabalhar diretamente com a distribuição das propriedades efetivas na estrutura, Isto ocorre, de maneira indireta, quando se utiliza o modelo de material SIMP parametrizando apenas o módulo de Young do material, como é o caso proposto no trabalho de Silva e Paulino (2005). Neste caso, o parâmetro $\rho$ não precisa ser interpretado como uma densidade volumétrica, mas apenas como uma parametrização artificial do problema. Assim, é obtida uma distribuição ótima da propriedade efetiva, que no caso Silva e Paulino (2005) é o módulo de Young. Posteriormente, pode ser utilizado um modelo de material adequado, porém de forma inversa, para se obter a densidade volumétrica a partir do módulo de Young. Outra abordagem seria a utilização de métodos de projeto de material, nos quais se utiliza o MOT a fim de definir a geometria da microestrutura formada por dois materiais, que tenha a propriedade efetiva desejada (SIGMUND, 1994; SILVA; FONSECA; KIKUCHI, 1998)

Entretanto, esta abordagem só pode ser utilizada quando se está interessado em determinar a distribuição de apenas uma das propriedades efetivas do material e as demais propriedades não influenciam o problema. Isto ocorre pois as propriedades efetivas estão relacionadas e a determinação de uma microestrutura real, que garanta um conjunto de propriedades, pode não ser factível. Por exemplo, não é possível projetar um material com alta rigidez e com densidade próxima de zero. O mesmo pode ocorrer entre as propriedades elásticas e térmicas do material. Portanto, para acoplar todas as propriedades efetivas do material é necessário se utilizar um ou mais modelos de material, de forma que as premissas quanto a geometria da microestrutura sejam as mesmas.

Como já afirmado, outro ponto a ser definido é a respresentação do campo de densidades. Os trabalhos que tratam de problemas unidimensionais (MARKWORTH; SAUNDERS, 1995; TANAKA et al., 1996; TANIGAWA; MATSUMOTO, 1997; OOTAO et al., 1999) utilizam funções parametrizadas para representar estas distribuições, assim é possível escolher funções contínuas e suficientemente suaves. 
Aqui se observa a vinculação entre a forma de se parametrizar a distribuição do campo de densidades volumétricas e a escolha do modelo de material, pois, de um modo geral, deixam de ser válidos quando se tem uma transição rápida da microestrutura em função do espaço, ou quando as inclusões têm tamanho característico da mesma ordem de grandeza que o gradiente da propriedades (TORQUATO, 1998; ABOUDI; PINDERA; ARNOLD, 1999), conforme discutido na subseção 4.3.1. Assim, no caso das funções unidimensionais, é possível selecionar funções que sejam contínuas, o que é uma característica do campo de densidades volumétricas, e suficientemente suaves, para que o modelo de material adotado continue válido.

Entretanto, esta abordagem de utilização de uma única função para parametrizar o campo de densidades não é eficiente para o caso de problemas bi ou tri-dimensionais. Assim, os trabalhos de Cho e Ha (2002), Cho e Park (2003), Cho e Choi (2004), Cho e Shin (2004) utilizam super-elementos que parametrizam o campo de densidades através de funções bi-lineares, da mesma forma que o campo de deslocamentos é interpolado no interior do elemento finito isoparamétrico utilizado na análise. Uma representação esquemática dessa forma de parametrização do campo de densidades está apresentada na Figura 7.1.

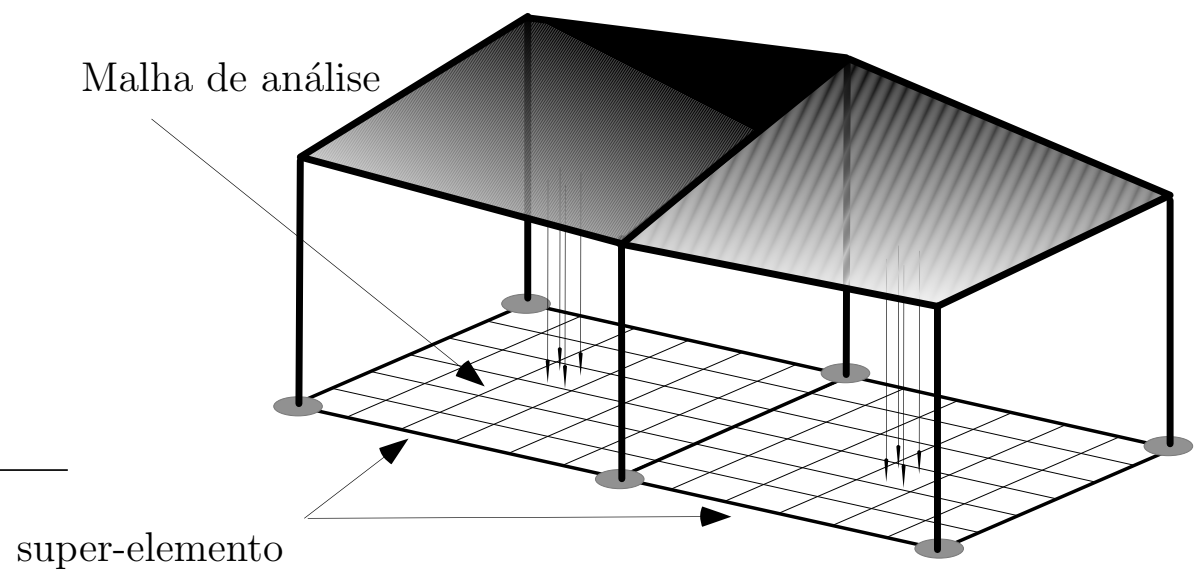

Figura 7.1: Representação esquemática da parametrização da distribuição de densidade volumétrica proposta por Cho e Ha (2002)

Observa-se na Figura 7.1 que os valores de densidades volumétricas e conseqüentemente as propriedades efetivas do material, são transferidas para a malha de elementos finitos nos pontos de Gauss de cada elemento da malha mais discretizada.

Esta forma de parametrização proposta por Cho e Ha (2002) é similar a formulação de elemento isoparamétrico com gradiente, proposta por Kim e Paulino (2002), desenvolvida para a análise de estruturas com gradiente de propriedades. 
O elemento isoparamétrico com gradiente foi utilizado para parametrizar o campo de densidades por Chen e Tong (2005) e Silva e Paulino (2005), e por Turteltaub (2002, 2005) que, apesar de não citar o trabalho de Kim e Paulino (2002), utiliza a mesma idéia.

A formulação do elemento isoparamétrico com gradiente considera que a distribuição de propriedades no interior do elemento é controlada através de valores nodais que são interpolados pelas mesmas funções de forma utilizadas no MEF. Assim, o campo de densidades volumétricas $\rho$ fica dado por:

$$
\rho=\sum_{i=1}^{4} \rho_{i} N_{i}
$$

onde $N_{i}$ representa um conjunto de funções forma tal que $0<\rho \leq 1$. Uma descrição completa da interpolação da densidade volumétrica empregada neste trabalho será feita adiante na seção 7.4.1.

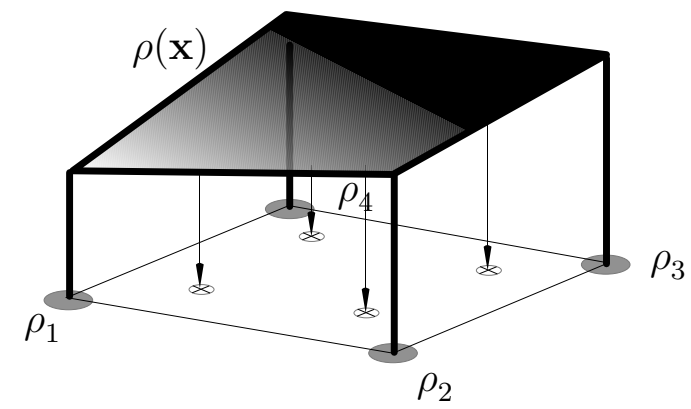

- Representação dos nós do elemento

Representação dos pontos de integração de Gauss

Figura 7.2: Representação esquemática da interpolação das grandezas definidas nos nós do elementos e transferidas para a formulação do elemento através do pontos de Gauss. (KIM; PAULINO, 2002)

Uma representação esquemática do elemento isoparamétrico com gradiente está apresentada na Figura 7.2, onde se observa as variáveis de controle nodais $\rho_{i}$ que parametrizam o campo de densidades volumétricas, e os pontos de Gauss que recebem o valor da densidade sobre os mesmos. O trabalho de Kim e Paulino (2002) demonstra que a utilização do elemento com gradiente minimiza a descontinuidade da tensão entre cada elemento da malha. Aqui vale notar que os elementos isoparamétricos com gradiente não garantem a continuidade do campo de tensões, pois uma característica do MEF baseado nos deslocamentos é que a derivada do campo de deslocamentos é descontínua. 


\subsection{Formulação proposta}

Nesta seção será apresentada a formulação proposta neste trabalho para se fazer a otimização da distribuição de material em estruturas constituída por materiais com gradação de funcional. Inicialmente, na subseção 7.4.1, será feita uma descrição do modelo de material adotado e da forma com que o campo de densidades é parametrizado. Na seção seguinte (7.4.2), será apresentado o problema de otimização em si, junto com uma discussão das decisões realizadas.

\subsubsection{Modelo de material e parametrização do campo de densidades volumétricas}

Neste trabalho optou-se por utilizar um modelo de material genérico, de modo a ter uma maior flexibilidade quanto às possíveis microestruturas representadas por este modelo. Dessa forma, foram utilizadas interpolações dos limites superior e inferior de Hashin-Shtrikman (H-S) apresentados na subseção 4.3.2. Assim, têm-se as propriedades efetivas do material dadas por:

$$
\begin{aligned}
& K^{H}(\rho)=\phi(\rho) K_{\max }(\rho)+(1-\phi(\rho)) K_{\min }(\rho) \\
& G^{H}(\rho)=\phi(\rho) G_{\max }(\rho)+(1-\phi(\rho)) G_{\min }(\rho)
\end{aligned}
$$

onde $K_{\max }, K_{\min }, G_{\max }$, e $G_{\min }$ são dados pelas equações $4.23,4.24,4.25$ e 4.26, respectivamente, a função $\phi(\rho)$ é responsável pela interpolação entre os limites superior e inferior do módulo de compressibilidade e de cisalhamento. A interpolação $\phi(\rho)$ fornece a flexibilidade desejada para o modelo de material, de modo que este possa se aproximar a outros modelos de material.

Observe que os valores de $K_{\max }, K_{\min }, G_{\max }$, e $G_{\min }$ são dados a partir das propriedades dos dois materiais base que constituem o MGF, aqui será considerado um material mais $(+)$ com propriedades $K^{+}, G^{+}, \varrho^{+}$e $\sigma_{y}^{+}$e um material menos (-) com propriedades $K^{-}, G^{-}, \varrho^{-}$e $\sigma_{y}^{-}$. Sendo que os módulos de compressibilidade e cisalhamento atendem a relação $K^{+}>K^{-}$e $G^{+}>G^{-}$, já a tensão de escoamento $\left(\sigma_{y}^{+}\right.$e $\left.\sigma_{y}^{-}\right)$e as densidades $\left(\varrho^{+}\right.$e $\left.\varrho^{-}\right)$de cada material não precisam atender a nenhuma relação.

A partir das equações 7.2 e 7.3 é possível escrever o módulo de Young e o coeficiente de Poisson do material, como 7.4 e 7.5, respectivamente:

$$
E^{H}(\rho)=\frac{9 K^{H}(\rho)}{1+3 \frac{K^{H}(\rho)}{G^{H}(\rho)}}
$$




$$
\nu^{H}(\rho)=\frac{1-2 / 3 \frac{G^{H}(\rho)}{K^{H}(\rho)}}{2+2 / 3 \frac{G^{H}(\rho)}{K^{H}(\rho)}}
$$

É importante ressaltar que, ao se utilizar uma interpolação dos limites de Hashin-Shtrikman (H-S) é garantida a existência de uma microestrutura real composta pelos dois materiais pré-selecionados que possui as propriedades efetivas previstas. Entretanto, isto só será válido para os Materiais com Gradação Funcional se o campo de densidade volumétrica variar de maneira suficientemente suave para que os limites de H-S continuem válidos, conforme discutido na subseção 4.3.2.

A definição de quão suave deve ser o campo de densidades volumétricas, deve ser feita com base nos materiais e processos de fabricação escolhidos para a construção da estrutura com gradiente.

Neste trabalho são propostas duas abordagens para a definição da função de interpolação $\phi(\rho)$. A primeira e mais simples é de considerar $\phi(\rho)$ constante. Assim temos:

$$
\phi(\rho)=\kappa
$$

onde

$$
\kappa \in\left[\begin{array}{ll}
0 & 1
\end{array}\right]
$$

Esta abordagem é utilizada por Turteltaub (2002, 2005).

A segunda abordagem foi inspirada nos trabalhos de Tanaka et al. (1996) e Reiter e Dvorak (1998), e considera uma função de interpolação que aproxima as propriedades efetivas do material ao limite inferior de Hashin-Shtrikman (HS), para densidades volumétricas baixas, e ao limite superior, para densidades volumétricas altas, além de fazer uma transição suave entre os dois intervalos. Com este objetivo foi escolhida a função dada por 7.4.1:

$$
\varphi(\rho)=\frac{\cos (\pi \rho)}{2}+\frac{1}{2}
$$

que é usada de forma recursiva, de modo a se obter a transição desejada. Assim, neste trabalho, foi utilizada a função 7.9:

$$
\phi(\rho)=\varphi(\varphi(\varphi(\varphi(\varphi(\rho)))))
$$

É importante notar que os limites da zona de transição bem como a função foram definidas arbitrariamente. A definição desta função se baseia apenas na idéia de que o módulo de elasticidade deve ser proximo do limite inferior Hashin- 
Shtrikman (H-S) quando a fase menos rígida exerce o papel de matriz e do limite superior quando esta fase exerce o papel de inclusão.

Para melhor ilustrar essa interpolação, a Figura 7.3 apresenta o módulo de Young em termos da fração volumétrica, para um MGF hipotético, onde os materiais base possuem módulo de Young igual a 0.1 e 1.

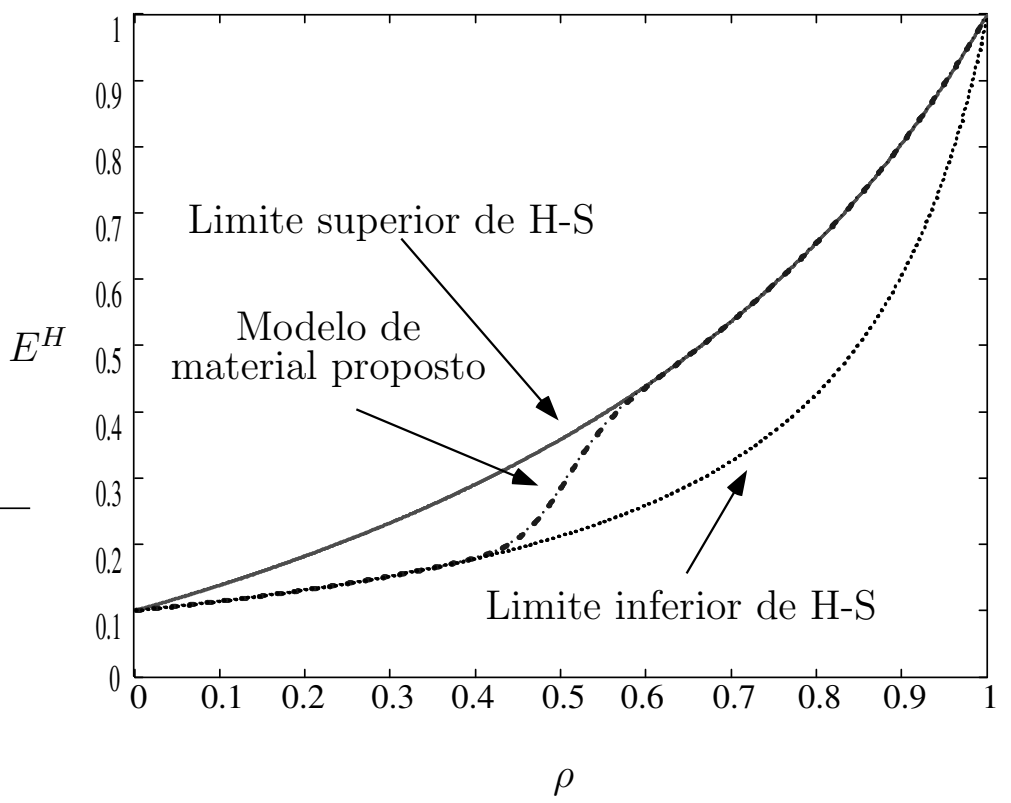

Figura 7.3: Exemplo da variação do Módulo de Young segundo o modelo de material dado pelas equações 7.2, 7.3 e 7.9. O módulo de Young foi calculado em termos do módulo de compressibilidade e cisalhamento pela relação 7.4

A densidade real do material composto é dada de maneira direta pela média ponderada das densidades de cada um dos materiais. Esta função está representada em 7.10:

$$
\varrho^{H}(\rho)=\rho \varrho^{+}+(1-\rho) \varrho^{-}
$$

Quanto a parametrização do campo de densidades neste trabalho foi utilizado o elemento isoparamétrico apresentado na seção 7.3, assim o campo de densidades fica dado no interior de cada elemento por:

$$
\rho=\sum_{i=1}^{4} \rho_{i} N_{i}
$$

Observe-que matematicamente a formulação do elemento isoparamétrico com gradiente é idêntica a formulação ACDM, logo, neste trabalho foi utilizada a mesma implementação de elementos finitos apresentada no capítulo 5 . 


\subsubsection{Formulação do problema de otimização da distri- buição de material em estruturas com gradação fun- cional}

Aqui será apresentada a formulação proposta para o problema de otimização da distribuição de material em estruturas com gradação funcional.

Do ponto de vista da aplicação de métodos de otimização para o projeto da distribuição de material em estruturas com gradação funcional, neste trabalho são proposta duas funções objetivo diferentes a fim de tratar dois tipos de meta de projeto. O primeiro objetivo consiste na minimização da fração volumétrica do material de uma das fase, e o segundo consiste na maximização da inércia de rotação de um componente mecânico.

A formulação de minimização da fração volumétrica de material é um objetivo mais genérico, e pode ser aplicados a diversos problemas. Como por exemplo, minimizar o custo da materia prima envolvida, ou minimizar o peso da peça, no caso do material mais denso ser aquele terá o volume minimizado. Essa função objetivo é dada por:

$$
\min _{\rho} \int_{\Omega} \rho(x) d \Omega
$$

A formulação de maximização da inércia de rotação é um objetivo mais específico que se aplica ao projeto de rodas de inércia, também conhecido como volantes, que são discos rotativos utilizados para a armazenar energia cinética dentro de dispositivos. As rodas de inércia são utilizadas, por exemplo, em prensas mecânicas. Esta função objetivo é dada por:

$$
\max _{\rho} \int_{\Omega} r^{2}(x) \varrho(x) d \Omega
$$

onde $\varrho$ representa a densidade real do material e é dada em 7.10 e $r$ representa o raio entre o ponto $x$ e o eixo de rotação.

Apesar da diferença de aplicação de cada uma das funções objetivo, do ponto de vista matemático e de otimização os problemas ambas as formulações são similares uma vez que tanto a inércia de rotação e o volume, são funções lineares em relação a densidade volumétrica de material.

A principal questão na formulação proposta nesta seção é o tratamento das restrições de tensão, que é feito de forma independente de função objetivo. Assim, o desenvolvimento da formulação será feita utilizando a formulação de minimização de volume, a formulação de maximização da inércia será retomada 
apenas a apresentação da análise de sensibilidade na seção 7.4 .3 e no capítulo de resultados.

Inicialmente, conforme apresentado na seção 4.5, é válido considerar como critério de falha de um MGF, em uma primeira abordagem, a comparação da tensão de von Mises média em cada fase da microestrutura com a tensão de von Mises de escoamento de cada material. Assim, temos o problema de minimização de volume da fase mais $\left(\rho^{+}\right)$com restrição local de tensão dada por 7.13:

$$
\begin{aligned}
& \min _{\rho} \int_{\Omega} \rho^{+}(x) d \Omega \\
& \text { tal que } \frac{f_{v m}\left(\left\langle\boldsymbol{\sigma}^{+}\right\rangle\right)}{\left\langle\boldsymbol{\sigma}^{+}\right\rangle_{y}} \leq 1, \frac{f_{v m}\left(\left\langle\boldsymbol{\sigma}^{-}\right\rangle\right)}{\left\langle\boldsymbol{\sigma}^{-}\right\rangle_{y}} \leq 1
\end{aligned}
$$

onde $\left\langle\boldsymbol{\sigma}^{+}\right\rangle$e $\left\langle\boldsymbol{\sigma}^{-}\right\rangle$representam as médias das tensões nas fases mais $(+)$e menos $(-)$ do material, respectivamente, e são dadas pelas equações 4.7 e $4.17,\left\langle\boldsymbol{\sigma}^{+}\right\rangle_{y}$ e $\left\langle\boldsymbol{\sigma}^{-}\right\rangle_{y}$ representam as tensões de escoamento dos materiais, obtidas através de ensaios de tração em corpos de prova homogêneos constituídos pelos respectivos materiais. A função $f_{v m}(\cdot)$ representa o cálculo da tensão de von Mises, que é dada pela equação 4.54 .

Esta formulação apresenta um controle rigoroso da falha em cada um dos materiais, entretanto, apresenta o problema das singularidade das tensões, discutido na seção 6.3, devido ao mesmo fato apresentado por Duysinx e Bendsøe (1998), e discutido na seção 6.4, de que a tensão limitante definida por Cheng e Jiang (1992) pode ser maior que a tensão de escoamento do material. Isto ocorre pois as matrizes localizadoras de tensões $\left(\mathbf{B}^{+}\right.$e $\left.\mathbf{B}^{-}\right)$, dadas por 4.17 , não tendem a matriz nula quando a fração volumétrica da respectiva fase tende a zero.

Para melhor compreender esta situação, supondo a matriz $\mathbf{B}^{+}$calculada a partir do primeiro modelo de material proposto neste trabalho, representado pelas equações 7.2 e 7.3 associadas à equação 7.6. Isto é, considerando uma interpolação constante entre os limites de H-S e adotando $\kappa=0,5$.

Observa-se na Figura 7.4 como os valores da diagonal principal, isto é, $\mathbf{B}_{11}^{+}$, $\mathbf{B}_{22}^{+}$e $\mathbf{B}_{33}^{+}$, e os valores fora dela, $\mathbf{B}_{12}^{+}$e $\mathbf{B}_{21}^{+}$, variam em função da fração volumétrica do material mais $(+)$. Neste exemplo, a matriz $\mathbf{B}^{+}$foi calculada utilizando o tensor $\mathbf{S}^{\mathbf{H}}$ relativo ao estado plano de tensão.

Observa-se também que a matriz $\mathbf{B}^{+}$, neste caso de dimensões $3 \times 3$, tem a mesma estrutura que o tensor constitutivo para o caso de estado plano de tensão, $\operatorname{logo}, \mathbf{B}_{13}^{+}=\mathbf{B}_{31}^{+}=0$ e $\mathbf{B}_{23}^{+}=\mathbf{B}_{32}^{+}=0$. Os demais valores estão apresentados 

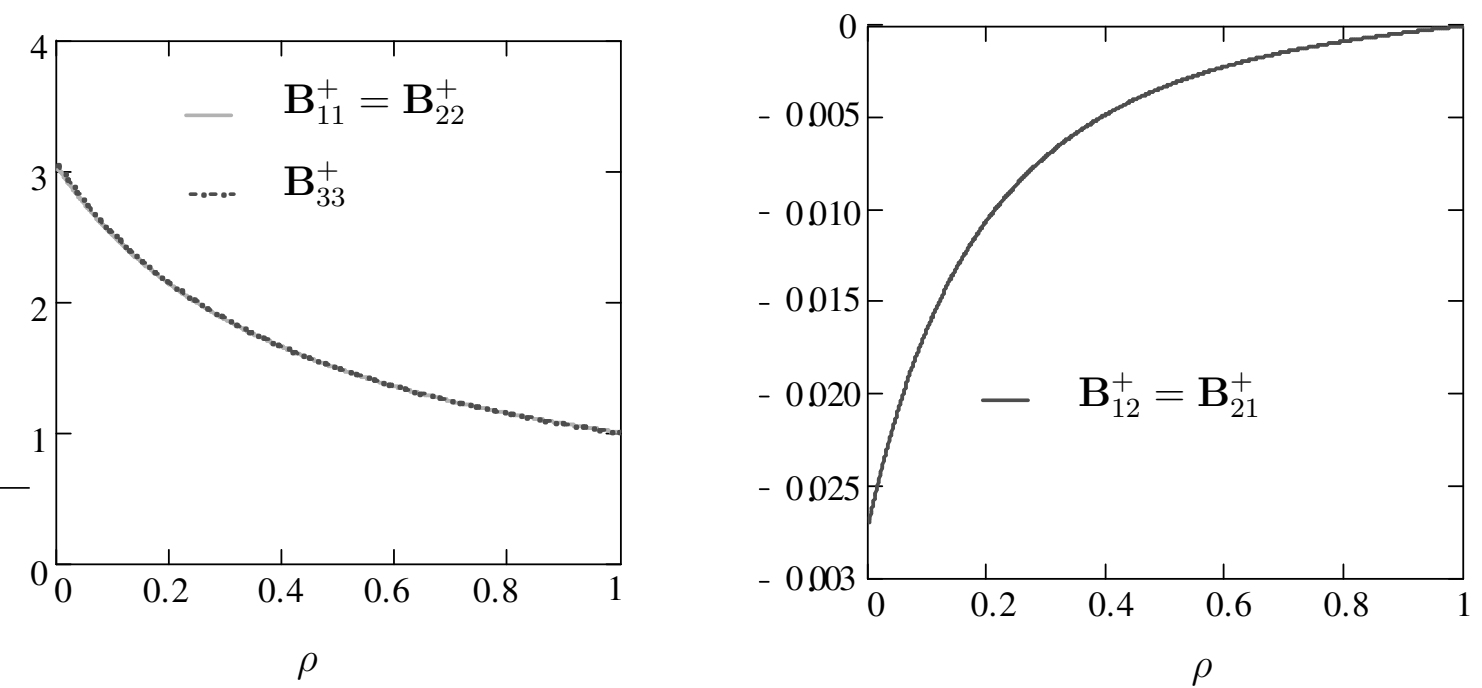

Figura 7.4: Gráficos dos elementos da matriz localizadora das tensões em termos da fração volumétrica do material mais $(+)$

na Figura 7.4, onde verifica-se que, para o caso de $\rho=1$, ou seja, um material homogêneo, esta matriz se transforma na matriz identidade, como era de ser esperar. Porém, no caso contrário, quando $\rho$ tende à zero a matriz $\mathbf{B}^{+}$não tende à uma matriz nula, ou seja, a tensão na fase que está desaparecendo tende a aumentar ao invés de desaparecer também, o que gera o problema da tensão limitante e, conseqüentemente, o fenômeno das topologias singulares. Aqui é importante ressaltar que a matriz $\mathbf{B}^{+}$é indefinida para $\rho=0$, pois ocorre uma divisão por zero na equação que a define (4.17).

Dado que a formulação 7.13 apresenta o fenômeno das topologias singulares, o que não é desejável, seria necessário utilizar o conceito de $\varepsilon$-relaxação, que está apresentado na subseção 6.3 e complementado para o caso de estruturas contínuas na seção 6.4; entretanto, neste trabalho optou-se por utilizar uma abordagem diferente para o tratamento deste problema.

Baseando-se na idéia de que se está distribuindo dois materiais, diferentemente do caso do MOT aplicado à estruturas tradicionais, sempre existirá material no Domínio Fixo Estendido (DFE), seja o material mais (+), o menos $(-)$ ou materiais intermediários, de modo que sempre poderá existir tensão em cada ponto do DFE. Assim, neste trabalho, é proposto um índice estimativo de falha do MGF dado pela média ponderada das tensão de von Mises em cada fase do material. Aqui, este índice será tratado como tensão de von Mises na microestrutura e dado por 7.14:

$$
f_{v m}\left(\left\langle\boldsymbol{\sigma}^{\text {micro }}\right\rangle\right)=\rho f_{v m}\left(\left\langle\boldsymbol{\sigma}^{+}\right\rangle\right)+(1-\rho) f_{v m}\left(\left\langle\boldsymbol{\sigma}^{-}\right\rangle\right)
$$


Observe que a média das tensões de von Mises em cada fase da microestrutura é diferente da tensão de von Mises calculada a partir da média das tensões na microestrutura, pois esta segunda seria dada por 7.15:

$$
f_{v m}(\langle\boldsymbol{\sigma}\rangle)
$$

onde $\langle\boldsymbol{\sigma}\rangle$, conforme apresentado na seção 4.2, seria dado por:

$$
\langle\boldsymbol{\sigma}\rangle=\rho\left\langle\boldsymbol{\sigma}^{+}\right\rangle+(1-\rho)\left\langle\boldsymbol{\sigma}^{-}\right\rangle
$$

ou seja, neste caso, se estaria fazendo o cálculo das tensões na macro-escala, logo, se desconsideraria o efeito de localização de tensão dado pelas matrizes $\mathbf{B}^{+}$e $\mathbf{B}^{-}$.

$\mathrm{Na}$ formulação aqui proposta, dada por 7.14, se faz a opção de evitar o fenômeno da singularidade das tensões em detrimento de um controle mais rigoroso das tensões em cada fase da microestrutura, uma vez que a média das tensões de von Mises em cada fase da microestrutura não é capaz de distinguir em que fase irá ocorrer a falha do material.

Assim, a equação 7.14 pode ser escrita de uma forma diferente que facilita a interpretação desta como um intensificador de tensão, devido à existência de uma microestrutura heterogênea, e explica como esta equação resolve o problema da singularidade das tensões.

Inicialmente, para simplificar a notação, adotaremos as relações 7.16:

$$
\begin{aligned}
\left\langle\sigma^{+}\right\rangle_{v m} & =f_{v m}\left(\left\langle\boldsymbol{\sigma}^{+}\right\rangle\right) \\
\left\langle\sigma^{+}\right\rangle_{v m} & =f_{v m}\left(\left\langle\boldsymbol{\sigma}^{-}\right\rangle\right) \\
\left\langle\sigma^{m i c r o}\right\rangle_{v m} & =f_{v m}\left(\left\langle\boldsymbol{\sigma}^{m i c r o}\right\rangle\right)
\end{aligned}
$$

Escrevendo, assim, a tensão de von Mises em cada fase da microestrutura segundo a notação apresentada na equação 4.54, temos:

$$
\left[\left\langle\sigma^{+}\right\rangle_{v m}\right]^{2}=\langle\boldsymbol{\sigma}\rangle^{T} \mathbf{B}^{+T} \mathbf{V} \mathbf{B}^{+}\langle\boldsymbol{\sigma}\rangle
$$

e

$$
\left[\left\langle\sigma^{-}\right\rangle_{v m}\right]^{2}=\langle\boldsymbol{\sigma}\rangle^{T} \mathbf{B}^{-T} \mathbf{V} \mathbf{B}^{-}\langle\boldsymbol{\sigma}\rangle
$$

Logo, pode-se escrever a equação 7.14 como 7.19

$$
\left[\left\langle\sigma^{\text {micro }}\right\rangle_{v m}\right]^{2}=\rho\left[\langle\boldsymbol{\sigma}\rangle^{T} \mathbf{B}^{+T} \mathbf{V B}^{+}\langle\boldsymbol{\sigma}\rangle\right]+(1-\rho)\left[\langle\boldsymbol{\sigma}\rangle^{T} \mathbf{B}^{-T} \mathbf{V B}^{-}\langle\boldsymbol{\sigma}\rangle\right]
$$


e então, com alguma manipulação algébrica, temos 7.20:

$$
\left[\left\langle\sigma^{\text {micro }}\right\rangle_{v m}\right]^{2}=\langle\boldsymbol{\sigma}\rangle^{T} \underbrace{\left[\rho\left(\mathbf{B}^{+}\right)^{T} \mathbf{V B}^{+}+(1-\rho)\left(\mathbf{B}^{-}\right)^{T} \mathbf{V} \mathbf{B}^{-}\right]}_{\mathbf{B}_{v m}}\langle\boldsymbol{\sigma}\rangle
$$

Desse modo, fica definida a matriz de cálculo da tensão de von Mises $\mathbf{B}_{v m}$, e se torna possível escrever a tensão de von Mises na microestrutura como 7.21:

$$
\left[\left\langle\sigma^{m i c r o}\right\rangle_{v m}\right]^{2}=\langle\boldsymbol{\sigma}\rangle^{T} \mathbf{B}_{v m}\langle\boldsymbol{\sigma}\rangle
$$

Novamente, assim como na subseção 7.4.2, tomando como exemplo a interpolação constante dos limites de $\mathrm{H}-\mathrm{S}$, adotando $\kappa=0,5$ para dois materiais com módulo de Young 0.1 e 1, e considerando a estrutura em estado plano de tensão, é possível representar graficamente os valores da matriz $\mathbf{B}_{v m}$, dados por 7.20. Estes valores são apresentados no gráfico da Figura 7.5:
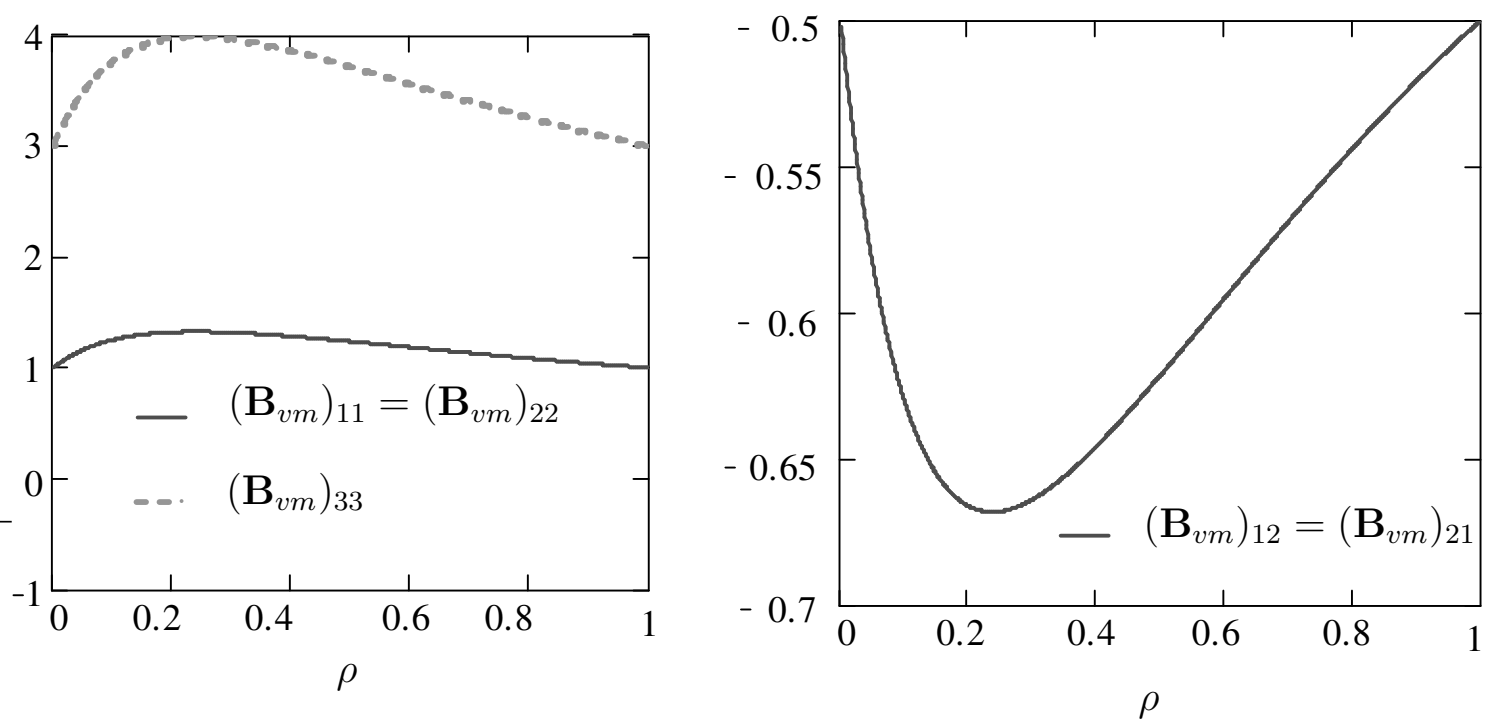

Figura 7.5: Gráficos dos elementos da matriz de cálculo da tensão de von Mises em termos da fração volumétrica do material mais $(+)$

Neste caso, para os valores limites de densidade volumétrica $\rho$, a matriz $\mathbf{B}_{v m}$ deve ser igual à matriz $\mathbf{V}$, dada por 4.55, que, no caso de materiais em estado plano de tensão, é dada por 7.22 :

$$
\mathbf{V}=\left[\begin{array}{ccc}
1 & \frac{-1}{2} & 0 \\
\frac{-1}{2} & 1 & 0 \\
0 & 0 & 3
\end{array}\right]
$$

Observa-se na Figura 7.5 que os valores das matrizes $\mathbf{B}_{v m}$ tendem aos valores da matriz $\mathbf{V}$ para $\rho$ tendendo a zero e para $\rho$ tendendo a um. Ou seja, com a uti- 
lização da matriz $\mathbf{B}_{v m}$ para se fazer o cálculo do índice estimativo de falha de um Material com Gradação Funcional (MGF), o fenômeno das topologias singulares não irá ocorrer, pois, no limite (0 ou 1), quando se tem um material homogêneo, seja o material mais $(+)$ ou o menos $(-)$, a tensão calculada é exatamente a tensão de von Mises, sem a influência dos localizadores de tensão.

Para as densidades intermediárias observa-se que a tensão de von Mises é intensificada levando em consideração a influência dos localizadores de tensão.

Assim, é possível substituir a restrição do problema 7.13 pela restrição 7.23 :

$$
\left[\left\langle\boldsymbol{\sigma}^{\text {micro }}\right\rangle_{v m}\right]^{2} \leq\left[\left\langle\boldsymbol{\sigma}^{\text {micro }}\right\rangle_{r e f}\right]^{2}
$$

Entretanto, aqui se observa a necessidade de se utilizar um valor único de referência para compará-lo com a tensão de von Mises na microestrutura definida anteriormente.

Neste trabalho são propostas duas formas de estimativa da tensão de referência.

O primeiro modelo proposto foi baseada no trabalho de Swan e Kosaka (1997a) que propõem que a tensão de referência do material composto deve se manter entre as tensões de referência dos modelos de Voigt e Reuss. Seguindo esta idéia, neste trabalho é proposto a que a tensão de referência seja dada pela média harmonica das tensões de referência de cada um dos materiais envolvidos, assim esta pode ser representada por 7.24:

$$
\left[\left\langle\sigma^{\text {micro }}\right\rangle_{r e f}\right]^{2} \equiv\left[\frac{\rho(x)}{\left\langle\sigma^{+}\right\rangle_{y}^{2}}+\frac{1-\rho(x)}{\left\langle\sigma^{-}\right\rangle_{y}^{2}}\right]^{-1}
$$

Neste modelo, a tensão de escoamento tende a se manter mais próxima da tensão de escoamento do material mais fraco em um maior intervalo de densidades volumétricas. Assim, esse modelo tende a fornecer projetos mais conservativos. Esse é um ponto positivo um vez que não se sabe ao certo qual é a tensão de escoamento de um material composto, e mais especificamente, de um MGF. Outra vantagem desta proposta é que a tensão de referência se mantém dentro dos limites da tensão de referência dos modelos de Voigt e Reuss independentemente de qual fase possui a maior tensão de referência. Ou seja, este modelo pode ser aplicado para tanto MsGF em que $\left.\left\langle\sigma^{+}\right\rangle_{y}\right\rangle\left\langle\sigma^{-}\right\rangle_{y}$ ou no caso de $\left\langle\sigma^{+}\right\rangle_{y}\left\langle\left\langle\sigma^{-}\right\rangle_{y}\right.$.

A Figura 7.6(a) apresenta a curva dada pela função 7.24 no caso de $\left.\left\langle\sigma^{+}\right\rangle_{y}\right\rangle$ $\left\langle\sigma^{-}\right\rangle_{y}$ e a Figura 7.6(b) no caso inverso, assim, pode-se observar o caráter con- 
servativo da estimativa da tensão de referência proposta neste trabalho.

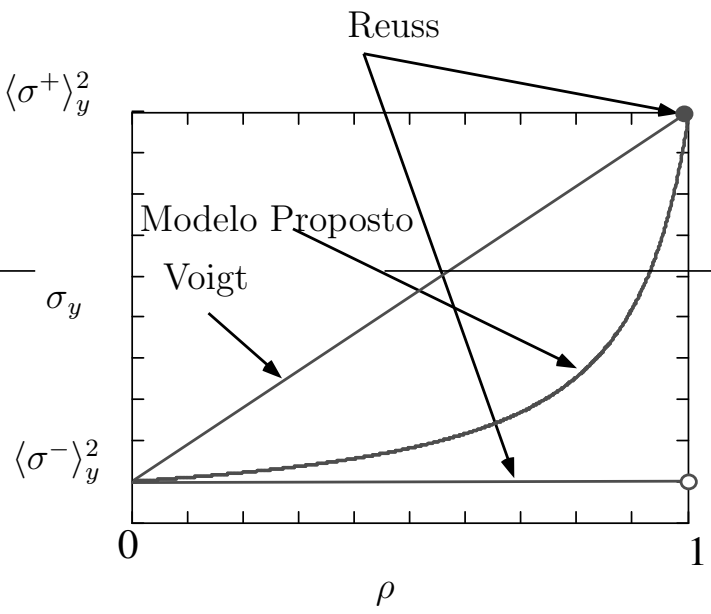

(a) Caso de $\left\langle\sigma^{+}\right\rangle_{y}^{2}>\left\langle\sigma^{-}\right\rangle_{y}^{2}$

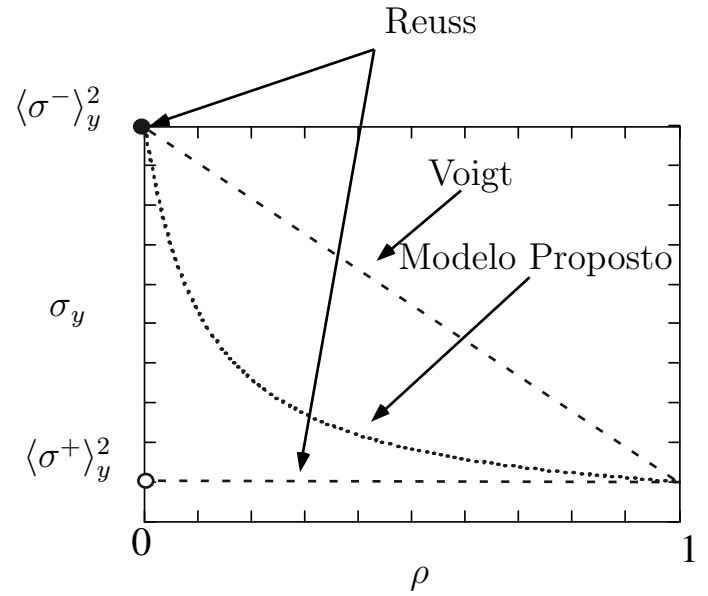

(b) Caso de $\left\langle\sigma^{+}\right\rangle_{y}^{2}<\left\langle\sigma^{-}\right\rangle_{y}^{2}$

Figura 7.6: Gráficos representativos da tensão de escoamento segundo os modelos de Voigt Reuss e o modelo proposto neste trabalho

O segundo modelo proposto se baseia na mesma idéia que o modelo anterior e consiste em definir a tensão de referência apenas média ponderada penalizada das tensões de referência de cada fase envolvida, assim este modelo fica dado por 7.25:

$$
\left[\left\langle\sigma^{\text {micro }}\right\rangle_{r e f}\right]^{2} \equiv \rho(x)^{s}\left\langle\sigma^{+}\right\rangle_{y}^{2}+(1-\rho(x))\left\langle\sigma^{-}\right\rangle_{y}^{2}
$$

onde $s$ é um parâmetro de ajuste da função, que permite deixar o a curva da tensão de referência mais próxima ou mais afastada das tensões de referência de Voigt e de Reuss.

Uma desvantagem deste modelo é que este é valido apenas para o caso $\left.\left\langle\sigma^{+}\right\rangle_{y}\right\rangle$ $\left\langle\sigma^{-}\right\rangle_{y}$, pois no caso contrário a tensão de referência não atende a proposição de Swan e Kosaka (1997a) de se manter dentro das tensões de referência dos modelos de Voigt e Reuss. A vantagem desse modelo é a flexibilidade fornecida pelo parâmetro $s$.

Com a definição de um índice estimativo de falha $\left(\left\langle\boldsymbol{\sigma}^{\text {micro }}\right\rangle_{v m}\right)$ e uma tensão de referência única $\left(\left\langle\sigma^{\text {micro }}\right\rangle_{\text {ref }}\right)$, é possível escrever o problema original como 7.26:

$$
\begin{aligned}
& \min _{\rho} \int_{\Omega} \rho(x) d \Omega \\
& \text { tal que } \frac{\left[\left\langle\boldsymbol{\sigma}^{\text {micro }}\right\rangle_{v m}\right]^{2}}{\left[\left\langle\boldsymbol{\sigma}^{\text {micro }}\right\rangle_{r e f}\right]^{2}} \leq 1
\end{aligned}
$$


Neste ponto, têm-se uma formulação para o problema de otimização da distribuição de material em estruturas com gradiente de propriedades, considerando restrição de tensão, que não apresenta o fenômeno das topologias singulares. Porém, o problema relativo ao alto número de restrições, devido à característica local da restrição de tensões, discutida nas seções 6.1 e 6.4, ainda está presente.

Assim, aqui se optou, em uma primeira abordagem, por utilizar uma restrição global de tensão, tal qual as propostas por Park (1995), Yang e Chen (1996) e Duysinx e Bendsøe (1998). Dessa forma, o problema 7.26 passa a ser escrito como 7.27:

$$
\begin{aligned}
& \min _{\rho} \int_{\Omega} \rho(x) d \Omega \\
& \text { tal que } \\
& \left.\qquad \frac{1}{\Omega} \int_{\Omega}\left(\frac{\left[\left\langle\boldsymbol{\sigma}^{\text {micro }}\right\rangle_{v m}\right]^{2}}{\left[\left\langle\boldsymbol{\sigma}^{\text {micro }}\right\rangle_{\text {ref }}\right]^{2}}\right)^{p}\right]^{\frac{1}{p}} \leq 1
\end{aligned}
$$

onde $\Omega$ representa o volume da estrutura, $p$ representa o peso na norma-p que irá ponderar a influência da tensão máxima do problema $\left\langle\boldsymbol{\sigma}^{\text {micro }}\right\rangle_{v m}$ representa a tensão de von Mises na microestrutura, dado por 7.21 e $\left\langle\boldsymbol{\sigma}^{\text {micro }}\right\rangle_{\text {ref }}$ representa a tensão de comparação dada por 7.24.

A partir da formulação proposta em 7.27, seguindo a mesma notação, foi implementada e estudada também a formulação dada por 7.28:

$$
\min _{\rho} \int_{\Omega} \rho(x) d \Omega
$$

tal que

$$
\left[\frac{1}{\Omega} \int_{\Omega}\left(\max \left\{\frac{\left[\left\langle\boldsymbol{\sigma}^{\text {micro }}\right\rangle_{v m}\right]^{2}}{\left[\left\langle\boldsymbol{\sigma}^{\text {micro }}\right\rangle_{\text {ref }}\right]^{2}}-1,0\right\}\right)^{p}\right]^{\frac{1}{p}} \leq 0
$$

Nesta nova formulação contribuem para a norma-p das tensões apenas as regiões que possuem tensão de von Mises na microestrutura acima da tensão de referência, ou seja, apenas os pontos que estão falhando. A idéia dessa formulação é fazer um melhor controle da restrição de tensão de modo a desconsiderar a influência das tensões nos pontos em que não está ocorrendo falha. Esta formulação, apesar de similar à anterior, possui um comportamento significativamente diferente da anterior durante o processo iterativo de otimização, isto porque esta apresenta uma descontinuidade dada pela função $\max \{\cdot, \cdot\}$ 
Antes de prosseguir, aqui vale a pena fazer um resumo dos modelos de material propostos neste trabalho. A Tabela 7.1 apresenta os dois modelos de material utilizados para prever o módulo de Young do MGF.

\begin{tabular}{c|c} 
Denominação & Modelos para interpolação dos limites de H-S \\
\hline \hline H-S-linear & $\phi(\rho)=\kappa$ onde \\
& $\kappa \in\left[\begin{array}{ll}0 & 1\end{array}\right]$ \\
H-S-transição & $\phi(\rho)=\varphi(\varphi(\varphi(\varphi(\varphi(\rho)))))$ onde \\
& $\varphi(\rho)=\frac{\cos (\pi \rho)}{2}+\frac{1}{2}$
\end{tabular}

Tabela 7.1: Resumo dos modelos de material propostos para MsGF

Para facilitar a referência aos modelos foram dados nomes a cada um deles, assim o modelo de interpolação linear do limites de H-S foi chamado de de "H-Slinear", enquanto o modelo não linear que tenta melhor representar a região de transição foi chamado de "H-S-transição".

A Tabela 7.2 apresenta os dois modelos utilizados para estimar a tensão de referência dos materiais, neste caso também foram dados nomes aos modelos, conforme apresentado na Tabela 7.2.

\begin{tabular}{c|c} 
Denominação & Modelos para Tensão de Refêrencia \\
\hline \hline Tensão-M. A. & {$\left[\left\langle\sigma^{\text {micro }}\right\rangle_{r e f}\right]^{2} \equiv \rho(x)^{s}\left\langle\sigma^{+}\right\rangle_{y}^{2}+\left(1-\rho(x)^{s}\right)\left\langle\sigma^{-}\right\rangle_{y}^{2}$} \\
Tensão-M. H. & {$\left[\left\langle\sigma^{\text {micro }}\right\rangle_{r e f}\right]^{2} \equiv\left[\frac{\rho(x)}{\left\langle\sigma^{+}\right\rangle_{y}^{2}}+\frac{1-\rho(x)}{\left\langle\sigma^{-}\right\rangle_{y}^{2}}\right]^{-1}$}
\end{tabular}

Tabela 7.2: Resumo dos modelos propostos para estimativa da tensão de referência para MsGF

Assim, o modelo que se utiliza de um média aritmética das tensões de referência foi denominado de "Tensão-M. A.", já aquele que utiliza uma média harmônica foi denominado "Tensão-M. H." .

Um estudo da influência desse modelos de material é feita nos exemplos apresentados nas seções 10.2 e 10.3 .

\subsubsection{Formulação do problema na forma discreta e análise de sensibilidade}

Aqui será apresentada a discretização das formulações propostas na seção anterior, o procedimento adotado é similar ao realizado para o caso de otimização de 
estrutura tradicionais, compostas por apenas um material, que foi apresentada na subseção 6.5.2.

Inicialmente, será tratado o problema 7.27, que na sua forma discreta é dado por 7.29:

$$
\begin{aligned}
& \min _{\rho} \sum_{e=1}^{M} \int_{\Omega_{e}} \rho(x) d \Omega_{e} \\
& \text { tal que } \\
& \left.\qquad \frac{1}{\Omega} \sum_{e=1}^{M} \Omega_{e}\left(\frac{\left[\left\langle\boldsymbol{\sigma}^{\text {micro }}\right\rangle_{\text {vm }}^{e}\right]^{2}}{\left[\left\langle\boldsymbol{\sigma}^{\text {micro }}\right\rangle_{\text {ref }}^{e}\right]^{2}}\right)^{p}\right]^{\frac{1}{p}} \leq 1
\end{aligned}
$$

onde $M$ representa o número de elementos da malha, $\Omega_{e}$ representa o volume do elemento e, $\left\langle\boldsymbol{\sigma}^{\text {micro }}\right\rangle_{v m}^{e}$ e $\left\langle\boldsymbol{\sigma}^{\text {micro }}\right\rangle_{\text {ref }}^{e}$ representam a tensão de von Mises na microestrutura e a tensão de referência, respectivamente; ambas calculadas no centro do elemento $e$.

O mesmo procedimento, apresentado na subseção 6.5.2, de fazer a expansão em série de Taylor e o cálculo das derivadas das funções envolvidas no problema, é aqui utilizada.

A aplicação deste procedimento à função objetivo de minimização de volume é idêntica à apresentada para problema com apenas um material, logo esta não será re-apresentada. Já para o caso de maximização da inércia de rotação, a função objetivo na sua forma discretizada é dada por:

$$
I(\boldsymbol{\rho})=\sum_{e=1}^{M} \int_{\Omega_{e}} r^{2}(x) \varrho(x) d \Omega_{e}
$$

Agora, para avaliar a função 7.30 com a parametrização de densidades do modelo ACDM é necessário escrever esta função, em termos das variáveis nodais. Assim tem-se:

$$
I(\boldsymbol{\rho})=\left.\sum_{e=1}^{M} 2 \pi \int_{z} \int_{r}\left[r^{3}\left(\sum_{j=1}^{4} \rho_{j} N_{j}(s, t)\right) \varrho^{+}\left(1-\left(\sum_{j=1}^{4} \rho_{j} N_{j}(s, t)\right)\right) \varrho^{-}\right] d r d z\right|_{e}
$$

e seguindo o mesmo procedimento de expansão em séries de Taylor e considerando apenas o termos de primeira ordem. Para aplicar o método de PLS basta calcular 
a derivada de $I(\boldsymbol{\rho})$ em relação a $\rho_{i}$. E esta é dada por 7.32:

$$
\frac{d I(\boldsymbol{\rho})}{d \rho_{i}}=\left.\sum_{e=1}^{M}\left(2 \pi \int_{z} \int_{r} r^{3}\left[N_{i}(s, t) \varrho^{+}-N_{i}(s, t) \varrho^{-}\right] d r d z\right)\right|_{e}
$$

A seguir será apresentado o mesmo procedimento para a restrição do problema proposto.

Aqui, para facilitar a notação e a implementação, será considerado o quadrado da tensão de von Mises como medida de comparação. Assim, aqui será definido:

$$
\left\langle\boldsymbol{\sigma}^{m i c r o}\right\rangle_{v m^{2}}^{e} \equiv\left[\left\langle\boldsymbol{\sigma}^{m i c r o}\right\rangle_{v m}^{e}\right]^{2}
$$

$$
\left\langle\boldsymbol{\sigma}^{m i c r o}\right\rangle_{r e f^{2}}^{e} \equiv\left[\left\langle\boldsymbol{\sigma}^{m i c r o}\right\rangle_{r e f}^{e}\right]^{2}
$$

Então restrição fica dada por:

$$
G_{1} \equiv\left[\frac{1}{\Omega} \sum_{e=1}^{M} \Omega_{e}\left(\frac{\left\langle\boldsymbol{\sigma}^{\text {micro }}\right\rangle_{v m^{2}}^{e}}{\left\langle\boldsymbol{\sigma}^{\text {micro }}\right\rangle_{r e f^{2}}^{e}}\right)^{p}\right]^{\frac{1}{p}}-1 \leq 0
$$

Fazendo a expansão em série de Taylor, com apenas os elementos de primeira ordem, têm-se:

$$
G_{1}=G_{1}\left(\boldsymbol{\rho}^{0}\right)+\sum_{i=1}^{N} \frac{d G_{1}\left(\boldsymbol{\rho}^{0}\right)}{d \rho_{i}}\left[\rho_{i}-\rho_{i}^{0}\right]
$$

De forma similar ao apresentado na subseção 6.5.2, $G_{1}$ é uma função implícita de $\rho_{i}$ de modo que será utilizado o método adjunto assim temos a sensibilidade de $G_{1}$ dada por:

$$
\frac{d G_{1}\left(\boldsymbol{\rho}^{0}\right)}{d \rho_{i}}=\underbrace{\frac{\partial G_{1}\left(\boldsymbol{\rho}^{0}\right)}{\partial \rho_{i}}}_{\text {Parte explícita }}+\underbrace{\boldsymbol{\lambda}^{T}\left(\frac{d \mathbf{f}}{d \rho_{i}}-\frac{d \mathbf{K}}{d \rho_{i}} \mathbf{d}\right)}_{\text {Parte implícita }}
$$

onde

$$
\mathbf{K} \boldsymbol{\lambda}^{T}=\frac{d G_{1}\left(\boldsymbol{\rho}^{0}\right)}{d \mathbf{d}}
$$

que é chamado de problema adjunto. E de forma similar ao apresentado na seção 6.5.2, a derivada $\frac{d G_{1}\left(\boldsymbol{\rho}^{0}\right)}{d \mathbf{d}}$ representa um vetor de derivadas de $G_{1}$ em função dos deslocamentos $d_{i}$ conforme representado na equação 6.49

Inicialmente, será apresentada a sensibilidade do termo explícito da equação 
7.37 que é dado por:

$$
\begin{aligned}
\frac{\partial G_{1}\left(\boldsymbol{\rho}^{0}\right)}{\partial \rho_{i}} & =\frac{1}{p}\left[\frac{1}{\Omega} \sum_{e=1}^{M} \Omega_{e}\left(\frac{\left\langle\boldsymbol{\sigma}^{\text {micro }}\right\rangle_{v m^{2}}^{e}}{\left\langle\boldsymbol{\sigma}^{\text {micro }}\right\rangle_{r e f^{2}}^{e}}\right)^{p}\right]^{\frac{1-p}{p}} \cdot \\
& \frac{1}{\Omega} \sum_{e=1}^{M}\left[\Omega_{e} p\left(\frac{\left\langle\boldsymbol{\sigma}^{\text {micro }}\right\rangle_{v m^{2}}^{e}}{\left\langle\boldsymbol{\sigma}^{\text {micro }}\right\rangle_{r e f^{2}}^{e}}\right)^{p-1} \cdot\right. \\
& \left.\frac{\frac{d\left\langle\boldsymbol{\sigma}^{\text {micro }}\right\rangle_{v m^{2}}^{e}}{d \rho_{i}}\left\langle\boldsymbol{\sigma}^{\text {micro }}\right\rangle_{r e f^{2}}^{e}-\frac{\left\langle\boldsymbol{\sigma}^{\text {micro }}\right\rangle_{r e f^{2}}^{e}}{d \rho_{i}}\left\langle\boldsymbol{\sigma}^{\text {micro }}\right\rangle_{v m^{2}}^{e}}{\left[\left\langle\boldsymbol{\sigma}^{\text {micro }}\right\rangle_{r e f^{2}}^{e}\right]^{2}}\right]
\end{aligned}
$$

Para facilitar as deduções que seguem, é importante ressaltar que, ao se parametrizar o campo de densidades através de elementos finitos com gradiente, conforme apresentado na seção 7.4.1, deve-se fazer derivada do campo em função densidade nodal, que fica dada por:

$$
\frac{\partial \rho}{\partial \rho_{i}}=N_{i}
$$

O cálculo das derivadas $\frac{d\left\langle\boldsymbol{\sigma}^{\text {micro }}\right\rangle_{v m^{2}}^{e}}{d \rho_{i}}$ e $\frac{\left\langle\boldsymbol{\sigma}^{\text {micro }}\right\rangle_{r e f^{2}}^{e}}{d \rho_{i}}$ deve ser feito conforme o modelo de material adotado. Assim, temos a derivada tensão da referência 7.25 dada por

$$
\frac{d\left\langle\boldsymbol{\sigma}^{\text {micro }}\right\rangle_{r e f^{2}}^{e}}{d \rho_{i}}=2 \rho \frac{\partial \rho}{\partial \rho_{i}}\left[\left\langle\sigma^{+}\right\rangle_{y}\right]^{2}-2 \rho \frac{\partial \rho}{\partial \rho_{i}}\left[\left\langle\sigma^{-}\right\rangle_{y}\right]^{2}
$$

e no caso da tensão de referência 7.24, sua derivada é dada por:

$$
\begin{aligned}
\frac{d\left\langle\boldsymbol{\sigma}^{\text {micro }}\right\rangle_{r e f^{2}}^{e}}{d \rho_{i}} & =-\left[\frac{\rho}{\left[\left\langle\sigma^{+}\right\rangle_{y}\right]^{2}}+\frac{1-\rho}{\left[\left\langle\sigma^{-}\right\rangle_{y}\right]^{2}}\right]^{-2} . \\
& {\left[\frac{\partial \rho}{\partial \rho_{i}}\left(\frac{1}{\left[\left\langle\sigma^{+}\right\rangle_{y}\right]^{2}}-\frac{1}{\left[\left\langle\sigma^{-}\right\rangle_{y}\right]^{2}}\right)\right] }
\end{aligned}
$$

e para a tensão de von Mises na microestrutura temos:

$$
\frac{d\left\langle\boldsymbol{\sigma}^{\text {micro }}\right\rangle_{v m}^{e}}{d \rho_{i}}=\frac{\partial\langle\boldsymbol{\sigma}\rangle^{T}}{\partial \rho_{i}} \mathbf{B}_{v m}\langle\boldsymbol{\sigma}\rangle+\langle\boldsymbol{\sigma}\rangle^{T} \frac{\partial \mathbf{B}_{v m}}{\partial \rho_{i}}\langle\boldsymbol{\sigma}\rangle+\langle\boldsymbol{\sigma}\rangle^{T} \mathbf{B}_{v m} \frac{\partial\langle\boldsymbol{\sigma}\rangle}{\partial \rho_{i}}
$$

O cálculo da derivada de $\mathbf{B}_{v m}$ é um pouco mais complexo. Considerando a matriz $\mathbf{B}_{v m}$ dada por:

$$
\mathbf{B}_{v m}=\rho\left(\mathbf{B}^{+}\right)^{T} \mathbf{V B}^{+}+(1-\rho)\left(\mathbf{B}^{-}\right)^{T} \mathbf{V B}^{-}
$$


então temos:

$$
\begin{aligned}
\frac{\partial \mathbf{B}_{v m}}{\partial \rho_{i}} & =\frac{\partial \rho}{\partial \rho_{i}}\left(\left(\mathbf{B}^{+}\right)^{T} \mathbf{V} \mathbf{B}^{+}\right)+\rho\left[\frac{\partial\left(\mathbf{B}^{+}\right)^{T}}{\partial \rho_{i}} \mathbf{V B}^{+}+\left(\mathbf{B}^{+}\right)^{T} \mathbf{V} \frac{\partial \mathbf{B}^{+}}{\partial \rho_{i}}\right]+ \\
& -\frac{\partial \rho}{\partial \rho_{i}}\left(\left(\mathbf{B}^{-}\right)^{T} \mathbf{V} \mathbf{B}^{-}\right)+(1-\rho)\left[\frac{\partial\left(\mathbf{B}^{-}\right)^{T}}{\partial \rho_{i}} \mathbf{V B}^{-}+\left(\mathbf{B}^{-}\right)^{T} \mathbf{V} \frac{\partial \mathbf{B}^{-}}{\partial \rho_{i}}\right]
\end{aligned}
$$

onde

$$
\frac{\partial \mathbf{B}^{+}}{\partial \rho_{i}}=\left(\left(\mathbf{S}^{+}-\mathbf{S}^{-}\right)^{-1}\right) \frac{\rho \frac{\partial \mathbf{S}^{H}}{\partial \rho_{i}}-\frac{\partial \rho}{\partial \rho_{i}}\left(\mathbf{S}^{H}-\mathbf{S}^{-}\right)}{\rho^{2}}
$$

e

$$
\frac{\partial \mathbf{B}^{-}}{\partial \rho_{i}}=-1\left(\left(\mathbf{S}^{+}-\mathbf{S}^{-}\right)^{-1}\right) \frac{(1-\rho) \frac{\partial \mathbf{S}^{H}}{\partial \rho_{i}}+\frac{\partial \rho}{\partial \rho_{i}}\left(\mathbf{S}^{H}-\mathbf{S}^{+}\right)}{(1-\rho)^{2}}
$$

Para se avaliar estas duas equações (7.47 e 7.46), é necessário calcular a derivada de $\mathbf{S}^{H}$. Assim, esta fica dada por:

$$
\begin{gathered}
\frac{\partial \mathbf{S}^{H}}{\partial \rho_{i}}=\frac{\partial \mathbf{S}^{H}}{\partial E^{H}}\left(\frac{\partial E^{H}}{\partial K^{H}} \frac{\partial K^{H}}{\partial \rho}+\frac{\partial E^{H}}{\partial G^{H}} \frac{\partial G^{H}}{\partial \rho}\right) \frac{\partial \rho}{\partial \rho_{i}}+ \\
\frac{\partial \mathbf{S}^{H}}{\partial \nu^{H}}\left(\frac{\partial \nu^{H}}{\partial K^{H}} \frac{\partial K^{H}}{\partial \rho}+\frac{\partial \nu^{H}}{\partial G^{H}} \frac{\partial G^{H}}{\partial \rho}\right) \frac{\partial \rho}{\partial \rho_{i}}
\end{gathered}
$$

e, considerando $\mathbf{C}^{\mathbf{H}}$ dado por 5.2, temos no caso de estruturas axissimétricas

$$
\left(\mathbf{C}^{\mathbf{H}}\right)^{-1} \equiv \mathbf{S}^{H}=\left[\begin{array}{cccc}
E^{-1} & -\frac{v}{E} & -\frac{v}{E} & 0 \\
-\frac{v}{E} & E^{-1} & -\frac{v}{E} & 0 \\
-\frac{v}{E} & -\frac{v}{E} & E^{-1} & 0 \\
0 & 0 & 0 & 2 \frac{1+v}{E}
\end{array}\right]
$$

e

$$
\begin{aligned}
\frac{\partial \mathbf{S}^{H}}{\partial E^{H}}= & {\left[\begin{array}{cccc}
-E^{-2} & \frac{v}{E^{2}} & \frac{v}{E^{2}} & 0 \\
\frac{v}{E^{2}} & -E^{-2} & \frac{v}{E^{2}} & 0 \\
\frac{v}{E^{2}} & \frac{v}{E^{2}} & -E^{-2} & 0 \\
0 & 0 & 0 & -2 \frac{1+v}{E^{2}}
\end{array}\right] } \\
\frac{\partial \mathbf{S}^{H}}{\partial \nu^{H}}= & {\left[\begin{array}{cccc}
0 & -E^{-1} & -E^{-1} & 0 \\
-E^{-1} & 0 & -E^{-1} & 0 \\
-E^{-1} & -E^{-1} & 0 & 0 \\
0 & 0 & 0 & 2 E^{-1}
\end{array}\right] }
\end{aligned}
$$

considerando $E^{H}$ e $\nu^{H}$ dados por 7.4 e 7.5 , respectivamente, temos:

$$
\frac{\partial E^{H}}{\partial K^{H}}=\frac{9}{\left(1+3 \frac{K^{H}}{G^{H}}\right)}-\frac{27 K^{H}}{G^{H}\left(1+3 \frac{K^{H}}{G^{H}}\right)^{2}}
$$




$$
\frac{\partial E^{H}}{\partial G^{H}}=\frac{27\left(K^{H}\right)^{2}}{\left[\left(1+3 \frac{K^{H}}{G^{H}}\right) G^{H}\right]^{2}}
$$

e

$$
\begin{gathered}
\frac{\partial \nu^{H}}{\partial K^{H}}=\frac{2 / 3 G^{H}}{\left(K^{H}\right)^{2}\left(2+2 / 3 \frac{G^{H}}{K^{H}}\right)}+\frac{2 / 3\left(1-2 / 3 \frac{G^{H}}{K^{H}}\right) G^{H}}{\left[\left(2+2 / 3 \frac{G^{H}}{K^{H}}\right) K^{H}\right]^{2}} \\
\frac{\partial \nu^{H}}{\partial G^{H}}=-\frac{2 / 3}{K^{H}\left(2+2 / 3 \frac{G^{H}}{K^{H}}\right)}-\frac{2 / 3\left(1-2 / 3 \frac{G^{H}}{K^{H}}\right)}{\left(2+2 / 3 \frac{G^{H}}{K^{H}}\right)^{2} K^{H}}
\end{gathered}
$$

considerando também $K^{H}(\rho)$ e $G^{H}(\rho)$ dados por 7.2 e 7.3 , respectivamente, temos:

$$
\begin{array}{r}
\frac{\partial K^{H}}{\partial \rho}=\frac{\partial \phi(\rho)}{\partial \rho} K_{\max }(\rho)+\phi(\rho) \frac{\partial K_{\max }(\rho)}{\partial \rho}- \\
\frac{\partial \phi(\rho)}{\partial \rho} K_{\min }(\rho)+(1-\phi(\rho)) \frac{\partial K_{\min }(\rho)}{\partial \rho} \\
\frac{\partial G^{H}}{\partial \rho}=\frac{\partial \phi(\rho)}{\partial \rho} G_{\max }(\rho)+\phi(\rho) \frac{\partial G_{\max }(\rho)}{\partial \rho}- \\
\frac{\partial \phi(\rho)}{\partial \rho} G_{\min }(\rho)+(1-\phi(\rho)) \frac{\partial G_{\min }(\rho)}{\partial \rho}
\end{array}
$$

e, finalmente, considerando $K_{\max }(\rho), K_{\min }(\rho), G_{\max }(\rho)$ e $G_{\min }(\rho)$ dados por 4.23, $4.24,4.25$ e 4.26 , respectivamente, temos:

$$
\begin{aligned}
\frac{\partial K_{\max }}{\partial \rho} & =-K^{-}+K^{+}+\frac{\rho\left(K^{+}-K^{-}\right)^{2}}{(1-\rho) K^{+}+\rho K^{-}+G 1}- \\
& \frac{(1-\rho)\left(K^{+}-K^{-}\right)^{2}}{(1-\rho) K^{+}+\rho K^{-}+G^{+}}+\frac{(1-\rho) \rho\left(K^{+}-K^{-}\right)^{2}\left(K^{-}-K^{+}\right)}{\left((1-\rho) K^{+}+\rho K^{-}+G^{+}\right)^{2}}
\end{aligned}
$$




$$
\begin{aligned}
\frac{\partial G_{\min }}{\partial \rho} & =-G^{-}+G^{+}+\frac{\rho\left(G^{+}-G^{-}\right)^{2}}{(1-\rho) G^{+}+\rho G^{-}+\frac{K^{-} G^{-}}{K^{-}+2 G^{-}}}- \\
& \frac{(1-\rho)\left(G^{+}-G^{-}\right)^{2}}{(1-\rho) G^{+}+\rho G^{-}+\frac{K^{-} G^{-}}{K^{-}+2 G^{-}}}+\frac{(1-\rho) \rho\left(G^{+}-G^{-}\right)^{2}\left(G^{-}-G^{+}\right)}{\left((1-\rho) G^{+}+\rho G^{-}+\frac{K^{-} G^{-}}{K^{-}+2 G^{-}}\right)^{2}}
\end{aligned}
$$

Assim, tem-se a derivada de todos os termos necessários para o cálculo da parte explícita da equação 7.37, dada pela equação 7.39 .

Para completar a derivada apresentada na equação 7.37, é necessário fazer o cálculo das derivadas que envolvem a parte implícita da equação, inicialmente apresentaremos as derivadas em função de $\rho_{i}\left(\frac{d \mathbf{f}}{d \rho_{i}}\right.$ e $\left.\frac{d \mathbf{K}}{d \rho_{i}}\right)$.

A derivada do vetor de carregamento $\mathbf{f}$ em função de $\rho_{i}$ é dada de forma similar ao apresentado na subseção 6.5.2, a menos da derivada da força de campo dada pela equação 6.55, que no caso de um MGF por 7.62:

$$
\frac{d \mathbf{f}_{c}}{d \rho_{i}}=\left(\frac{\partial \rho}{\partial \rho_{i}} \varrho^{+}-\frac{\partial \rho}{\partial \rho_{i}} \varrho^{-}\right)\left[\begin{array}{c}
\omega r_{p} \\
a_{z}
\end{array}\right]
$$

uma vez que a força de campo em si, é dada por:

$$
\mathbf{f}_{c}=\rho \varrho^{+}+(1-\rho) \varrho^{-}\left[\begin{array}{c}
\omega r_{p} \\
a_{z}
\end{array}\right]
$$

conectividade dos elementos.

A derivada da matriz de rigidez em termos de $\rho_{i}$ também é obtida de forma similar ao apresentado na subseção 6.5.2, porém difere apenas no cálculo da derivada de $\mathbf{C}_{e}^{\mathbf{H}}$ que é dada por:

$$
\begin{gathered}
\frac{d \mathbf{C}_{e}^{\mathbf{H}}}{d \rho_{i}}=\frac{\partial \mathbf{C}_{e}^{\mathbf{H}}}{\partial E^{H}}\left(\frac{\partial E^{H}}{\partial K^{H}} \frac{\partial K^{H}}{\partial \rho}+\frac{\partial E^{H}}{\partial G^{H}} \frac{\partial G^{H}}{\partial \rho}\right) \frac{\partial \rho}{\partial \rho_{j}}+ \\
\frac{\partial \mathbf{C}_{e}^{\mathbf{H}}}{\partial \nu^{H}}\left(\frac{\partial \nu^{H}}{\partial K^{H}} \frac{\partial K^{H}}{\partial \rho}+\frac{\partial \nu^{H}}{\partial G^{H}} \frac{\partial G^{H}}{\partial \rho}\right) \frac{\partial \rho}{\partial \rho_{j}}
\end{gathered}
$$

Observa-se que a equação 7.64 é similar à equação 7.48 à exceção dos termos envolvendo $\mathbf{C}_{e}^{\mathbf{H}}$, que estão representados nas equações 7.65 e 7.66 :

$$
\frac{\partial \mathbf{C}_{e}^{\mathbf{H}}}{\partial E^{H}}=\frac{1}{(1+\nu)(1-2 \nu)}\left[\begin{array}{cccc}
1-\nu & \nu & \nu & 0 \\
\nu & 1-\nu & \nu & 0 \\
\nu & \nu & 1-\nu & 0 \\
0 & 0 & 0 & \frac{1-2 \nu}{2}
\end{array}\right]
$$




$$
\frac{\partial \mathbf{C}_{e}^{\mathbf{H}}}{\partial \nu^{H}}=\left[\begin{array}{cccc}
\left(\frac{\partial \mathbf{C}_{e}^{\mathbf{H}}}{\partial \nu^{H}}\right)_{1,1} & \left(\frac{\partial \mathbf{C}_{e}^{\mathbf{H}}}{\partial \nu^{H}}\right)_{1,2} & \left(\frac{\partial \mathbf{C}_{e}^{\mathbf{H}}}{\partial \nu^{H}}\right)_{1,3} & 0 \\
\left(\frac{\partial \mathbf{C}_{e}^{\mathbf{H}}}{\partial \nu^{H}}\right)_{2,1} & \left(\frac{\partial \mathbf{C}_{e}^{\mathbf{H}}}{\partial \nu^{H}}\right)_{2,2} & \left(\frac{\partial \mathbf{C}_{e}^{\mathbf{H}}}{\partial \nu^{H}}\right)_{2,3} & 0 \\
\left(\frac{\partial \mathbf{C}_{e}^{\mathbf{H}}}{\partial \nu^{H}}\right)_{3,1} & \left(\frac{\partial \mathbf{C}_{e}^{\mathbf{H}}}{\partial \nu^{H}}\right)_{3,2} & \left(\frac{\partial \mathbf{C}_{e}^{\mathbf{H}}}{\partial \nu^{H}}\right)_{3,3} & 0 \\
0 & 0 & 0 & \left(\frac{\partial \mathbf{C}_{e}^{\mathbf{H}}}{\partial \nu^{H}}\right)_{4,4}
\end{array}\right]
$$

onde os termos da diagonal principal e aqueles acima desta são dados por:

$$
\begin{aligned}
\left(\frac{\partial \mathbf{C}_{e}^{\mathbf{H}}}{\partial \nu^{H}}\right)_{1,1} & =\left(\frac{\partial \mathbf{C}_{e}^{\mathbf{H}}}{\partial \nu^{H}}\right)_{2,2}=\left(\frac{\partial \mathbf{C}_{e}^{\mathbf{H}}}{\partial \nu^{H}}\right)_{3,3}= \\
& -\frac{E(1-v)}{(1+v)^{2}(1-2 v)}+2 \frac{E(1-v)}{(1+v)(1-2 v)^{2}}-\frac{E}{(1+v)(1-2 v)} \\
\left(\frac{\partial \mathbf{C}_{e}^{\mathbf{H}}}{\partial \nu^{H}}\right)_{1,2} & =\left(\frac{\partial \mathbf{C}_{e}^{\mathbf{H}}}{\partial \nu^{H}}\right)_{1,3}=\left(\frac{\partial \mathbf{C}_{e}^{\mathbf{H}}}{\partial \nu^{H}}\right)_{2,3}= \\
& -\frac{E v}{(1+v)^{2}(1-2 v)}+2 \frac{E v}{(1+v)(1-2 v)^{2}}+\frac{E}{(1+v)(1-2 v)} \\
\left(\frac{\partial \mathbf{C}_{e}^{\mathbf{H}}}{\partial \nu^{H}}\right)_{4,4}= & -\frac{E(1 / 2-v)}{(1+v)^{2}(1-2 v)}+2 \frac{E(1 / 2-v)}{(1+v)(1-2 v)^{2}}-\frac{E}{(1+v)(1-2 v)}
\end{aligned}
$$

já os termos abaixo da diagonal principal não estão explicitamente representados, uma vez que esta matriz é simétrica.

Os demais termos da equação 7.64 estão representados em 7.52, 7.53, 7.54, $7.55,7.56,7.57,7.58,7.59,7.60$ e 7.61 .

Seguindo o cálculo das derivadas que envolvem a parte implícita da equação 7.37, a derivada $\frac{d G_{1}\left(\boldsymbol{\rho}^{0}\right)}{d \mathbf{d}}$ do problema adjunto 7.38, que, assim como dito anteriormente, representa um vetor cujas componentes são as derivadas de $G_{1}$ em função dos deslocamentos $d_{i}$, e estas são dadas, para o $n g$ graus de liberdade do problema, por:

$$
\begin{aligned}
\frac{d G_{1}\left(\boldsymbol{\rho}^{0}\right)}{d d_{i}} & =\frac{1}{p}\left[\frac{1}{\Omega} \sum_{e=1}^{M} \Omega_{e}\left(\frac{\left\langle\boldsymbol{\sigma}^{\text {micro }}\right\rangle_{v m^{2}}^{e}}{\left\langle\boldsymbol{\sigma}^{\text {micro }}\right\rangle_{r e f^{2}}^{e}}\right)^{p}\right]^{\frac{1-p}{p}} \cdot \\
& \frac{1}{\Omega} \sum_{e=1}^{M}\left[\Omega_{e} p\left(\frac{\left\langle\boldsymbol{\sigma}^{\text {micro }}\right\rangle_{v m^{2}}^{e}}{\left\langle\boldsymbol{\sigma}^{\text {micro }}\right\rangle_{\text {ref }}^{e}}\right)^{p-1} \cdot \frac{d\left\langle\boldsymbol{\sigma}^{\text {micro }}\right\rangle_{v m^{2}}^{e}}{d d_{i}} \frac{1}{\left\langle\boldsymbol{\sigma}^{\text {micro }}\right\rangle_{\text {ref }}^{e}}\right]
\end{aligned}
$$

onde

$$
\frac{d\left\langle\boldsymbol{\sigma}^{\text {micro }}\right\rangle_{v m}}{d d_{i}}=\frac{\partial\langle\boldsymbol{\sigma}\rangle_{e}^{T}}{\partial d_{i}} \mathbf{B}_{v m}\langle\boldsymbol{\sigma}\rangle_{e}+\langle\boldsymbol{\sigma}\rangle_{e}^{T} \mathbf{B}_{v m} \frac{\partial\langle\boldsymbol{\sigma}\rangle_{e}}{\partial d_{i}}
$$

e $\frac{\partial\langle\boldsymbol{\sigma}\rangle_{e}}{\partial d_{i}}$ é dado de forma idêntica ao problema de estruturas tradicionais, e está representado pela equação 6.66 .

Assim têm-se definido todos os termos necessários para o cálculo da sensibi- 
lidade da restrição do problema 7.29 dada por 7.37 .

Para se obter a derivada do problema 7.28 que na sua forma discreta é dado por 7.72 :

$$
\begin{aligned}
& \min _{\rho} \sum_{e=1}^{M} \int_{\Omega_{e}} \rho(x) d \Omega \\
& \text { tal que } \\
& \left.\qquad \frac{1}{\Omega} \sum_{e=1}^{M} \Omega_{e}\left(\max \left\{\frac{\left[\left\langle\boldsymbol{\sigma}^{\text {micro }}\right\rangle_{v m}\right]^{2}}{\left[\left\langle\boldsymbol{\sigma}^{\text {micro }}\right\rangle_{\text {ref }}\right]^{2}}-1,0\right\}\right)^{p}\right]^{\frac{1}{p}} \leq 0
\end{aligned}
$$

basta aplicar o mesmo procedimento descrito para o problema 7.29, porém, fazendo a somatória apenas considerando os elementos que estão falhando, assim como foi feito para o problema 6.35 na subseção 6.5.2 


\section{Implementação numérica}

Nesta seção será apresentada a implementação numérica dos problemas de $O T$ apresentados nas seções 6.5 e 7.4 .

Neste trabalho foi desenvolvido um único software, contendo as implementações de três formulações para os dois problemas propostos. Para o problema de otimização topológica de estruturas tradicionais, foi implementada a formulação de OT com restrição global de tensão e a formulação de OT com restrição local de tensão. Já para o problema de otimização da distribuição de material em estruturas constituídas por MsGF, foi implementada apenas a restrição global de tensão, desse modo este problema será denominado Otimização da distribuição de material em estruturas com gradação funcional.

Conforme descrito no capítulo 3, neste software foram implementados dois métodos de otimização, Para o problema de OT com restrição global de tensão e o problema de Otimização da distribuição de material em estruturas com gradação funcional foi implementado um algoritmo de PLS Já para o problema de OT com restrição local de tensão foi implementado o MLA. Inicialmente será apresentado o método de PLS.

A PLS aplicada ao MOT possui 3 blocos básicos que devem trocar informações entre si, que são: a implementação do MEF; o cálculo da função objetivo, restrições e respectivas análise de sensibilidades; e o algoritimo de otimização.

O Algoritmo 3 apresenta os principais passos da implementação da PLS no software de OT

O primeiro passo do Algoritmo 3 consiste na leitura dos dados de entrada do problema. Neste trabalho, estes dados são gerados com o auxílio das ferramentas de pré-processamento de um software comercial, neste caso por facilidade de foi utilizado o software ANSYS ${ }^{\circledR}$ 8.0, onde é gerada a geometria e aplicado os carregamentos, tanto externo (forças aplicadas aos nós) quanto os esforços de inércia (rotação e aceleração). 


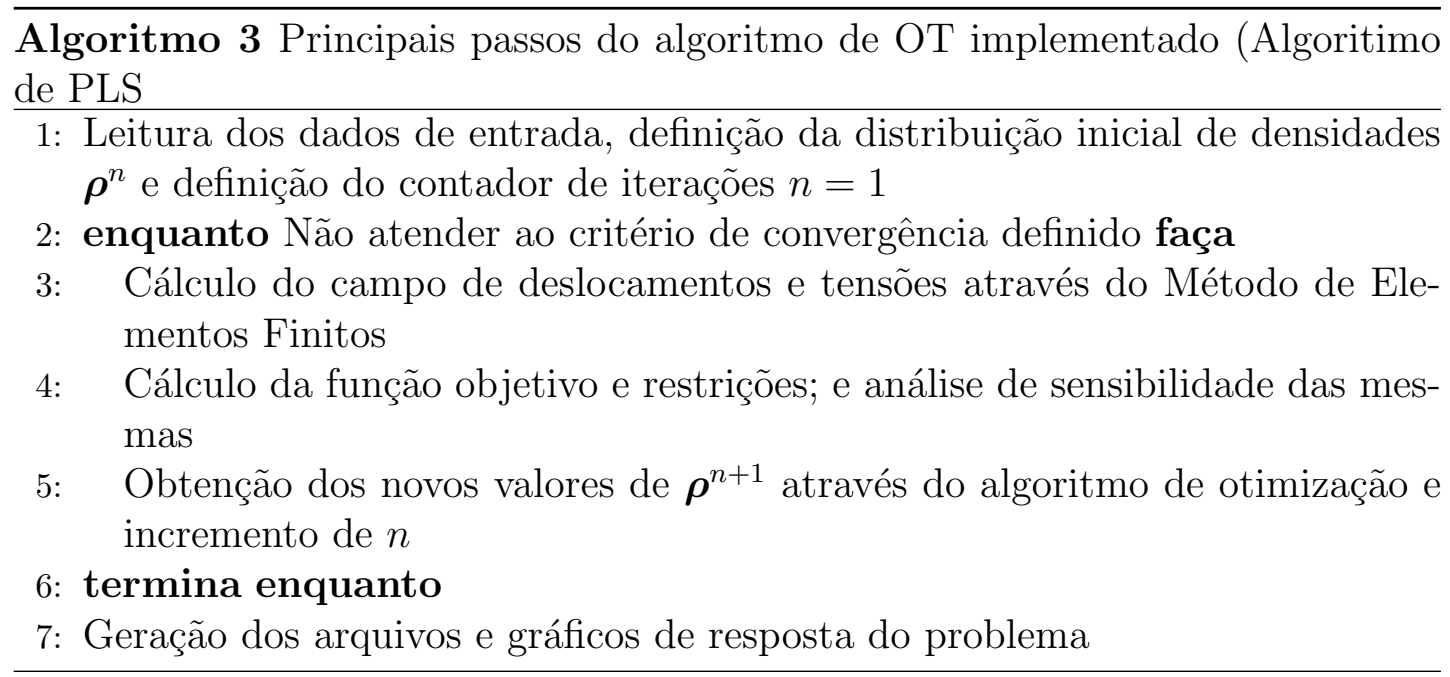

A partir do modelo em ANSYS ${ }^{\circledR}$ é gerado um arquivo em formato ASCII, através do comando Archive Model $\rightarrow$ Write, que é lido pelo software desenvolvido, este arquivo contém as coordenadas nodais da malha, a conectividade dos elementos, as propriedades mecânicas dos materiais envolvidos, no caso de estruturas com gradiente de propriedades, o vetor de força externa aplicada, a indicação dos graus de liberdade restritos, o número de elementos $(M)$ e o número de nós $(N)$. Ou seja todos os dados necessários para o Método de Elementos Finitos.

A matriz de conectividade conect define os nós que compõem cada elemento, no caso de elementos de quatro nós estes são os vértices do quadrilátero. A partir desses valores o software cria as matrizes fixas ID, matriz dos graus de liberdade não restritos já enumerados, a matriz edof formada pela conectividade dos elementos, o vetor fext que contém as forças externas nodais aplicadas a estrutura e a matriz de coordenadas nodais coord.

A partir da montagem da matriz ID, obtém-se o valor de ksize, que representa o número de graus de liberdade livres do modelo. Com a matriz ID e edof, desenvolve-se a matriz LM que representa a conectividade dos graus de liberdade não restritos de cada elemento.

Em posse das matrizes fext, LM, ksize, coord e conect é possível se iniciar o terceiro passo do Algoritmo 3 que consiste no cálculo dos campos de deslocamento e tensões da estrutura.

Para criar o sistema linear $\mathbf{K d}=\mathbf{f}$, apresentado no capítulo 5, é necessário, inicialmente criar às matrizes de rigidez local dos elementos. Para isso utiliza-se a informação de conect e coord. Cada elemento possui uma matriz 8 × 8 que relaciona as forças aplicadas aos nós com os respectivos deslocamentos. 
Calculada a matriz local deve-se então inserir seus valores na matriz global K, que, a princípio, possui o tamanho ksize x ksize, porém, neste software a matriz global $\mathbf{K}$ é montada diretamente na sua forma esparsa, que é representada através dos vetores i ja que faz a relação entre uma posição $i j$ da matrix "cheia" $\mathbf{K}$ e a posição $a$ do vetor sa que irá conter apenas os valores não nulos de $\mathbf{K}$, essa forma de indexação de matriz esparsa é apresentada em Press et al. (1999).

A importância de se utilizar a representação da matriz $\mathbf{K}$ na sua forma esparsa, é devido ao grande número de elementos nulos presentes em $\mathbf{K}$ que utilizam a memória RAM do microcomputador porém não acrescenta informação na matriz K. Esta situação é característica do sistema linear presente no MEF (BATHE, 1996). O número de elementos nulos da matriz $\mathbf{K}$ irá depender da numeração dos elementos da malha, porém a razão entre o tamanho de $\mathbf{K}$ e seu número de elementos não nulos tem a mesma ordem de grandeza para diversas malhas comumente utilizadas.

Para exemplificar essa diferença, a malha do problema apresentado na Figura 8.1 possui 4000 elementos e 4141 nós, podendo possuir até 8282 graus de liberdade, porém aplicando as condições de contorno este número é reduzido para 8181 graus de liberdade, o que implica em uma matriz K de 8181 linhas por 8181 colunas, logo possui 66.928.761 posições, porém o número de posições não nulas para essa matriz é apenas 143.577, ou seja é necessário armazenar apenas 0,21\% das posições da matriz. Logo, é fácil observar a importância do armazenamento da matriz $\mathbf{K}$ na sua forma esparsa a fim de otimizar o uso da memória RAM do microcomputador.

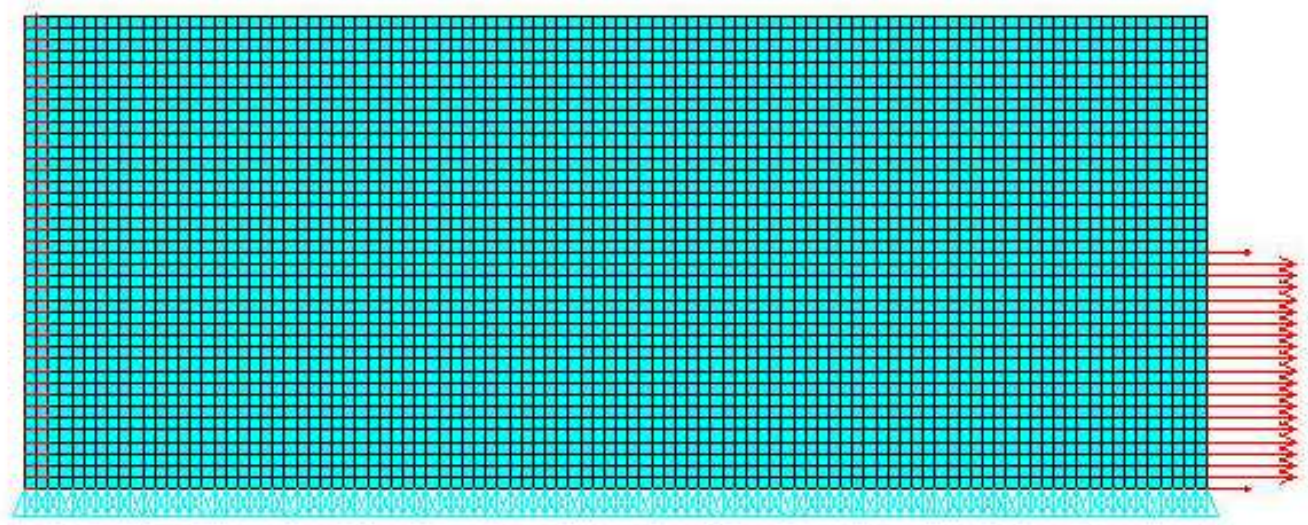

Figura 8.1: Malha exemplo para apresentação do número de elementos nulos da matriz de rigidez global $\mathbf{K}$

Para completar o sistema linear $\mathbf{K d}=\mathbf{f}$ é necessário calcular o vetor $\mathbf{f b}$, que 
representa as forças de campo aplicadas a estrutura. Tal qual a matriz de rigidez local, o vetor $\mathrm{fb}$ é calculado utilizando a geometria do elemento e os valores de densidade e aceleração do elemento.

Neste ponto é necessário resolver o sistema linear $\mathbf{K d}=\mathbf{f}$, para isso é utilizada a rotina linbcg disponível em Press et al. (1999). Esta rotina resolve sistemas lineares utilizando o Método dos Gradientes Bi-Conjugados para Sistemas Esparsos (MGBSE). Dessa forma o valor dos deslocamentos são determinados em vetor ub de tamanho ksize.

Com posse dos deslocamentos, é possível calcular o campo de tensões na estrutura. Assim, se inicia o quarto passo do Algoritmo 3, em que se é calculado o valor da função objetivo e feita análise de sensibilidade.

Para o cálculo da função objetivo são implementadas as equações apresentadas nas seções 6.5 e 7.4. Para realizar a análise de sensibilidade do problema, através do método adjunto, conforme apresentado nas seções 6.5.2 e 7.4.3, é necessário a solução do sistema linear:

$$
\mathbf{K} \boldsymbol{\lambda}^{T}=\frac{d G_{1}(\boldsymbol{\rho})}{d \mathbf{d}}
$$

Logo, novamente é utilizada a rotina $l$ inbcg, que nos fornece os valores de $\boldsymbol{\lambda}$ e conseqüentemente possibilita o cálculo dos valores das derivadas da restrição em função das variáveis de projeto $\rho_{i}$.

No caso da parametrização da densidade volumétrica ser feita pelo modelo ACDM, ou através dos elementos isoparamétricos com gradiente, o número de variáveis de projeto (nvars) será igual ao número de nós $(N)$ da malha de elementos finitos,

Com posse dos gradientes da funções objetivo e restrição, é possível se iniciar o quinto passo do Algoritmo 3, em que os novos valores das densidades nodais $\boldsymbol{\rho}^{n+1}$ são definidos.

Para a solução numérica desse problema de otimização, neste trabalho, é utilizado algoritmo de Programação Linear (PL) implementado na rotina dsplp, desenvolvido por Hanson e Hiebert (1993), e que é parte integrante da biblioteca livre SLATEC. A rotina dsplp necessita como dados de entrada a sensibilidade da função objetivo e das restrições do problema, além das restrições de caixa das variáveis de projeto, que neste caso são os limites móveis da PLS.

Um ponto importante para o bom funcionamento do algoritmo de PLS é a correta definição dos limites móveis em cada passo da PL. Neste trabalho, foi 
utilizada uma formulação de atualização dos limites móveis proposta por Cardoso (2000), e que é apresentada no Algoritmo 4.

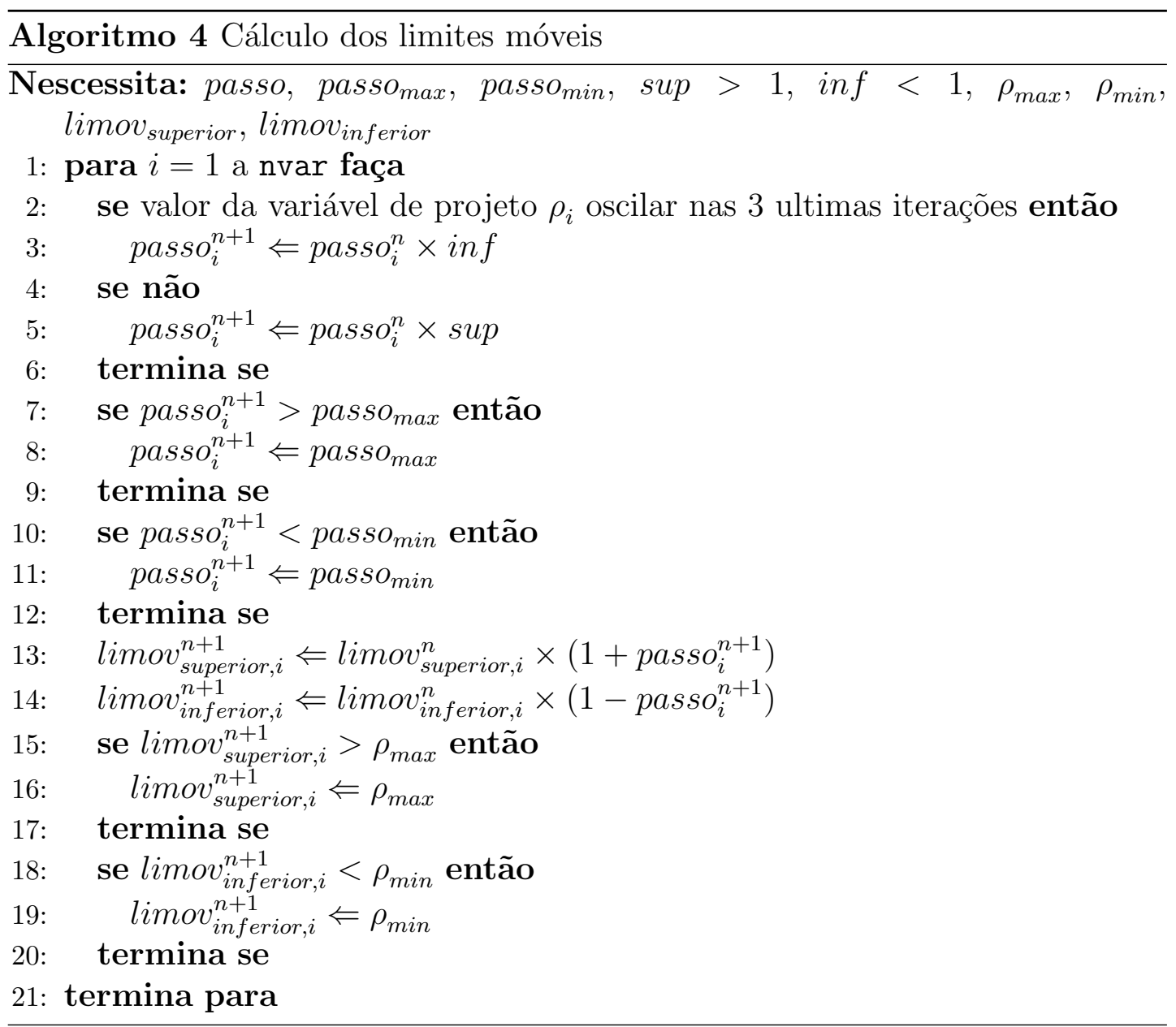

Com utilização deste algoritmo, é necessária apenas a definição prévia dos valores máximo e mínimo do limite móvel, representados por passo $_{\max }$ e passo $_{\min }$, e a definição do valor do incremento e do decremento representados por sup, inf, respectivamente. Assim, o Algoritmo 4 se encarrega de alterar, caso a caso, os limites móveis da cada variável de projeto afim de evitar as oscilações do campo de densidade devido a não-linearidade da restrição de tensão.

Outro ponto importante ao se aplicar a PLS considerando restrições, como as restrições de tensão, é que, conforme a distribuição inicial de densidades do problema, pode-se iniciar o problema em um ponto não viável do espaço de solução, e conseqüentemente, é possível que o problema linearizado a ser resolvido pela PL não tenha solução. Em termos práticos isto significa que a rotina de dsplp retorna um mensagem de erro, indicando não ter encontrado solução viável para o problema linearizado

Para evitar est problema foi utilizado o conceito de "variáveis artificiais", assim como prevista dentro do MAM. Dessa forma, qualquer distribuição de ma- 
terial representa um ponto viável do espaço de solução do problema linearizado.

Dessa forma, no caso da formulação 7.29 para estruturas constituídas por MsGF, esta é implementada como 8.1:

$$
\min _{\rho, \beta} \sum_{e=1}^{M} \int_{\Omega_{e}} \rho(x) d \Omega_{e}+k_{\beta} \beta
$$

tal que

$$
\begin{aligned}
& {\left[\frac{1}{\Omega} \sum_{e=1}^{M} \Omega_{e}\left(\frac{\left[\left\langle\boldsymbol{\sigma}^{\text {micro }}\right\rangle_{v m}^{e}\right]^{2}}{\left[\left\langle\boldsymbol{\sigma}^{\text {micro }}\right\rangle_{\text {ref }}^{e}\right]^{2}}\right)^{p}\right]^{\frac{1}{p}}-1-\beta \leq 0} \\
& 0<\rho_{\min } \leq \rho \leq 1 \\
& \beta \geq 0
\end{aligned}
$$

onde $k_{\beta}$ representa uma constante pré-definida e $\beta$ a variável artificial que deve ser maior ou igual a 0. Assim, a distribuição inicial de densidades pode ser escolhida de forma arbitrária, sem que se caia em um problema linearizado sem solução viável, pois o valor de $\beta$ sempre pode ser alto o suficiente a fim de tornar a restrição global de tensão satisfeita.

Essa, mesmo formulação foi aplicada aos demais problemas, assim o problema 7.72, também para estrutura constituídas por MsGF, foi implementado na forma dada por 8.2:

$$
\min _{\rho, \beta} \sum_{e=1}^{M} \int_{\Omega_{e}} \rho(x) d \Omega+k_{\beta} \beta
$$

tal que

$$
\begin{aligned}
& {\left[\frac{1}{\Omega} \sum_{e=1}^{M} \Omega_{e}\left(\max \left\{\frac{\left[\left\langle\boldsymbol{\sigma}^{\text {micro }}\right\rangle_{v m}^{e}\right]^{2}}{\left[\left\langle\boldsymbol{\sigma}^{\text {micro }}\right\rangle_{r e f}^{e}\right]^{2}}-1,0\right\}\right)^{p}\right]^{\frac{1}{p}}-\beta \leq 0} \\
& 0<\rho_{\min } \leq \rho \leq 1 \\
& \beta \geq 0
\end{aligned}
$$

E o problema 6.35, para o problema de OT de estruturas tradicionais consi- 
derando restrição global de tensão foi implementado na forma dada por 8.3:

$$
\underset{\rho, \beta}{\operatorname{minimizar}} \sum_{e=1}^{M} \int_{\Omega_{e}} \rho d \Omega_{e}+K_{q} \sum_{e=1}^{M} \int_{\Omega_{e}} \rho(1-\rho) d \Omega_{e}+k_{\beta} \beta
$$

tal que

$$
\begin{aligned}
& {\left[\frac{1}{\Omega} \sum_{e=1}^{M} \Omega_{e}\left(\max \left\{\frac{f_{v m}\left(\langle\boldsymbol{\sigma}\rangle_{e}\right)}{\rho^{q}} \frac{1}{\langle\boldsymbol{\sigma}\rangle_{y}}-\varepsilon(1-\rho), 0\right\}\right)^{p}\right]^{\frac{1}{p}}-1-\beta \leq 0} \\
& 0<\rho_{\min } \leq \rho \leq 1 \\
& \beta \geq 0
\end{aligned}
$$

Através da implementação utilizando a variável $\beta$, o software se tornou mais robusto conforme será apresentado nos capítulos 9 e 10.

Após a definição dos limites móveis, aplica-se sobre os mesmos, caso desejado, o filtro apresentado na seção 2.5.2, mais especificamente pela equação 2.18, Assim, os limites móveis são alterados de forma a garantir a independência da malha, porém o processo de convergência se torna mais lento, justamente pela alteração dos limites móveis.

Assim, com a definição dos limites móveis e da sensibilidade das funções envolvidas, a rotina dsplp é capaz de fornecer os novos valores de $\boldsymbol{\rho}^{n+1}$.

O procedimento iterativo representado pelos passos 3, 4 e 5 do Algoritmo 3, é então repetido, até que o critério de convergência seja atendido. Neste trabalho foi utilizado como critério de convergência a máxima variação $\rho_{i}$ entre duas iterações

Após a convergência executa-se o passo 7 do Algoritmo 3, em que são geradas os arquivos saídas do problema, que consistem em gráficos de convergências das funções envolvidas e imagens em formato Encapsulated PostScript (EPS) representando os campos das grandezas mecânicas da estrutura. Assim finaliza-se o algoritmo de OT utilizando a PLS.

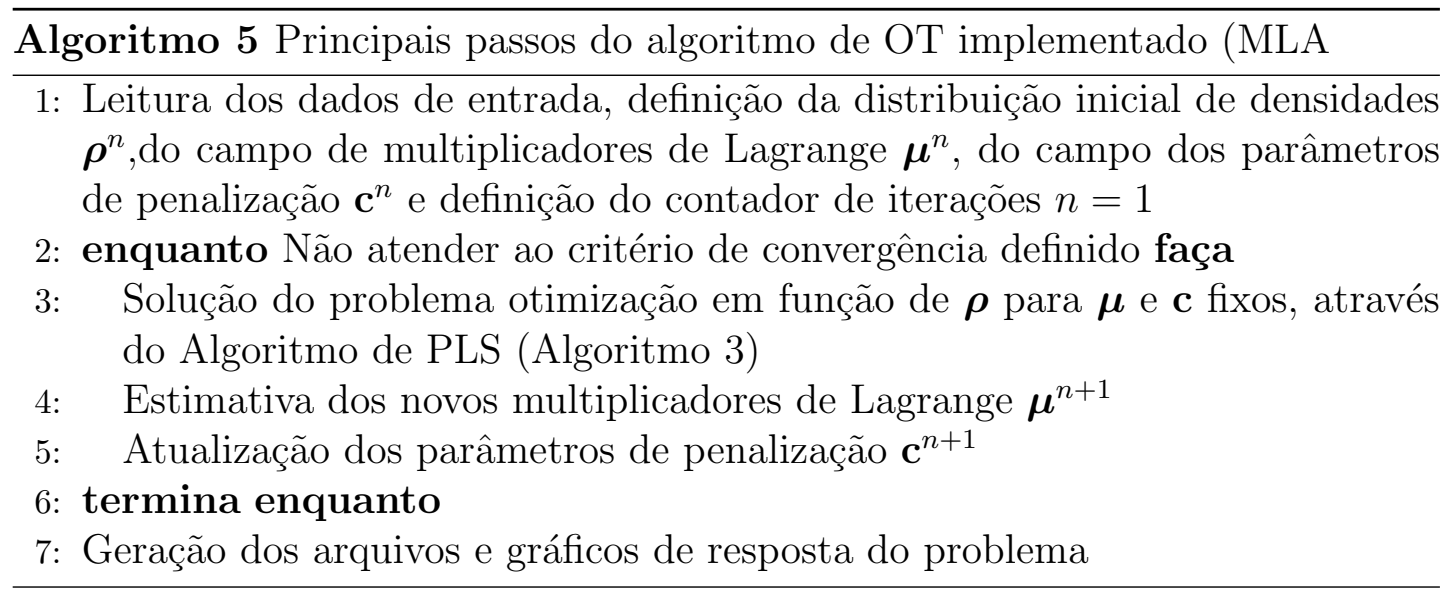


Para o problema de OT com restrição local de tensão foi implementado o MLA. Esse algoritmo foi implementado no mesmo software que o Algoritmo 3, assim este possui as mesmas etapas 3, 4, 5 do algoritmo anterior, porém estas fazem parte da etapa 3 do algoritmo do MLA. Os principais passos do MLA implementado estão apresentados no Algoritmo 5. 


\section{Resultados: Otimização Topológica com restrição de tensão}

Neste capítulo são apresentados os resultados obtidos para o problema tradicional de otimização topológica considerando restrição de tensão. A seção 9.1 apresenta os resultados obtidos para o problema de OT com restrição global de tensão e a seção 9.2 apresenta os resultados obtidos com a formulação OT com restrição local de tensão.

\subsection{Otimização Topológica considerando restrição global de tensão}

Inicialmente, com o intuito de discutir os parâmetros envolvidos na formulação de OT com restrição global de tensão, apresentada na seção 6.5, na subseção 9.1.1 é apresentada a solução de um problema simples de uma barra sujeita a tração axial.

O segundo exemplo, apresentado na subseção 9.1.2, visa demonstrar a capacidade do método frente a problemas mais complexos, assim, é resolvido o problema de uma viga bi-apoiada com carregamento a meio vão, conhecida na literatura como viga $\mathrm{MBB}$.

No terceiro exemplo, apresentado na subseção 9.1.3, é resolvido o problema de uma estrutura em formato de L invertido. Na literatura este exemplo é apresentado como um teste para verificar a capacidade do método de fornecer soluções sem pontos de concentração de tensão.

\subsubsection{Exemplo 1: Barra sujeita a tração axial}

O exemplo utilizado para apresentar e discutir a formulação exposta na seção 6.5 para o caso de estruturas tradicionais consiste em uma barra sob tração axial. 
A Figura 9.1(a) apresenta a geometria e as condições de contorno aplicadas à barra, que, no caso consiste em uma tração uniforme igual $0,25 P a$ aplicada nas extremidades da barra.

Para aplicar o MOT, foi considerado a simetria axial do problema e também a simetria em relação ao plano horizontal que corta a barra ao meio, possibilitando assim uma redução do número de elementos da malha e, conseqüentemente, a redução do número de graus de liberdade e número de variáveis de projeto. A

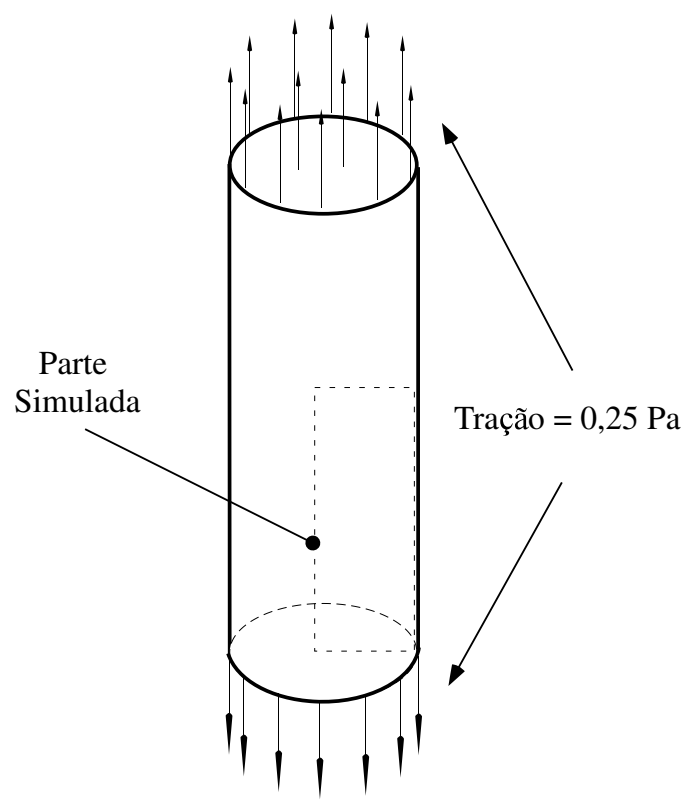

(a) Estrutura inteira

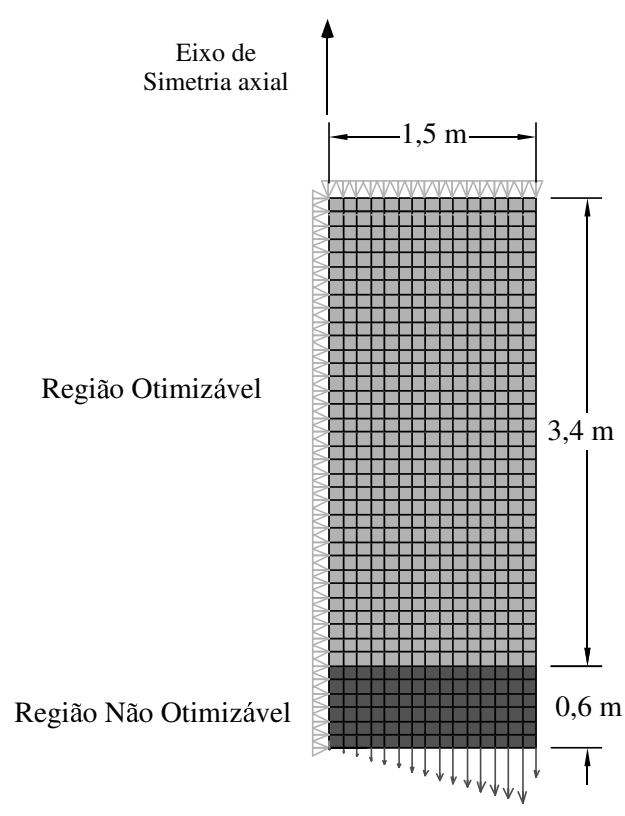

(b) Malha

Figura 9.1: Representação da malha de elementos finitos, condições de contorno e dimensões das regiões otimizáveis e não otimizáveis (malha com 600 elementos, 656 nós, e 545 variáveis de projeto no problema de otimização.)

Figura 9.1(b) apresenta a malha utilizada nos exemplos que seguem. Neste caso, as densidades nodais dos elementos da extremidade da barra, representados pela região sombreada, foram mantidas fixas. Na extremidade da barra foram aplicadas forças nodais que equivalem a pressão uniforme de 0,25Pa. Foi escolhido um material com propriedades dada por:

$$
\begin{gathered}
E=100 \\
\nu=0,3 \\
\langle\sigma\rangle_{y}=1,0
\end{gathered}
$$

Analisando o problema proposto, é esperado que a estrutura otimizada possua uma seção transversal no plano de simetria, com área igual a $25 \%$ da seção transversal total, que neste caso representa uma barra de raio igual $0,75 \mathrm{~m}$. 
Adiante será apresentada um discussão sobre os parâmetros envolvidos na formulação proposta.

Inicialmente foi estudada a influência da distribuição inicial de densidades, assim, neste caso foram sintetizadas quatro estruturas, todas com densidade inicial $\rho_{0}$ constante ao longo de todo o DFE. As densidades escolhidas foram $\rho_{0}=0,001$, $\rho_{0}=0,25, \rho_{0}=0,50 \rho_{0}=0,75$ e $\rho_{0}=1,0$. Para isolar a influência da distribuição inicial de densidades, não foi utilizado o método da continuação em nenhum dos parâmetros, e optou-se por utilizar parâmetros brandos para a norma-p e $\varepsilon$-relaxação. Assim, foi utilizado $p=6$ e $\varepsilon=1,0$.

Os resultados finais para $\rho=0,25, \rho=0,50, \rho=0,75$ e $\rho=1,0$ são apresentados na Figura 9.2. A estrutura obtida para $\rho=0,001$ não é representada, pois esta resultou em uma estrutura vazia. A tensão de von Mises máxima e o volume da estrutura final estão indicados na legenda de cada figura.

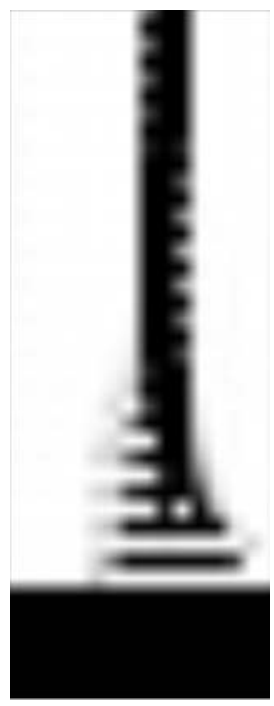

(a) $\rho_{0}=0,25$;

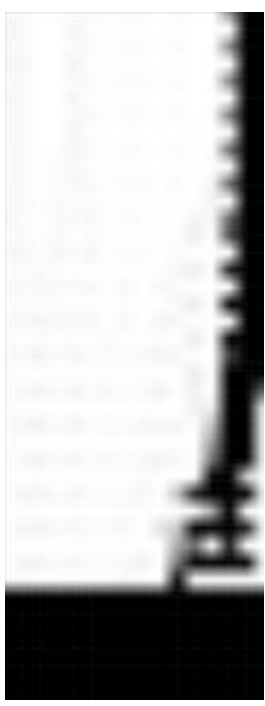

(b) $\rho_{0}=0,50$

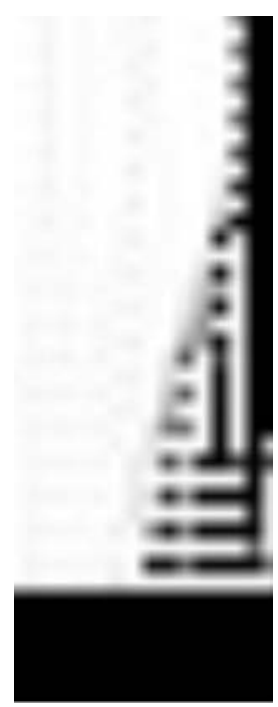

(c) $\rho_{0}=0,75$

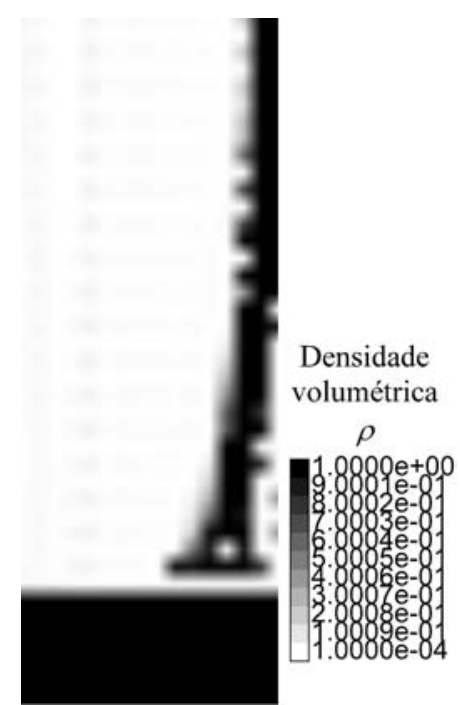

(d) $\rho_{0}=1,0$

Figura 9.2: Soluções finais para diferentes distribuições iniciais de densidade considerando $\varepsilon=1,0, p=6, q=3$; (a) Tensão de von Mises máx.

$\left(f_{v m}(\langle\boldsymbol{\sigma}\rangle)_{\max }\right) 2,28 P a$, Volume final 36\%; (b) $f_{v m}(\langle\boldsymbol{\sigma}\rangle)_{\max }=2,17 P a$, Volume final $38 \%$; (c) $f_{v m}(\langle\boldsymbol{\sigma}\rangle)_{\max }=2,02 P a$, Volume final $40 \%$; (d) $f_{v m}(\langle\boldsymbol{\sigma}\rangle)_{\max }=2,02 P a$, Volume final $38 \%$

A partir dos resultados apresentados nas Figuras 9.2, é possível concluir que o campo de densidades inicial influencia o leiaute obtido. Isto significa que, do ponto de vista da otimização, cada leiaute representa um ponto ótimo local do problema. Continuando a avaliação da influência da densidade inicial na solução obtida, foram sintetizadas mais quatro estruturas, também com densidade inicial $\rho_{0}$ constante, porém, neste caso foi diminuído o valor de $\varepsilon$ de 1,0 para 0,1 . Os leiautes obtidos estão apresentados na Figura 9.3. 


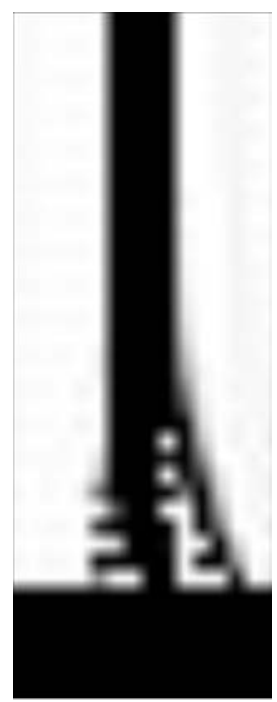

(a) $\rho_{0}=0,25$

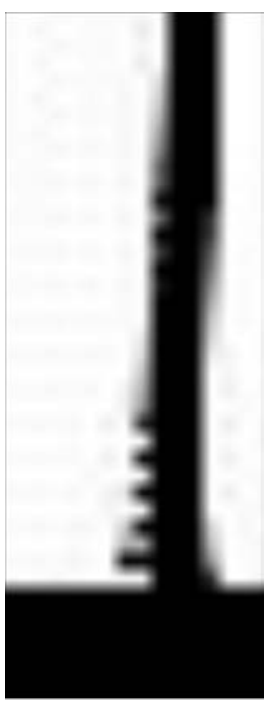

(b) $\rho_{0}=0,50$

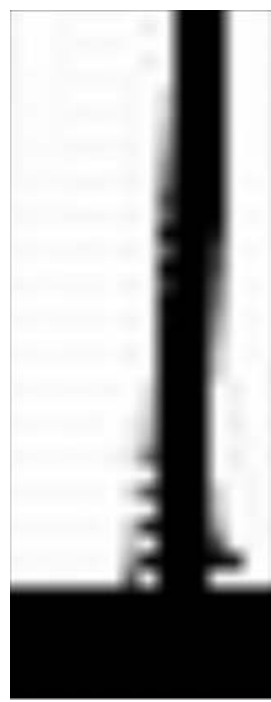

(c) $\rho_{0}=0,75$

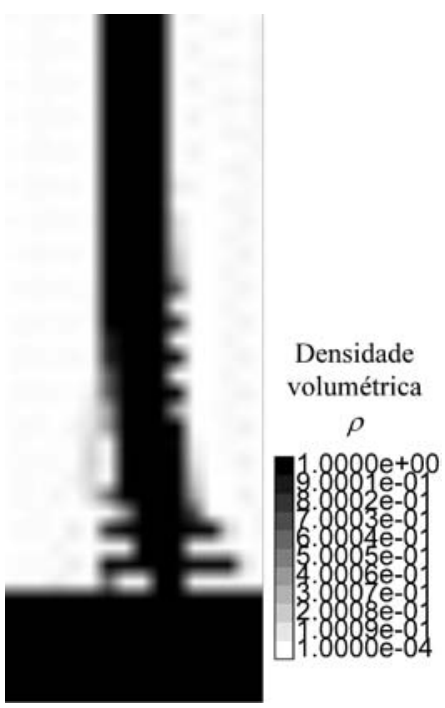

(d) $\rho_{0}=1,0$

Figura 9.3: Soluções finais para diferentes distribuições iniciais de densidade considerando $\varepsilon=0,1, p=6, q=3$; (a) Tensão von Mises máx $\left(f_{v m}(\langle\boldsymbol{\sigma}\rangle)_{\max }\right)$

$1,72 P a$, Volume final $42 \%$ (b) $f_{v m}(\langle\boldsymbol{\sigma}\rangle)_{\max }=1,12 P a$, Volume final $43 \%$ (c) $f_{v m}(\langle\boldsymbol{\sigma}\rangle)_{\max }=1,12 P a$, Volume final $43 \%$ (d) $f_{v m}(\langle\boldsymbol{\sigma}\rangle)_{\max }=1,16 P a$, Volume final $42 \%$

Novamente, observa-se na Figura 9.3 que a distribuição inicial de densidades altera o leiaute obtido e, comparando as estruturas obtidas $\operatorname{com} \varepsilon=1,0$ (Figura 9.2) em relação as estruturas obtidas com $\varepsilon=0,1$ (Figura 9.3), observa-se que o valor de $\varepsilon$ também altera o espaço de solução, modificando a posição dos pontos ótimos. Esta situação é prevista na literatura e está apresentada na seção 6.3.

Do ponto de vista prático, a escolha dos parâmetros iniciais irá definir o leiaute básico da estrutura e a alteração destes parâmetros através do método da continuação irá apenas refinar o leiaute obtido. A única forma de garantir se existe um ponto ótimo melhor do que aquele obtido, no caso da implementação utilizada neste trabalho, é fazer uma varredura do espaço de solução através da alteração da distribuição inicial de densidade e dos parâmetros $p$ e $\varepsilon$.

A principal característica indesejável nas estruturas apresentadas nas Figuras 9.2 e 9.3 é a distribuição de densidades em um padrão geométrico de camadas, que em alguns casos gera estruturas desconexas. Este padrão de camadas é geometricamente similar ao padrão descrito por Rahmatalla e Swan (2004), porém, as causas aparentemente são diferentes, uma vez que, no caso da formulação proposta estas oscilações são influenciadas pelo valor de $\varepsilon$, conforme será apresentado adiante.

O segundo ponto a ser estudado foi a influência do parâmetro $\varepsilon$, responsável pela relaxação do problema. Assim, foram sintetizadas estruturas para $\varepsilon=0,01$, 
$\varepsilon=0,001$, e neste caso, não foi feita a continuação do valor de $\varepsilon$. Os resultados obtidos são apresentados na Figura 9.4, junto com os resultados para $\varepsilon=1,0 \mathrm{e}$ $\varepsilon=0,1$ apresentados nas Figuras 9.2(d) e 9.3(d), respectivamente. O volume de cada estrutura está designado na legenda da figura.

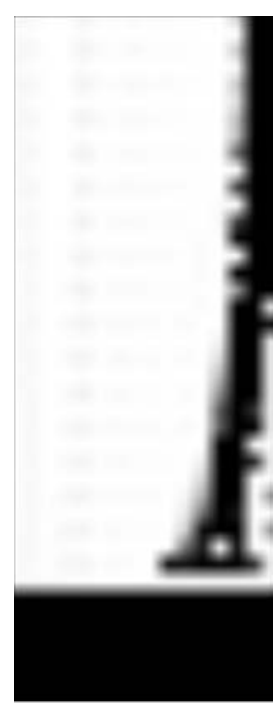

(a) $\varepsilon=1,0$

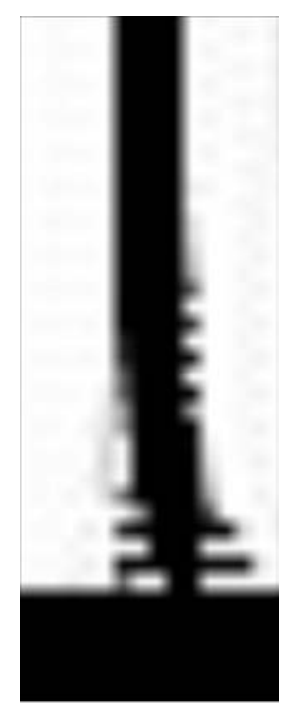

(b) $\varepsilon=0,1$

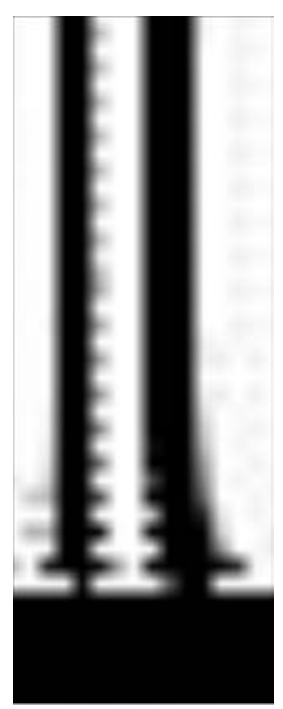

(c) $\varepsilon=0,01$

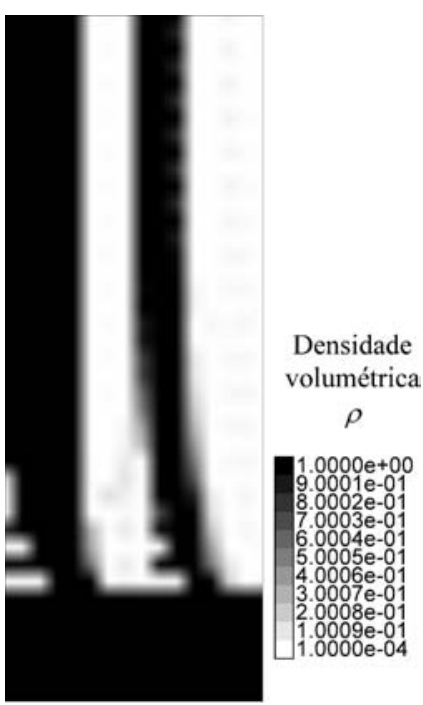

(d) $\varepsilon=0,001$

Figura 9.4: Comparação dos resultados obtidos para diferentes valores de $\varepsilon$ sem fazer a continuação, considerando os demais parâmetros constantes ( $p=6$, $q=3$ ) e distribuição inicial de densidades constante e igual a 1,0 (a) $f_{v m}(\langle\boldsymbol{\sigma}\rangle)_{\max }=2,02 P a$; Volume final 38\% (b) $f_{v m}(\langle\boldsymbol{\sigma}\rangle)_{\max }=1,03 P a$; Volume final $42 \%$ (c) $f_{v m}(\langle\boldsymbol{\sigma}\rangle)_{\max }=1,02 P a$; Volume final $45 \%$ (d) $f_{v m}(\langle=1,15 \boldsymbol{\sigma}\rangle)_{\max }=P a$; Volume final $44 \%$

Analisando os resultados apresentados na Figura 9.4, é possível verificar que o valor de $\varepsilon$ altera o ponto ótimo influenciando duas características da estrutura obtida: a presença do padrão de camadas e o nível de tensão na estrutura.

A medida que é diminuído o valor de $\varepsilon$, diminui a presença dos padrões de camadas na estrutura obtida. Entretanto, a medida que se diminui o valor de $\varepsilon$, a solução obtida possui um maior volume. Observando a Figura 9.4, é possível notar que o volume da estrutura aumenta e a máxima tensão mecânica diminui com o diminuição de $\varepsilon$.

Com base nos resultado obtidos e apresentados na Figura 9.4, verifica-se a necessidade de se fazer a diminuição continua do valor de $\varepsilon$ de modo a evitar o surgimento do padrão de ilhas e ao mesmo tempo conservar o desempenho da estrutura ou seja, o baixo volume da estrutura obtida para valores altos de $\varepsilon$.

Dessa forma, o valor de $\varepsilon$ foi alterado ao longo das iterações, caracterizando assim um método de continuação. Com base nas discussões apresentadas na seção 6.3 , foi utilizada uma variação contínua de $\varepsilon$, ou seja, a cada iteração $\varepsilon$ é 
decrescido de uma porcentagem em relação à iteração anterior. Assim, a medida que o valor $\varepsilon$ se aproxima do valor desejado a sua diminuição se torna mais suave, permitindo que o algoritmo de otimização "acompanhe" o deslocamento do ponto ótimo.

Para verificar a influência da continuação do parâmetro $\varepsilon$, as estruturas apresentadas na Figura 9.2 foram sintetizadas novamente, porém fazendo a continuação de $\varepsilon$. Assim, foram utilizadas as mesmas distribuições iniciais de densidades $\left(\rho_{0}=0,25 ; \rho_{0}=0,50 ; \rho_{0}=0,75\right.$ e $\left.\rho_{0}=1,0\right)$ e $\varepsilon$ foi mantido constante e igual à 1,0 durante as 100 primeiras iterações a fim de que a solução convergisse para os mesmos pontos ótimos representativos dos leiautes expostos na Figura 9.2. As soluções obtidas são apresentadas na Figura 9.5.

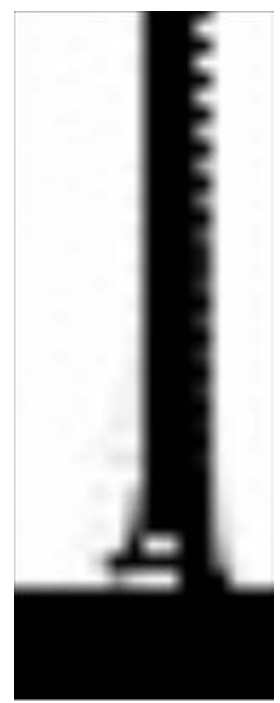

(a) $\rho_{0}=0,25$; Tensão von Mises máx. 1,38Pa)

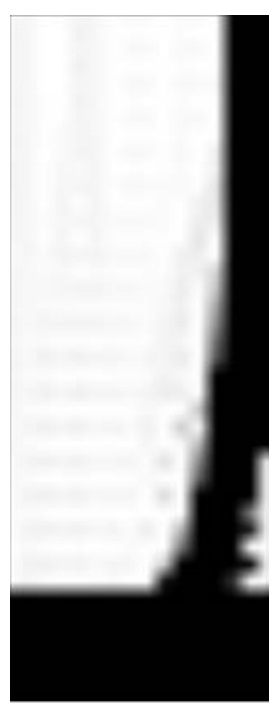

(b) $\rho_{0}=0,50$; Tensão von Mises máx. 0,97Pa)

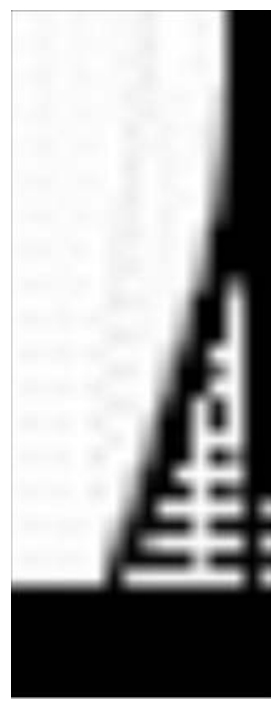

(c) $\rho_{0}=0,75$; Tensão von Mises Mises máx. 1,00Pa) máx.1, 35Pa)

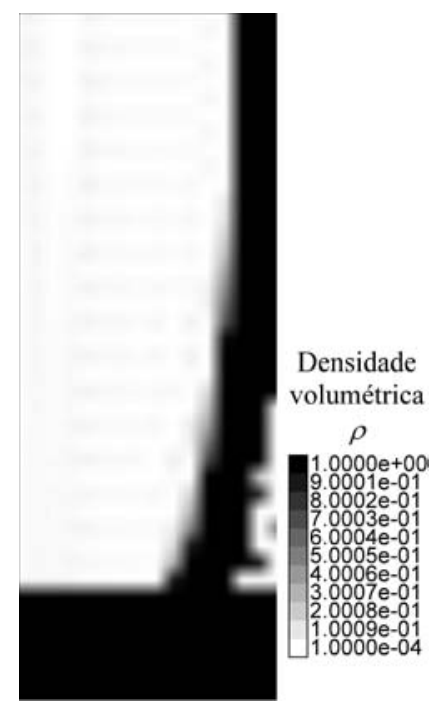

(d) $\rho_{0}=1,0$; Tensão von

Figura 9.5: Comparação da solução final para diferentes distribuições iniciais de densidade considerando continuação de $\varepsilon$, partindo de $\varepsilon=1,0$ até

$$
\varepsilon=0,0001, p=6, q=3 \text {. }
$$

Comparando as estruturas apresentadas na Figura 9.5 com aquelas apresentadas na Figura 9.2, que foram sintetizadas utilizando $\varepsilon=1,0$, observa-se que o leiaute da estrutura se mantém o mesmo para as diferentes distribuições iniciais de densidade e as regiões que apresentam o padrão geométrico de camadas são diminuídas. A Figura 9.6 apresenta os campos de tensão de von Mises nas estruturas representadas nas Figuras 9.2(d) e 9.5(d).

Analisando o campo da tensão de von Mises, apresentados na Figura 9.6, das estruturas sintetizadas utilizando e sem utilizar a continuação de $\varepsilon$, observa-se que, ao fazer a continuação de $\varepsilon$, são minimizadas as regiões que apresentam o 


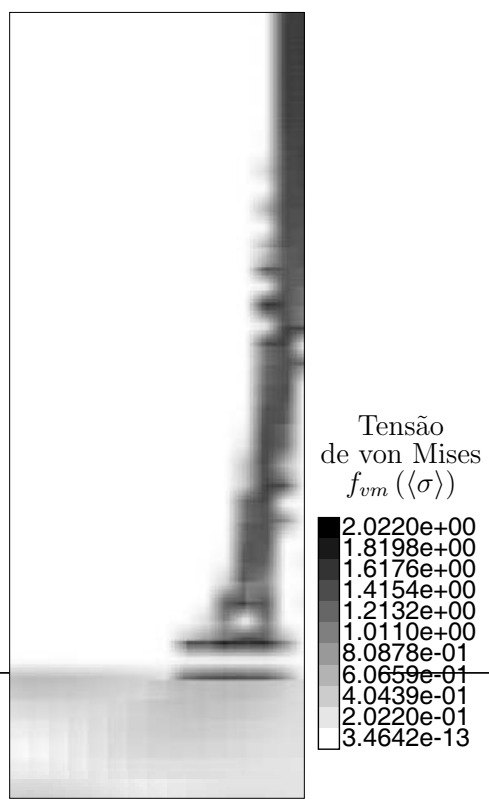

(a) Tensão de von Mises na estrutura representada na Figura 9.2(d) $(\varepsilon=1,0)$

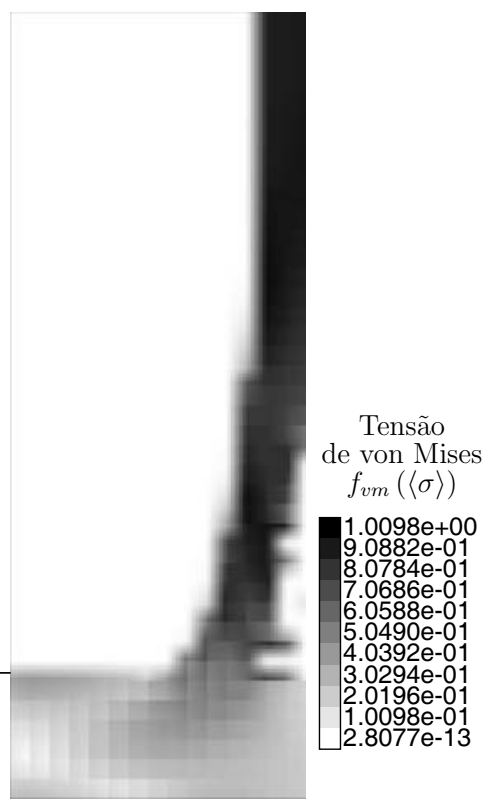

(b) Tensão de von Mises na estrutura representada na Figura 9.5(d) (Continuação de $\varepsilon$ )

Figura 9.6: Comparação do campo de tensão de von Mises nas estrutura obtidas utilizando e sem utilizar a continuação do valor de $\varepsilon$

padrão geométrico de camadas e, conseqüentemente, é reduzida a máxima tensão mecânica, que ocorre justamente devido à intensificação gerada por este padrão geométrico.

Observa-se também na Figura 9.5(d) que utilizando a continuação de $\varepsilon$ é possível obter uma estrutura com contornos bem definidos e que atende a restrição de tensão imposta no problema. Neste caso, observa-se, na Figura 9.6(b), que a máxima tensão mecânica é igual a 1,009Pa, praticamente igual a tensão de escoamento do material 1,0Pa.

O terceiro parâmetro a ser estudado é o valor de $p$ na norma-p. Matematicamente, quanto maior o valor de $p$ mais a função global se aproxima da máxima tensão local no domínio, o que permite concluir que, ao menos a princípio, quanto maior o valor de $p$ melhor será o controle da tensão máxima da estrutura.

Dessa forma, foi feito um estudo para três valores de $p$, que são $p=14$, $p=22$, e $p=30$, e mantendo o método da continuação percentual para o valor de $\varepsilon$. Para se evitar problemas numéricos, foi feita a continuação do valor de $p$, porém, neste caso a continuação foi feita de forma discreta, incrementando o valor de $p$ a cada 100 iterações. Assim, para sintetizar a estrutura com $p=14$, foi utilizada a seqüência, $p=6 ; 14$, para $p=22$ foi utilizado $p=6 ; 14 ; 22$, e para $p=30$, foi utilizado $p=6 ; 14 ; 22 ; 30$.

Analisando o gráfico de convergência da Figura 9.7, inicialmente, observa-se 


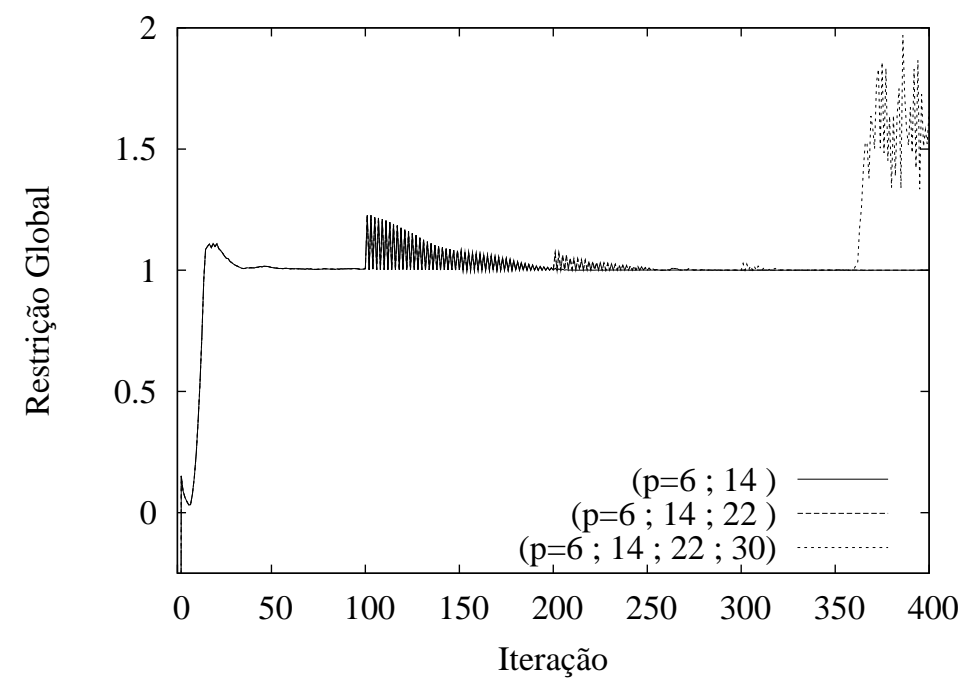

Figura 9.7: Curva de convergência da restrição de global de tensão para as três continuações do valor $p$ ( solução com $p=6 ; 14$, solução com $p=6 ; 14 ;, 22$ e solução com $p=6 ; 14 ; 22 ; 30$.)

que devido à forma com que foi feita a continuação, as curvas se sobrepõem para o mesmo valores de $p$. Observa-se, também, que na iteração 100, 200 e 300 a curva de convergência da restrição global de tensão oscila devido ao incremento de $p$. A restrição, em princípio, deve ser menor ou igual à 1,0, porém, quando ocorre um aumento de $p$ a restrição é violada, e com o passar das iterações, o algoritmo encontra uma nova solução viável para o novo valor de $p$. Isso ocorre para as continuações $p=6 ; 14$, e $p=6 ; 14 ; 22$, entretanto, para a continuação $p=6 ; 14 ; 22 ; 30$ o algoritmo não é capaz de encontrar uma nova solução viável e a restrição diverge, como se observa a partir da iteração 350, no gráfico da Figura 9.7 .

As soluções obtidas com as continuações de $p$ estão representadas na Figura 9.8 , onde se observa que a estrutura obtida com a continuação $p=6 ; 14 ; 22 ; 30$ apresenta os contornos menos definidos, devido à presença de uma região cinza ao redor da estrutura. Analisando os campos de tensão de von Mises nestas estruturas, apresentados na Figura 9.9, observa-se que, para a solução obtida com $p=6 ; 14 ; 22$, a máxima tensão de von Mises é menor do que para a solução obtida $p=6 ; 14$, como era previsto, pelo fato de que o aumento de $p$ leva a um melhor controle da tensão máxima. Porém, conforme mostrado no gráfico da Figura 9.7, no caso da continuação $p=6 ; 14 ; 22 ; 30$, a restrição diverge e a máxima tensão mecânica na estrutura passa a ser maior do que para a continuação $p=6 ; 14 ; 22$.

Comparando os resultado obtidos com a continuação do valor de $p$ (Figura 9.9) com o resultado obtido com a continuação de $\varepsilon$ (Figura 9.6(b)), observa-se 


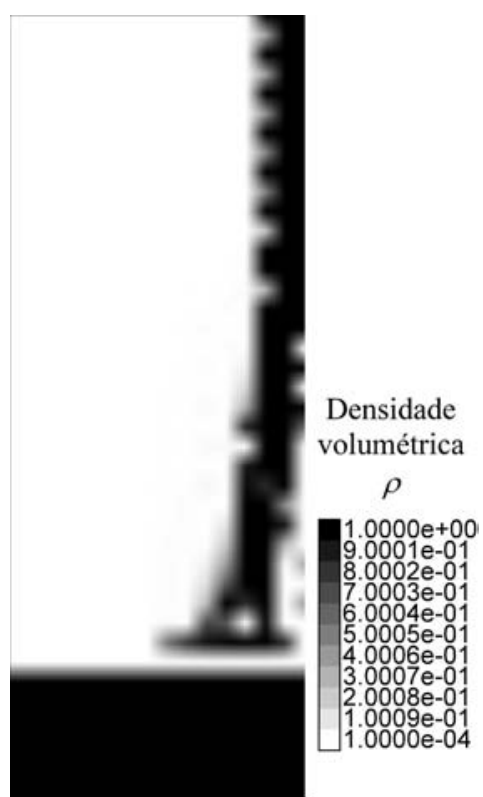

(a) $p=6 ; 14$

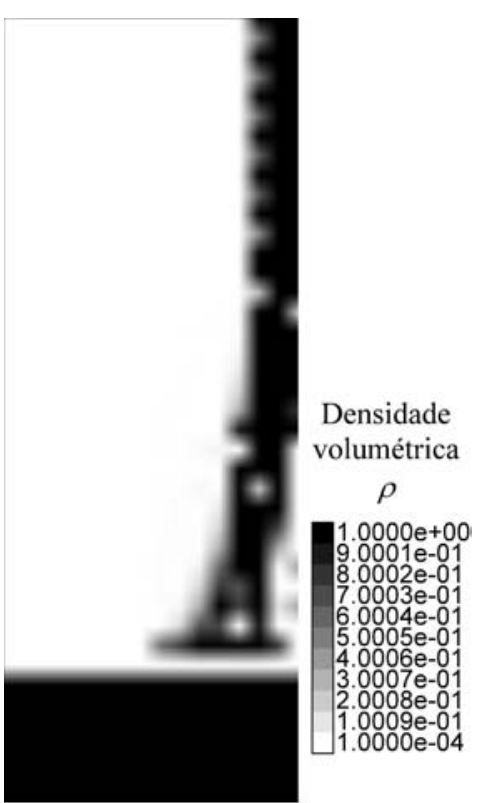

(b) $p=6 ; 14 ; 22$

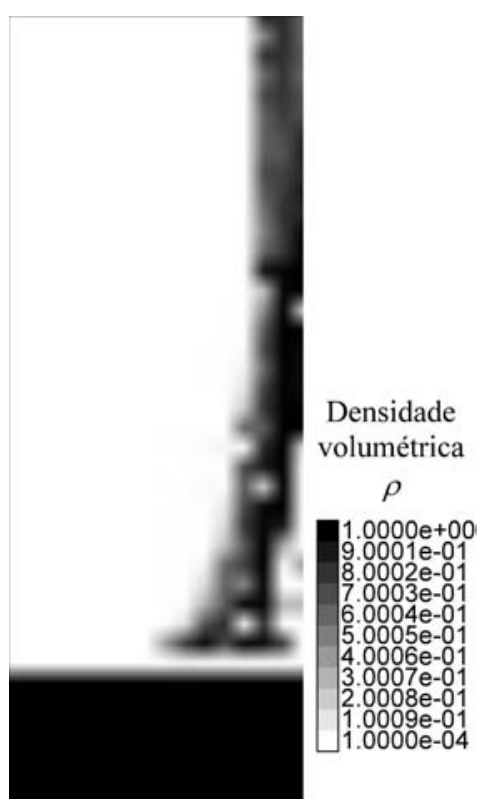

(c) $p=6 ; 14 ; 22 ; 30$

Figura 9.8: Soluções finais obtidas com a continuação de parâmetro $p$, considerando $q=3$ e $\varepsilon=1$

que o parâmetro $\varepsilon$ fornece um melhor controle da máxima tensão de von Mises em relação ao parâmetro $p$, uma vez que o primeiro influencia o surgimento do padrão geométrico de camadas, acarretando no surgimento de pontos de intensificação de tensão, já o segundo não.

O último parâmetro a ser estudado foi a influência do filtro, dado pela equação 2.18, na solução obtida. Para isso, novamente, foram sintetizadas as estruturas apresentadas na Figura 9.5, isto é, foi considerado a continuação de $\varepsilon$ partindo de $\varepsilon=1,0$ até $\varepsilon=0,0001$, através da continuação percentual e adotou-se $p=6 \mathrm{e}$ $q=3$. Entretanto, neste caso, foi considerado o filtro com raio igual à dimensão da aresta de um elemento. O filtro foi mantido ligado durante as primeiras 200 iterações e desligado nas 200 iterações seguintes, a fim de permitir uma boa definição dos contornos da estrutura. As estruturas obtidas estão apresentadas na Figura 9.10.

Comparando os resultados apresentados na Figura 9.10, em que foi utilizado o filtro, com os apresentados Figura 9.5, observa-se que o filtro é capaz de minimizar as regiões que apresentam o padrão geométrico de camadas. Este efeito se mostrou mais pronunciado nas estruturas com distribuição de densidade inicial igual a $0,25 \%$ e $0,75 \%$ (Figuras $9.10($ a) e $9.10(\mathrm{c})$ ), justamente as estruturas que apresentam as maiores regiões com o padrão geométrico de camadas quando o filtro não é aplicado (Figuras 9.5(a) e 9.5(c)).

Aqui vale a pena notar que não é interessante utilizar apenas o filtro para 


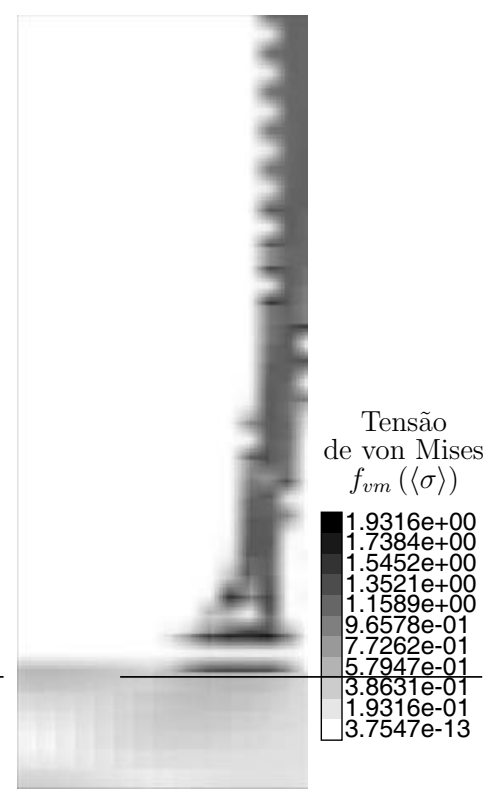

(a) $p=6 ; 14$

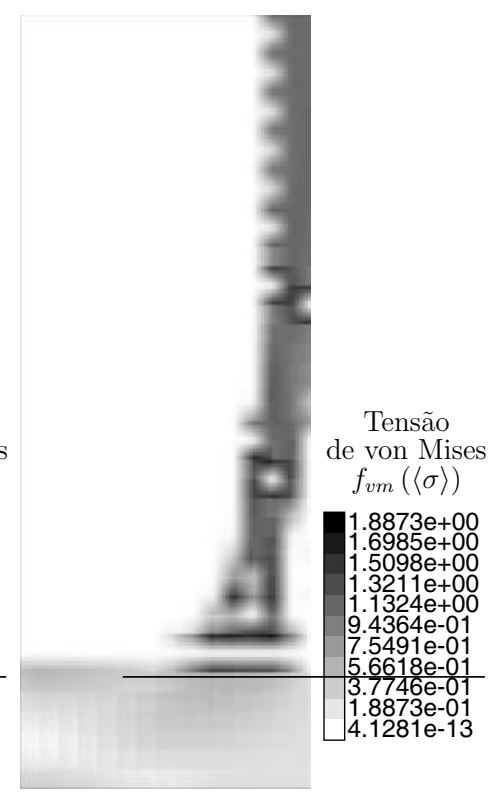

(b) $p=6 ; 14 ; 22$

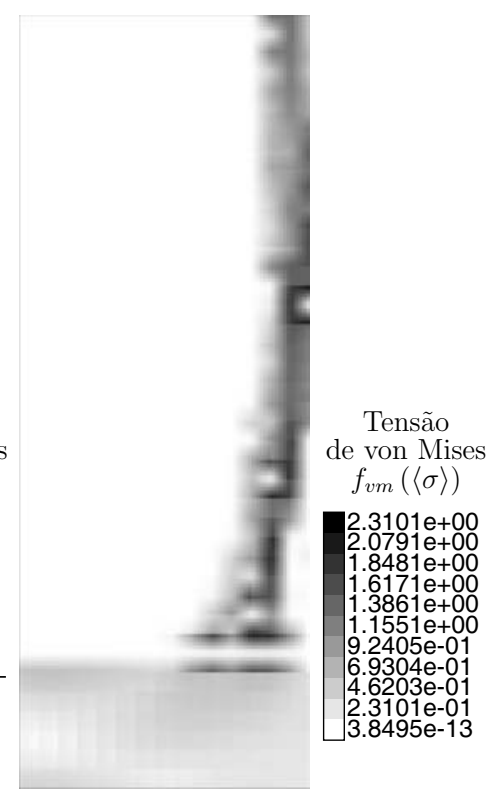

(c) $p=6 ; 14 ; 22 ; 30$

Figura 9.9: Campo de tensão de von Mises nas as estruturas obtidas com a continuação de parâmetro $p$, considerando $q=3$ e $\varepsilon=1$

a minimização das regiões com o padrão geométrico de camadas, uma vez que este atua de forma artificial no problema. É mais aconselhável trabalhar com a continuação de $\varepsilon$, tal qual foi apresentado anteriormente, e apenas utilizar o filtro como última alternativa para a retirada dos padrões de camada.

Outra influência do filtro, pode ser verificada analisando as estruturas representadas nas Figuras 9.5(b), 9.5(c) e 9.5(d), que foram obtidas sem a utilização de filtros, Nestas Figuras observam-se duas topologias diferentes, uma para o caso de $\rho_{0}=0,5$ e $\rho_{0}=1,0$ e outra para o caso de $\rho_{0}=0,75$. Comparando as com as estruturas obtidas com a utilização do filtro, representadas pelas Figuras 9.10(b), 9.10(c) e 9.10(d), verifica-se apenas uma topologia para as três estruturas. Esta situação indica que o filtro, de certa forma, faz com que o problema se torne mais estável e convirja para o mesmo ponto ótimo, esta situação pode ser melhor compreendida se interpretarmos os filtro como uma forma de diminuir a flexibilidade do campo de densidades e, assim, restringir o espaço de soluções.

A partir dos estudos apresentados, é possível melhor compreender a influência da distribuição inicial de densidades $\rho$, do parâmetro de relaxação $\varepsilon$ e do parâmetro de $p$ da norma-p, na solução obtida pelo MOT. Dessa modo, é possível utilizar estes parâmetros de forma racional a fim de se obter a estrutura desejada, ou seja, a que possua o mínimo volume tal que a restrição de tensão seja atendida.

Assim, foi sintetizada uma estrutura otimizada para o caso da barra sob tração axial em estudo. Para melhor representar o campo de tensões, este problema foi 


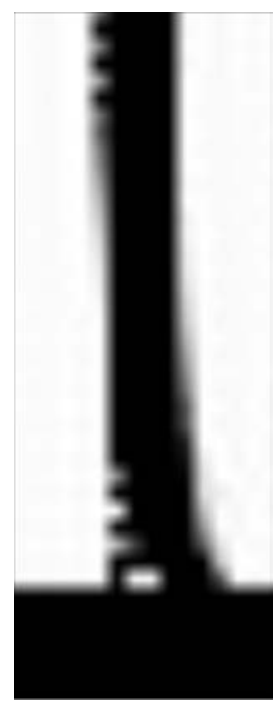

(a) $\rho_{0}=0,25$

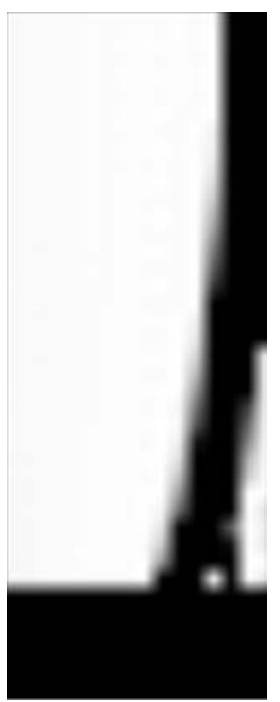

(b) $\rho_{0}=0,50$

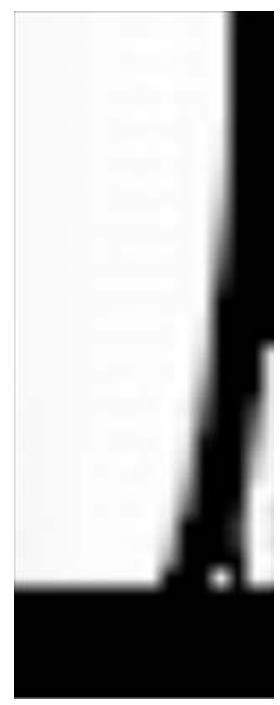

(c) $\rho_{0}=0,75$

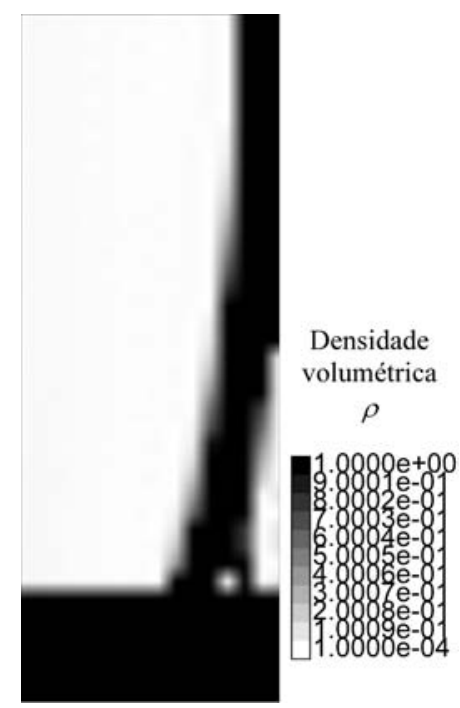

(d) $\rho_{0}=1,0$

Figura 9.10: Comparação da solução final para diferentes distribuições iniciais de densidade considerando filtro aplicado nas primeiras 200 iterações, continuação de $\varepsilon$ partindo de $\varepsilon=1,0$ até $\varepsilon=0,0001, p=6, q=3$

tratado com uma malha mais discretizada, apresentada na Figura 9.11(a). Nesta malha os elementos possuem dimensões $0,033 \mathrm{~m}$ por $0,033 \mathrm{~m}$. E após um estudo dos parâmetros $p$ e $\varepsilon$, foi possível encontrar seus valores ótimos para o caso da malha mais refinada. A Figura 9.11(b) apresenta a solução obtida fazendo a continuação de $p=6 ; 14 ; 22$, o valor de $\varepsilon$ foi decrescido de 0,1 até 0,0001 , utilizando a continuação percentual, e o filtro com raio igual a $0,05 m$ foi ligado durante as 200 primeiras iterações.

Neste caso o filtro foi utilizado com o intuito de, além de minimizar as regiões que apresentam o padrão geométrico de camada, garantir a unicidade de solução em relação às estruturas sintetizadas com os mesmos parâmetros iniciais, porém, com malha menos discretizadas. No caso as estruturas representadas nas Figuras $9.10(\mathrm{~d})$ e $9.5(\mathrm{~d})$.

Analisando a solução obtida com a malha mais refinada, apresentada na Figura 9.11(b), pode-se observar que a estrutura apresenta os contornos bem definidos e formados por curvas suaves que impedem a ocorrência de concentrações de tensão na estrutura. Isto pode ser observado na Figura 9.12, que apresenta o campo da tensão de von Mises no DFE com valor máximo igual à 1,0038Pa, ou seja, apenas 0,38\% acima da tensão de escoamento.

Através desse resultado, é possível concluir que a formulação proposta na seção 6.5 é capaz de sintetizar estruturas com mínima massa que atendam ao critério de restrição de tensão especificado. 


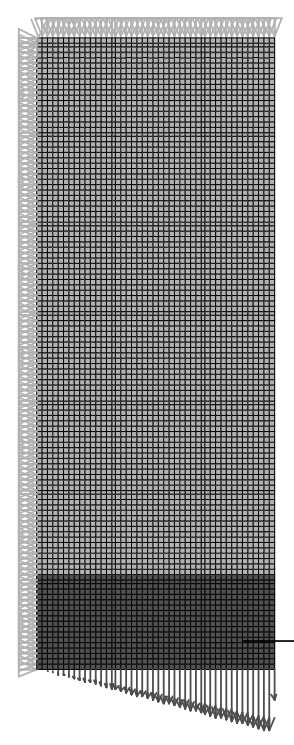

(a) Malha refinada

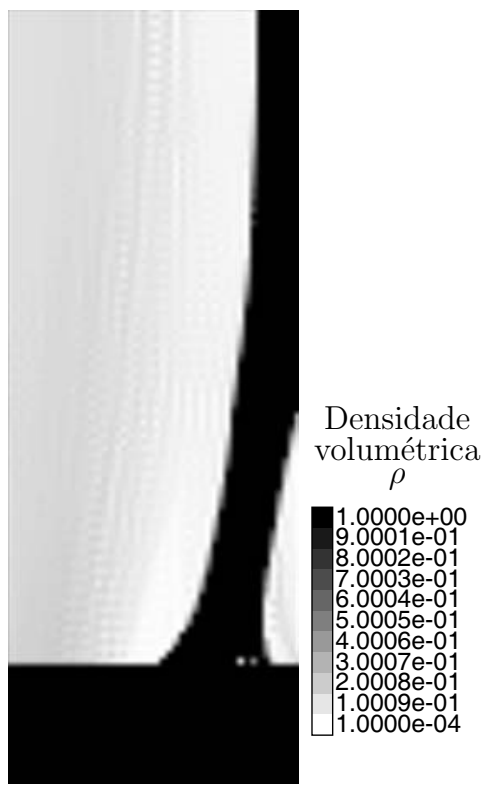

(b) Solução obtida

Figura 9.11: Representação da malha refinada utilizada para o problema da barra sujeita a tração e a respectiva solução (malha com 5400 elementos, 5556 nós, e 4693 variáveis de projeto no problema de otimização)

Para melhor compreender o comportamento da restrição global de tensão, utilizada neste trabalho, e dada por:

$$
G_{1} \equiv\left[\frac{1}{\Omega} \sum_{e \in A t v}\left(\frac{f_{v m}\left(\langle\boldsymbol{\sigma}\rangle_{e}\right)}{\rho^{q}} \frac{1}{\langle\boldsymbol{\sigma}\rangle_{y}}-\varepsilon(1-\rho)\right)^{p}\right]^{\frac{1}{p}} \leq 1
$$

Será apresentado, para a solução obtida com a malha mais refinada, o campo de tensão na microestrutura, que é dada por:

$$
\frac{f_{v m}\left(\langle\boldsymbol{\sigma}\rangle_{e}\right)}{\rho^{q}}
$$

e também o campo da componente da restrição de tensão dada por:

$$
\frac{f_{v m}\left(\langle\boldsymbol{\sigma}\rangle_{e}\right)}{\rho^{q}} \frac{1}{\langle\boldsymbol{\sigma}\rangle_{y}}-\varepsilon(1-\rho)
$$

. Esta aqui será chamada de função de falha relaxada.

Inicialmente, deve-se ressaltar que, apesar de se estar interessado em encontrar uma estrutura constituída apenas por material homogêneo, isto é, $\rho=1,0$ ou $\rho=0,001$, o critério de tensão é aplicado sobre a tensão na microestrutura de um material poroso. Após a aplicação do conceito de $\varepsilon$-relaxação, do ponto de vista da otimização, a restrição é feita não mais sobre a tensão na microestrutura, mas sim sobre a função de falha relaxada, que no caso deve ser igual a 1,0.

Analisando o campo de tensão na microestrutura para o problema da malha 


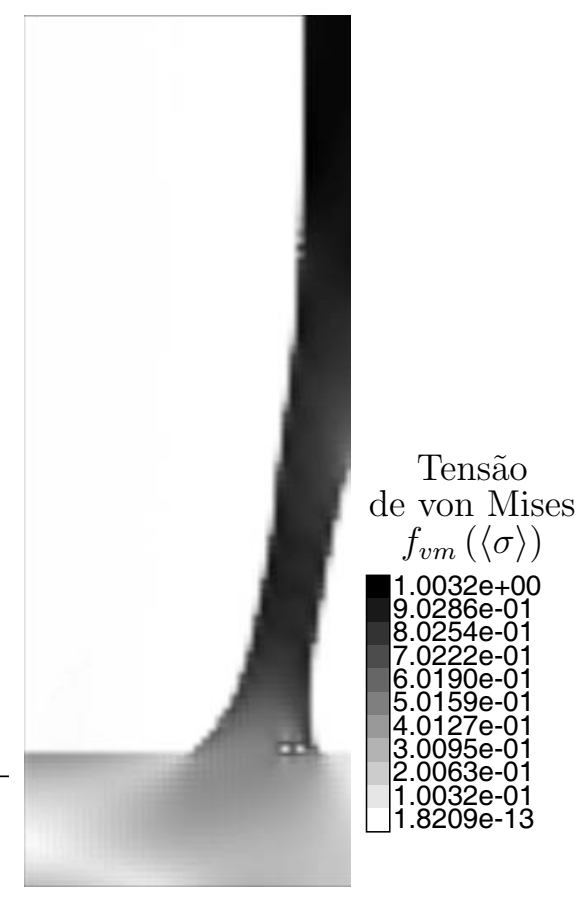

Figura 9.12: Campo da tensão de von Mises na macro-escala, para a solução obtida com a malha refinada apresenta na Figura 9.11(b)

mais refinada, representado na Figura 9.13(a), observa-se que este é praticamente constante em todo o DFE, com um valor próximo de 1,0Pa, à exceção da região onde ocorre a localização de tensão, na junção entre o domínio otimizável e o não otimizável, em que a tensão salta, localmente, para um valor próximo de 2,0Pa.

Agora, analisando o campo função de falha relaxada, dada por 9.1 e representada na Figura 9.13(b), observa-se que a restrição global da função de falha gera uma distribuição de densidades em que o campo da função de falha é aproximadamente constante e igual a 1,0. Do ponto de vista da otimização esta resposta é coerente, uma vez que a restrição global faz um controle apenas sobre a média da função de falha relaxada. O interessante, porém, é que a tensão na estrutura é de fato controlada e apresenta seu valor máximo, apenas ligeiramente acima do desejado, 0,38\% neste caso, enquanto a tensão de falha relaxada, localmente apresenta um valor $13 \%$ acima do desejado.

Finalmente, apenas para efeito de comparação, foi obtido através da formulação tradicional de minimização da flexibilidade com restrição de volume, uma estrutura com fração volumétrica igual a $25 \%$ da região otimizável, de modo que a tensão de von Mises no plano de simetria fosse, na média, igual a 1, 0Pa. A estrutura obtida está apresentada na Figura 9.14(a). Na Figura 9.14(b) está apresentado o campo de tensão de von Mises nesta estrutura, onde observa-se que a seção transversal da barra no plano de simetria possui raio igual a, aproximadamente, $0,74 m$, que gera uma tensão igual a 1,04Pa, apenas $4 \%$ acima do 


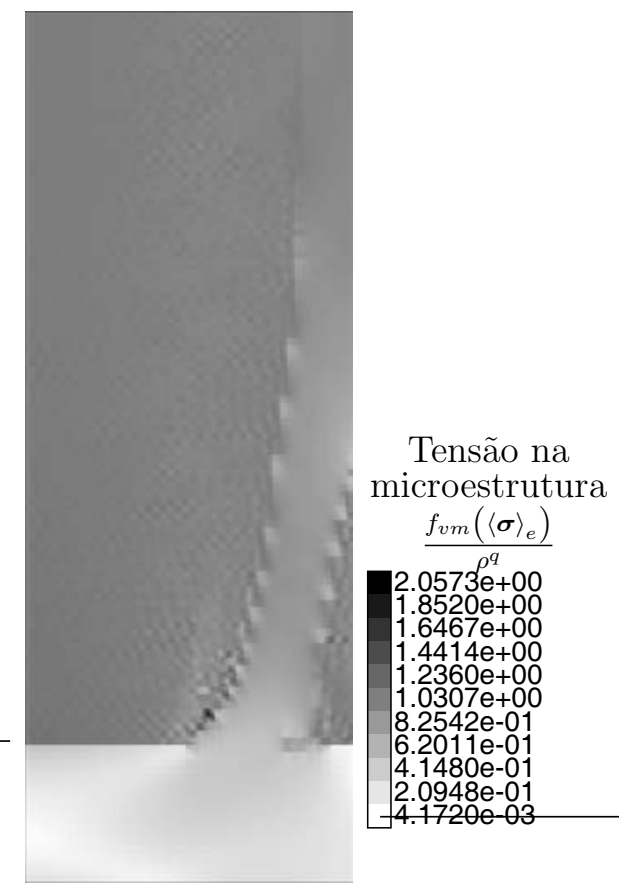

(a) Tensão na microestrutura

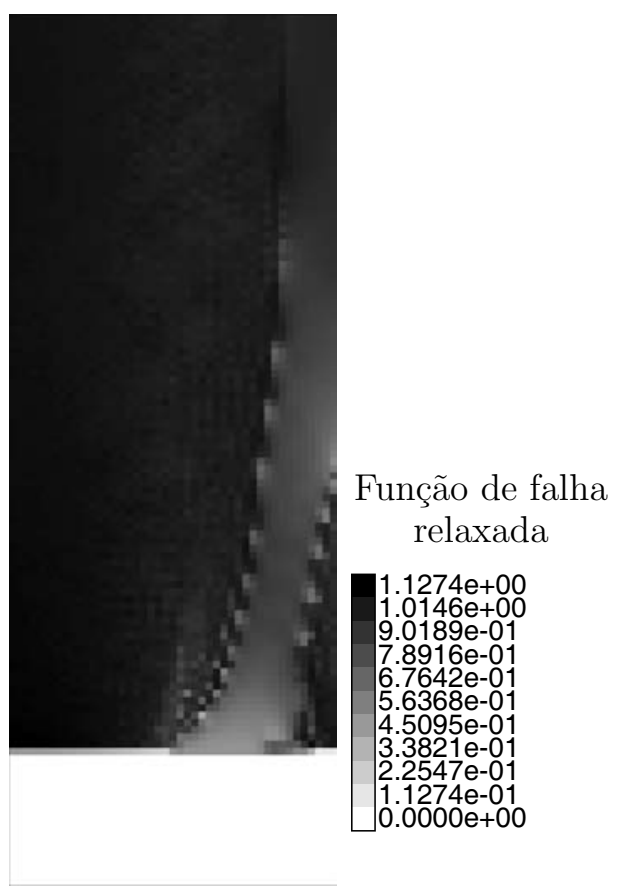

(b) Função de falha relaxada

Figura 9.13: Campos de tensão na microestrutura e da função de falha relaxada para a solução apresentada na Figura 9.11)

esperado. Porém a tensão máxima na estrutura é igual a 1, $52 P a$, isto é, $52 \%$ acima do esperado.

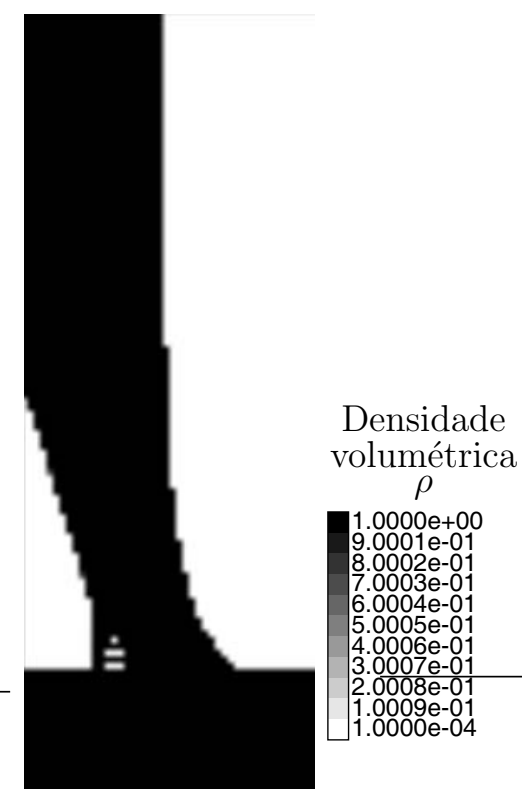

(a) Solução

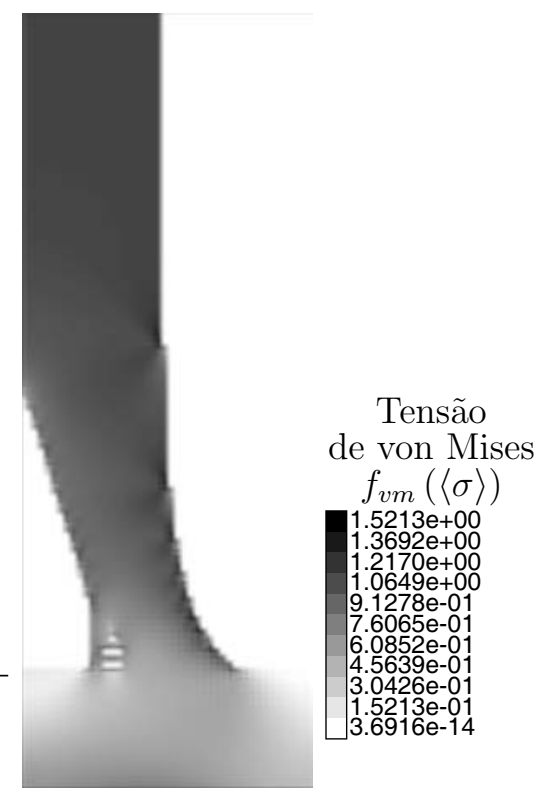

(b) Tensão de von Mises na macro-escala

Figura 9.14: Solução para o problema de minimização da flexibilidade com restrição de $25 \%$ de volume, utilizando continuação para a penalização $q=1,2,3$, e filtro dos limites móveis com raio igual 0,11

Analisando este resultado, fica claro, não somente, que a solução para mínima flexibilidade não é a solução ótima para o problema mínimo volume com restrição 
de tensão mecânica, o que é óbvio do ponto de vista matemático, mas também que a formulação tradicional, de mínima flexibilidade não é capaz de fornecer ao engenheiro projetista uma solução que não apresente concentração de tensão, mesmo para um problema simples como o de uma barra sujeita à tração axial.

\subsubsection{Exemplo 2: Viga MBB}

A viga MBB é um dos exemplos mais clássicos de OT e foi apresentado pela primeira vez em Olhoff, Bendsøe e Rasmussen (1991). Este problema consiste em uma viga bi-apoiada em EPT e com carregamento a meio vão. A viga MBB é assim conhecida pois este problema foi sugerido pela empresa aeronáutica alemã Messerchmitt-Bolkow-Blohm GmbH (MBB). A figura 9.15 apresenta a geometria e as condições de contorno aplicadas à viga MBB.

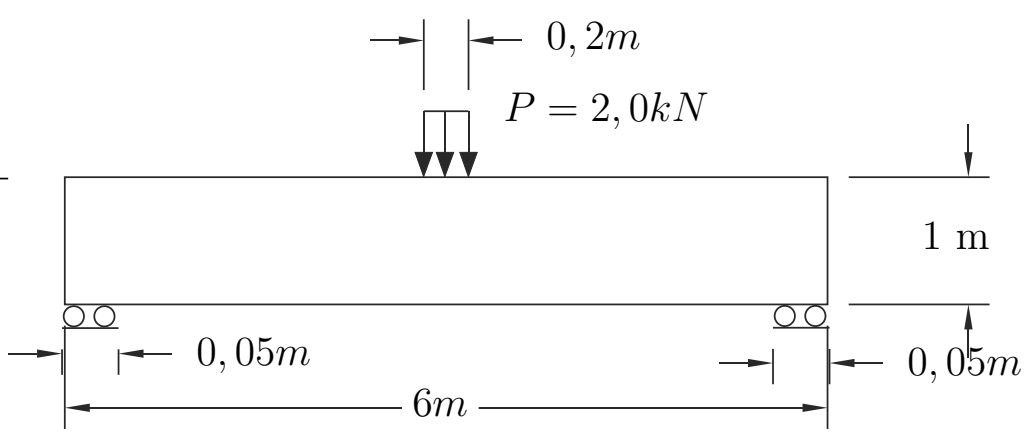

Figura 9.15: Viga bi-apoiada com carregamento transversal (MBB)

Devido à condição de simetria, foi sintetizada apenas metade da estrutura da viga. Para isto foi utilizada uma malha de 4800 elementos em EPT, conforme apresentada na figura 9.16.

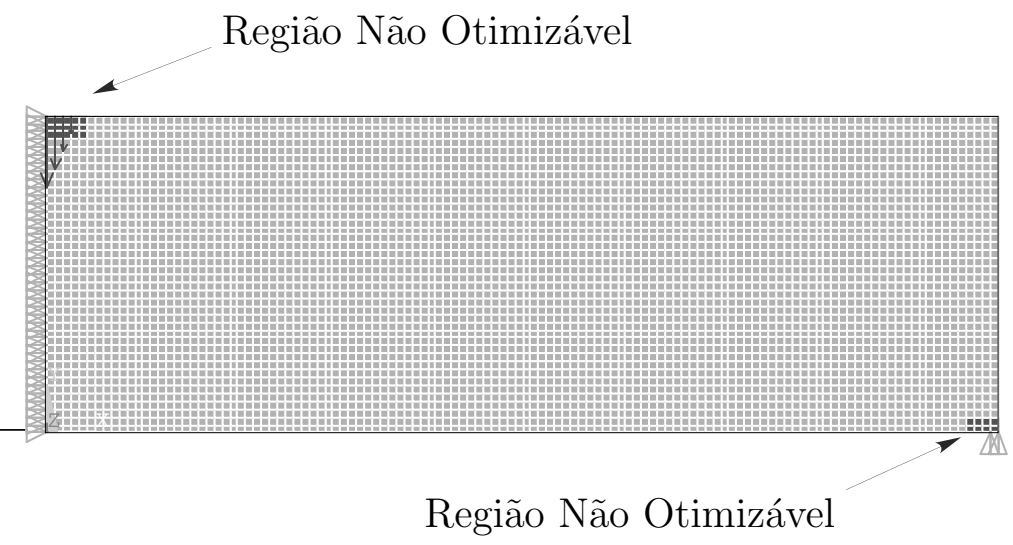

Figura 9.16: Malha utilizada para a síntese da estrutura da viga MBB

Seguindo o trabalho de Pereira (2001) foram adotadas as seguintes propriedades de material. 


$$
\begin{gathered}
E=21 M P a \\
\nu=0,3 \\
\langle\sigma\rangle_{y}=17,8 \mathrm{KPa}
\end{gathered}
$$

Com base nas discussões sobre os parâmetros $p$ e $\varepsilon$ e a utilização do filtro, apresentadas na subseção 9.1.1, foi feita uma procura pelos parâmetros ótimos para o problema da viga MBB discretizada com a malha apresentada na Figura 9.16 .

Este estudo permitiu concluir que, neste caso, a estrutura com melhor definição dos contornos, sem problemas de padrão de camadas e que melhor atende ao critério de falha imposto é obtida fazendo a continuação do parâmetro $p$ da forma do $p=6 ; 12 ; 24 ; 48$, sendo que, entre cada incremento de $p$, foram realizadas 100 iterações, o valor de $\varepsilon$ foi mantido constante e igual a 0,1 nas 100 primeiras iteração e diminuído gradativamente entre as iterações 100 e 200, até o valor mínimo de 0,001 , e então $\varepsilon$ foi mantido constante até o final.

Neste exemplo, para reduzir o surgimento das densidades intermediárias, foi utilizada a função de penalização dada por 6.30.

Para retirar as regiões cinzas da solução, porém sem alterar a geometria obtida, o parâmetro $K_{q}$ foi mantido igual a 0 nas 200 primeiras iterações, permitindo assim que o algoritmo definisse uma geometria básica da estrutura, e então foi aumentado para 2,0 e mantido constante nas 200 últimas iterações. O valor de $\beta$ foi mantido constante e igual a $10^{7}$ durante todo processo iterativo

Assim, com os parâmetros aqui descritos, obteve-se a solução apresentada na Figura 9.17.

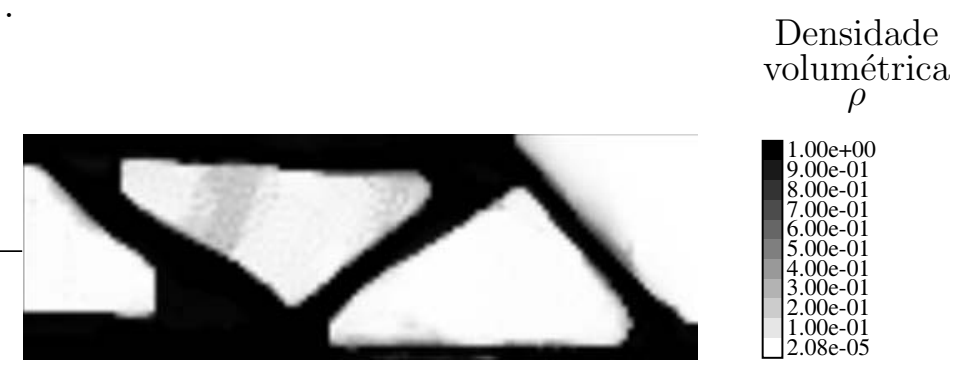

Figura 9.17: Solução final obtida para a viga MBB utilizando o termo de penalização das densidades intermediárias

Esta solução, apesar do método fornecer um solução limpa, com poucas regiões cinzas, não foi capaz de atender às restrições de tensão impostas, como se observa na Figura 9.18.

Acreditamos que isso ocorre devido a alguns fatores. O primeiro é o fato de inserir a variável de folga $\beta$ na restrição, o que permite que a restrição global seja 
Tensão de von Mises

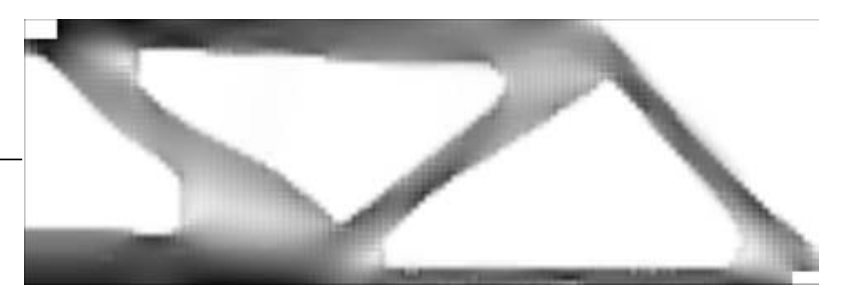
$f_{v m}(\langle\sigma\rangle)$

$2.54 \mathrm{e}+04$

$2.28 \mathrm{e}+04$

$2.03 \mathrm{e}+04$

$1.77 \mathrm{e}+04$
$1.52 \mathrm{e}+04$

$1.52 \mathrm{e}+04$
$1.27 \mathrm{e}+04$

$1.01 \mathrm{e}+04$

$7.61 \mathrm{e}+03$

$.07 \mathrm{e}+03$

2. $54 \mathrm{e}+03$

$3.76 \mathrm{e}-12$

Figura 9.18: Campo da tensão de von Mises para a solução da viga MBB apresentada na Figura 9.17

violada. Porém, a inserção desta variável é necessária para a solução do problema através do método de PLS, pois sem ela, a solução caminha frequentemente para pontos do espaço de solução em que o algoritmo de PL não encontra solução viável.

Esta situação de violação da restrição se torna mais problemática com a inserção da função de penalização das densidades intermediárias, pois caso o parâmetro $K_{q}$ seja definido com um valor muito alto, esta função terá mais influência na solução do que o termo $k_{\beta}$, que penaliza a violação da restrição. Isso cria uma solução de compromisso entre encontrar uma solução limpa, ou seja sem escala de cinzas, e encontrar um solução que atende as restrições de tensão.

Esta situação pode ser verificada quando o mesmo problema é resolvido, porém com parâmetro $K_{q}$ mantido igual a 0 . O resultado obtido para este caso está representado na Figura 9.19 e o respectivo campo de tensões está representado na Figura 9.20.

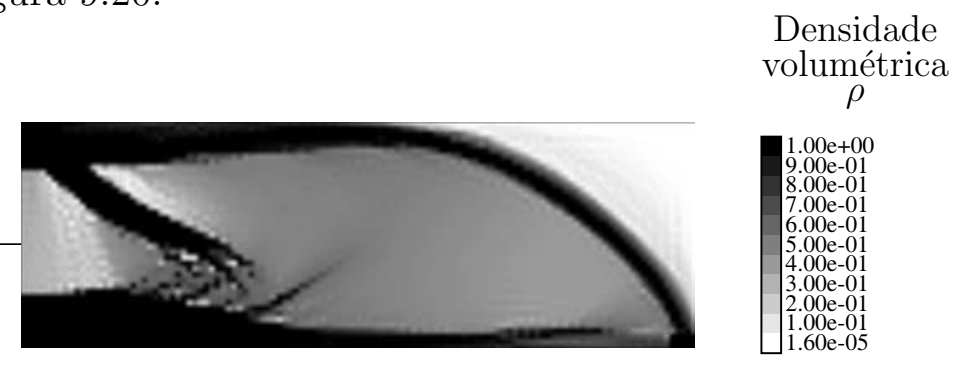

Figura 9.19: Solução final obtida para a viga MBB sem utilizar o termo de penalização das densidades intermediárias

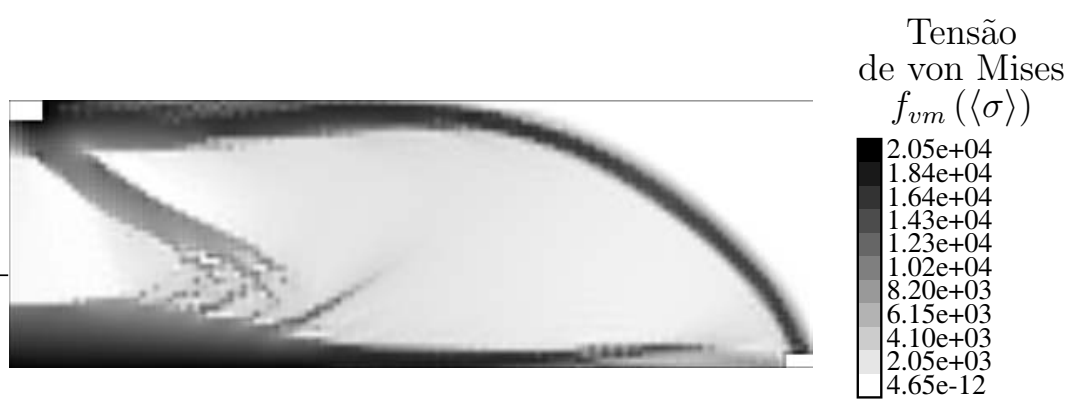

Figura 9.20: Campo da tensão de von Mises para a solução da viga MBB sem utilizar o termo de penalização das densidades intermediárias 
Inicialmente, analisando a estrutura obtida, se verifica claramente a necessidade do termo de penalização das densidades intermediárias para se obter uma estrutura limpa. Agora, analisando o campo de tensões deste problema, observase que a máxima tensão mecânica é $23 \%$ menor do que na estrutura obtida com o termo de penalização das densidades intermediárias.

Outro ponto que demonstra a influência negativa do termo de penalização das densidades intermediárias na restrição de tensão, é que na solução que este termo foi empregado, o valor final de $k_{\beta}$ oscila em torno de 0,2 enquanto no problema sem o termo de penalização o valor final de $k_{\beta}$ é idêntico a 0 .

\subsubsection{Exemplo 3: Estrutura em formato de L invertido}

O problema da estrutura em formato de L invertido, ou simplesmente em formato de L, é um problema teste para verificar o desempenho das formulações de OT com restrição de tensão. O ponto interessante desse problema é que o Domínio Fixo Estendido apresenta um ponto de concentração de tensão devido à quina interna do formato de L. O ângulo reto entre as arestas do DFE faz com que a tensão neste ponto seja, a principio, infinita; porém, com a discretização do DFE elementos finito, a tensão neste ponto passa ter um valor limitado. Assim, definindo uma tensão de escoamento $\langle\sigma\rangle_{y}$ menor do que a tensão nesta quina, para a malha em questão, o método de otimização deve ser capaz de retirar material desta região evitando assim a concentração de tensão.

Este problema, foi abordado nos trabalhos de Duysinx e Sigmund (1998) e Pereira, Fancello e Barcellos (2004), porém, apenas Pereira, Fancello e Barcellos (2004) apresentam um resultado sem a presença de concentração de tensão.

Neste trabalho o problema da estrutura em formato L foi adaptada para um problema axissimétrico. A geometria da estrutura bem como seu carregamento estão apresentados na Figura 9.21. A malha de elementos finitos utiliza neste exemplo está apresentada na Figura 9.22. Para uma boa definição do campo de tensão na região da quina interna do L, foi utilizada uma malha de 6400 elementos distribuídos de forma favorável a se obter uma maior discretização na região próxima à quina, conforme se observa-se na Figura 9.22

Neste caso foram adotadas as seguintes propriedades para o material

$$
\begin{gathered}
E=1.17 \cdot 10^{5} \\
\nu=0,3 \\
\langle\sigma\rangle_{y}=175
\end{gathered}
$$




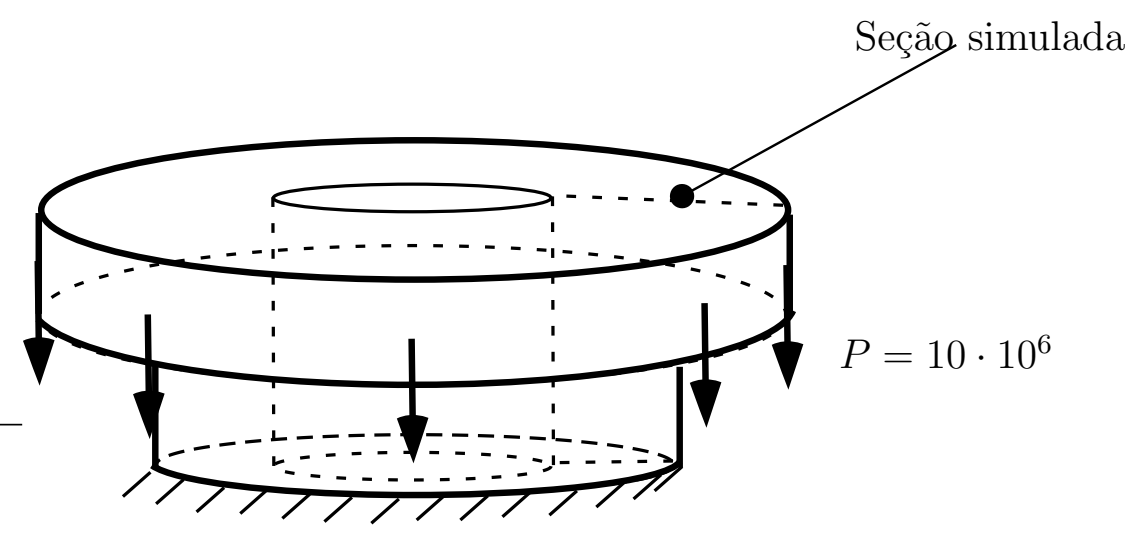

Figura 9.21: Geometria da estrutura em formato de L para o caso axissimétrico

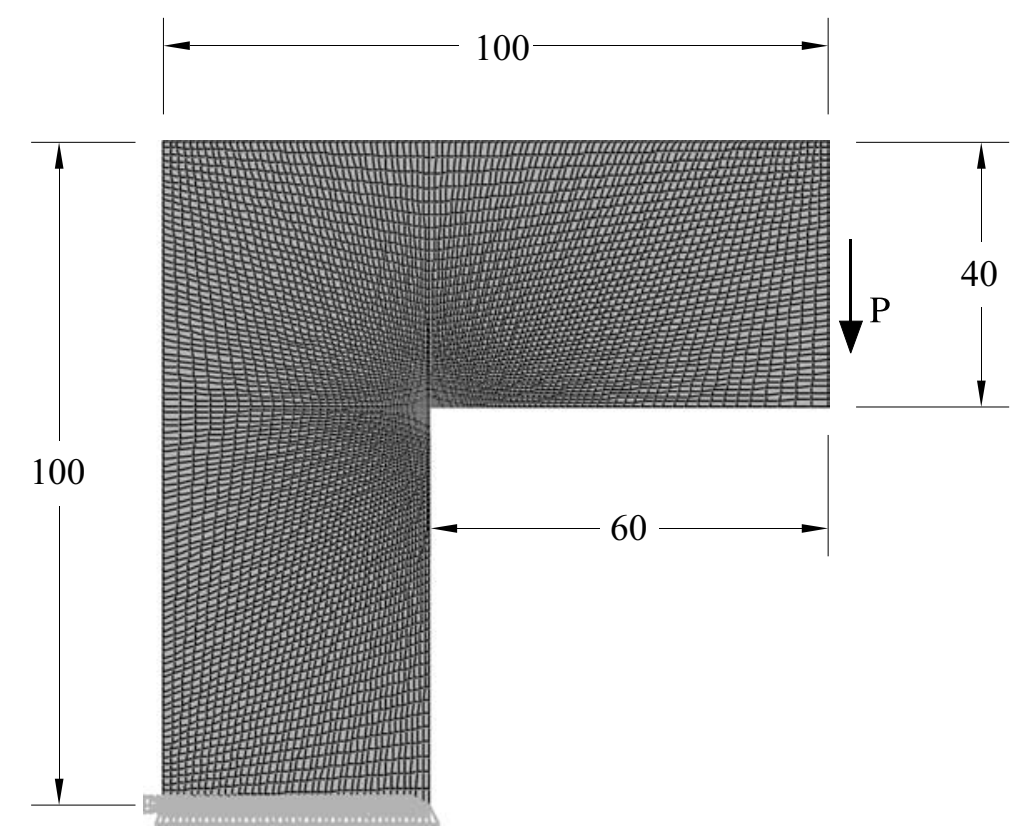

Figura 9.22: Geometria da estrutura em formato de L para o caso axissimétrico

Assim como no exemplo anterior, após um estudo para a determinação dos parâmetros que fornecem um resultado que atende à restrição de tensão, que não possui regiões extensas com densidades intermediárias e que não apresente problemas de padrão de camada, foi definida a seguinte combinação de parâmetros.

A continuação do parâmetro $p$ foi feita na forma do $p=12 ; 24 ; 30$, sendo que foram 15 iterações com $p=12$, 70 iterações com $p=24$, mais 215 iterações com $p=30$, perfazendo um total de 300 iterações. $\mathrm{O}$ valor de $\varepsilon$ foi mantido constante e igual a 1 nas 60 primeiras iteração e diminuído gradativamente entre as iterações 60 e 85, até o valor mínimo de 0,001 , e então $\varepsilon$ foi mantido constante até o final. A função de penalização dada por 6.30 também foi utiliza, neste caso o parâmetro $K_{q}$ foi mantido igual a 0 nas 60 primeiras iterações e igual 5 nas demais 240 iterações. Nas primeiras 60 iterações em que o o parâmetro $K_{q}$ foi mantido igual a 0 , o filtro com raio igual a 1.3 ficou ligado e então foi desligado 
nas demais 240 iterações. Assim, com estes parâmetros obteve-se o resultado apresentado na Figura 9.23.

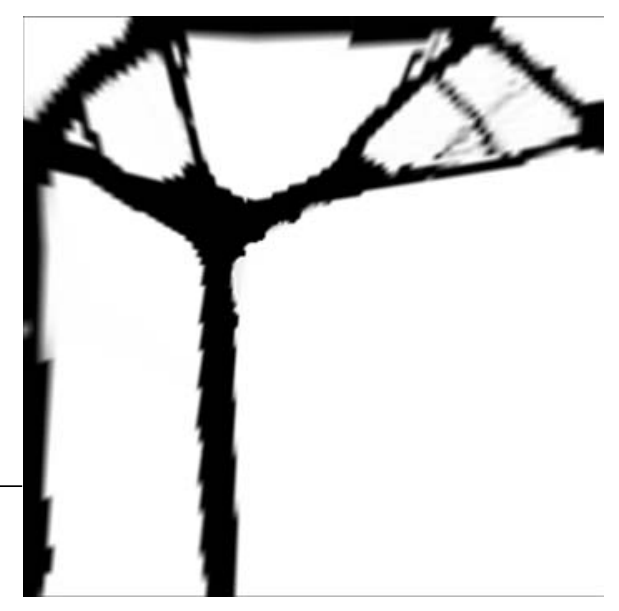

$$
\begin{gathered}
\text { Densidade } \\
\text { volumétrica } \\
\rho
\end{gathered}
$$

$1.00 \mathrm{e}+00$

9.00e-01

$8.00 \mathrm{e}-01$

7.00e-01

6.00e-01

$5.00 \mathrm{e}-01$

4.00e-01

3.00e-01

$2.00 \mathrm{e}-01$

$1.00 \mathrm{e}-01$

$1.00 \mathrm{e}-05$

Figura 9.23: Solução final obtida para a estrutura em forma de L

Analisando a solução fornecida pelo MOT, observa-se que o método retirou material da região próxima à quina substituindo a geometria com duas arestas a 90 graus, por um nova geometria arredondada sem a concentração de tensão. Esta situação pode ser melhor avaliada analisando o campo de tensão de von Mises apresentado na Figura 9.24.

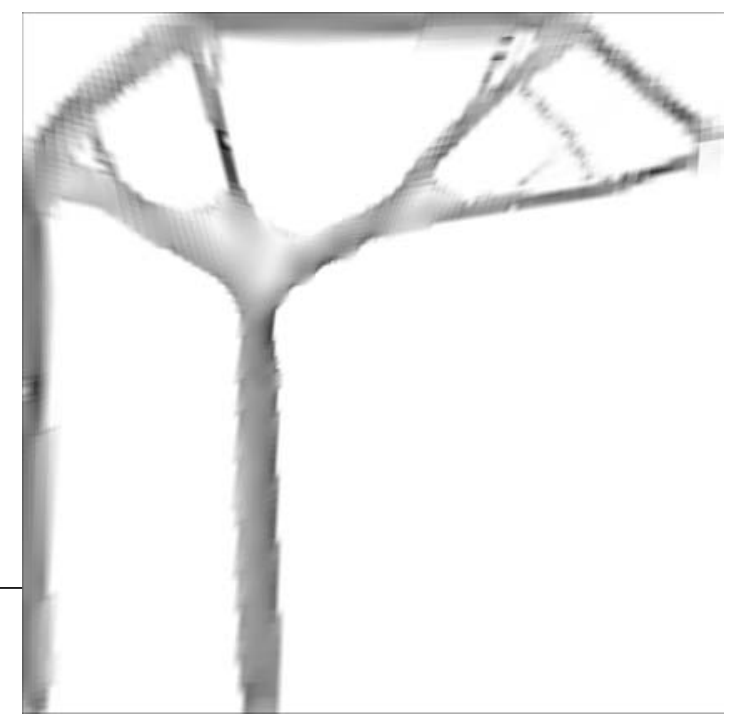

Figura 9.24: Campo da tensão de von Mises para a solução da estrutura em forma de L apresentada na Figura 9.23

Na Figura 9.24, observa-se que a tensão na região próxima a quina é aproximadamente constante e da ordem de 170. Entretanto, apesar do método fornecer uma solução que evita o ponto de concentração de tensão do DFE, a máxima tensão na estrutura ainda é maior que a tensão de escoamento definida para o problema. Porém, esta tensão ocorre em dois pontos distintos da estrutura e se 
deve à oscilação do campo de densidades, onde se esboça um início do problema de padrão de camadas.

A título de comparação entre a formulação de OT com restrição de tensão e a formulação de maximização da rigidez com restrição de volume, este mesmo problema foi resolvido com esta segunda formulação. Para tornar os resultados comparáveis, a fração de volume foi limitada em $0,45 \%$ do volume inicial do DFE, que é a fração volume da estrutura obtida com a formulação com restrição de tensão. A solução obtida para a formulação de maximização da rigidez está apresentada na Figura 9.25.

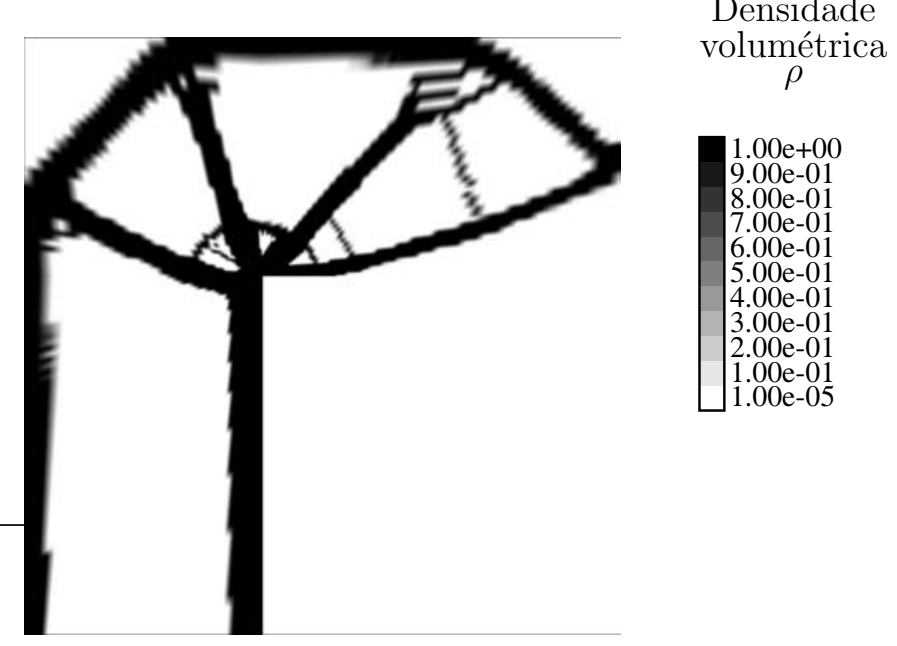

Figura 9.25: Solução final obtida para a estrutura em forma de L, para o problema de maximização da rigidez

Analisando este resultado, observa-se que para maximizar a rigidez o método utiliza toda a seção transversal da região superior da estrutura, criando assim o ponto de concentração de tensão na quina do DFE. A tensão neste ponto, para a malha empregada neste exemplo igual a aproximadamente $4 \cdot 10^{7}$, ou seja $10^{6}$ vezes maior do que a solução obtida com a formulação de restrição de tensão.

Este exemplo, demonstra a capacidade da formulação de OT com restrição global de tensão em fornecer estruturas que evitam os pontos de concentração de tensão, e mostra claramente que a formulação de maximização da rigidez não é capaz de fornecer um resultado similar.

\subsection{Otimização Topológica considerando restrição local de tensão}

Nesta seção serão apresentados os resultados da formulação de OT com restrição local de tensão (Problema 6.34), apresentada na seção 6.5. 
Inicialmente, na subseção 9.2.1 é tratado um problema simples de uma viga sujeita a tração axial. Este problema é apresentado a fim de validar a formulação e o algoritmo do MLA implementado neste trabalho.

Na subseção 9.2.2, é apresentada a solução do problema da viga bi-apoiada com carregamento a meio vão, amplamente conhecida como viga MBB. Neste exemplo é apresentada a influência do termo de regularização adicionado à função objetivo.

No terceiro e último exemplo obtido com a formulação de OT com restrição local de tensão, é apresentado, na seção 9.2 .3 o problema de otimização da estrutura em forma de L.

\subsubsection{Exemplo 1: Barra sujeita a tração uniaxial}

Inicialmente, é tratado um problema simples a fim de validar a formulação apresentada e o algoritmo implementado no software. Para isso, foi escolhido um problema cuja solução ótima é conhecida. Neste caso foi resolvido o problema de uma barra sujeita tração uniaxial, na qual a tensão aplicada na extremidade da barra é igual à tensão de escoamento do material. Diferentemente do exemplo da seção 9.1.1, aqui foi considerada uma estrutura em Estado Plano de Tensão. A geometria e as condições de contorno aplicadas a esta barra estão apresentadas na Figura 9.26.

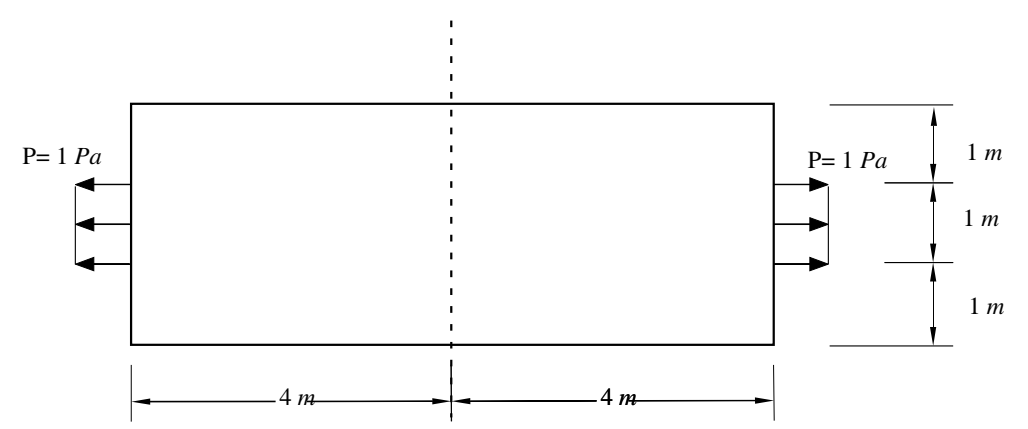

Figura 9.26: Geometria e condições de contorno do problema da barra sob tração uniaxial

Para sintetizar a estrutura, foi considerada a simetria em relação ao eixo vertical, e apenas metade da geometria foi dicretizada. A malha e as condições de contorno aplicadas oa modelo de elementos finitos estão representadas na Figura 9.27 .

Esta malha possui 1312 elementos e 1386 nós, criando assim um problema de otimização com 1386 variáveis e 1312 restrições não-lineares. Ou seja mesmo 


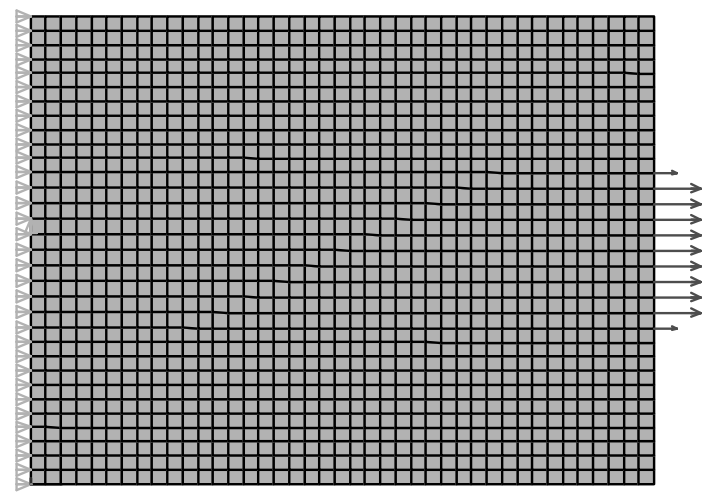

Figura 9.27: Malha e condições de contorno utilizadas no problema da barra sujeita a tração uniaxial

em um problema simples como este, do ponto de vista da otimização tem um problema complexo, com um grande número de restrições. Foram adotadas as seguintes propriedades de material:

$$
\begin{gathered}
E=100 P a \\
\nu=0,3 \\
\langle\sigma\rangle_{y}=1 P a
\end{gathered}
$$

Aqui vale notar que na formulação de OT com restrição local de tensão o termo de regularização $F_{r}(\boldsymbol{\rho})$ foi utilizado pois este não altera os limites móveis da PLS e assim, diferentemente do filtro, não influencia a convergência do problema.

Neste exemplo, foi considerado o parâmetro de regularização $K_{r}$ constante e igual a 0,001 e o parâmetro de penalização das densidades intermediárias $K_{q}=0.5$, o valor de $\varepsilon$ foi definido igual a 0,001. Para o MLA, foi adotado, um campo inicial dos multiplicadores de lagrange, constante e igual a 0.0001 $\left(\mu_{j}^{0}=0.0001\right)$, os termos de penalização $c_{j}$ iniciais foram definidos igual a $0,01 \mathrm{e}$ para sua atualização foi definido $\gamma=1,1$ e $v=0,5$. Utilizando estes parâmetros obteve-se a estrutura apresentada na Figura 9.28.

Analisando este resultado, observa-se que o método foi capaz de fornecer a estrutura de mínima massa que atende à restrição de tensão. Neste caso a solução ótima é uma barra de altura igual ao comprimento em que está aplicado o carregamento, uma vez que o carregamento aplicado é igual à tensão de escoamento de $1 P a$.

Observando o campo da função de falha relaxada, apresentado na Figura 9.29, observa-se que esta restrição foi atendida, sendo que esta é praticamente igual a 0 ou negativa sobre todo o DFE.

Analisando agora o gráfico de convergência da função lagrangeano aumen- 


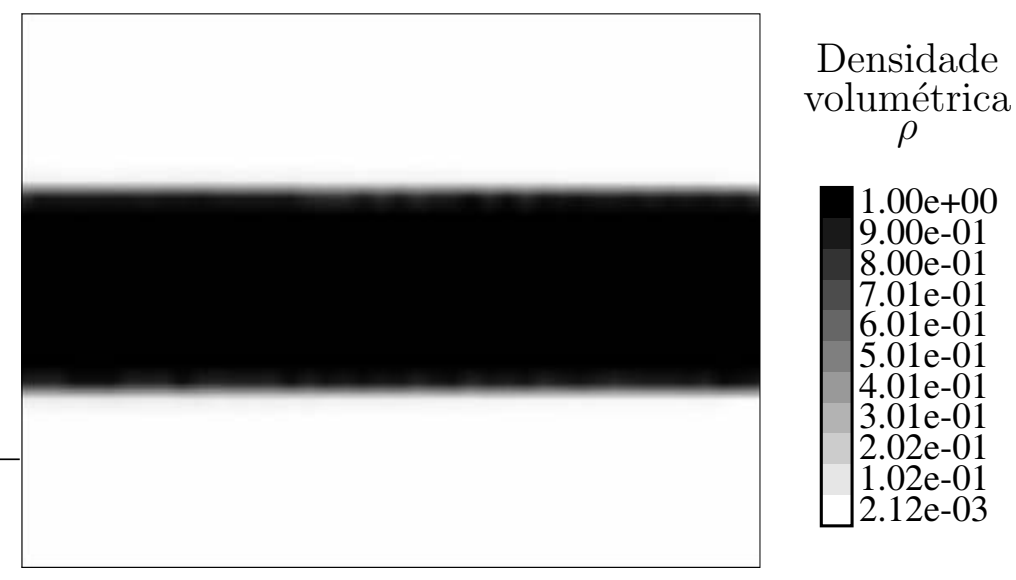

Figura 9.28: Solução obtida para barra sujeita a tração uniaxial

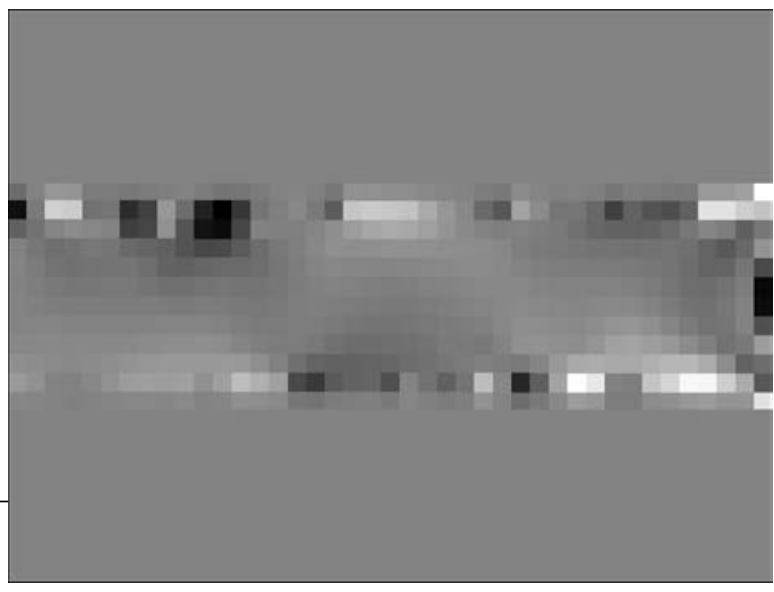

Função de Falha

Relaxada

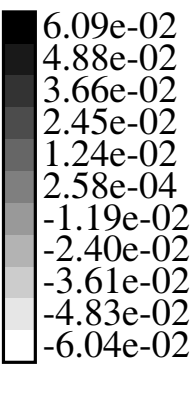

Figura 9.29: Campo da função de falha para solução do problema da barra sujeita a tração uniaxial

tado, apresentado na Figura 9.30, observa-se que na segunda iteração do MLA, a função objetivo sofre um acréscimo brusco devido à atualização automática dos multiplicadores de lagrange. Após esta oscilação o algoritmo converge em apenas 20 iterações. Aqui vale notar qu a cada iteração do MLA é resolvido um problema de PLS que utiliza $n$ iterações para convergir. Neste exemplo o número máximo de iterações internas da PLS foi fixado igual a 30.

Antes de apresentar os demais resultados, é importante observar que a convergência do MLA é dependente da definição correta dos parâmetros envolvidos em sua formulação, em especial a constante de penalização das restrições $c_{j}$. A experiência com este método, nos permitiu concluir que o valor de $c_{j}$ associado aos demais parâmetros da formulação faz com que o algoritmo do MLA convirja para diferentes mínimos do espaço de solução, ou mesmo divirja; e esta situação de divergência se agrava conforme o aumento do número de restrições do problema. 


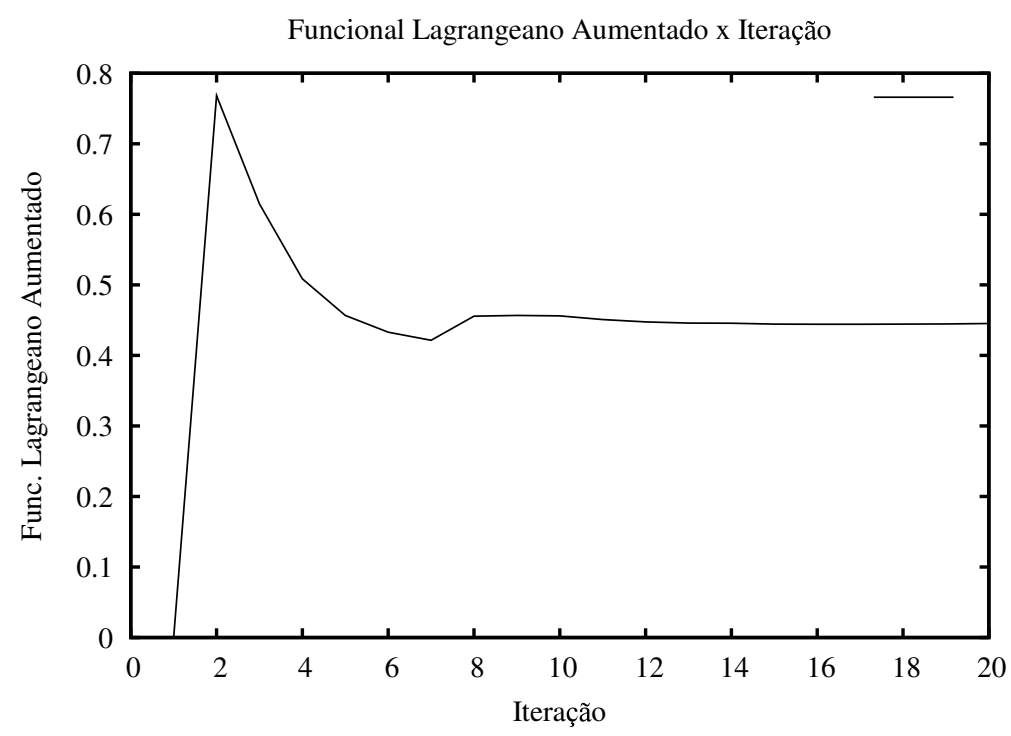

Figura 9.30: Curva de convergência do MLA para o caso da viga sujeita a tração uniaxial

\subsubsection{Exemplo 2: Viga MBB}

O problema da viga MBB, apresentada na seção 9.1.2, também foi resolvido utilizando a formulação de OT com restrição local de tensão. A geometria, a malha de elementos finitos e as propriedades do material são as mesma das utilizadas na seção 9.1.2.

Aqui vale ressaltar que a malha empregada possui 4800 elementos e 4961 nós. Isto significa que o algoritmo de otimização está tratando um problema com 4961 variáveis de projeto e 4800 restrições, o que significa um problema complexo, em especial devido ao elevado número de restrições não-lineares.

Neste trabalho, este exemplo será utilizado para demonstrar a influência do termo de regularização 6.33 apresentado na seção 6.5.1.

Assim, foram sintetizadas estruturas com 3 valores de $K_{r}: K_{r}=0,03, K_{r}=$ 0,003, $K_{r}=0,001$. Nestes três casos foi utilizado como parâmetro de penalização das densidades intermediárias $K_{q}=0,0$ nas 10 primeiras iterações e $K_{q}=0,95$ nas demais. A valor de $\varepsilon$ foi definido constante e igual a 0,001 .

Para o MLA foram adotas as seguintes constantes para o Algoritmo 2 apresentado no capítulo 3: os multiplicadores de lagrange iniciais foram definidos igual a $0.0001\left(\mu_{j}^{0}=0.0001\right)$, os termos de penalização $c_{j}$ iniciais foram definidos igual a 0,01 e para sua atualização foi definido $\gamma=1,1$ e $v=0,5$.

A estrutura obtida para $K_{r}=0,03$ está representada na Figura 9.31 e o campo da função de falha relaxada dessa estrutura está apresentado no Figura 9.32 . 


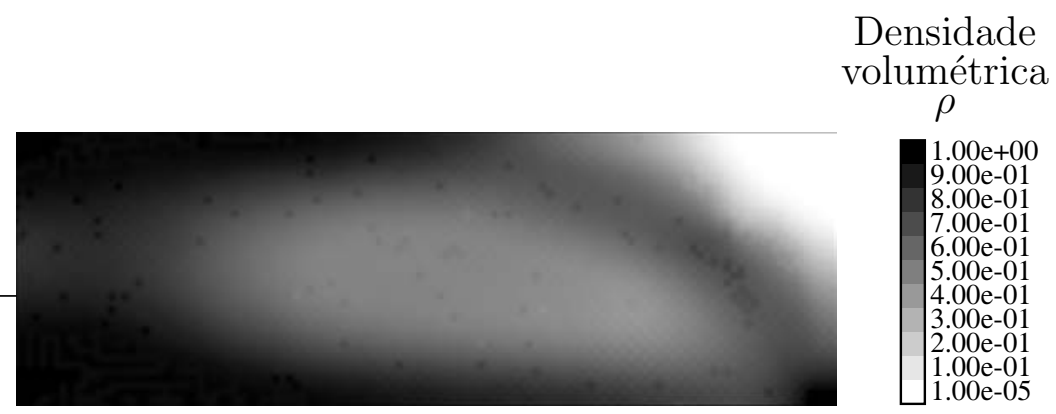

Figura 9.31: Solução obtida para a viga MBB utilizando como fator de regularização $K_{r}=0,03$

Função de Falha Relaxada
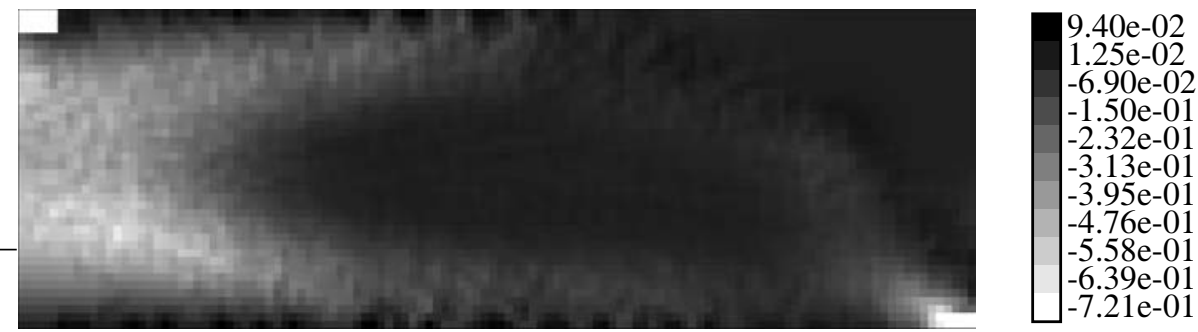

Figura 9.32: Campo de função de falha para estrutura obtida com fator de regularização $K_{r}=0,03$

Observando o campo de densidades desta solução (Figura 9.31), verifica-se que o termo de regularização ponderado por $K_{r}=0,03$ exerce uma forte influência sobre a resposta e não permite que o método gere uma estrutura com contornos bem definidos. Agora, verificando o campo da função de falha, apresentado na Figura 9.32, verifica-se que a restrição de tensão na sua forma $\varepsilon$-relaxada foi atendida na maior parte da estrutura, excedendo a restrição de valor menor ou igual a 0 em apenas 0,09 .

Seguindo a análise da influência do parâmetro de regularização, a Figura 9.33 apresenta a solução obtida utilizando valor de $K_{r}=0,003$ e seu respectivo campo da função de falha $\varepsilon$-relaxada está representado na Figura 9.34

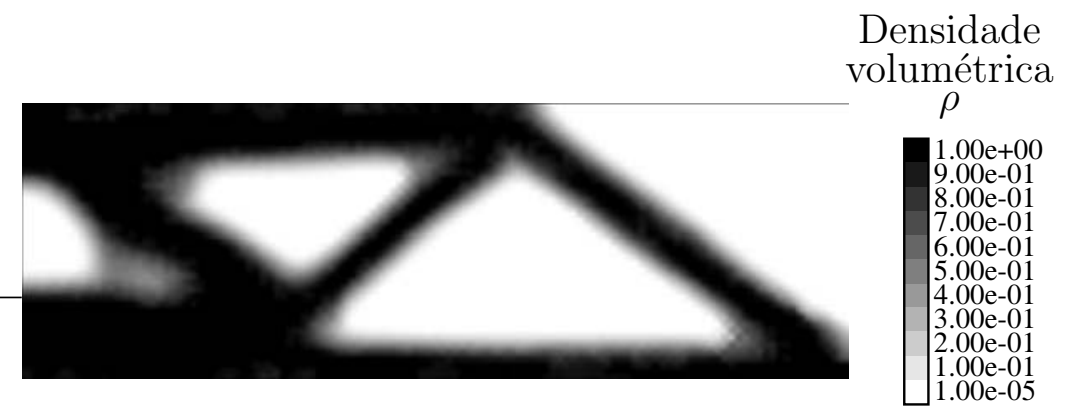

Figura 9.33: Solução obtida para a viga MBB utilizando como fator de regularização $K_{r}=0,003$

Neste caso, observa-se na Figura 9.33 que para o valor de $K_{r}=0,003$ o método foi capaz de fornecer uma estrutura com contornos relativamente bem 
Função de Falha Relaxada
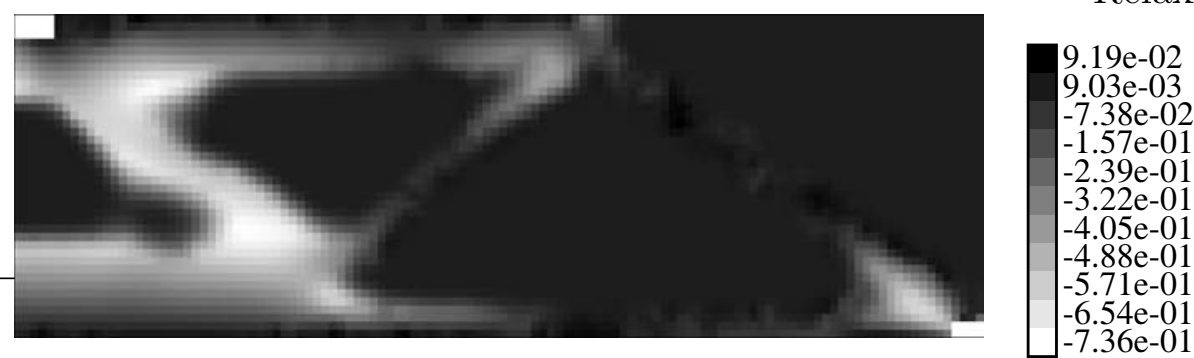

Figura 9.34: Campo de função de falha para estrutura obtida com fator de regularização $K_{r}=0,003$

definidos e que atende a restrição de tensão, como se verifica no Figura 9.34 que representa o campo da função de falha relaxado com valores menores que $0 \mathrm{em}$ quase toda a sua extensão.

Finalmente, a Figura 9.35 apresenta a estrutura obtida para $K_{r}=0,001$ e o respectivo campo da função de falha é apresentado na Figura 9.36.

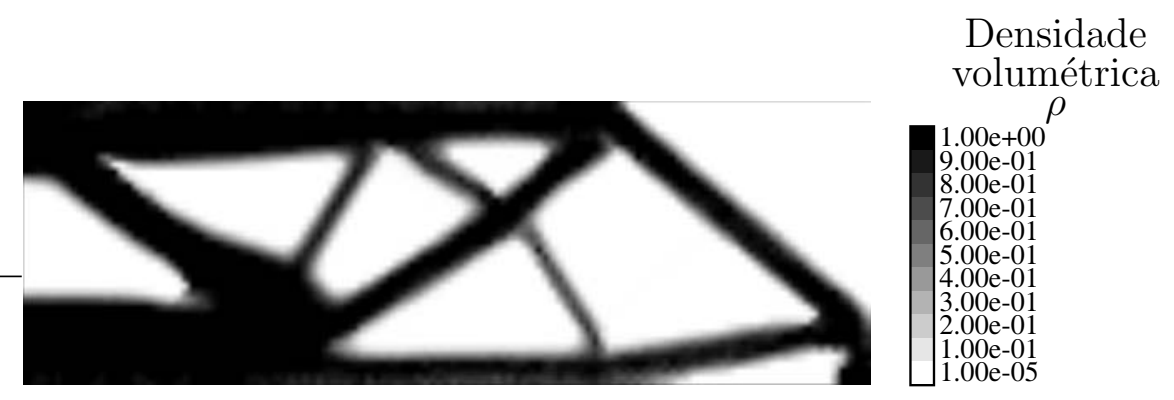

Figura 9.35: Solução obtida para a viga MBB utilizando como fator de regularização $K_{r}=0,001$

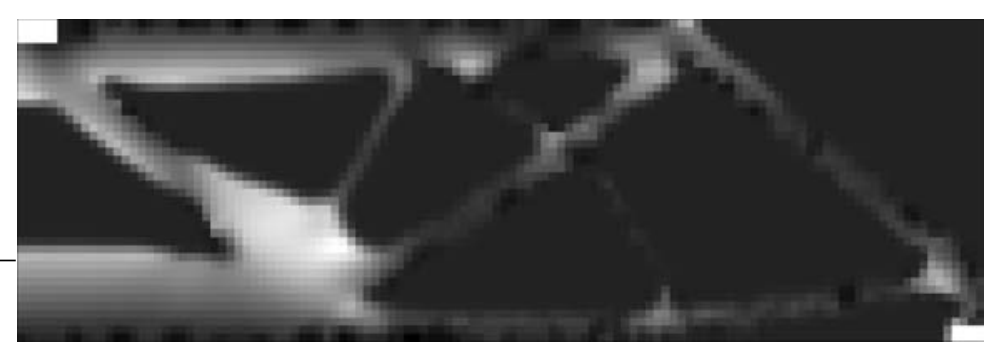

Função de Falha Relaxada

Figura 9.36: Campo de função de falha para estrutura obtida com fator de regularização $K_{r}=0,001$

Neste caso, observa-se que um valor ainda menor de regularização, permite que o método forneça soluções com barras mais delgadas, porém restrição de tensão é ligeiramente violada. Como se observa na Figura 9.36 o campo a função de falha relaxada excedeu a restrição em no máximo 0,12 .

A título de comparação com o trabalho de Pereira (2001) os resultados apresentados por ele para o problema da viga MBB apresenta geometrias similares, 
porém com o campo de função de falha com valores máximos da ordem de $1 \cdot 10^{-4}$. Acreditamos que esta diferença entre os resultados ocorre devido a diferença entre os parâmetros internos do MLA utilizados em cada trabalho, e também pela diferença dos algoritmos utilizados para a solução do problema sem restrições interno ao MLA

\subsubsection{Exemplo 3: Estrutura em formato de L}

O problema da estrutura em formato L também foi resolvido utilizando a formulação de OT com restrição local de tensão. Neste caso o problema foi tratado com uma estrutura em EPT e sua geometria esta representada na Figura 9.37. A

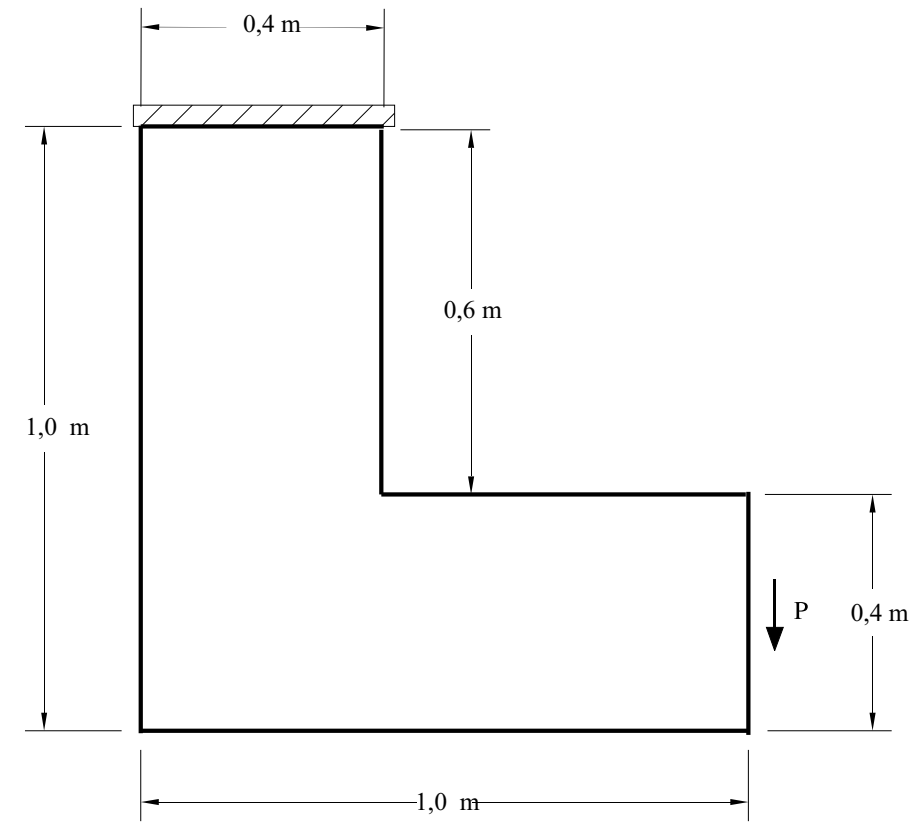

Figura 9.37: Geometria da estrutura em formato de L

malha de elementos finitos utilizada é apresentada na Figura 9.38 e possui 6400 elementos e 6601 nós, assim o problema de otimização envolve 6400 restrições não-lineares.

Foram adotadas a seguintes propriedades para o material

$$
\begin{gathered}
E=100 P a \\
\nu=0,3 \\
\langle\sigma\rangle_{y}=42,42 P a
\end{gathered}
$$

Neste exemplo não foi possível encontrar uma combinação de parâmetros que fizesse o algoritmo convergir. Porém observou-se que para uma dada combinação de parâmetros, a solução MLA passa pelo pontos ótimo, porém não converge para este ponto. Desse modo, optou-se por interromper o processo iterativo 


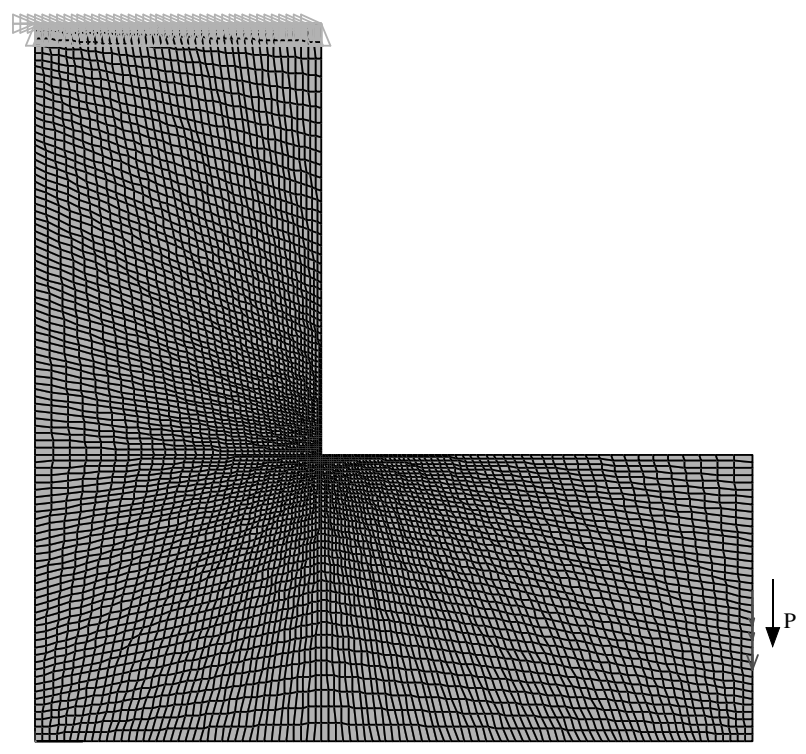

Figura 9.38: Malha de elementos finitos utilizada na solução da estrutura em formato de L

prematuramente. A interrupção foi feia com base na visualização do resultado a cada iteração, possibilitando assim escolher um resultado bem definido.

Assim, foi considerado o parâmetro de regularização $K_{r}$ constante e igual a 0,01, o parâmetro de penalização das densidades intermediárias $K_{q}=0,95$, o valor de $\varepsilon$ foi definido igual a 0,0001. Para o MLA foi adotado, um campo inicial dos multiplicadores de lagrange constante e igual a $0,0001\left(\mu_{j}^{0}=0,0001\right)$, os termos de penalização $c_{j}$ iniciais foram definidos igual a 0,9 e para sua atualização foi definido $\gamma=1,5$ e $v=0,5$.

Assim, executando 21 iterações do MLA, com os parâmetros acima definidos obteve-se a geometria representada na Figura 9.39.

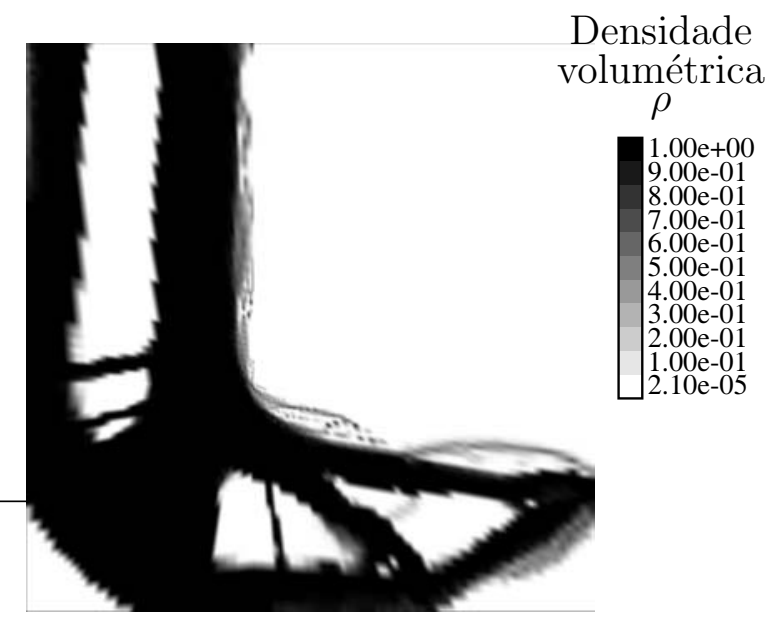

Figura 9.39: Solução obtida para a estrutura em formato de L

Analisando a geometria da estrutura obtida, observa-se que o método retirou o material da região de concentração de tensão, fornecendo um geometria arre- 
dondada para esta região. Este arredondamento faz com a que a máxima tensão mecânica, que a princípio é infinita devido ao ângulo reto entre as arestas, se torne finita, conforme discutido na subseção 9.1.3.

Esta geometria permitiu que a restrição de função de falha relaxada fosse atendida em quase toda a totalidade do DFE, pois esta possui apenas valores negativos ou ligeiramente acima de zero. Isto pode ser verificado na Figura 9.40 que apresenta o campo da função de falha relaxada da estrutura otimizada.

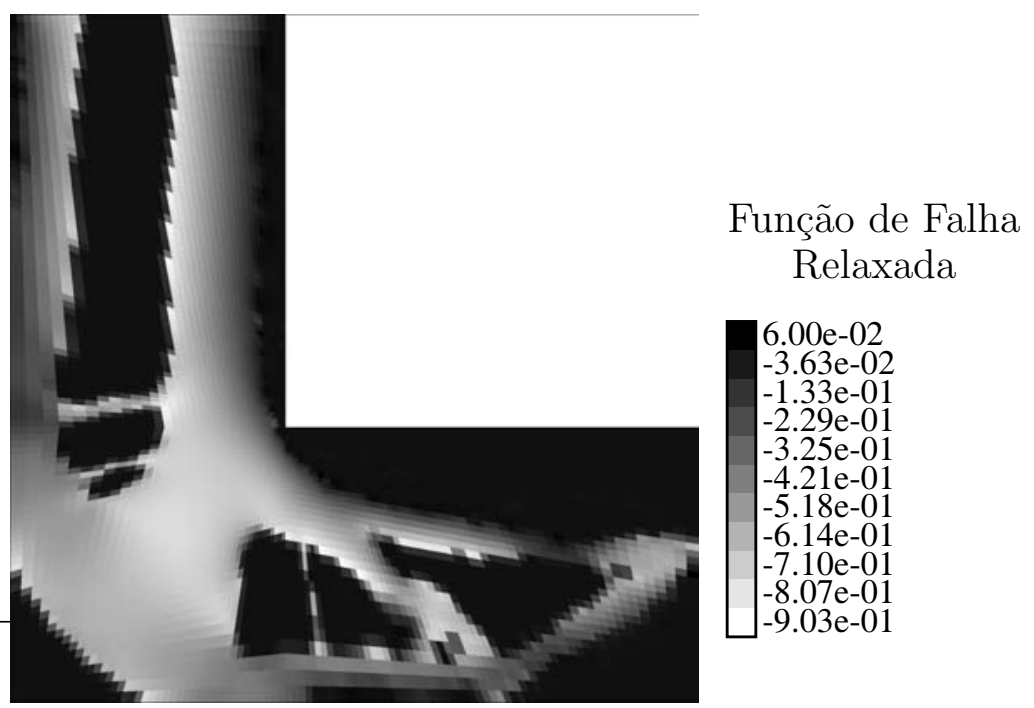

Figura 9.40: Campo de função de falha relaxada da estrutura apresentada na Figura 9.39

Com este exemplo, pode-se concluir que, apesar de não se ter obtido a convergência do MLA este foi capaz de fornecer um solução otimizada que atende a restrição de tensão.

Comparando este resultado com aqueles apresentados no trabalho de Pereira (2001), observa-se que ambos apresentam resultados semelhantes, a menos das regiões cinzas presentes no resultado da Figura 9.39. Acredita-se que a diferença nos resultados se deve ao fato de que neste exemplo não foi possível obter a convergência do MLA, o que dificultou a utilização do termo penalizador das densidades intermediárias na fase final do processo iterativo.

Acredita-se também que esta dificuldade em se obter a convergência se deve ao fato utilizar-se um algoritmo de Programação Linear Seqüencial (PLS) para a solução do problema de otimização interno ao MLA. O trabalho de Pereira (2001) utiliza algoritmo de otimização BOX-QUACAN proposto por Friedlander, Martínez e Raydan (1995) associado ao método de regiões de confiança (FRIEDLANDER; MARTíNEZ; SANTOS, 1994). Atualmente (06/2006) estes algoritmos, bem como algoritmos aprimorados, estão disponíveis no endereço de eletrônico 
"Www. ime.usp.br/ egbirgin/tango/" 


\section{Resultados: Problema de distribuição material em estruturas com gradação funcional}

Este capítulo apresenta os resultado obtidos para o problema de otimização da distribuição de material em estruturas com gradação funcional.

Inicialmente, na seção 10.1, é apresentado um problema simples de barra sob tração axial em que é estudado a influência dos parâmetros da formulação e é feita uma comparação entre as formulações apresentadas em 7.27 e 7.28.

Na seção seguinte, 10.2, é apresentada a otimização da distribuição de material na parede de um cilindro sujeito a pressão externa. Neste exemplo é feita uma discussão dos modelos de material e modelos de estimativa da tensão de referência dos MsGF.

Aumentando o nível de complexidade do problema tratado, na seção 10.3 é apresentado o problema de otimização da distribuição de material no interior de um disco de turbina a gás. Neste problema, além das forças externas, são consideradas as forças de campo devido à rotação do disco. Este exemplo também é utilizado para discutir a influência do modelo de material.

Para finalizar, na seção 10.4 é apresentado um resultado com a formulação de maximização da inércia de rotação, proposto na subseção 7.4.2. Neste caso o problema em questão é a maximização da inércia de rotação de uma roda de inércia.

\subsection{Exemplo 1: Barra sujeita a tração axial}

Neste trabalho, a aplicação do MOT no problema de otimização da distribuição de material em estruturas constituídas por MsGF foi, inicialmente, estudada 
utilizando um problema simples de uma barra sujeita a tração axial.

Neste caso foi utilizado o modelo de material H-S-linear, apresentado na seção 7.4.1 (representado na Tabela 7.1), considerando $\kappa=1.0$. O seja, limite superior de H-S é utilizado para definira as propriedades efetivas do material.

Para testar a formulação foi escolhido um MGF fictício com uma grande diferença entre os módulos de Young das fases dos materiais que o constituem. Apesar de pouco realista para os MsGF, do ponto de vista numérico, quanto maior a diferença entre os módulos de elasticidade, maior o valor da intensificação da tensão de von Mises dada pela matriz $\mathbf{B}_{v m}$. Assim, é possível por a prova a implementação proposta.

As propriedades escolhidas para cada um dos materiais estão representadas na Tabela 10.1 .

\begin{tabular}{l|c|c}
\hline & Material (+) & Material (-) \\
Propriedades & & \\
\hline Módulo de Young & 100 & 1 \\
Coeficiente de poisson & 0,3 & 0,3 \\
Tensão de Referência & 1.5 & $1,05 \cdot 10^{-4}$ \\
\hline
\end{tabular}

Tabela 10.1: Propriedades mecânicas das fases constituintes do MGF adotadas para o problema da barra sob tração axial

O gráfico da Figura 10.1(a) apresenta a curva do modelo de material utilizado e o gráfico da Figura 10.1(b) apresenta os valores de três elementos da diagonal principal da matriz $\mathbf{B}_{v m}$, onde observa-se que as componentes de tensão $\sigma_{r}, \sigma_{\theta}$ e $\sigma_{z}$ são intensificadas em até, aproximadamente, 9 vezes.

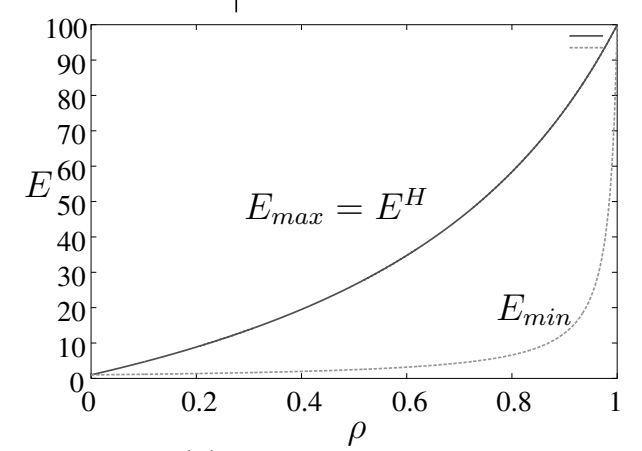

(a) Modelo de material

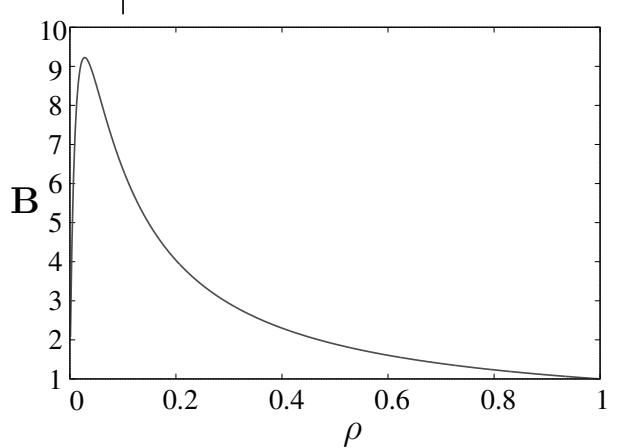

(b) $\left(\mathbf{B}_{v m}\right)_{11}=\left(\mathbf{B}_{v m}\right)_{22}=\left(\mathbf{B}_{v m}\right)_{33}$

Figura 10.1: Curva do modelo de material e dos elementos da matriz $\mathbf{B}_{v m}$

Devido ao fato de não se ter conhecimento um problema de otimização da distribuição de material em uma estrutura com gradiente de propriedades com solução conhecida, foi escolhido um problema em que se pode ter uma idéia 
intuitiva da solução ótima. Neste caso, optou-se por utilizar uma barra sujeita à tração axial de $1 P a$ apenas na sua região central, conforme apresentada na Figura 10.2(a). Assim, utilizando o MEF em sua formulação axissimétrica, foi simulado apenas um quarto da seção longitudinal da barra, onde foram aplicadas as condições de contorno de simetria, e forças nodais equivalentes a tração de $1 P a$, conforme ilustrado na Figura 10.2(b).

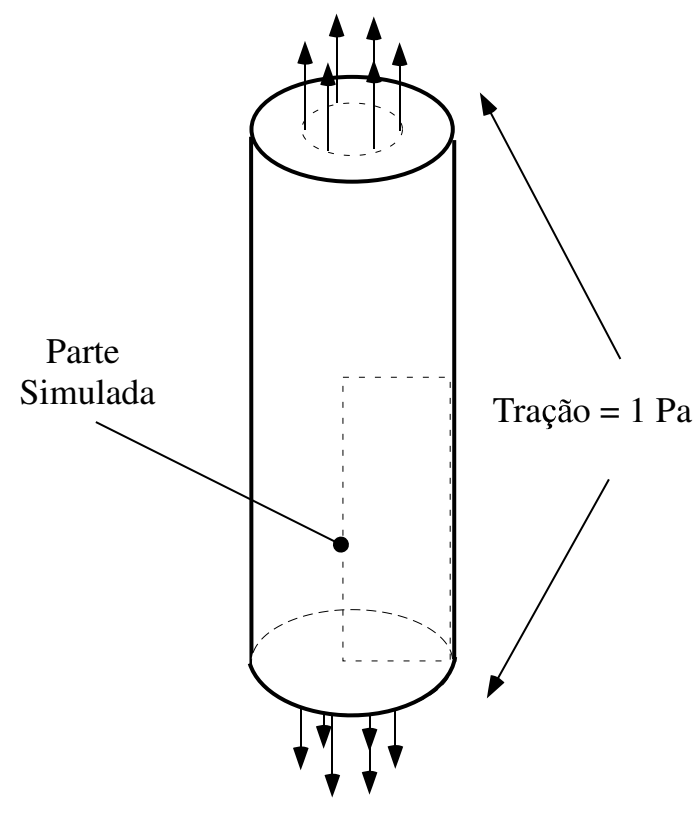

(a) Estrutura inteira

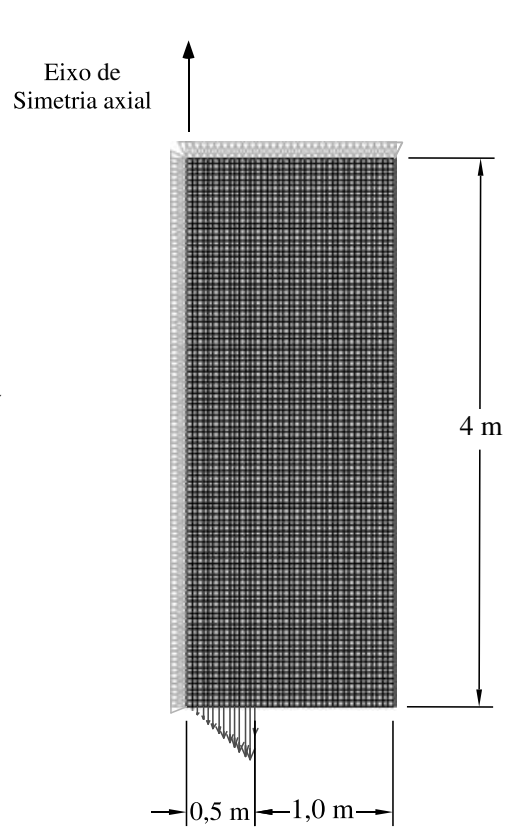

(b) Malha

Figura 10.2: Representação da malha de elementos finitos e condições de contorno (malha com 3800 elemento, 3939 nós e variáveis de projeto no problema de otimização.)

Inicialmente foi considerada a formulação dada pela equação 7.28 , que tem a restrição abaixo reproduzida:

$$
\left[\frac{1}{\Omega} \int_{\Omega}\left(\max \left\{\frac{\left[\left\langle\boldsymbol{\sigma}^{\text {micro }}\right\rangle_{v m}\right]^{2}}{\left[\left\langle\boldsymbol{\sigma}^{\text {micro }}\right\rangle_{\text {ref }}\right]^{2}}-1,0\right\}\right)^{p}\right]^{\frac{1}{p}} \leq 0
$$

A primeira questão a ser estudada nesta implementação foi a influência dos limites móveis na solução obtida; dessa forma, adotaram-se três intervalos para o passo máximo e mínimo ( passo $_{\max }$, passo $_{\min }$ ), que entram como parâmetros do Algoritmo 4 do capítulo 8 que, por sua vez, faz a atualização dos limites móveis a cada iteração. Os intervalos representam a máxima e a mínima variação percentual em relação ao valor da variável a cada passo da PL. Assim, foi definido um primeiro intervalo, denominado de "LM estreito", com os valores passo $_{\max }=$ $1 \%$, passo $_{\min }=0,1 \%$, um intervalo "LM médio" com os valores passo $\max =10 \%$, 
passo $_{\min }=1 \%$ e um intervalo "LM largo" passo $_{\max }=20 \%$, passo $_{\min }=10 \%$. Os resultados obtidos para cada um dos casos estão representados na Figura 10.3. Observando as distribuições de material obtidas, é notória a influência dos limites

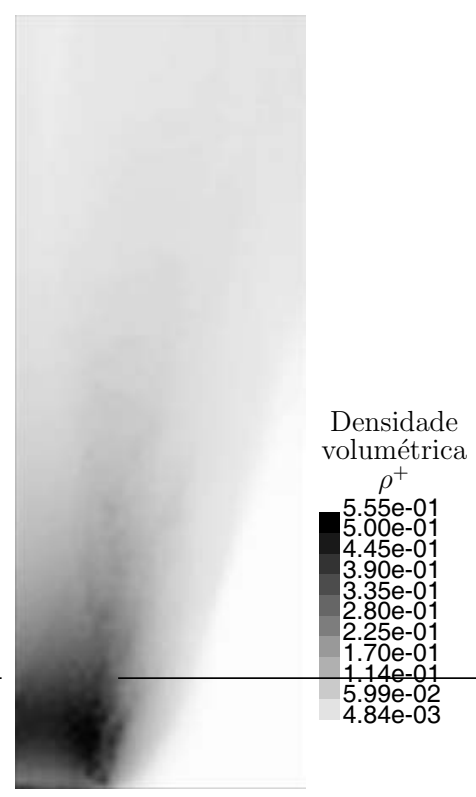

(a) LM (estreitos)

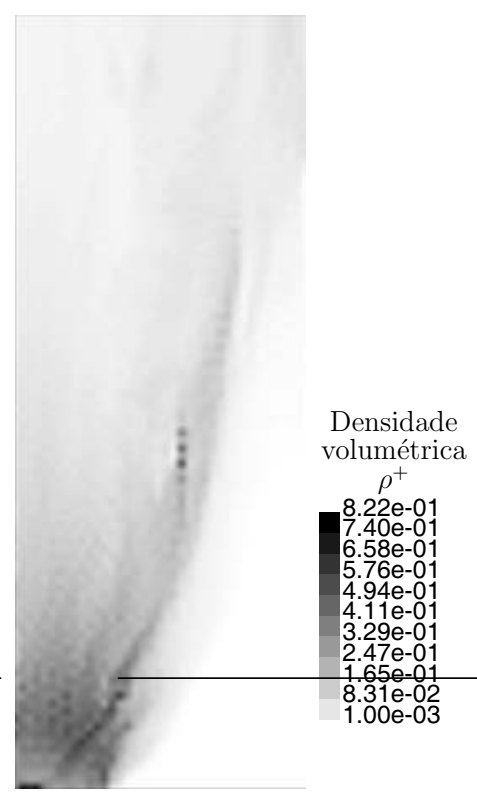

(b) LM (médios)

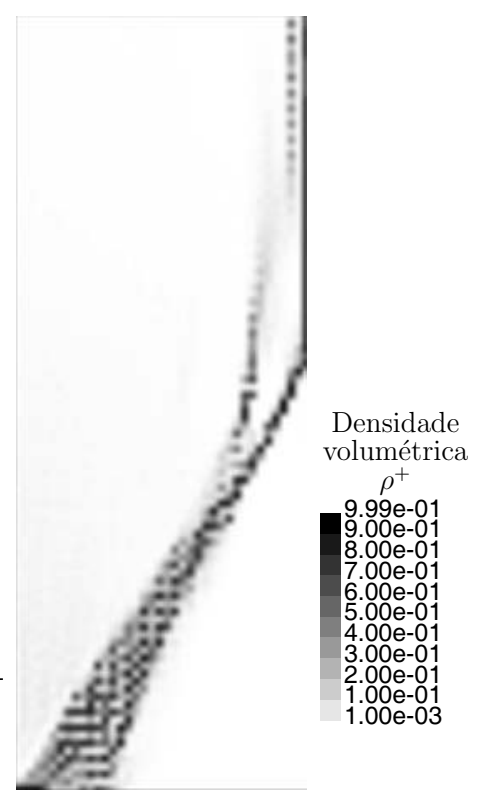

(c) LM (largos)

Figura 10.3: Soluções finais obtidas com diferentes limites móveis, considerando $p=2$

móveis sobre a solução.

Analisando as curvas de convergência do número de elementos ativos, ou seja, aqueles que possuem a tensão maior do que a tensão de referência, apresentada na Figura 10.4, observa-se que, quanto maior o intervalo permitido para os limites móveis, maior é o número de elementos ativos na restrição, e maior é a oscilação deste número entre as iterações.

Apesar de ser um tanto óbvio que, quanto mais largos são os limites móveis, maiores serão as oscilações do campo de densidades e, conseqüentemente, maiores as oscilações do campo de tensão e, assim, do número de elementos ativos no problema, um ponto importante, que a análise do gráfico apresentado na Figura 10.4 suscita, é que, com a formulação 7.28, ocorre uma troca do conjunto de elementos que compõem a restrição a cada iteração.

Esta oscilação, ou troca do conjunto de elementos que compõem a restrição, é prejudicial ao processo de otimização baseado na PLS, pois a cada passo, ou seja, a cada PL, o algoritmo de otimização receberá apenas as informações, na forma de gradiente, sobre aqueles elementos que estão ativos e, assim, se na iteração seguinte o conjunto de elementos ativos mudar bruscamente, de modo que a intersecção entre estes conjuntos de elementos seja nula, será resolvido um 


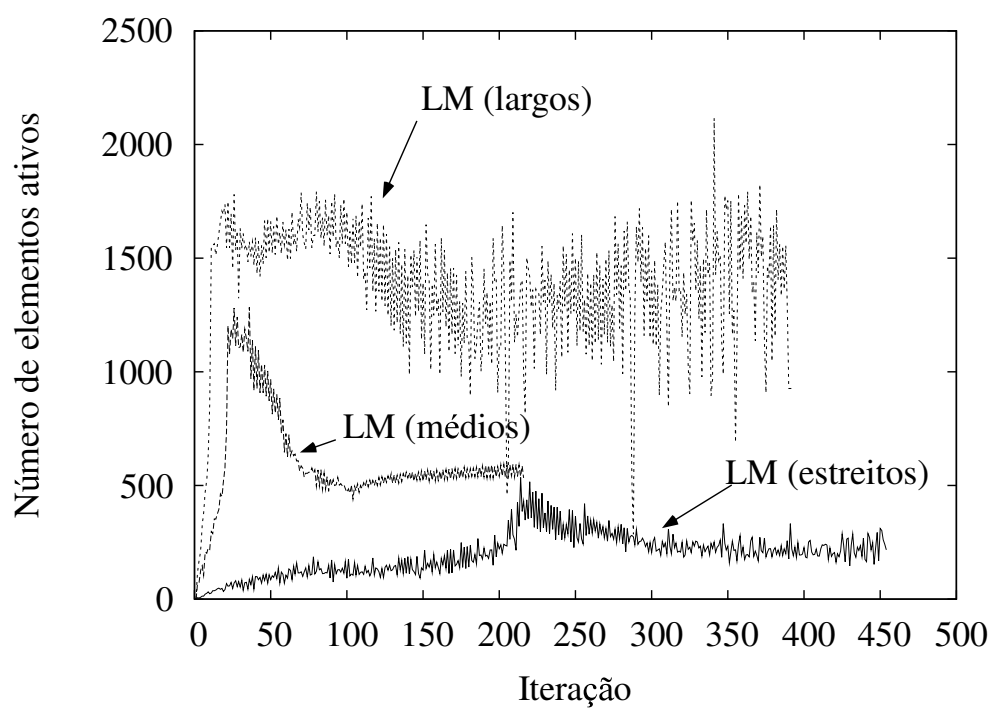

Figura 10.4: Curva de convergência do número de elementos ativos no problema para três condições de limites móveis: LM (estreitos), LM (médios) e LM (largos) )

problema de PL distinto do problema anterior.

Esta situação seria diferente se, a cada iteração, o conjunto de elementos que compõem a restrição fosse sempre reduzindo, de tal forma que um conjunto estivesse contido dentro do conjunto referente à iteração anterior.

Dada esta situação, duas são as abordagens que podem ser adotadas para minimização desse problema. Uma é escrever a restrição do problema 7.28 sem a função $\max \{\cdot, \cdot\}$, assim, este fica igual ao problema 7.27 , cuja restrição é abaixo reproduzida:

$$
\left[\frac{1}{\Omega} \int_{\Omega}\left(\frac{\left[\left\langle\boldsymbol{\sigma}^{\text {micro }}\right\rangle_{v m}\right]^{2}}{\left[\left\langle\boldsymbol{\sigma}^{\text {micro }}\right\rangle_{\text {ref }}\right]^{2}}\right)^{p}\right]^{\frac{1}{p}} \leq 1
$$

A outra abordagem é utilizar a formulação 8.2, isto é, manter a função $\max \{\cdot, \cdot\}$ na restrição, porém utilizando o conceito de "variáveis artificiais", apresentado no capítulo 8. A restrição do problema 8.2 está abaixo reproduzida:

$$
\left[\frac{1}{\Omega} \sum_{e=1}^{M} \Omega_{e}\left(\max \left\{\frac{\left[\left\langle\boldsymbol{\sigma}^{\text {micro }}\right\rangle_{\text {vm }}^{e}\right]^{2}}{\left[\left\langle\boldsymbol{\sigma}^{\text {micro }}\right\rangle_{\text {ref }}^{e}\right]^{2}}-1,0\right\}\right)^{p}\right]^{\frac{1}{p}}-1-\beta \leq 0
$$

Com esta formulação, é possível iniciar o problema com uma distribuição de densidades em que todos, ou grande parte dos elementos, compõem a restrição e, assim, garante-se que o problema de PL receba informações, na forma de gradientes, sobre todo o domínio e, conseqüentemente, com a evolução do processo iterativo, este conjunto de elementos é reduzido até se aproximar de zero. 
É importante notar que, conforme apresentado no capítulo 8, todas as implementações utilizam o conceito de "variáveis artificiais", o que permite fazer a continuação dos valores de $p$ sem que o algoritmo de PL falhe.

Assim, otimizando a distribuição de material através da primeira abordagem, dada pela a formulação 7.27 , isto é sem a função $\max \{\cdot \cdot \cdot \cdot$, obtém-se a distribuição apresentada na Figura 10.5. Observa-se nesta figura que o software

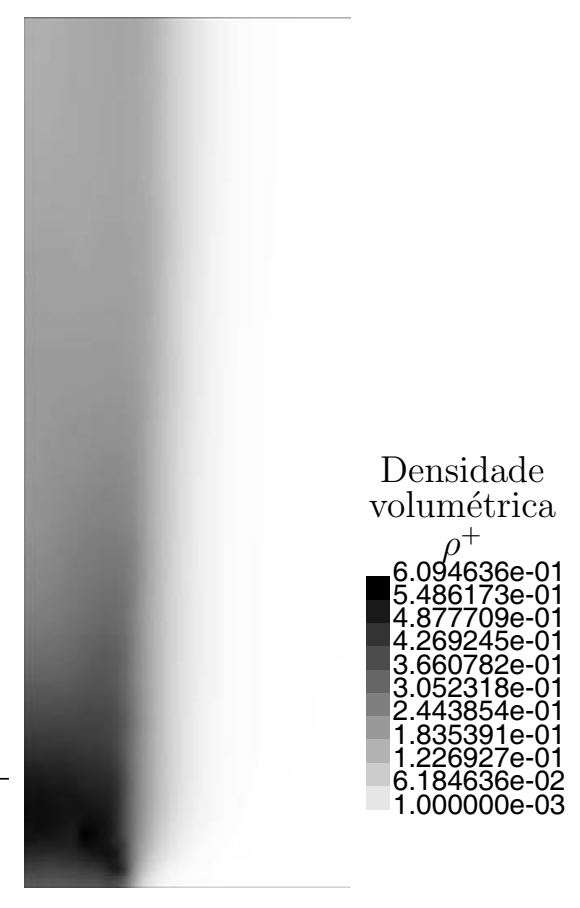

Figura 10.5: Solução obtida através da formulação 7.27, (sem a função $\max \{\cdot, \cdot\})$, considerando a continuação de $p=2 ; 20 ; 50 ; 100$ e filtro com raio igual a dimensão da aresta do elemento

sintetizou uma distribuição de material que se aproxima de uma barra suportando a carga apenas na região onde esta é aplicada, porém esta barra não necessita de toda a rigidez e resistência do material mais $(+)$, de tal forma que esta barra possui densidades volumétricas cada vez menores a medida que se afasta do ponto de aplicação do carregamento e as tensões se distribuem sobre toda a seção transversal. Atentando para a região próxima à aplicação da carga, observa-se uma distribuição de material particular que garante o máximo índice de falha igual a 1,06 .

Analisando o gráfico da Figura 10.6, que apresenta a curva de convergência da restrição global de tensão para este problema, observa-se que há um salto no valor da restrição na iteração 100, que é decorrente da mudança do valor de $p$ de 2 para 20, e novos saltos na iteração 200 e 300, decorrentes também das mudanças de $p$. Entretanto, apesar das oscilações da restrição global, permitidas pela utilização da variável $\beta$, a restrição tende ao 1 enquanto $\beta$ tende a zero, fornecendo assim 
a solução ótima desejada.

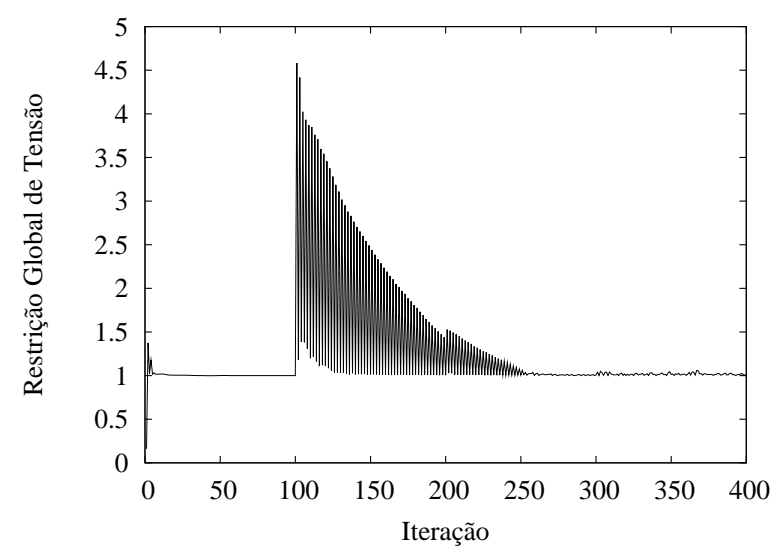

Figura 10.6: Curva de convergência da restrição global de tensão do problema tratado através da formulação 7.27 , (sem a função $\max \{\cdot, \cdot\}$ ), considerando a continuação de $p=2 ; 20 ; 50 ; 100$

Resolvendo o mesmo problema, porém com a formulação 8.2, isto é, mantendo a função $\max \{\cdot, \cdot\}$ e partindo de uma distribuição inicial de densidades em que se possui um grande número de elementos compondo a restrição global de tensão, além de considerar a continuação $p=2 ; 20 ; 50 ; 100$, obtém-se a distribuição de material apresentada na Figura 10.7(a). O campo do índice de falha desta é representado na Figura 10.7(b).

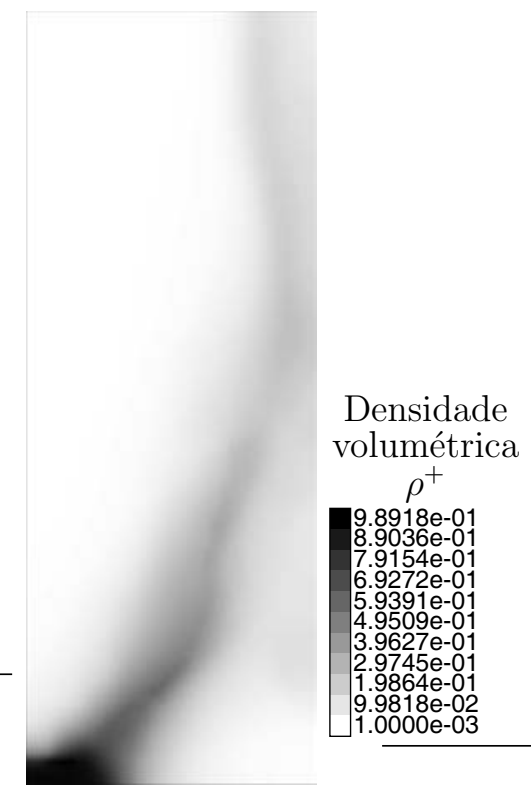

(a) Solução Final

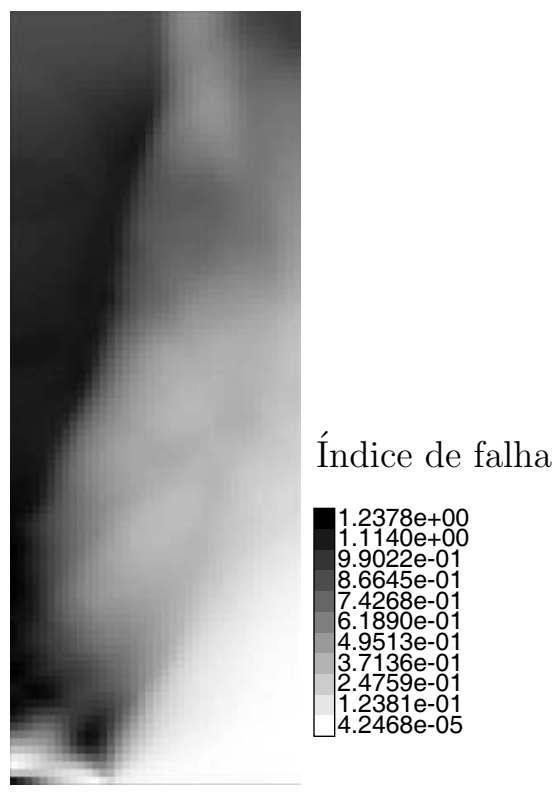

(b) Indice de falha na estrutura

Figura 10.7: Solução obtida através da formulação 7.28, (com a função $\max \{\cdot, \cdot\}$ ), considerando a continuação de $p=2 ; 20 ; 50 ; 100$ e filtro com raio igual à dimensão da aresta do elemento

Analisando estas figuras, observa-se que apesar da distribuição de material apresentar um campo com variação suave, este não é suficiente para controlar as 
tensões mecânicas da estrutura, como se verifica na Figura 10.7(b), que apresenta o máximo índice de falha igual a 1,23.

Entretanto, se forem analisadas as distribuições de material ao final de cada passo do processo de continuação de $p$, verifica-se que a distribuição ótima para $p=20$ se aproxima da distribuição obtida com a formulação sem a função $\max \{\cdot, \cdot\}$, apresentada na Figura 10.5. A Figura 10.8 apresenta as distribuições otimizadas de densidade volumétrica para cada valor de $p$ e o máximo índice de falha de cada estrutura está apresentado na legenda.
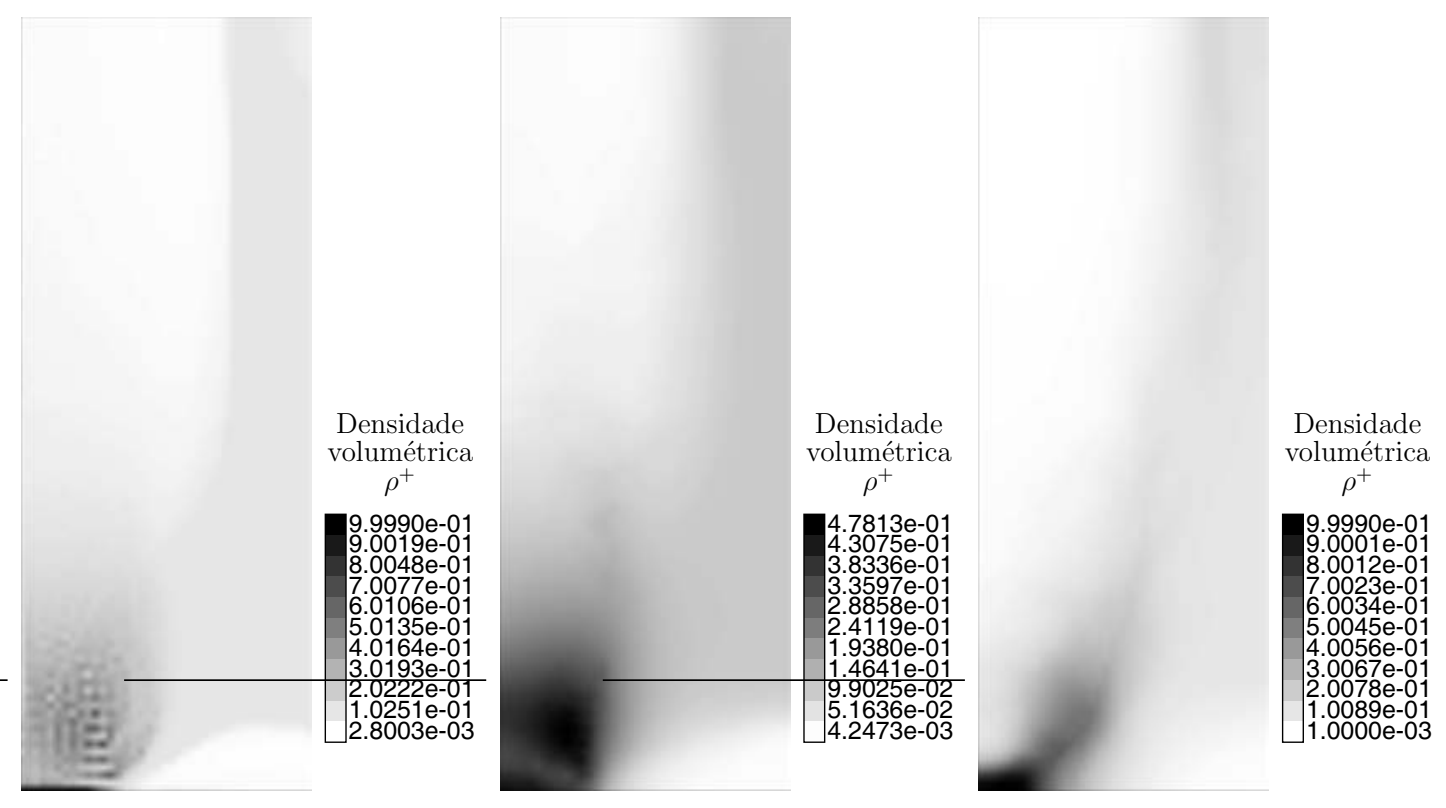

(a) Solução para $p=2$; (b) Solução para $p=20$; (c) Solução para $p=50$; Máximo índice de falha 1,22 Máximo índice de falha 1,09 Máximo índice de falha 1,25

Figura 10.8: Soluções ao final de cada passo da continuação de $p$

Analisando as soluções obtidas ao final de cada passo da continuação de $p$, apresentadas em 10.8, em conjunto com o gráfico de convergência da restrição global de tensão, apresentado na Figura 10.9, é possível melhor compreender a influência de $\beta$ na formulação 8.2 .

Inicialmente, é possível observar na curva de convergência (Figura 10.9) que a distribuição inicial de densidades, no caso um campo homogêneo com $\rho^{+}=0,1$, apresenta altos valores de índice de falha e, conseqüentemente, a restrição global de tensão é violada. Dessa forma, é possível iniciar o processo de otimização de um ponto inviável do espaço de solução, garantindo que o algoritmo de PL receba informações de grande parte dos elementos. Porém, para que o algoritmo de PL encontre uma solução viável, é necessário que este adote um alto valor de $\beta$ e, assim, com o decorrer das iterações, o valor de $\beta$ é gradativamente diminuído pelo próprio algoritmo, uma vez que este é somado à função objetivo. 
Ao final de 100 iterações a restrição global atinge um valor próximo de 0 , enquanto $\beta$ é praticamente zero $(0,03)$. Entretanto, se observarmos a distribuição de material e o máximo índice de falha para a iteração 100, apresentado na Figura 10.8(a), observa-se que a distribuição de material obtida gera um campo de tensões que viola a restrição em $22 \%$. Esta situação indica que o valor de $p=2$ não é suficiente para representar de forma adequada o pico de tensão.

Seguindo o processo iterativo, o valor de $p$ é aumentado para 20, o que gera algumas oscilações da restrição global nas iterações seguintes; entretanto, estas voltam a diminuir, e na iteração 200 é obtida um distribuição de material cujo campo de tensões viola a máxima tensão mecânica em apenas $9 \%$.

Aumentando ainda mais os valores de $p, p=50$ e $p=100$, observa-se que a restrição global começa a divergir e, ao final do processo de otimização, a estrutura obtida possui um índice de falha igual a 1,23 e a restrição global apresenta um valor próximo de 0,2 .

Assim, com base nestas observações, é possível concluir que para a formulação 8.2 é necessário utilizar menores valores de $p$.

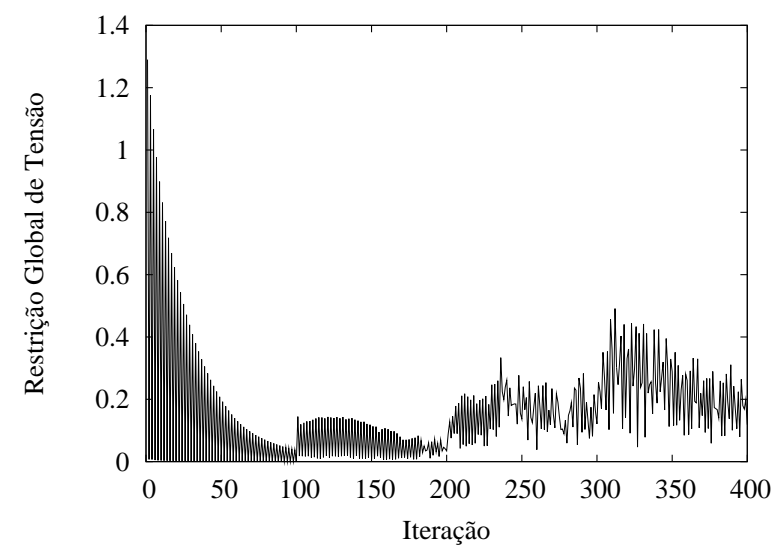

Figura 10.9: Curva de convergência da restrição global de tensão do problema tratado através da formulação 7.28 , (com a função $\max \{\cdot, \cdot\}$ ), considerando a continuação de $p=2 ; 20 ; 50 ; 100$

Comparando o gráfico da Figura 10.6 com o gráfico apresentado na Figura 10.7 e tendo como base a discussão aqui apresentada, pode-se concluir que a formulação com a função $\max \{\cdot, \cdot\}$ apresenta um comportamento mais instável do que o da formulação sem a função $\max \{\cdot, \cdot\}$. Isto pode ser explicado simplesmente devido ao fato da função $\max \{\cdot, \cdot\}$ inserir uma descontinuidade ao problema e assim dificultar a convergência. Entretanto, a experiência com as duas formulações demonstrou que ambas são capazes de obter resultados similares, desde que sejam utilizados os valores adequados de $p$, associados à utilização do filtro. 


\subsection{Exemplo 2: Cilindro sujeito a pressão ex- terna}

O segundo exemplo trata da otimização da distribuição de material na parede de um cilindro sujeito a pressão externa. Com o objetivo de se avaliar melhor os modelos de material propostos, neste problema será considerado um MGF real, composto por uma fase metálica de Titânio (Ti) e um fase cerâmica de Nitreto de Silício $\left(\mathrm{Si}_{3} \mathrm{~N}_{4}\right)$.

A fase cerâmica foi adotada como material mais $(+)$ e a metálica como material menos (-). As propriedades mecânicas de cada fase estão dadas na tabela 10.2 (CHO; CHOI, 2004), porém o coeficiente de poisson adotado é igual a 0, 3 para ambas as fases, a fim de assegurar as relações $K^{+}>K^{-}$e $G^{+}>G^{-}$, que são premissas do modelo de material.

\begin{tabular}{l|c|c}
\hline \multirow{2}{*}{ Propriedades } & Material (+) & Material (-) \\
\cline { 2 - 3 } & $\mathrm{Si}_{3} \mathrm{~N}_{4}$ & $\mathrm{Ti}$ \\
\hline Módulo de Young (GPa) & 310 & 117 \\
Coeficiente de poisson & 0,27 & 0,32 \\
Tensão de Referência (MPa) & $400^{a}$ & $175^{b}$ \\
\hline
\end{tabular}

${ }^{a}$ Resistência a Tração

${ }^{b}$ Tensão de escoamento

Tabela 10.2: Propriedades mecânicas das fases constituintes do MGF adotada para o problema do cilindro sujeito a pressão externa

Conforme apresentado na seção 7.4.1, foram propostas duas formas de se definir as propriedades elásticas do modelo de material em função da densidade volumétricas das fases, que foram denominadas: H-S-linear e H-S-transição.

Também foram propostas duas formas de se obter a tensão mecânica de referência: o modelo Tensão-M.A. e o Modelo-M.H. Neste exemplo, estes quatro modelos serão agrupados dois a dois, definindo assim duas abordagens para o modelo de material.

Dessa forma, a abordagem 1 consiste em utilizar o modelo de material H-S linear, para se obter as propriedades elásticas do material efetivo. Neste caso foi adotado $\kappa=0,5$. Para obter a tensão de referência efetiva é utilizado o modelo Tensão-M.A. $\operatorname{com} s=2$.

A abordagem 2 consiste em utilizar o modelo de material H-S-transição para definição das propriedades efetivas, e para obter tensão de referência, é utilizado o modelo Tensão-M.H. 
Do ponto de vista da otimização de estruturas constituídas por MsGF, a abordagem 2 apresenta uma hierarquia sobre a abordagem 1, pois a abordagem 2 utiliza um modelo de material mais fiel para a representação das propriedades elásticas efetivas do MGF e a tensão de referência é dada de forma mais conservadora. Ou seja, os resultados obtido com a abordagem 2 são, a princípio, mais confiáveis.

Para melhor ilustrar as duas abordagens, a Figura 10.10 apresenta o gráfico do módulo de Young em função da densidade volumétrica de cerâmica (Material mais; +). Neste gráfico observa-se que a diferença entre as duas abordagens

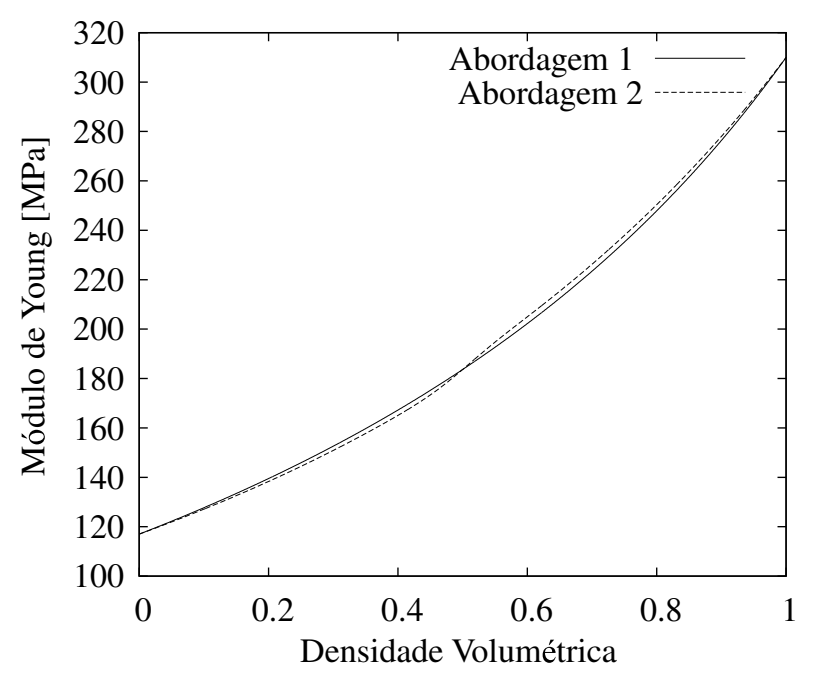

Figura 10.10: Módulo de Young efetivo do MGF para a abordagem 1 e a abordagem 2

é pequena, pois os módulos de Young das duas fases possuem a mesma ordem de grandeza; neste exemplo a cerâmica é 2,6 vezes mais rígida que o metal. A diferença entre a abordagem 1 e a abordagem 2 se torna mais pronunciada quando a relação entre a rigidez é em torno de 10 vezes, conforme apresentado no gráfico da Figura 7.3.

O quadrado da tensão de referência em função da fração volumétrica é apresentado na Figura 10.11 para o MGF em questão. Aqui optou-se por representar o quadrado da tensão de referência, pois a formulação proposta considera a restrição sobre o quadrado das tensões de von Mises. E assim é possível fazer uma interpretação mais precisa do comportamento do método de otimização e de seu resultado.

As duas abordagens para a modelagem do MGF foram utilizadas na otimização da distribuição de material em um cilindro sujeito à pressão externa de 110 MPa. A geometria e o carregamento estão representados na Figura 10.12 e a malha de elementos finitos axissimétricos está representada na Figura 10.13. 


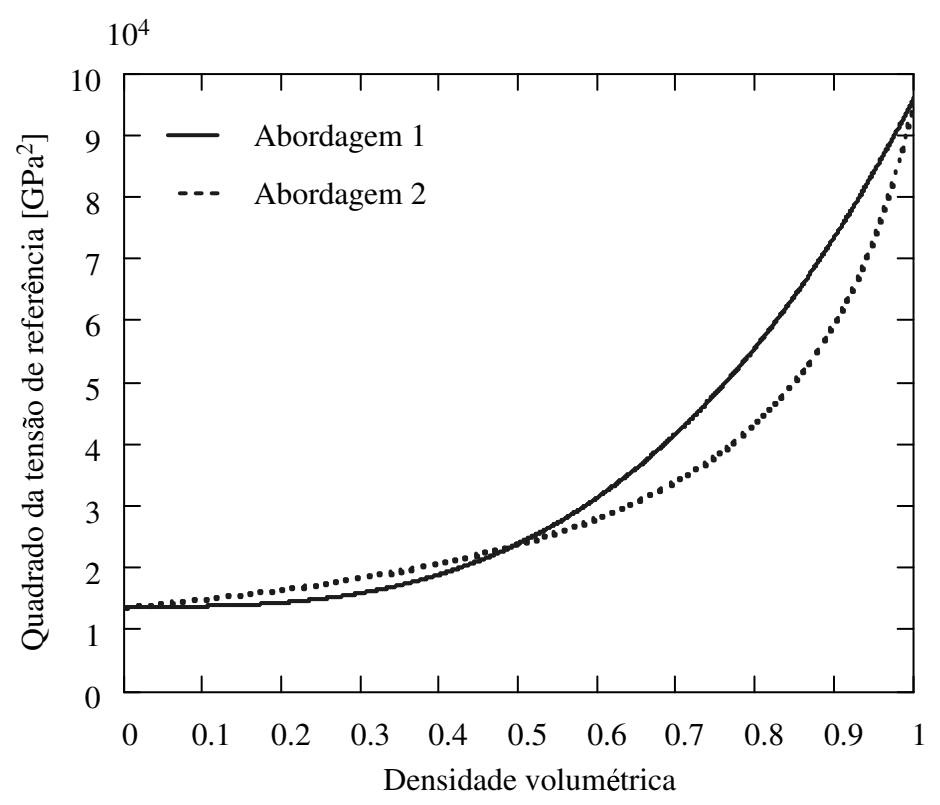

Figura 10.11: Tensão de referência para MGF para a abordagem 1 e a abordagem 2

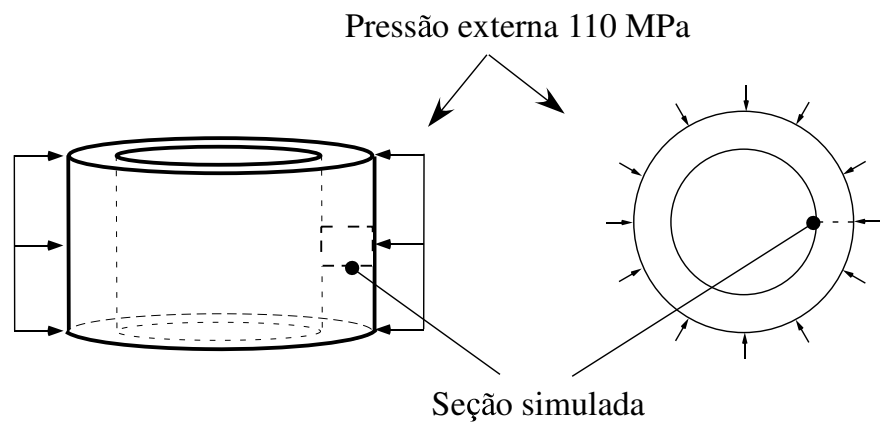

Vista em perspectiva

Vista de topo

Figura 10.12: Representação esquemática do cilindro sujeito a pressão externa e respectiva seção simulada através do MEF axissimétrico

Neste exemplo, em todas as sínteses foi aplicada a formulação 7.27 (sem a função $\max \{\cdot, \cdot\})$, uma vez que esta se mostrou mais estável, conforme demonstrado no exemplo 10.1 .

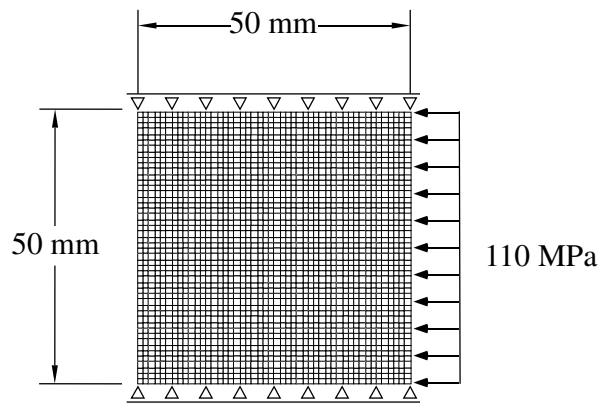

Figura 10.13: Representação da malha de elementos finitos, condições de contorno (malha com 2304 elementos, 2401 nós e 2401 variáveis de projeto no problema de otimização.) 
Inicialmente, serão apresentados os resultados obtidos com a abordagem 1. A Figura 10.14(a) apresenta a solução obtida para a distribuição inicial de densidades homogêneas e a continuação do parâmetro $p$ na forma $p=10 ; 25 ; 50 ; 75$. Analisando o resultado obtido, observa-se que o Titânio, que é o material menos

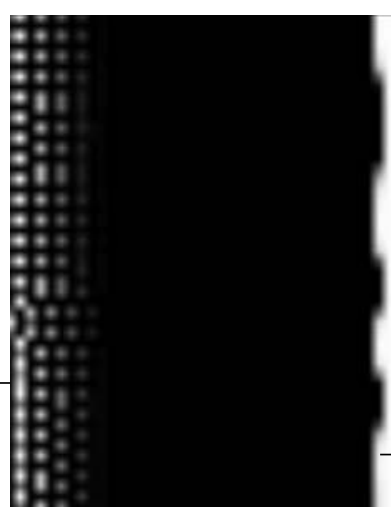

(a) Distribuição de Material
Densidade volumétrica $\rho^{+}$
$9.9990 \mathrm{e}-01$ $9.0001 \mathrm{e}-01$ $8.0012 \mathrm{e}-01$

$7.0023 \mathrm{e}-01$

$6.0034 \mathrm{e}-01$

$5.0045 \mathrm{e}-01$

$4.0056 \mathrm{e}-01$

$3.0067 \mathrm{e}-01$

$2.0078 \mathrm{e}-01$

$1.0089 e-01$
$1.0000 e-03$ Índice de falha

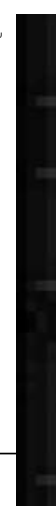

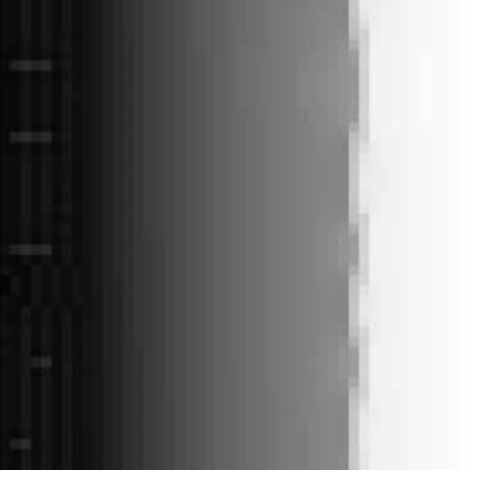

(b) Campo do índice de falha

Figura 10.14: Solução obtida e campo do índice de falha, utilizando a abordagem 1 para representação do material, e fazendo a continuação de $p=10 ; 25 ; 50 ; 75$, iniciando com distribuição homogênea de densidades

$$
\rho^{+}=0,999
$$

rígido, é retirado da parte externa do cilindro, criando uma interface clara entre os dois materiais. Na região interna, observa-se que a distribuição de Titânio apresenta uma oscilação espacial, criando um padrão de pontos.

Para compreender esta distribuição de material, é necessário analisar o campo do índice de falha no cilindro, apresentado na Figura 10.14(b). Nesta figura observa-se que existe uma concentração de tensão, gerada pela interface metalcerâmica na região mais externa do cilindro, Esta situação não é esperada no caso de uma estrutura constituída de MGF, porém a concentração ocorre apenas porque o o pico de tensão apresenta um índice de falha da ordem de 0,7 , ou seja, a tensão é menor que tensão de referência.

Observa-se também que, apesar das oscilações do campo de densidades na região interna do cilindro, estas não se verificam no campo do índice de falha, e isto se deve a dois fatores. O primeiro é que este padrão geométrico é capaz de minimizar o volume da cerâmica e, assim, minimizar a função objetivo, porém sem diminuir a rigidez da região, o que acarretaria em maiores deformações e, conseqüentemente, maiores tensões. O outro fator que pode gerar tais oscilações, apesar de não comprovado, é que o índice de falha calculado no centro do elemento não é capaz de restringir tais oscilações. Por exemplo,no caso da tensão aumente nas regiões próximas aos nós, esta não será percebida pela restrição de tensão adotada. 
Com o intuito de retirar as oscilações do campo de densidades, o mesmo problema foi resolvido, porém utilizando o filtro espacial, sendo que, nas iterações iniciais, o raio de abrangência do filtro é igual a 3 vezes a aresta do elemento e, ao final, este é diminuído para 2 vezes a aresta do elemento. O resultado da distribuição de material, bem como o campo do índice de falha, estão representados na Figura 10.15.

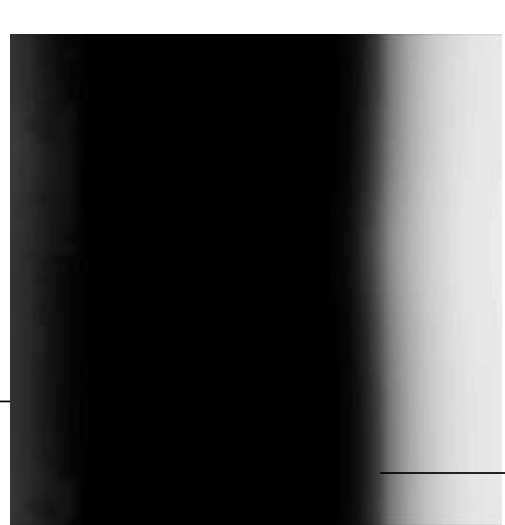

(a) Distribuição de Material

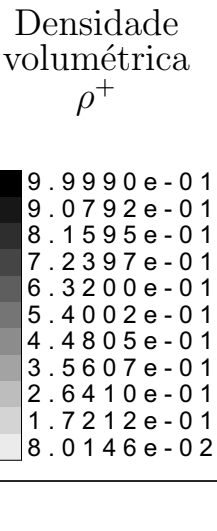

Densidade

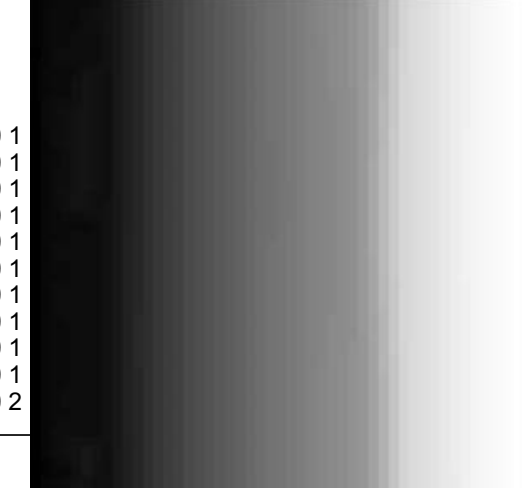

(b) Campo do índice de falha Índice de falha

Figura 10.15: Solução obtida e campo do índice de falha, utilizando a abordagem 1 para representação do material; fazendo a continuação de $p=10 ; 25 ; 50 ; 75$; iniciando com distribuição homogênea de densidades $\rho^{+}=0,999$ e adotando o filtro de raio igual a 3 vezes a aresta do elemento para $p=10$ e duas vezes a aresta para os demais valores de $p$

Comparando este resultado apresentado na Figura 10.15(a), com o resultado obtido sem a utilização do filtro, verifica-se que ambos fornecem campos de índice de falha muito similares, porém as oscilações do campo de densidades são retiradas. Em ambos os resultados apresentados, observa-se que o máximo índice de falha da estrutura é de 1,06, ou seja, apenas $6 \%$ acima da tensão de referência.

Continuando a análise das duas abordagens de representação do MGF, o mesmo problema foi resolvido utilizando a abordagem 2. Assim, inicialmente foi sintetizada a distribuição de material do cilindro, utilizando os mesmo parâmetros adotados para a solução com a abordagem 1 (Figura 10.14), isto é, fazendo a continuação de $p$ na forma $p=10$; 25 ; 50 ; 75, e sem utilizar o filtro. A única diferença é a distribuição inicial de densidades, que foi adotada igual a 0,25. Entretanto, no caso do problema com a abordagem 1, a solução obtida com as densidades iniciais igual a 0,25 é idêntica à solução obtida com distribuição inicial de densidades 0,999. O resultado obtido neste caso, com a abordagem 2, está apresentado na Figura 10.16, junto com o respectivo campo de índice de falha. Analisando a distribuição de material apresentada na Figura 10.16(a), observa-se que esta é significativamente diferente daquela apresenta na Figura 


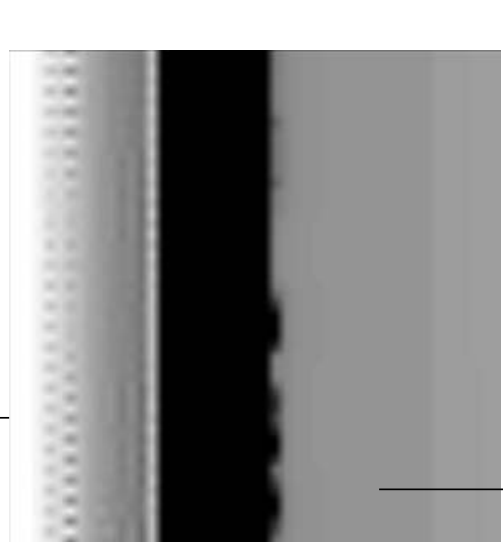

(a) Distribuição de Material
Densidade volumétrica

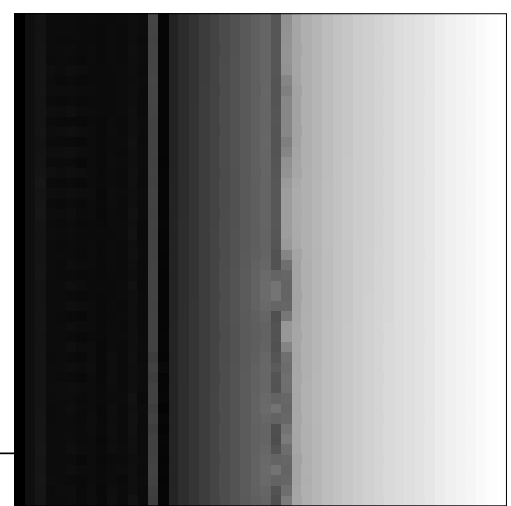

Índice de falha

(b) Campo do índice de falha

Figura 10.16: Solução obtida e campo do índice de falha, utilizando a abordagem 2 para representação do material, e fazendo a continuação de $p=10 ; 25 ; 50 ; 75$, iniciando com distribuição homogênea de densidades

$$
\rho^{+}=0,25
$$

10.14(a). A única semelhança é a tentativa de diminuir a fração volumétrica de cerâmica nas regiões mais internas e externas do cilindro.

Observando o campo de índice de falha gerado por esta distribuição de material, e apresentado na Figura 10.16(b), observa-se que o método não foi capaz de encontrar uma distribuição que atendesse ao critério de falha, pois o máximo índice de falha é igual à 1,6. Aparentemente, esta distribuição de material ocorre porque o algoritmo de otimização fica preso em um mínimo local e não consegue sair desse mínimo local independentemente do valor de $k_{\beta}$ utilizado na formulação 8.1 .

Com o intuito de melhorar a solução obtida com a abordagem 2, o mesmo problema foi resolvido utilizando o filtro espacial, e o resultado obtido está apresentado na Figura 10.17(a), enquanto o respectivo campo de índice de falha é apresentado na Figura 10.17(b). Observando estas Figuras, verifica-se que a solução obtida é mais conservadora, ou seja, possui mais cerâmica, que é o material mais rígido e resistente neste caso. Assim o campo de índice de falha apresenta valor máximo igual a 1,05, que representa um valor aceitável para a restrição global de tensão.

Avaliando estes resultados do ponto de vista do algoritmo de otimização podese concluir que a diferença dos resultados se dá devido aos modelos de estimativa de tensão de referência. Avaliando o gráfico da Figura 10.11, observa-se que para as densidades volumétricas maiores que 0,5, o modelo de Tensão-M.A., adotado na abordagem 1, fornece tensões de referência maiores, o que faz com que o método de otimização prefira valores de densidade mais baixos, uma vez que minimizam a função objetivo e sem prejudicar em demasia a restrição do 


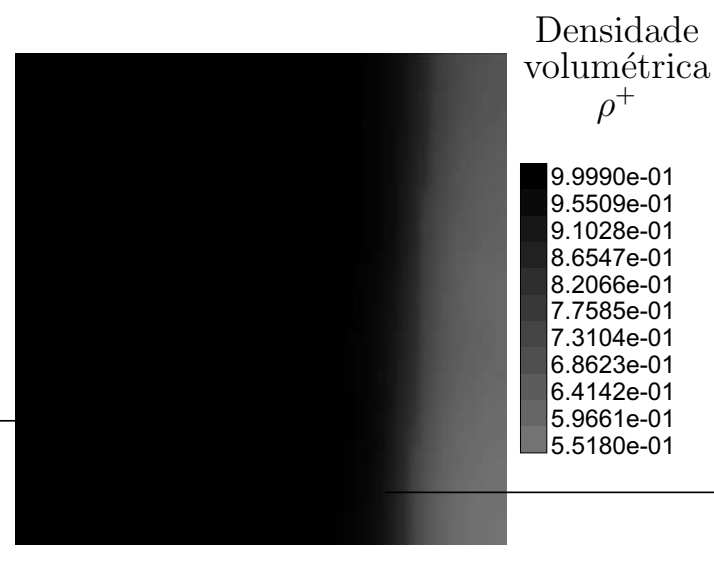

(a) Distribuição de Material

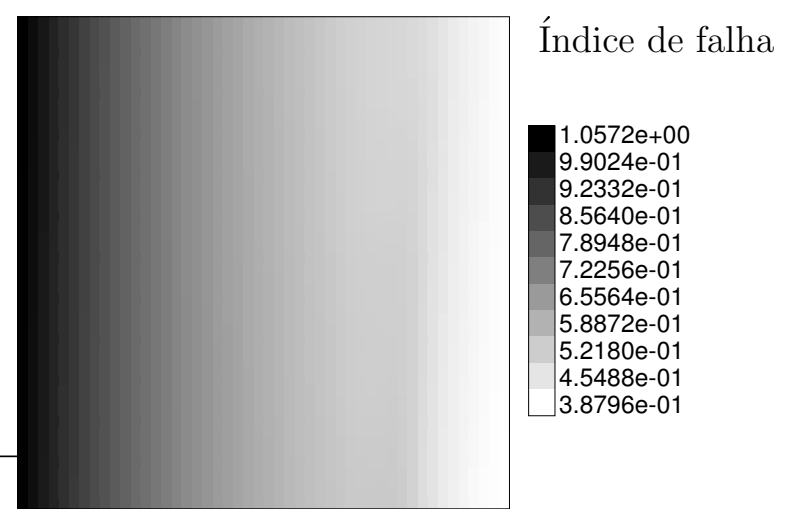

(b) Campo do índice de falha

Figura 10.17: Solução obtida e campo do índice de falha, utilizando a abordagem 1 para representação do material; fazendo a continuação de $p=10 ; 25 ; 50 ; 75$; iniciando com distribuição homogênea de densidades $\rho^{+}=0,25$ e adotando o filtro de raio igual a 3 vezes a aresta do elemento para $p=10$ e duas vezes a aresta para os demais valores de $p$

problema.

Esta situação se observa claramente ao comparar as densidades volumétricas na região externa do vaso de pressão para as soluções obtidas pela abordagem 1, apresentada na Figura 10.15(a), e pela abordagem 2, apresentada na Figura 10.17(a). A a solução obtida pela abordagem 2 tem como mínima densidade $\rho^{+}=0,51$ enquanto pela abordagem 1 a densidade mínima é igual a 0,08 .

Ainda sob o ponto de vista do método de otimização, é possível compreender alteração drástica do resultado obtido com e sem o filtro, no problema com a abordagem 2 .

De maneira qualitativa, o fato da curva do quadrado da tensão de referência para a abordagem 2 ser mais abrupta faz com que o espaço de solução se torne mais mal comportado. Esta situação é similar à influência da penalização $q$ do modelo de material SIMP, discutida através do gráfico da Figura 2.4. Isto fez com que, neste caso, a solução ficasse presa em um mínimo local, porém com a utilização do filtro o método de otimização passa a fazer outro caminho pelo espaço de solução, que neste caso levou a um ponto ótimo melhor do que o anterior.

\subsection{Exemplo 3: Disco de turbina a gás}

O terceiro exemplo acrescenta mais um componente ao problema de otimização, que são as forças de campo, neste caso a força centrifuga. Devido a elevada rotação do disco de uma turbina a gás, a força centrifuga exerce um papel importante no 
carregamento da estrutura, que não pode ser desprezada.

Do ponto de vista do problema de otimização, as forças de campo dependentes da densidade inserem mais uma não-linearidade ao problema. Por exemplo, no problema clássico de OT para maximização da rigidez de uma estrutura sujeita apenas a forças externas, a função objetivo é monotônica, porém, se forem consideradas forças de campo dependentes da densidade, a função objetivo passa a ser não monotônica. Assim, este exemplo visa mostrar a capacidade do método de otimização proposto de tratar esta situação.

Neste exemplo, seguindo a análise feita no problema anterior, também será discutida a influência dos modelos de material na solução do problema.

A geometria e as condições de contorno do disco de turbina adotado foram baseadas no trabalho de Liu, Parks e Clarkson (2002), que propuseram uma geometria otimizada para um disco homogêneo. Esta geometria está apresentada na Figura 10.18, que apresenta apenas seção transversal no plano $(x, y)$. Isso só é possível pois a estrutura possui simetria axial em relação ao eixo $x$ e simetria em relação ao plano $(x, z)$.

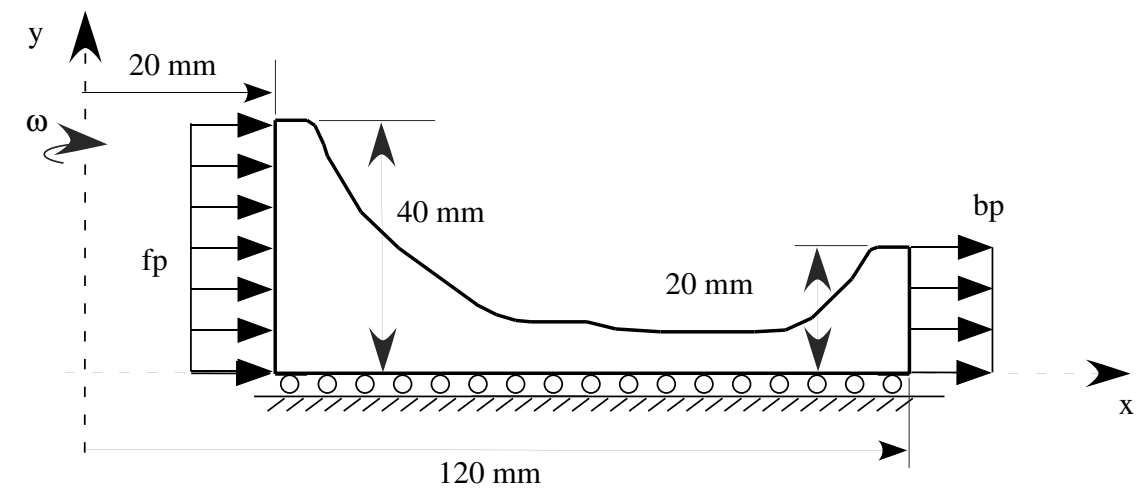

Figura 10.18: Representação esquemática da geometria e condições de contorno do disco de turbina a gás

Este disco está sujeito a três classes de carregamento. Uma pressão interna resultante do encaixe forçado entre o disco e o eixo, que é representada na Figura 10.18 por $f p=40 \mathrm{MPa}$. Uma força distribuída aplicada radialmente na face externa do disco, que representa o carregamento exercido pelas pás da turbina e é representada por $b p=200 \mathrm{MPa}$. A terceira classe de carregamento é a força centrifuga distribuída no interior do disco devido à rotação $\omega=2000 \mathrm{rpm}$.

Neste exemplo, foram adotados dois materiais fictícios, porém, um com propriedades representantes dos materiais cerâmicos, como cerâmicas de engenharia $\mathrm{Si}_{3} \mathrm{~N}_{4}$ e $\mathrm{Al}_{2} \mathrm{O}_{3}$, e outro das ligas metálicas, como as ligas de Níquel e Molibidênio. Aqui o material representante das cerâmicas será denominado "C" e o das ligas 
metálicas "M". Para atender ao critério de $K^{+}>K^{-}$e $G^{+}>G^{-}$, o material "C" foi adotado como material mais $(+)$. As propriedades mecânicas dos materiais foram obtidas em Ashby (1999) e são apresentadas na tabela 10.3.

\begin{tabular}{l|c|c}
\hline & Material $(+)$ & Material (-) \\
\cline { 2 - 3 } Propriedades & "C" & "M" \\
\hline Densidade $\left(\mathrm{kg} / \mathrm{m}^{3}\right)$ & 4000 & 9000 \\
Módulo de Young (GPa) & 350 & 110 \\
Coeficiente de poisson & 0.25 & 0.3 \\
Tensão de Referência (MPa) & 3500 & 300 \\
\hline
\end{tabular}

Tabela 10.3: Propriedades mecânicas das fases constituintes do MGF para o problema do disco de turbina a gás

Aqui vale notar que apesar desses materiais não serem necessariamente um par metal/cerâmica capaz de constituir um MGF, estes materiais representativos foram adotados a fim de evidenciar a influência das propriedades do material sobre o resultados obtidos. Também é importante ressaltar que a tensão de referência do material cerâmico representa à resistência de compressão.

Para poder comparar o disco de turbina a gás constituído de MGF com uma distribuição otimizada de cada uma das fases, inicialmente, foram analisados os campos de tensão e, conseqüentemente, os campos de índice de falha de discos homogêneos constituídos de material "C"e "M". Assim, pôde-se observar que um disco feito totalmente com o material "C"possui a máxima tensão de von Mises 23 vezes menor do que a tensão de referência do material, e o disco constituído de material "M"tem a máxima tensão mecânica 8 vezes maior que a tensão de referência deste material. Dessa forma, a tarefa do método de otimização é encontrar a distribuição de material que atenda ao critério de resistência com a mínima quantidade de material "C".

Continuando a discussão apresentada no exemplo anterior (seção 10.2), o problema do disco de turbina a gás foi resolvido 6 vezes, perfazendo todas as combinações possíveis entre os modelos de material H-S-linear e H-S-transição e os modelos de estimativa das tensões de referência Tensão-M.H. e Tensão-M.A. para $s=1$ e para $s=3$.

Em todos os resultados foi utilizada a continuação $p=15 ; 30 ; 60 ; 120$, garantindo, assim, uma boa aproximação do pico máximo de tensão da estrutura.

Inicialmente, na Figura 10.19, são apresentados os resultados utilizando o modelo de tensão de referência Tensão-M.A. com $s=1$. 


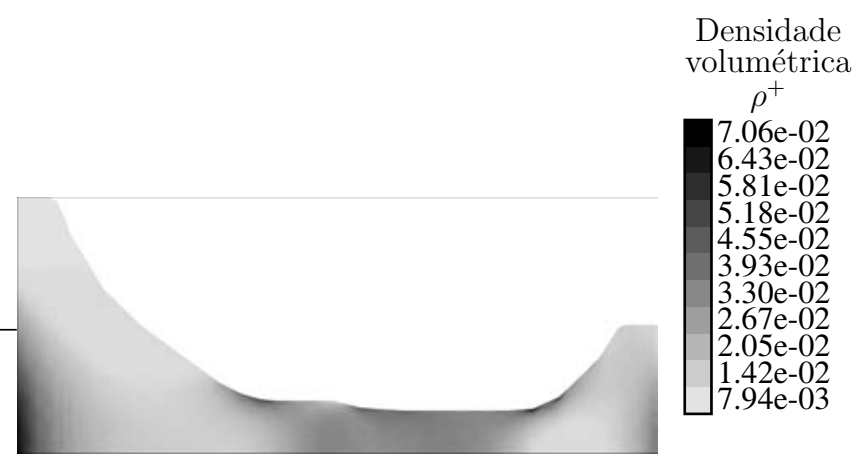

(a) Solução para H-S-linear

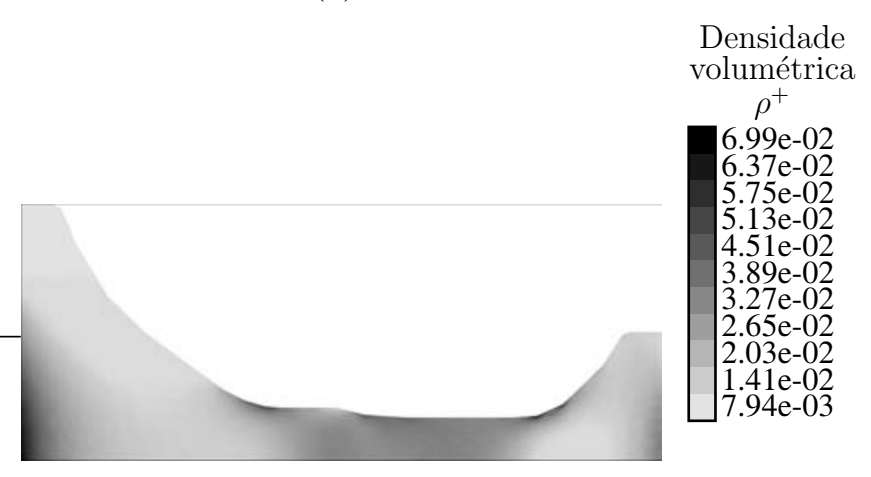

(b) Solução para H-S-transição

Figura 10.19: Comparação das soluções obtidas utilizando os modelos de material H-S-linear e o H-S-transição, ambos utilizando a tensão de referência dada pelo modelo Tensão-M.A. com $s=1$

Observando estes resultados, a primeira conclusão a que se pode chegar é a pequena influência do modelo de material na solução do problema, ambos os resultados apresentam um campo de distribuição de material muito similar. Esta situação pode ser compreendida pelo fato de que o módulo de Young de ambos os materiais possuem a mesma ordem de grandeza e, então, assim como no exemplo anterior, as curvas dos modelos de material H-S-linear e H-S-transição, são muito próximas, como se observa no gráfico da Figura 10.10. Esta situação de similaridade dos resultados se manteve nos seis resultados obtidos. Dessa forma, serão apresentados apenas os resultados para o modelo H-S-transição.

Outro ponto a ser observado são os baixos valores das densidades do material "C", que é o material que se deseja minimizar. Assim, este exemplo demonstra que o método foi capaz de obter um disco turbina constituído basicamente de material metálico, porém, com uma distribuição de material cerâmico com frações volumétricas baixas, de no máximo igual 0,7\%, que atende aos critérios de falha. Ou seja, comparando com a solução do disco homogêneo de material "M", o disco com gradação funcional é capaz de diminuir o máximo índice de falha da estrutura de 8 para 1.03 que é o máximo índice de falha deste estrutura, como 
pode ser observado adiante, na Figura 10.20, que apresenta o campo do índice de falha para a solução apresentada na Figura 10.19(b).

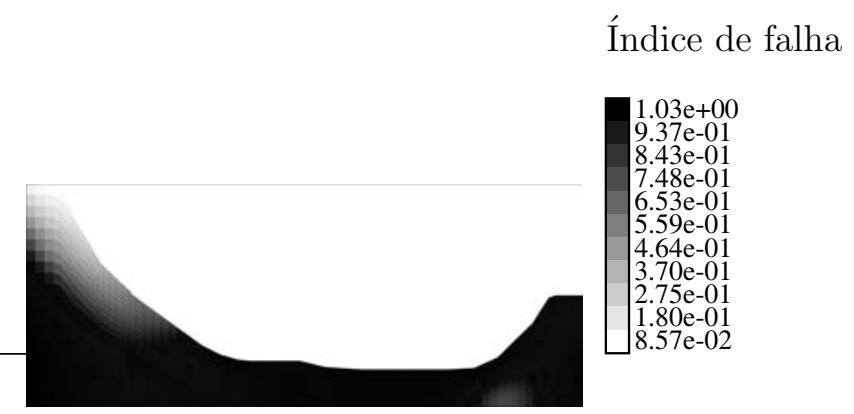

Figura 10.20: Índice de falha da soluções obtida utilizando o modelo de material H-S-transição associado ao modelo Tensão-M.A. com $s=1$

Continuando a análise da influência do modelo de estimativa da tensão de referência, a Figura 10.21 apresenta os resultados obtidos com os modelos de Tensão-M.A e Tensão M.H.

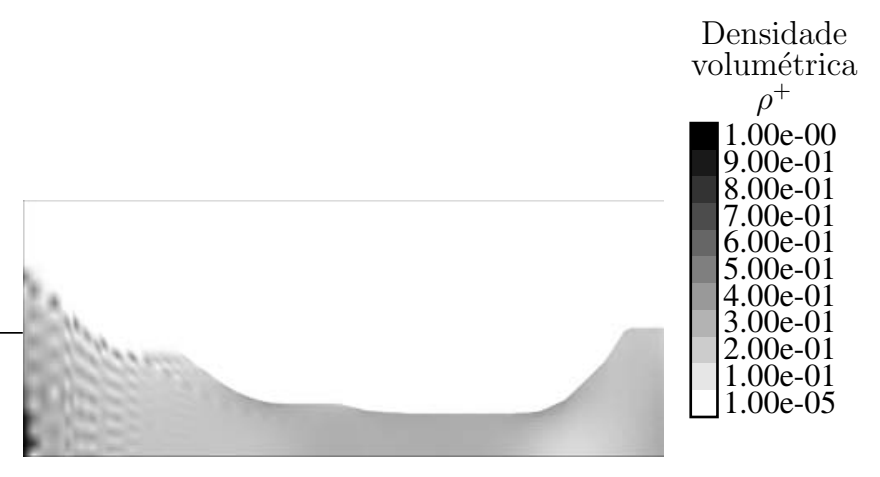

(a) Solução para o modelo Tensão-M.A. com $s=3$

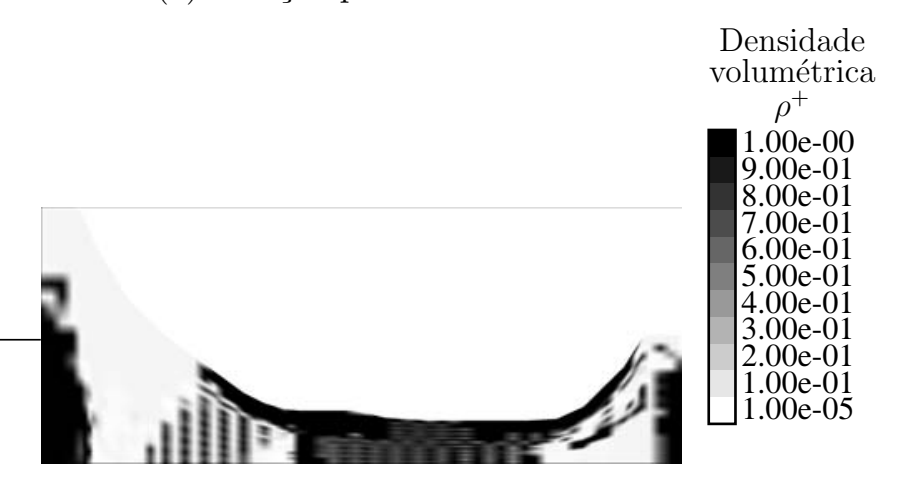

(b) Solução para o modelo Tensão-M.H.

Figura 10.21: Comparação das soluções obtidas utilizando o modelo de material H-S-transição associado aos modelos Tensão-M.A. com $s=3$ e o modelo Tensão-M.H.

Observando estes resultados, o primeiro ponto a se concluir é a nítida diferença entres eles. Apesar de ambos os resultados apresentarem a máxima fração volumétrica igual a 1 , o resultado com o modelo Tensão M.A. para $s=3$ apresenta 
uma distribuição suave de material, já o resultado com o modelo Tensão-M.H. a distribuição de material apresenta interfaces bem definidas e poucas regiões com densidade intermediária.

Ambos os resultados apresentam uma oscilação do campo de densidades, principalmente na região interna do disco. Estas oscilações são similares àquelas obtidas no exemplo 10.2, mais especificamente no resultado da Figura 10.14(a). E, conforme discutido anteriormente, estas oscilações ocorrem, provavelmente, pelo fato de que o campo de índice de falha avaliado no centro do elemento não apresenta estas oscilações, permitindo assim a oscilação do campo de densidades.

Para melhor compreender os resultados obtidos, é interessante analisar as curvas da tensão de referências dos modelos de estimativa adotados, o gráfico da Figura 10.22 apresenta a curva para os três modelos utilizados, Tensão-M.A com $s=1$, Tensão-M.A. com $s=3$ e Tensão-M.H. Analisando este gráfico, observa-se

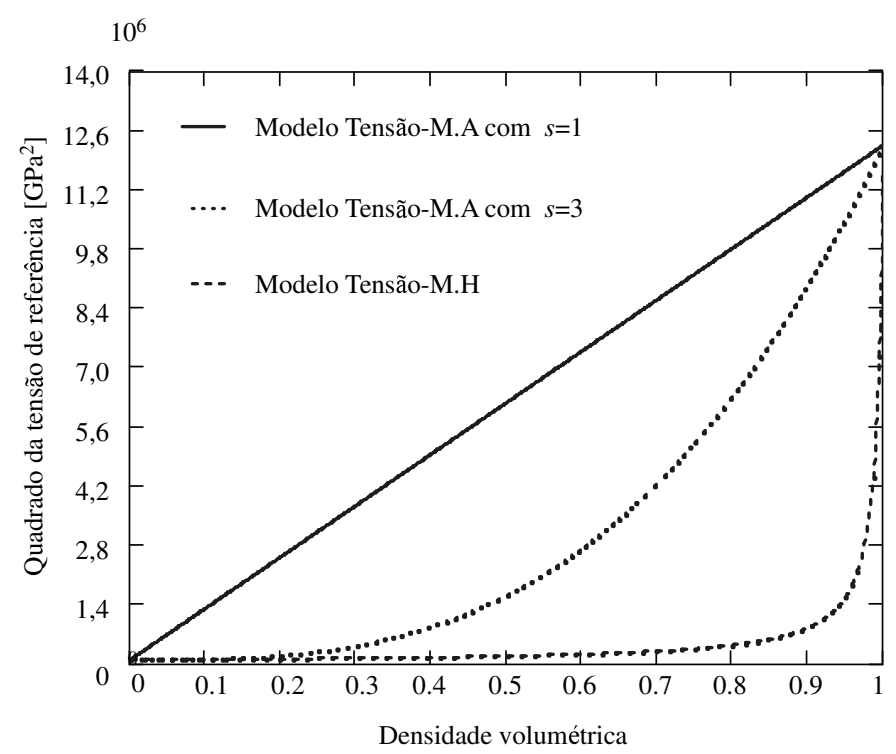

Figura 10.22: Comparação do quadrado das tensões de referência dadas pelos modelos: Tensão-M.A. com $s=1$, Tensão-M.A. com $s=3$ e Tensão-M.H.

que, neste caso em que as tensões de referência tem uma ordem de grandeza de intervalo o modelo Tensão-M.H. apresenta uma curva que se aproxima das tensões de referência do modelo de Reuss (Figura 4.7), ou seja, uma curva muito próxima da tensão de referência do material mais fraco para as densidades abaixo de 0,9 , e para valores maiores que 0,9 a tensão de referência se aproxima rapidamente da tensão do material mais resistente. Já a curva do modelo Tensão M.A com $s=1$ é proxima da curva do modelo de Voigt (Figura 4.7), e a curva do modelo Tensão-M.A com $s=3$ apresenta um comportamento intermediário entre os dois modelos. Aqui vale notar que as curvas apenas se aproximam dos modelos Voigt e Reuss, pois estes modelos, são baseados na tensão de escoamento dos materiais 
e não no quadrado da tensão, como está sendo considerado neste caso.

Assim, a primeira conclusão a que se pode chegar é que as distribuições de material, apresentadas nas Figuras 10.19(b), 10.21(a) e 10.21(b), são otimizadas para modelos de material particulares, partindo de um modelo próximo do modelo de Voigt e se aproximando do modelo de Reuss. Conseqüentemente, a escolha de cada uma destas soluções para um possível projeto da estrutura deve ser feita com base no modelo de material que mais se aproxima do comportamento real do MGF adotado.

Do ponto de vista do algoritmo de otimização, a influência dos modelos de estimativa da tensão de referência na obtenção de uma solução com distribuição mais suave ou com interfaces melhor definidas pode ser explicada pelo mesmo fato apresentado no exemplo 2 de que o modelo Tensão-M.H. penaliza as densidades intermediárias, abaixando drasticamente a tensão de referência, com pode ser observado no gráfico da Figura 10.22.

Analisando apenas o resultado obtido com o modelo Tensão-M.H. (Figura 10.21(b)) verifica-se que este apresenta duas características indesejadas: uma é a oscilação do campo de densidades, que pode ser atribuída a um problema numérico, e o outro são as interfaces bem definidas entre os materiais, que, apesar de não gerar picos de tensão acima da tensão de referência, do ponto de vista construtivo, são regiões mais frágeis que as homogêneas ou regiões de transição suave.

Neste caso é possível se utilizar do filtro proposto para a regularização do problema e, assim, restringir a solução do problema, apenas entre aquelas que possuem uma distribuição suave de material. Assim, foi obtida novamente a solução otimizada para o modelo de material Tensão-H.S., porém com filtro espacial definido com raio igual àa $1 \mathrm{~mm}$. A solução obtida está apresentada na Figura 10.23(a) e seu respectivo campo de falha na Figura 10.23(b).

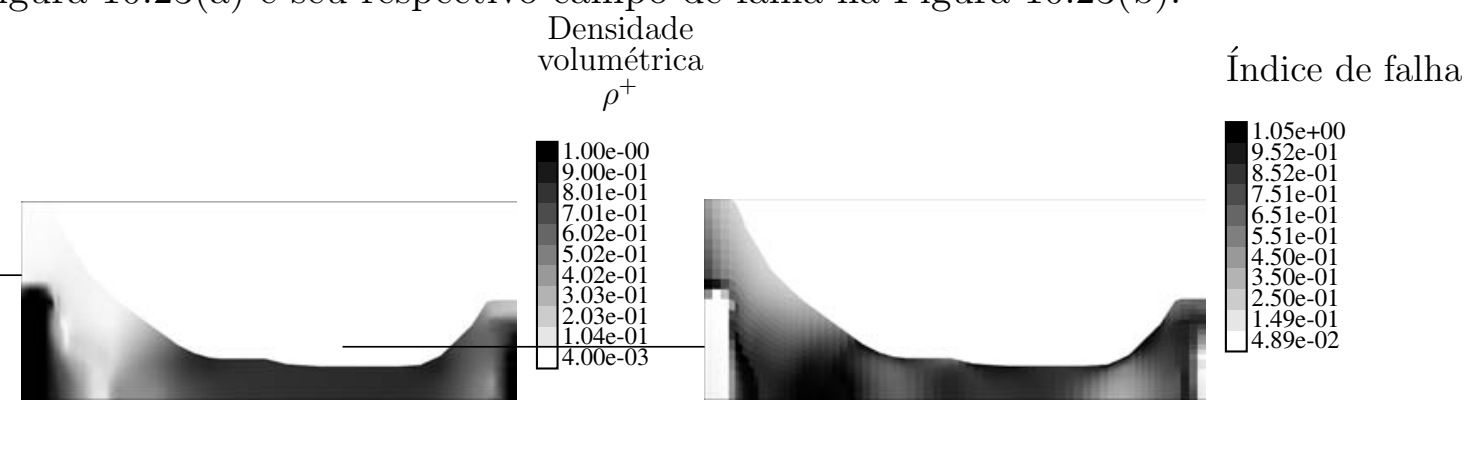

(a) Distribuição de material

(b) Índice de falha

Figura 10.23: Solução obtida utilizando o modelo de material H-S-transição associada ao modelo Tensão-M.H. e com filtro de raio $r=1 \mathrm{~mm}$ 
Analisando este resultado, verifica-se que o filtro foi capaz de suprimir as oscilações do campo de densidade, entretanto, apesar de se afastar do ponto ótimo, uma vez que o volume total de material "C" do resultado sem filtro (49\%) é menor do que o volume de material "C" na solução com filtro (61\%), em ambos os casos a restrição de tensão foi respeitada. O máximo índice de falha para a solução obtida sem o filtro é de 1,04 e para o caso com o filtro é de 1.05, como pode ser observado na figura $10.23(\mathrm{~b})$

\subsection{Exemplo 4: Maximização da inércia de rotação de uma roda de inércia (Volante)}

O último exemplo tem por objetivo apresentar um resultado utilizando a formulação de maximização da inércia de rotação considerando restrição de tensão, conforme proposto na subseção 7.4.2, e associada à restrição de tensão proposta na formulação 7.27 , ou seja, sem a função $\max \{\cdot, \cdot\}$.

Neste exemplo, a tarefa do otimizador é encontrar um campo de distribuição de material que maximize a inércia de rotação, porém, atendendo ao critério de falha.

O aspecto interessante desse exemplo é que, quanto maior a inércia de rotação, maiores são as forças centrifugas e, conseqüentemente, as tensões no disco.

Neste exemplo, é considerado um disco de geometria e dimensões dadas pela Figura 10.24. Este disco está sujeito apenas à ação de forças centrífugas, devido à rotação constante de $\omega=1 \mathrm{rad} / \mathrm{s}$

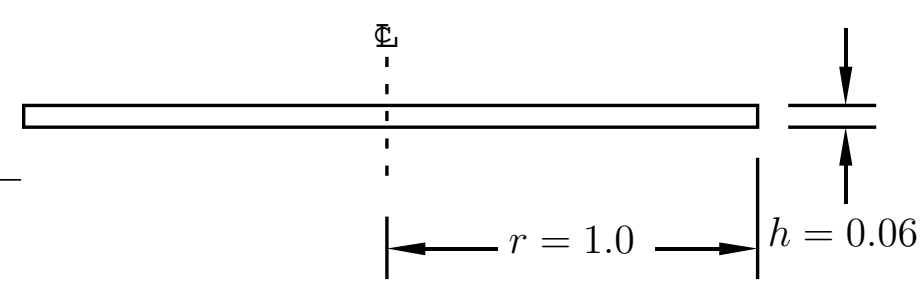

Figura 10.24: Geometria da roda de inércia

Utilizando o MEF em sua formulação axissimétrica e considerando que o disco possui simetria axial e também em relação a ao seu plano médio, foi simulado apenas um quarto da geometria, onde foram aplicadas as condições de contorno. Para isto foi utilizada a malha de elementos finitos apresentada na Figura 10.25.

Neste caso foi adotado um MGF fictício, cujas fases possuem a mesma tensão 
Figura 10.25: Malha de elementos finitos adotada adotada para a solução do problema da roda de inércia

de referência. As propriedades destes materiais estão representadas na Tabela .

\begin{tabular}{l|c|c}
\hline & Material (+) & Material (-) \\
Propriedades & & \\
\hline Densidade & 1 & 1,0 \\
Módulo de Young & 0,3 & 0,1 \\
Coeficiente de poisson & 0,3 \\
Tensão de Referência & 0.265 & 0.265 \\
\hline
\end{tabular}

Tabela 10.4: Propriedades mecânicas das fases constituintes do MGF adotado para o problema da roda de inércia

Assim, aplicando o método de otimização proposto neste trabalho, foi obtida a distribuição de material apresentada na Figura 10.26.

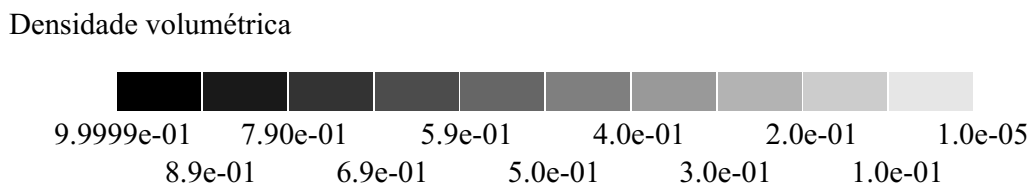

Figura 10.26: Distribuição de material obtida

Para se ter uma noção mais precisa da distribuição de material no interior do disco, o gráfico da Figura 10.27 apresenta a fração volumétrica do material mais $(+)$ em função do raio, e o módulo de Young do MGF resultante.

Analisando este resultado, observa-se que o método de otimização concentrou o material menos rígido e mais pesado na região externa do disco, aumentado assim a inércia de rotação. Na região interna do disco o material menos rígido é distribuído de tal forma que a máxima tensão no disco fica apenas ligeiramente acima da tensão de escoamento, como se observa no gráfico da Figura 10.28. Neste exemplo a tensão de von Mises ultrapassa a tensão de referência em apenas $1 \%$.

A título de comparação, um disco homogêneo constituído apenas com material mais rígido, possui a máxima tensão mecânica aproximadamente igual a 0, 36 


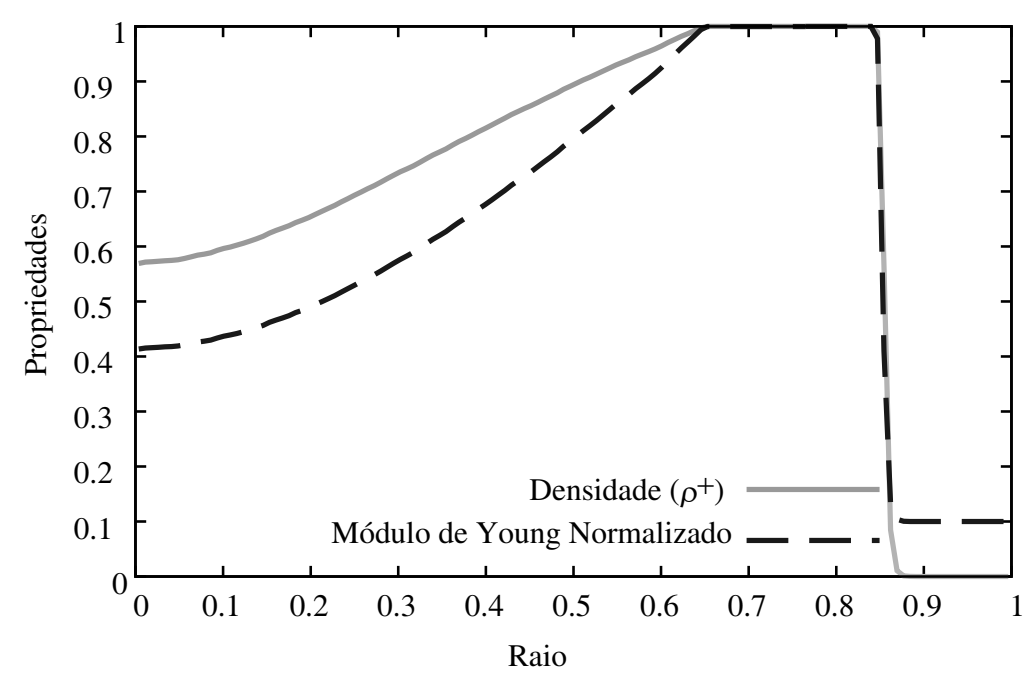

Figura 10.27: Distribuição de densidades e módulo de Young em função do raio da roda de inércia

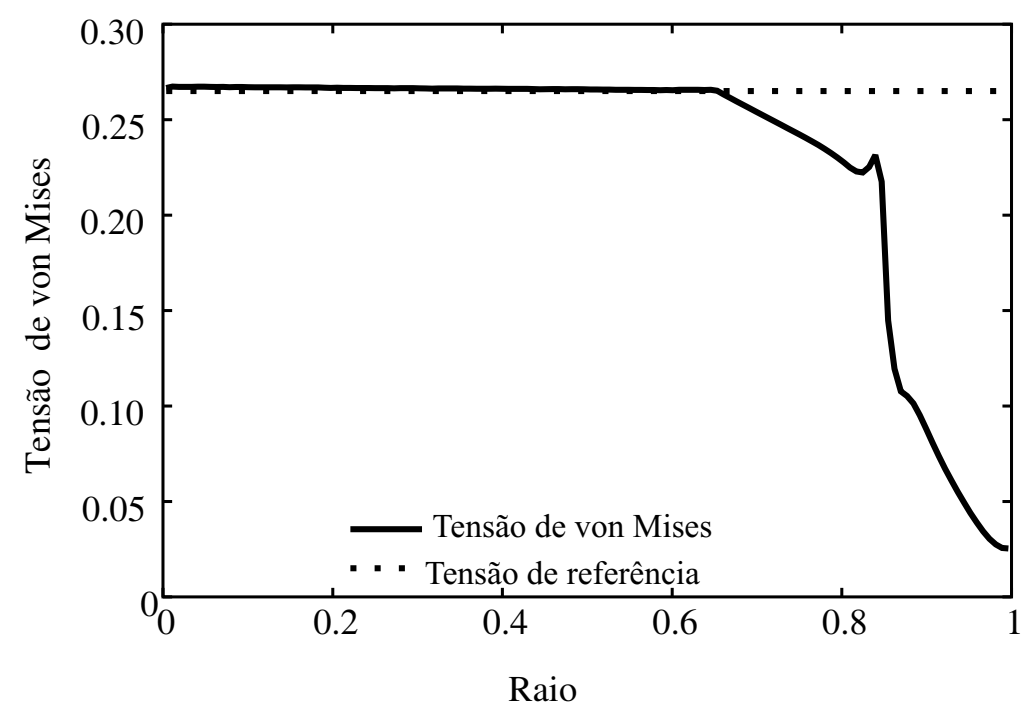

Figura 10.28: Tensão de von Mises em função do raio da roda de inércia

ou seja, 44\% acima da máxima tensão mecânica do disco de MGF. A inércia de rotação do disco otimizado é da ordem de $52 \%$ maior que a do disco homogêneo.

Esta comparação nos permite concluir que a formulação de maximização da inércia de rotação considerando restrição de tensão, pode vir a ser aplicada ao projeto de rodas de inércia de alto desempenho, que são capazes de atingir velocidades elevadas sem que ocorra a falha do material. 


\section{Conclusões Finais e Sugestões para desenvolvimentos futuros}

Este trabalho teve como objetivo estudar e implementar o Método de Otimização Topológica considerando restrição de tensão, para então aplicá-lo a duas classes de problemas: o projeto de estruturas tradicionais e o projeto de estruturas constituídas por MsGF.

Ao tratar primeira classe de problemas, a da Otimização Topológica considerando restrição de tensão, este trabalho inicia-se por uma revisão do MOT aplicado ao projeto de estruturas contínuas e discute os problemas inerentes a esta formulação, isto é, a dependência da malha, o surgimento de cinzas na solução final, bem como o problema de instabilidade de tabuleiro.

Nas implementações desenvolvidas neste trabalho, estes problemas foram tratados através da utilização de um filtro espacial, da formulação ACDM e pela inserção de um termo de regularização na função objetivo.

Aprofundando-se na aplicação do MOT considerando restrição de tensão, foi feita uma revisão bibliográfica do tema e foi apresentado o fenômeno das topologias singulares. Assim, com base na literatura descrita, foram apresentadas duas formulações de OT: a OT com restrição global de tensão e a OT com restrição local de tensão. Ambas as formulações foram implementadas e seus resultados discutidos.

Fazendo uma análise geral sobre os resultados obtidos com a formulação de OT com restrição global de tensão, pode-se concluir que a formulação que utiliza a norma-p da função de falha $\varepsilon$-relaxada, na forma que foi implementada neste trabalho, é capaz de fornecer resultados bem definidos que atendem à restrição de tensão imposta. Porém, a qualidade dos resultados é fortemente dependente da definição correta dos parâmetros do método da continuação e da penalização das densidades intermediárias. 
Em específico para o caso da estrutura em formato de L, que é um problema teste para o MOT com restrição de tensão, esta formulação foi capaz de fornecer um solução bem definida e que evita a concentração de tensão da inerente à geometria. Assim, pode-se concluir que este método é capaz de fornecer resultados similares aos apresentados na literatura, obtidos com a formulação de restrição local de tensão (PEREIRA; FANCELLO; BARCELLOS, 2004)

Analisando de maneira geral os resultados obtidos com a formulação de OT com restrição local de tensão, pode-se concluir que este é capaz de fornecer soluções que atendem ao critério de restrição local de tensão; embora estas não sejam tão bem definidas como as obtidas para o caso da restrição global de tensão.

Acreditamos que isto se deve ao fato de não ter sido possível definir os parâmetros do MLA associados às constantes de penalização, regularização e $\varepsilon$-relaxação que fornecem soluções bem definidas. Outro ponto que pode ter prejudicado a convergência e conseqüentemente a obtenção de resultados melhor definidos é o fato de se ter utilizado um algoritmo linear para a solução do problema interno do MLA.

Assim, em relação à OT aplicada ao projeto de estruturas sujeitas a restrição de tensão, verifica-se que em ambas as abordagens, os resultados obtidos são fortemente dependentes da correta definição dos parâmetros envolvidos. Isto torna a obtenção de estruturas bem definidas uma tarefa árdua que depende apenas da intuição do engenheiro projetista que deverá atuar pelo processo de tentativa e erro.

Acreditamos, portanto, que ainda é necessário desenvolver uma formulação e, principalmente, uma implementação numérica que seja mais robusta do que as atualmente existentes na literatura.

Para a segunda classe de problemas, a de otimização da distribuição de material em estruturas constituídas de Materiais com Gradação Funcional, este trabalho faz uma apresentação dos modelos de material aplicados ao MOT e faz uma discussão entre estes modelos e aqueles utilizados especificamente para a simulação de MsGF. Também é feita uma discussão sobre os critérios de falha de materiais compostos e como estes são inseridos no problema de OT com restrição de tensão.

Com base nestas discussões foram propostos dois modelos de material, e associadas aos modelos de material, foram apresentadas as possíveis formas de considerar as tensões na microestrutura dos materiais compostos. Ainda sobre 
o critério de falha de materiais compostos, foram propostos dois modelos para estimar a tensão de referência dos MsGF. Estes modelos de material foram implementados e seus resultados discutidos.

Foi apresentada também uma revisão bibliográfica da aplicação de métodos de otimização no projeto de estruturas com gradação funcional, na qual se discutem as formas de parametrização do campo de densidades volumétricas e os modelos de material empregados.

Foi feita um análise do fenômeno das topologias singulares para o problema de otimização da distribuição de material em estruturas com gradação funcional. A partir dessa análise, foi proposta uma modificação do cálculo da tensão de von Mises na microestrutura, de modo a evitar o fenômeno das topologias singulares.

Com base na literatura apresentada foi proposta e implementada uma formulação de minimização do volume de uma das fases do MGF, considerando uma restrição global de tensão dada pela norma-p, e uma outra que considera a maximização da inércia de rotação associada à mesma restrição. Nesta implementação foram considerados os modelos de material propostos.

Analisando os resultados obtido com essa formulação, pode-se concluir que a restrição de tensão através da norma-p foi capaz de fornecer distribuições de material que atendem ao critério de falha pré-definido. Pôde-se concluir também que o modelo de material e a estimativa da tensão de referência adotados exercem uma forte influência sobre a distribuição de material otimizada.

\subsection{Sugestões de desenvolvimentos futuros}

Como trabalhos futuros para o desenvolvimento da aplicação do MOT ao projeto de estruturas tradicionais sujeitas à restrição de tensão, com base na literatura e na experiência adquirida neste trabalho, sugere-se:

\section{Estudar a possibilidade de utilização de elementos finitos híbridos .}

Na literatura não foi encontrada nenhuma referência significativa em relação à utilização de elementos híbridos associados à OT. Acreditamos que a utilização destes elementos pode vir a melhorar o comportamento do problema, uma vez que com o campo de tensão contínuo seria possível aplicar uma restrição de tensão em cada nó da malha. Assim, associado ao modelo ACDM, a restrição de tensão e o campo de densidades ficariam mais acoplados, evitando assim as oscilações do campo de densidades das soluções. 
É importante notar que apesar da expectativa de melhorar o comportamento do problema a utilização desta classe de elementos acrescenta outras dificuldades ao problema, como por exemplo, o maior número de graus de liberdade do MEF e o aparecimento de zeros na diagonal principal de seu sistema linear.

\section{Considerar a plasticidade no modelo de elementos finitos .}

A inserção do fenômeno de plasticidade no problema de OT considerando restrição local de tensão pode vir a alterar o espaço de solução, de modo a minimizar ou mesmo excluir o fenômeno das topologias singulares. Intuitivamente, a idéia é que no momento em que uma região se plastifica, o campo de tensão ao seu redor é relaxado, o que alteraria o espaço de solução podendo, talvez, evitar o fenômeno das topologias singulares. Aqui vale ressaltar que a inserção do fenômeno de plasticidade no software desenvolvido neste trabalho não é trivial e envolve o desenvolvimento de novas teorias como por exemplo, a consideração de plasticidade em elementos de densidade intermediária.

\section{Inserir métodos de refino h-adaptativo .}

A idéia de inserir métodos de refino h-adaptativo é a de melhorar a precisão do campo de tensão, porém sem acarretar grandes prejuízos em relação ao tempo computacional. Na literatura existem trabalhos que utilizam métodos de refino da malha de elementos finitos associado ao MOT. Porém, a utilização de métodos de refino h-adaptativo associado ao problema de restrição de tensão local, tratado pelo MLA, ainda é um tópico a ser desenvolvido.

Quanto ao problema de projeto de estruturas constituídas de Materiais com Gradação Funcional, existem duas vertentes possíveis para a continuidade deste trabalho. A primeira e mais simples é continuar o estudo adotando um modelo de material baseado nos limites de Hashin-Shtrikman, e a segunda é partir para a associação do MOT a uma análise multi-escala do MGF utilizando modelos de alta ordem propostos na literatura.

Na primeira proposta, sugere-se como desenvolvimento futuro para o tópico:

\section{Estudar e propor modelos de material mais realistas .}

Do nosso ponto de vista, a principal deficiência dos modelos de estimativa da tensão de referência e dos modelos de material apresentados neste trabalho é a falta de parâmetros para se decidir qual é o modelo mais adequado 
para tratar um caso real. Assim, sugere-se a comparação das curvas de propriedades obtidas com os modelos baseados em H-S com os resultados dos modelos multi-escala, de modo a propor aproximações mais realistas e específicas para cada par de materiais constituintes de um MGF

\section{Inserir no problema informações sobre a derivada do campo de tensão} Nas estruturas constituídas por MsGF é interessante que se tenha uma distribuição de material que gere um campo de tensão sem saltos e descontinuidades. Assim, seria interessante inserir no problema formas de minimizar ou restringir o gradiente do campo de tensões. Isto pode ser feito através da minimização da norma de Sobolev, ou mesmo utilizando apenas o segundo termo dessa norma como restrição do problema. Para considerar o gradiente do campo de tensão, é interessante melhorar a qualidade do cálculo dos valores de tensão, assim é sugerido, também considerar a utilização de técnicas de Super-convergent Patch Recovery (SPR) ou Recovery by Equilibrium Patches (REP) (PAULINO et al., 1999) para a definição do campo de tensões.

\section{Propor um modelo de $\varepsilon$-relaxação associado aos MsGF .}

O problema de $\varepsilon$-relaxação esta descrito com certa profundidade para o caso do problema de OT com restrição tensão, porém, para o caso da otimização da distribuição de material, não existe um estudo aprofundado deste tema. Assim, seria interessante, a partir da formulação 7.13, com duas restrições locais, fazer testes numéricos para reproduzir o fenômeno das singularidades das tensões, e então propor um modelo de $\varepsilon$-relaxação específico para MsGF. A vantagem em se desenvolver um modelo de $\varepsilon$-relaxação está na possibilidade de se retirar da formulação proposta o cálculo estimativo da tensão de von Mises na micro-estrutura dada por 7.19. E assim, melhorar a qualidade do critério de falha, utilizando a tensão de von Mises em cada fase do material separadamente o que garante que a restrição de tensão seja atendida em cada fase da micro-estrutura.

A outra vertente, que considera modelos multi-escala associados a técnicas de OT, é, por um lado, interessante, pois se trabalharia com modelos de material mais específicos para a simulação de MsGF, porém, por outro, lado essa abordagem apresenta alguns obstáculos a serem transpostos. A princípio, são vislumbrados pelo menos dois grandes problemas: a definição da análise de sensibilidade do problema de otimização, uma vez que seu modelo de material não tem solução analítica fechada implicando num alto custo computacional de se fazer 
centenas de análises multi-escala durante o processo de otimização. Desta forma, considera-se que esta abordagem é desafiadora e merecedora de atenção. 


\section{Referências}

ABOUDI, J. Mechanics of composites, a unified micromechanical approach. In: Studies in Applied Mechanics 29. [S.l.]: Elservier, 1991. v. 29.

ABOUDI, J.; PINDERA, M. J.; ARNOLD, S. M. Elastic response of metal-matrix composites with tailored microstructures to thermal-gradients. International Journal for Numerical Methods In Engineering, v. 31, n. 10, p. 1393-1428, 1994.

ABOUDI, J.; PINDERA, M. J.; ARNOLD, S. M. Microstructural optimization of functionally graded composites subjected to a thermal gradient via the coupled higher-order theory. Composites Part B, v. 28B, p. 93-108, 1997.

ABOUDI, J.; PINDERA, M. J.; ARNOLD, S. M. Higher-order theory for functionally graded materials. Composites Part B - Engineering, v. 30, n. 8, p. 777-832, 1999.

ALLAIRE, G. Shape Optimization by the Homogenization Method, Applied Mathematical Sciences 146. New York: Springer-Verlag, 2002.

ALLAIRE, G.; AUBRY, S. On optimal microstructures for a plane shape optimization problem. Structural Optimization, v. 17, n. 2-3, p. 86-94, 1999.

ALlAIRE, G.; BONNETIER, E.; FRANCFORT, G.; JOUVE, F. Shape optimization by the homogenization method. Numerische Mathematik, v. 76, n. 1, p. 27-68, 1997.

ALLAIRE, G.; JOUVE, F.; MAILLOT, H. Topology optimization for minimum stress design with the homogenization method. Structural and Multidisciplinary Optimization, v. 28, n. 2-3, p. 87-98, 2004.

ALLAIRE, G.; JOUVE, F.; TOADER, A. M. Structural optimization using sensitivity analysis and a level-set method. Journal of Computational Physics, v. 194, n. 1, p. 363-393, 2004.

ALLAIRE, G.; KOHN, R. V. Optimal-design for minimum weight and compliance in plane-stress using extremal microstructures. European Journal of Mechanics /A-Solids, v. 12, n. 6, p. 839-878, 1993.

AMBROSIO, L.; BUTTAZZO, G. An optimal-design problem with perimeter penalization. Calculus of Variations and Partial Differentiation Equations, v. 1, n. 1, p. 55-69, 1993.

ANDREANI, R.; BIRGIN, E.; MARTINEZ, J.; SCHUVERDT, M. On Augmented Lagrangian methods with general lower-level constraint. [S.l.], 2005.

ASHBY, M. F. Materials Selection in Mechanical Design. [S.l.]: Butterworth Heinemann, 1999. 
BATHE, K. Finite Element Procedures. New Jersey: Prentice Hall, 1996.

BECKERS, M. Optimization de structures en variable discrete. Tese (Doutorado) - Universite de Liege, Belgium, 1997.

BECKERS, M.; FLEURY, C. A primal-dual approach in truss topology optimization. Computers \& Structures, v. 64, n. 1-4, p. 77-88, 1997.

BENDSØE, M. Optimal shape design as a material distribution problem. Structural Optimization, v. 1, p. 193-202, 1989.

BENDSØE, M. P.; KIKUCHI, N. Generating optimal topologies in structural design using a homogenization method. Computer Methods in Applied Mechanics and Engineering, v. 71, n. 2, p. 197-224, 1988.

BENDSØE, M. P.; SIGMUND, O. Material interpolation schemes in topology optimization. Archive of Applied Mechanics, v. 69, n. 9-10, p. 635-654, 1999.

BENDSØE, M. P.; SIGMUND, O. Topology Optimization: Theory Methods and Applications. Berlin: Springer-Verlag, 2003. ISBN 3-540-42992-1.

BENDSØE, M. P.; SOARES, C. A. M. (Ed.). Topology Design of Structures. Dordrecht: NATO ASI, Kluwer Academic Publishers, 1993.

BENSOUSSON, A.; LIONS, J.; PAPANICOLAOU, G. Assymptotic Analysis for periodic Structures. [S.l.]: North-Holland, 1978.

BERTSEKAS, D. P. Constrained Optimization and Lagrange Multiplier Methods. [S.l.]: Academic Press, 1982.

BOURDIN, B. Filters in topology optimization. International Journal for Numerical Methods In Engineering, v. 50, n. 9, p. 2143-2158, 2001.

BOUSSAA, D. Optimizing a compositionally graded interlayer to reduce thermal stresses in a coated tube. Comptes Rendus de L'Academie des Sciences Serie I Fascicule B-Mecanique Physique Astronomie, v. 328, n. 3, p. 209-215, 2000.

BRUYNEEL, M.; DUYSINX, P. Note on topology optimization of continuum structures including self-weight. Structural and Multidisciplinary Optimization, v. 29, n. 4, p. 245-256, 2005.

BRUYNEEL, M.; DUYSINX, P.; FLEURY, C. A family of mma approximations for structural optimization. Structural and Multidisciplinary Optimization, v. 24, n. 4, p. 263-276, 2002.

BUDIANSKY, B.; FLECK, N. A. Compressive failure of fiber composites. Journal of Mechanics and Physics of Solids, v. 41, n. 1, p. 183-211, 1993.

BULMAN, S.; SIENZ, J.; HINTON, E. Comparisons between algorithms for structural topology optimization using a series of benchmark studies. Computers E Structures, v. 79, n. 12, p. 1203-1218, 2001.

BURGER, M.; HACKL, B.; RING, W. Incorporating topological derivatives into level set methods. Journal of Computational Physics, v. 194, n. 1, p. 344-362, 2004 . 
BURGER, M.; OSHER, S. J. A survey on level set methods for inverse problems and optimal design. European Journal of Applied Mathematics, v. 16, p. 263-301, abr. 2005.

BURYACHENKO, V. A.; PAGANO, N. J. Non-local models of stress field concentrations and effective thermoelastic properties of random structure composites. Mathematics and Mechanics of Solids, v. 8, n. 4, p. 403-433, 2003.

CARDOSO, E. L. Controle de Complexidade na Otimização Topológica de Estruturas Contínuas. Dissertação (Mestrado) — Universidade Federal do Rio Grande do Sul, 2000.

CARDOSO, E. L.; FONSECA, J. S. O. Intermediate density reduction and complexity control in the topology optimization. In: Computational methods in engineering'99 - XX CILAMCE São Paulo. [S.l.: s.n.], 1999.

CHEN, B.; TONG, L. Thermomechanically coupled sensitivity analysis and design optimization of functionally graded materials. Computer Methods in Applied Mechanics and Engineering, v. 194, n. 18-20, p. 1891-1911, 2005.

CHENG, G.; JIANG, Z. Study on topology optimization with stress constraints. Engineering Optimization, v. 20, p. 129-148, 1992.

CHENG, G. D.; GUO, X. Epsilon-relaxed approach in structural topology optimization. Structural Optimization, v. 13, n. 4, p. 258-266, 1997.

CHENG, K. T.; OLHOFF, N. An investigation concerning optimal-design of solid elastic plates. International Journal of Solids And Structures, v. 17, n. 3, p. 305-323, 1981.

CHENG, K. T.; OLHOFF, N. Regularized formulation for optimal-design of axisymmetric plates. International Journal of Solids and Structures, v. 18, n. 2, p. $153-169,1982$.

CHERKAEV, A. Variational Methods for Structural Optimization, Applied Mathematical Sciences 140. New York: Springer-Verlag, 2000.

CHO, J. R.; CHOI, J. H. A yield-criteria tailoring of the volume fraction in metal-ceramic functionally graded material. European Journal of Mechanics /A-Solids, v. 23, n. 2, p. 271-281, 2004.

CHO, J. R.; HA, D. Y. I. Optimal tailoring of 2 d volume-fraction distributions for heat-resisting functionally graded materials using $\mathrm{fdm}$. Computer Methods in Applied Mechanics and Engineering, v. 191, n. 29-30, p. 3195-3211, 2002.

CHO, J. R.; ODEN, J. T. Functionally graded material: a parametric study on thermal-stress characteristics using the crank-nicolson-galerkin scheme. Computer Methods in Applied Mechanics and Engineering, v. 188, n. 1-3, p. 17-38, jul. 2000.

CHO, J. R.; PARK, H. J. Effective volume-fraction optimization for thermal stress reduction in fgms using irregular h-refinement. International Journal for Numerical Methods in Engineering, v. 58, n. 5, p. 749-770, 2003. 
CHO, J. R.; SHIN, S. W. Material composition optimization for heat-resisting fgms by artificial neural network. Composites Part A-Applied Science and Manufacturing, v. 35, n. 5, p. 585-594, 2004.

CHU, D. N.; XIE, Y. M.; HIRA, A.; STEVEN, G. P. Evolutionary structural optimization for problems with stiffness constraints. Finite Elements in Analysis and Design, v. 21, n. 4, p. 239-251, 1996.

CHU, D. N.; XIE, Y. M.; HIRA, A.; STEVEN, G. P. On various aspects of evolutionary structural optimization for problems with stiffness constraints. Finite Elements in Analysis and Design, v. 24, n. 4, p. 197-212, 1997.

DANTZIG, G. Linear Programming and Extensions. [S.l.]: Princeton University Press, 1963.

DUYSINX, P. Layout optimization: a mathematical programing approach. [S.1.], 1996.

DUYSINX, P. Solutions of Topology Optimization Problems with Sequential Convex Programing. June 2005. Apostila do Curso DCAMM Advanced school: Topology Optimization - Theory, Methods and Applications. Technical University of Denmark, Lyngby, Denmark.

DUYSINX, P.; BENDSØE, M. P. Topology optimization of continuum structures with local stress constraints. International Journal for Numerical Methods In Engineering, v. 43, n. 8, p. 1453-1478, 1998.

DUYSINX, P.; SIGMUND, O. New developments in handling stress contraints in optimal material distribution. In: AIAA, USAF, NASA, ISSMO. rth AIAA/USAF/NASA/ISSMO Symposium on Multidisciplinary Design Optimization. Saint Louis, MI, USA: Reston: American Institute of Aeronautics and Astronautics, 1998. v. 4906, p. 1-9.

DVORAK, G. J. Composite materials: Inelastic behavior, damage, fatigue and fracture. International Journal of Solids and Structures, v. 37, n. 1-2, p. 155-170, jan. 2000.

EMBURY, J. D.; FREUND, L. B.; NEEDLEMAN, A.; SHIH, C. F.; SPAEPEN, F.; SURESH, S. Sumary. Journal of the Mechanics and Physics of Solids, v. 44, p. 823-825, 1996.

ESCHENAUER, H. A.; OLHOF, N. Topology optimization of continuum structures. Applied Mechanic Review, v. 54, n. 4, p. 331-390, 2001.

ESCHENAUER H. A. KOBELEV, V.; SCHUMACHER, A. Bubble method for topology and shape optimization. Structural Optimization, v. 8, p. 42-51, 1994.

EVGRAFOV, A. Approximations of topology optimization problems using sizing optimization problems. Tese (Doutorado) - Chalmers University of Technology, Göteborg, Suécia, 2004.

EVGRAFOV, A. On globally stable singular truss topologies. Structural and Multidisciplinary Optimization, v. 29, n. 3, p. 170-177, 2005. 
EVGRAFOV, A.; PATRIKSSON, M. Stable relaxations of stochastic stressconstrained weight minimization problems. Structural and Multidisciplinary Optimization, v. 25, n. 3, p. 189-198, 2003.

EVGRAFOV, A.; PATRIKSSON, M. On the convergence of stationary sequences in topology optimization. International Journal for Numerical Methods in Engineering, v. 64, n. 1, p. 17-44, 2005.

FACCHINEI, F.; PANG, J.-S. Finite-dimensional Variational Inequalities and Complementarity Problems, Volume I. New York: Springer, 2003. (Springer Series in Operational Research).

FLECK, N.; SIVASHANKER, S.; SUTCLIFFE, M. Compressive failure of composites due to the microbuckle growth. European Journal of Mechanics, v. 16, p. $65-82,1997$.

FRIEDLANDER, A.; MARTíNEZ, J.; RAYDAN, M. A new method for largescale box constrained convex quadratic minimization problems. Optimization Methods and Software, v. 5, p. 57-74, 1995.

FRIEDLANDER, A.; MARTíNEZ, J.; SANTOS, S. A new trust-region algorithm for bound constrained minimization. Applied Mathematics and Optimization, v. 30, n. 3, p. 235-266, 1994.

FUCHS, M.; PALEY, M.; MIROSHNY, E. The aboudi micromechanical model for topology design of structures. Computers \& Structures, v. 73, n. 1-5, p. 355-362, 1999.

GASIK, M. M. Micromechanical modelling of functionally graded materials. Computational Materials Science, v. 13, n. 1-3, p. 42-55, 1998.

GUO, X.; CHENG, G. An extrapolation approach for the solution of singular optima. Structural and Multidisciplinary Optimization, v. 19, p. 255-262, 2000.

GUO, X.; CHENG, G.; YAMAZAKI, K. A new approach for the solution of singular optima in truss topology optimization with stress and local buckling constraints. Structural and Multidisciplinary Optimization, v. 22, n. 5, p. 364-372, 2001.

GUO, X.; CHENG, G. D.; YAMAZAKI, K. A note on stress-constrained truss topology optimization. Structural and Multidisciplinary Optimization, v. 27, n. 1-2, p. 136-137, 2004.

HABER, R. B.; JOG, C. S.; BENDSØE, M. P. A new approach to variabletopology shape design using a constraint on perimeter. Structural Optimization, v. 11, n. 1, p. 1-12, 1996.

HANSON, R. J.; HIEBERT, K. L. Subroutine DSPLP - Solve linear programming problems involving at most a few thousand constraints and variables. Takes advantage of sparsity in the constraint matrix. Part of SLATEC Common Mathematical Library, Version 4.1. July 1993. Acessado em Janeiro de 2005. Disponível em: <http://www.netlib.org/slatec/src/dsplp.f >.

HASHIN, Z. Analysis of composite-materials, a survey. Journal of Applied Mechanics-Transactions of the ASME, v. 50, n. 3, p. 481-505, 1983. 
HASHIN, Z.; SHTRIKMAN, S. A variational approach to the theory of the elastic behaviour of multiphase materials. Journal of the Mechanics and Physics of Solids, v. 11, n. 2, p. 127-140, 1963.

HASSANI, B.; HINTON, E. A review of homogenization and topology optimization iii. topology optimization using optimality criteria. Computers $\mathscr{E}$ Structures, v. 69, n. 6, p. 739-756, 1998.

HATTA, H.; TAYA, M. Effective thermal-conductivity of a misoriented short fiber composite. Journal Of Applied Physics, v. 58, n. 7, p. 2478-2486, 1985.

HEDIA, H. S. Comparison of one-dimensional and two-dimensional functionally graded materials for the backing shell of the cemented acetabular cup. Journal of Biomedical Materials Research Part B: Applied Biomaterials, v. 74B, n. 2, p. 732-739, 2005.

HUANG, J.; VENKATARAMAN, S.; RAPOFF, A. J.; HAFTKA, R. T. Optimization of axisymmetric elastic modulus distributions around a hole for increased strength. Structural and Multidisciplinary Optimization, v. 25, n. 4, p. 225-236, 2003.

HUANG, J. H.; FADEL, G. M.; BLOUIN, V. Y.; GRUJICIC, M. Bi-objective optimization design of functionally gradient materials. Materials $\& 5$ Design, v. 23, n. 7, p. 657-666, 2002.

JOG, C. S.; HABER, R. B. Stability of finite element models for distributedparameter optimization and topology design. Computer Methods in Applied Mechanics and Engineering, v. 130, n. 3-4, p. 203-226, 1996.

KERNER, E. H. The elastic and thermo-elastic properties of composite media. Proceedings of The Physical Society of London Section B, v. 69, n. 8, p. 808-813, 1956.

KIEBACK, B.; NEUBRAND, A.; RIEDEL, H. Processing techniques for functionally graded materials. Materials Science and Engineering A, v. 362, n. 1-2, p. 81-105, 2003.

KIM, J. H.; PAULINO, G. H. Isoparametric graded finite elements for nonhomogeneous isotropic and orthotropic materials. Journal of Applied Mechanics-Transactions of the ASME, v. 69, n. 4, p. 502-514, 2002.

KIM, T. S.; KIM, J. E.; KIM, Y. Y. Parallelized structural topology optimization for eigenvalue problems. International Journal of Solids And Structures, v. 41, n. 9-10, p. 2623-2641, 2004.

KIRSCH, U. Optimal topologies of structures. International Journal for Numerical Methods In Engineering, v. 42, p. 223-239, 1989.

KIRSCH, U. On singular topologies in optimum structural design. Structural Optimization, v. 2, n. 3, p. 133-142, 1990.

KOHN, R. V.; STRANG, G. Optimal-design and relaxation of variationalproblems .1. Communications on Pure and Applied Mathematics, v. 39, n. 1, p. 113-137, 1986. 
KOHN, R. V.; STRANG, G. Optimal-design and relaxation of variationalproblems .2. Communications on Pure and Applied Mathematics, v. 39, n. 2, p. 139-182, 1986.

KOHN, R. V.; STRANG, G. Optimal-design and relaxation of variationalproblems .3. Communications on Pure and Applied Mathematics, v. 39, n. 3, p. 353-377, 1986.

KOIZUMI, M. Fgm activities in japan. Composites Part B: Engineering, v. 28, n. 1-2, p. 1-4, 1997.

KRESS, G. R. Shape optimization of a flywheel. Structural and Multidisciplinary Optimization, v. 19, n. 1, p. 74-81, 2000.

LEE, W. Y.; STINTON, D. P.; BERNDT, C. C.; ERDOGAN, F.; LEE, Y. D.; MUTASIM, Z. Concept of functionally graded materials for advanced thermal barrier coating applications. Journal of the American Ceramic Society, v. 79, n. 12, p. 3003-3012, 1996.

LI, Q.; ; STEVEN, G. P.; XIE, Y. M. Evolutionary thickness design with stiffness maximization and stress minimization criteria. International Journal for Numerical Methods In Engineering, v. 52, p. 979-995, 2001.

LI, Q.; STEVEN, G. P.; QUERIN, O. M.; XIE, Y. M. Evolutionary shape optimization for stress minimization. Mechanics Research Communications, v. 26, n. 6, p. 657-664, 1999.

LIPTON, R. Design of functionally graded composite structures in the presence of stress constraints. International Journal of Solids and Structures, v. 39, n. 9, p. 2575-2586, 2002.

LIPTON, R. Stress constrained g closure and relaxation of structural design problems. Quarterly Of Applied Mathematics, v. 62, n. 2, p. 295-321, 2004.

LIU, J.-S.; PARKS, G.; CLARKSON, P. Topology/shape optimisation of axisymmetric continuum structures - a metamorphic development approach. Structural and Multidisciplinary Optimization, v. 29, p. 73-83, 2005.

LIU, J. S.; PARKS, G. T.; CLARKSON, P. J. Metamorphic development: a new topology optimization method for continuum structures. Structural and Multidisciplinary Optimization, v. 20, n. 4, p. 288-300, 2000.

LIU, J. S.; PARKS, G. T.; CLARKSON, P. J. Optimization of turbine disk profiles by metamorphic development. Journal of Mechanical Design, v. 124, n. 2, p. 192-200, 2002.

LIU, Z.; KORVINK, J.; HUANG, R. Structure topology optimization: fully coupled level set method via femlab. Structural and Multidisciplinary Optimization, v. 29, p. 407-417, 2005.

LUCIANO, R.; WILLIS, J. R. Bounds on non-local effective relations for random composites loaded by configuration-dependent body force. Journal of the Mechanics and Physics of Solids, v. 48, p. 1827-1849, 2000.

LUCIANO, R.; WILLIS, J. R. Non-local constitutive equations for functionally graded materials. Mechanics of Materials, v. 36, n. 12, p. 1195-1206, dez. 2004. 
MARKWORTH, A. J.; SAUNDERS, J. A model of structure optimization for functionally graded material. Materials Letters, v. 22, n. 1-2, p. 103-107, 1995.

MATSUI, K.; TERADA, K. Continuous approximation of material distribution for topology optimization. International Journal for Numerical Methods In Engineering, v. 59, n. 14, p. 1925-1944, 2004.

MEI, Y. L.; WANG, X. M. A level set method for structural topology optimization and its applications. Advances in Engineering Software, v. 35, n. 7, p. 415-441, 2004.

MICHELL, A. The limits of economy of material in frame-structures. Phil. Mag., v. 8, n. 47, p. 589-597, November 1904.

MORTENSEN, A.; SURESH, S. Functionally graded metals and metal-ceramic composites .1. processing. International Materials Reviews, v. 40, n. 6, p. 239-265, 1995.

NADEAU, J. C.; FERRARI, M. Microstructural optimization of a functionally graded transversely isotropic layer. Mechanics of Materials, v. 31, n. 10, p. 637-651, 1999.

NAVARRINA, F.; MUINOS, I.; COLOMINAS, I.; CASTELEIRO, M. Topology optimization of structures: A minimum weight approach with stress constraints. Advances in Engineering Software, v. 36, n. 9, p. 599-606, set. 2005.

NOVOTnY, A. A.; FEIJOO, R. A.; TAROCO, E.; PADRA, C. Topological sensitivity analysis. Computer Methods in Applied Mechanics and Engineering, v. 192, n. 7-8, p. 803-829, 2003.

OLHOFF, N.; BENDSØE, M. P.; RASMUSSEN, J. On cad-integrated structural topology and design optimization. Computer Methods in Applied Mechanics and Engineering, v. 89, n. 1-3, p. 259-279, 1991.

OOTAO, Y.; KAWAMURA, R.; TANIGAWA, Y.; IMAMURA, R. Optimization of material composition of nonhomogeneous hollow sphere for thermal stress relaxation making use of neural network. Computer Methods in Applied Mechanics and Engineering, v. 180, n. 1-2, p. 185-201, 1999.

OSHER, S. J.; SANTOSA, F. Level set methods for optimization problems involving geometry and constraints $i$. frequencies of a two-density inhomogeneous drum. Journal of Computational Physics, v. 171, n. 1, p. 272-288, 2001.

PARASHKEVOVA, L.; IVANOVA, J.; BONTCHEVA, N. Optimal design of functionally graded plates with thermo-elastic plastic behaviour. Comptes Rendus Mecanique, v. 332, n. 7, p. 493-498, 2004.

PARK, Y. K. Extensions of optimal layout design using the homogenization method. Tese (Doutorado) — University of Michigan, Ann Arbor, 1995.

PATRIKSSON, M.; PETERSSON, J. Existence and continuity of optimal solutions to some structural topology optimization problems including unilateral constraints and stochastic loads. Zeitschrift fur Angewandte Mathematik and Mechanik, v. 82, n. 7, p. 435-459, 2002. 
PAUlinO, G. H.; MENEZES, I. F. M.; NETO, J. B. C.; MARTHA, L. F. A methodology for adaptive finite element analysis: Towards an integrated computational environment. Computational Mechanics, v. 23, n. 5-6, p. 361-388, jun. 1999.

PEREIRA, J. Otimização Topológica de Componentes Mecânicos com Restrição sobre o Critério de Falha Material. Tese (Doutorado) — Universidade Federal de Santa Catarina, 2001.

PEREIRA, J. T.; FANCELlO, E. A.; BARCELlOS, C. S. Topology optimization of continuum structures with material failure constraints. Structural and Multidisciplinary Optimization, v. 26, n. 1-2, p. 50-66, 2004.

PETERSSON, J. On continuity of the design-to-state mappings for trusses with variable topology. International Journal of Engineering Science, v. 39, n. 10, p. 1119-1141, 2001.

PETERSSON, J.; SIGMUND, O. Slope constrained topology optimization. International Journal for Numerical Methods In Engineering, v. 41, n. 8, p. 1417-1434, 1998.

PINDERA, M.-J.; ABOUDI, J.; ARNOLD, S. M. Limitations of the uncoupled, rve-based micromechanical approach in the analysis of functionally graded composites. Mechanics of Materials, v. 20, n. 1, p. 77-94, mar. 1995.

Use of composites multi-phased and functionally graded materials. In: PINDERA, M.-J.; ABOUDI, J.; GLAESER, A. M.; ARNOLD, S. M. (Ed.). Composites Part B: Engineering. [S.l.]: Elsevier, 1997. v. 28, n. 1-2.

POMPE, W.; WORCH, H.; EPPLE, M.; FRIESS, W.; GELINSKY, M.; GREIL, P.; HEMPEL, U.; SCHARNWEBER, D.; SCHULTE, K. Functionally graded materials for biomedical applications. Materials Science and Engineering A, v. 362, n. 1-2, p. 40-60, 2003.

POULSEN, T. A. A simple scheme to prevent checkerboard patterns and onenode connected hinges in topology optimization. Structural and Multidisciplinary Optimization, v. 24, n. 5, p. 396-399, 2002.

POULSEN, T. A. A new scheme for imposing a minimum length scale in topology optimization. International Journal for Numerical Methods in Engineering, v. 57, p. 741-760, 2003.

PRESS, W. H.; TEUKOLSKY, S. A.; VETTERLING, W. T.; FLANNERY, B. P. Numerical Recipes in $C$ - The Art of Scientific Computing. [S.l.]: Cambridge University Press, 1999.

RAHMATALLA, S.; SWAN, C. C. Form finding of sparse structures with continuum topology optimization. Journal of Structural Engineering-ASCE, v. 129, n. 12, p. 1707-1716, 2003.

RAHMATALLA, S. F.; SWAN, C. C. A q4/q4 continuum structural topology optimization implementation. Structural and Multidisciplinary Optimization, v. 27, n. 1-2, p. 130-135, 2004. 
RAVICHANDRAN, K. S. Thermal residual stresses in a functionally graded material system. Materials Science and Engineering A, v. 201, n. 1-2, p. 269-276, out. 1995.

REITER, T.; DVORAK, G. J. Micromechanical models for graded composite materials: Ii. thermomechanical loading. Journal of the Mechanics and Pysics of Solids, v. 46, n. 9, p. 1655-1673, 1998.

REITER, T.; DVORAK, G. J.; TVERGAARD, V. Micromechanical models for graded composite materials. Journal of the Mechanics and Physics of Solids, v. 45, n. 8, p. 1281-1302, 1997.

REUSS, A. Berechnung der fliessgrenze von mishkristallen auf grund der plastizitätsbedingung für einkristalle. Zeitschrift fur Angewandte Mathematik and Mechanik, v. 9, p. 49, 1929.

ROSEN, B. W.; HASHIN, Z. Effective thermal expansion coefficients and specific heats of composite materials. International Journal of Engineering Science, v. 8, n. 2, p. 157-\&, 1970.

ROZVANY, G. On design-dependent constraints and singular topologies. Structural and Multidisciplinary Optimization, v. 21, p. 164-175, 2001.

ROZVANY, G.; BENDSØE, M. P.; KIRSCH, U. Layout optimization of structures. Applied Mechanics Review, v. 48, p. 41-119, 1995.

ROZVANY, G. I. N.; BIRKER, T. On singular topologies in exact layout optimization. Structural Optimization, v. 8, n. 4, p. 228-235, 1994.

ROZVANY, G. I. N.; ZHOU, M.; BIRKER, T. Generalized shape optimization without homogenization. Structural Optimization, v. 4, n. 3-4, p. 250-252, 1992.

SANCHES-PALENCIA, E. Non-homogeneous media and vibration theory. In: Lecture Notes in Physics, 12\%. [S.l.]: Springer, 1980.

SANCHEZ-PALENCIA, E.; ZAOUI, A. Homogenization techniques for composite media. In: Lecture Notes in Physics. [S.l.]: Springer-Verlag, 1985.

SANT'ANNA, H. M.; GUILHERME, C. E. M.; FONSECA, J. S. O. Topology optimization of continuum two-dimensional structures using a global stress objective function. In: Proceedings of COBEM 2003. [S.l.: s.n.], 2003.

SCHAPERY, R. Thermal expansion coefficient of composite materials based on energy principles. Journal of Composite Materials, v. 2, p. 380-404, 1968.

SCHOLTES, S. Convergence properties of a regularization scheme for mathematical programs with complementarity constraints. SIAM Jornal on Optimization, v. 11, n. 4, p. 918-936, 2001.

SCHWARZ, S.; MAUTE, K.; RAMM, E. Topology and shape optimization for elastoplastic structural response. Computer Methods in Applied Mechanics and Engineering, v. 190, n. 15-17, p. 2135-2155, 2001.

SETHIAN, J. A.; WIEGMANN, A. Structural boundary design via level set and immersed interface methods. Journal of Computational Physics, Academic Press Professional, Inc., San Diego, CA, USA, v. 163, n. 2, p. 489-528, 1999. ISSN 0021-9991. 
SHEU, C.; PRAGER, W. Recent developments in optimal structural design. Applied Mechanics Reviews, v. 21, p. 985-989, 1968.

SHIM, P. Y.; MANOOCHEHRI, S. Generating optimal configurations in structural design using simulated annealing. International Journal for Numerical Methods in Engineering, v. 40, n. 6, p. 1053-1069, 1997.

SIGMUND, O. Materials with prescribed constitutive parameters - an inverse homogenization problem. International Journal of Solids and Structures, v. 31, n. 17, p. 2313-2329, 1994.

SIGMUND, O. On the design of compliant mechanisms using topology optimization. Mechanics of Structures and Machines, v. 25, n. 4, p. 493-524, 1997.

SIGMUND, O.; PETERSSON, J. Numerical instabilities in topology optimization: A survey on procedures dealing with checkerboards, meshdependencies and local minima. Structural Optimization, v. 16, n. 1, p. 68-75, 1998.

SILVA, E.; FONSECA, J.; KIKUCHI, N. Optimal design of periodic piezocomposites. Computer Methods in Applied Mechanics and Engineering, v. 159, n. 1-2, p. 49-77, 1998.

SILVA, E. C. N. Topology optimization applied to the design of linear piezoelectric motors. Journal of Intelligent Material Systems and Structures, v. 14, n. 4-5, p. 309-322, 2003.

SILVA, E. C. N.; NISHIWAKI, S.; KIKUCHI, N. Topology optimization design of flextensional actuators. IEEE Transactions on Ultrasonics Ferroelectrics and Frequency Control, v. 47, n. 3, p. 657-671, 2000.

SILVA, E. C. N.; PAULINO, G. H. Topology optimization design of functionally graded structures. In: 6th World Congress on Structural an Multidisciplinary Optimization. [S.l.: s.n.], 2005.

SOKOLOWSKI, J.; ZOCHOWSKI, A. On the topological derivative in shape optimization. SIAM Journal on Control and Optimization, v. 37, n. 4, p. 1251-1272, 1999.

STEVEN, G. P.; LI, Q.; XIE, Y. M. Multicriteria optimization that minimizes maximum stress and maximizes stiffness. Computers $\&$ Structures, v. 80, n. 27-30, p. 2433-2448, 2002.

STOLPE, M. On Models and Methods for Global Optimization of Structural Topology. Tese (Doutorado) — Rotal Institute of Technology, Stockholm, Suécia, 2003.

STOLPE, M. Global optimization of minimum weight truss topology problems with stress, displacement, and local buckling constraints using branch-andbound. International Journal for Numerical Methods In Engineering, v. 61, n. 8, p. 1270-1309, 2004.

STOLPE, M.; SVANBERG, K. On the trajectories of penalization methods for topology optimization. Structural and Multidisciplinary Optimization, v. 21, n. 2, p. 128-139, 2001. 
STOLPE, M.; SVANBERG, K. On the trajectories of the epsilon-relaxation approach for stress-constrained truss topology optimization. Structural and Multidisciplinary Optimization, v. 21, n. 2, p. 140-151, 2001.

SUQUET, P. M. Elements of homogenization for inelastic sold mechanics. In: . [S.l.]: Springer-Verlag, 1985. cap. 4, p. 194-275.

SURESH, A.; MORTENSEN. Functionally graded metals and metal-ceramics composites: Part 2 thermomechanical behaviour. International Materials Reviews, v. 42, p. 85-116, 1997.

Mechanics and physics of layered and graded materials. In: SURESH, S.; NEEDLEMAN, A. (Ed.). Journal of the Mechanics and Physics of Solids. [S.l.]: Elsevier, 1996. v. 44, n. 5, p. 643-643.

SUZUKI, K.; KIKUCHI, N. A homogenization method for shape and topology optimization. Computer Methods in Applied Mechanics and Engineering, v. 93, n. 3, p. 291-318, 1991.

SVANBERG, K. The method of moving asymptotes a new method for structural optimization. International Journal for Numerical Methods In Engineering, v. 24, n. 2, p. 359-373, 1987.

SVANBERG, K. A class of globally convergent optimization methods based on conservative convex separable approximations. Siam Journal on Optimization, v. 12 , n. 2 , p. $555-573,2002$.

SVED, G.; GINOS, Z. Structural optimization under multiple loading. International Journal of Mechanical Sciences, v. 10, n. 10, p. 803-\&, 1968.

SWAN, C. C.; KOSAKA, I. Voigt-reuss topology optimization for structures with linear elastic material behaviours. International Journal for Numerical Methods in Engineering, v. 40, n. 16, p. 3033-3057, 1997.

SWAN, C. C.; KOSAKA, I. Voigt-reuss topology optimization for structures with nonlinear material behaviors. International Journal for Numerical Methods in Engineering, v. 40, n. 20, p. 3785-3814, 1997.

TANAKA, K.; WATANABE, H.; SUGANO, Y.; POTERASU, V. A multicriterial material tailoring of a hollow cylinder in functionally gradient materials: Scheme to global reduction of thermoelastic stresses. Computer Methods in Applied Mechanics and Engineering, v. 135, n. 3-4, p. 369-380, 1996.

TANIGAWA, Y.; MATSUMOTO, M. Optimization of material composition to minimize thermal stresses in nonhomogeneous plate subjected to unsteady heat supply. JSME International Journal Series A-Solid Mechanics and Material Engineering, v. 40, n. 1, p. 84-93, 1997.

TAYLOR, J. E.; BENDSØE, M. P. An interpretation for min-max structural design-problems including a method for relaxing constraints. International Journal of Solids and Structures, v. 20, n. 4, p. 301-314, 1984.

TORQUATO, S. Random heterogeneous media: Microstructure and improved bounds on effective properties. Applied Mechanical Review, v. 44, p. 37-76, 1991. 
TORQUATO, S. Morphology and effective properties of disordered heterogeneous media. International Journal of Solids and Structures, v. 35, n. 19, p. 2385-2406, 1998.

TORQUATO, S. Modeling of physical properties of composite materials. International Journal of Solids and Structures, v. 37, n. 1-2, p. 411-422, 2000.

TURTELTAUB, S. Optimal material properties for transient problems. Structural and Multidisciplinary Optimization, v. 22, p. 157-166, 2001.

TURTELTAUB, S. Optimal control and optimization of functionally graded materials for thermomechanical processes. International Journal of Solids and Structures, v. 39, n. 12, p. 3175-3197, 2002.

TURTELTAUB, S. Optimal non-homogeneous composites for dynamic loading. Structural and Multidisciplinary Optimization, v. 30, p. 101-112, 2005.

TURTELTAUB, S.; WASHABAUGH, P. Optimal distribution of material properties for an elastic continuum with structure-dependent body force. International Journal of Solids and Structures, v. 36, n. 30, p. 4587-4608, 1999.

VENKAYYA, V. B. Structural optimization: A review and some recommendations. International Journal for Numerical Methods In Engineering, v. 1978, p. 203-228, 1978.

VOIGT, W. Über die beziehung zwischen den beiden elastizitätskonstanten isotroper körper. Wied. Ann., v. 38, p. 573, 1889.

WAKASHIMA, K.; TSUKAMOTO, H. Mean-field micromechanics model and its application to the analysis of thermomechanical behavior of compositematerials. Materials Science And Engineering A-Structural Materials Properties Microstructure And Processing, v. 146, n. 1-2, p. 291-316, 1991.

WALPOLE, L. J. On bounds for overall elastic moduli of inhomogeneous systems .2. Journal Of The Mechanics And Physics Of Solids, v. 14, n. 5, p. 289-\&, 1966.

WALPOLE, L. J. On bounds for overall elastic moduli of inhomogeneous systems .i. Journal Of The Mechanics And Physics Of Solids, v. 14, n. 3, p. 151-\&, 1966.

WALPOLE, L. J. Elastic behavior of composite-materials theoretical foundations. Advances In Applied Mechanics, v. 21, p. 169-242, 1981.

WASIUTYNSKI, Z.; BRANDT, A. The present state of knowledge in the field of optimum design of structures. Applied Mechanics Reviews, v. 16, p. 341-346, 1963.

WENG, G. J. The theoretical connection between mori-tanaka's theory and the hashin-shtrikman-walpole bounds. International Journal of Engineering Science, v. 28, n. 11, p. 1111-1120, 1990.

YANG, R. J.; CHEN, C. J. Stress-based topology optimization. Structural Optimization, v. 12, n. 2-3, p. 98-105, 1996. 
YIN, H. M.; PAULINO, G. H.; BUTTLAR, W. G.; SUN, L. Z. Effective thermal conductivity of two-phase functionally graded particulate composites. Journal of Applied Physics, v. 98, n. 6, p. 063704, set. 2005.

YIN, H. M.; SUN, L. Z.; PAULINO, G. H. Micromechanics-based elastic model for functionally graded materials with particle interactions. Acta Marterialia, v. 52, n. 12, p. 3535-3543, 2004.

YULIN, M.; XIAOMING, W. A level set method for structural topology optimization and its applications. Advances in Engineering Software, v. 35, p. 415-441, 2004.

ZAOUI, A. Continuum micromechanics: Survey. Journal of Engineering Mechanics-ASCE, v. 128, n. 8, p. 808-816, 2002.

ZHANG, W. H.; DUYSINX, P. Dual approach using a variant perimeter constraint and efficient sub-iteration scheme for topology optimization. Computers $\&$ Structures, v. 81, n. 22-23, p. 2173-2181, 2003.

ZHANG, W. H.; FLEURY, C.; DUYSINX, P.; NGUYEN, V. H.; LASCHET, I. A generalized method of moving asymptotes (gmma) including equality constraints. Structural Optimization, v. 12, n. 2-3, p. 143-146, 1996.

ZHOU, M.; SHYY, Y. K.; THOMAS, H. L. Checkerboard and minimum member size control in topology optimization. Structural and Multidisciplinary Optimization, v. 21, n. 2, p. 152-158, 2001. 